\title{
Gambling by Ontario Casino Employees: \\ Gambling Behaviours, Problem Gambling, and Impacts of the Employment
}

\author{
by \\ Daniel Adams Guttentag

\begin{abstract}
A thesis
presented to the University of Waterloo

in fulfilment of the

thesis requirement for the degree of

Master of Environmental Studies

in

Geography - Tourism Policy \& Planning
\end{abstract}

Waterloo, Ontario, Canada, 2010

CDaniel Adams Guttentag 2010 
I hereby declare that I am the sole author of this thesis. This is a true copy of the thesis, including any required final revisions, as accepted by my examiners.

I understand that my thesis may be made electronically available to the public. 


\begin{abstract}
This study investigated various aspects of the gambling engaged in by Ontario casino employees. Five casinos participated in the study, which involved a survey sample of 934 employees and an interview sample of 21 employees. The study found that the casino employees exhibited rates of problem gambling that were over three times greater than rates that past studies have found in Ontario's general population. The employees' problem gambling was primarily explained by employees who increased their gambling after beginning their jobs and employees who were attracted to their jobs because of prior gambling involvement, although neither of these characteristics was especially common overall. The increases and decreases in gambling that some employees experienced after beginning their jobs were precipitated by a variety of workplace influences associated with the employees' exposure to gambling; their exposure to patrons; their exposure to the casino work environment; and the existence of training, regulations, and resources. The prevalence of problem gambling and other behavioural gambling patterns also were found to relate to numerous employment variables, such as department and shift. Based on all of these results, various policy recommendations and suggestions for future research are provided.
\end{abstract}

Keywords: gambling, casino employee, problem gambling, workplace influence 


\section{Acknowledgements}

I would like to very graciously thank the Ontario Lottery and Gaming Corporation and each facility that participated in this study for opening their doors to me and allowing me to conduct this research. By embracing this study they have demonstrated an admirable commitment to their employees and shown a commendable dedication toward progress through research, which should serve as an example to casinos worldwide. I received full, friendly support from every individual I worked with, including Betty Palantzas; Joel Berkovitz; and the managers, directors, and assistants from each of the participating facilities. Your efforts were instrumental in the successful completion of this study and it was a genuine pleasure to meet and work with each one of you.

I also wish to thank the Ontario Problem Gambling Research Centre for generously providing me with the research funding to conduct this study, as without this funding I would have been unable to undertake such a large project. Moreover, I am grateful for all of the invaluable non-financial support, in the form of assistance and input, that the team there has provided me. Your efforts were integral in transforming this study from an idea into a reality. I also wish to especially thank Judith Glynn, without whom I cannot imagine how this project would have been accomplished.

I would additionally like to thank my co-supervisors, Dr. Kevin Harrigan and Dr. Stephen Smith, for the invaluable guidance and assistance they offered me throughout the course of this study. Your efforts and insights have given me crucial support from start to finish. I also wish to thank my committee member, Dr. Bryan Smale, for his useful input and, along with my other professors - Dr. Geoffrey Wall, Dr. Judith Cukier, and Dr. Mark Havitz - for providing me with the foundation necessary to conduct this research. Furthermore, I wish to thank everyone at the University's Statistical Consulting Service for their helpful assistance, and Dr. John Goyder for his recommendations on the survey. 
I also send my gratitude to all of the casino employees who took the time to participate in this study by completing a survey and/or being interviewed. Your involvement with this study is greatly appreciated and I hope that some of you and your co-workers may benefit from my findings.

I also would like to extend a special thank you to my parents, who instilled in me a curiosity with which to approach the world, complemented by a sceptical outlook with which to view it. This mindset provided the motivation that kept me persistently working even on the longest days.

Finally, I wish to lovingly thank my beautiful wife, Joslyne, for supporting me unconditionally in this process ever since I first was applying to become a Master's student. Even in my most frustrated moments you could always make me smile, and your unyielding love and support will always be my cornerstone and what I cherish most. I also am grateful for the direct assistance and companionship that you offered during several stages of this project, allowing me to easily complete tasks that otherwise would have been practically unmanageable. I began this project as your fiancé and completed it as your husband, so I know that I will always look back at these months very fondly. 
For my wife, Joslyne. Te amo. 


\section{Table of Contents}

AUTHOR'S DECLARATION $\quad$ ii

ABSTRACT

ACKNOWLEDGEMENTS iv

DEDICATION vi

TABLE OF CONTENTS Vii

LIST OF TABLES $\quad$ xi

LIST OF ABBREVIATIONS $\quad$ xvii

\section{CHAPTER 1}

INTRODUCTION......................................................................................................................... 1

1.1 THE RESEARCH PROBLEM ............................................................................... 2

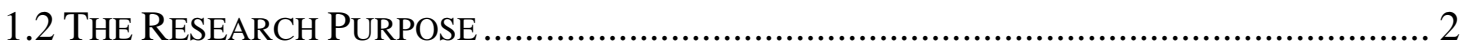

1.3 THE RESEARCH OBJECTIVES ......................................................................... 2

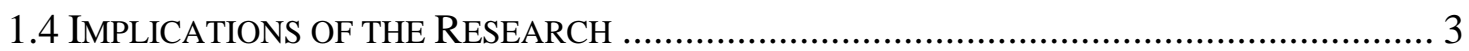

\section{CHAPTER 2}

LITERATURE REVIEW ........................................................................................................... 4

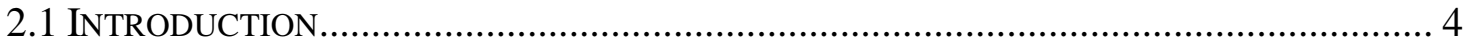

2.2 The History of CASinOS AND the ReCEnT Worldwide CASINo BoOM ................ 5

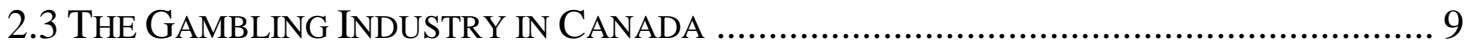

2.3.1 The Emergence of Casinos in Canada ……………….................................. 9

2.3.2 Canadian Casinos and the Employment Factor ……………………………... 12

2.4 Problem Gambling AND ITS PREVALENCE IN ONTARIO........................................... 14

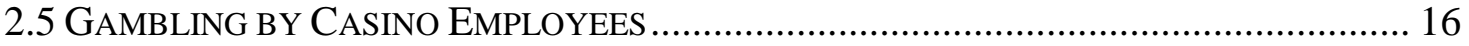

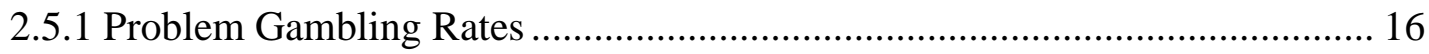

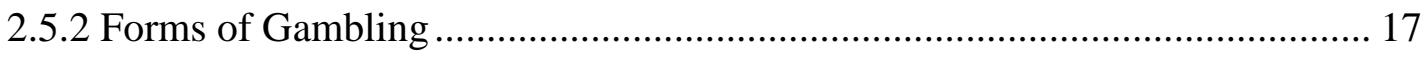

2.6 CHANGES IN GAMBLING BY CASINO EMPLOYEES ……............................................. 18

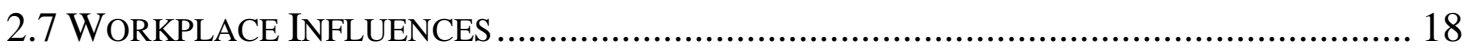

2.7.1 Exposure to Gambling ................................................................................ 19

2.7.2 Exposure to the Patrons …………………………...................................... 21 


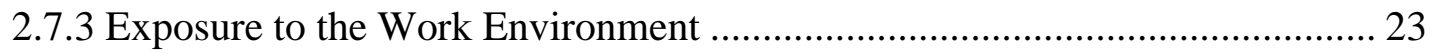

2.7.4 Training, Regulations, and Resources ....................................................... 25

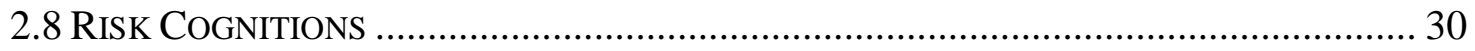

2.9 MotIVES FOR TAKING CASINO JobS .............................................................. 34

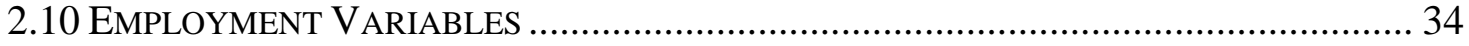

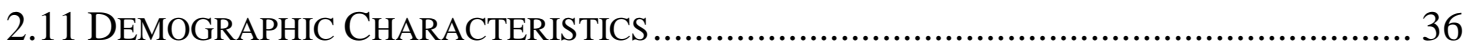

2.12 ExPlanations for Problem Gambling PREVAlence among CASino

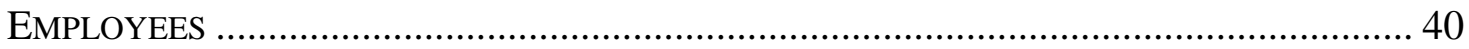

2.13 Why PREVEnTing EMPLOYeE Problem GAMBling Is BENEFICIAL FOR

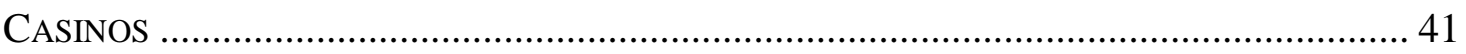

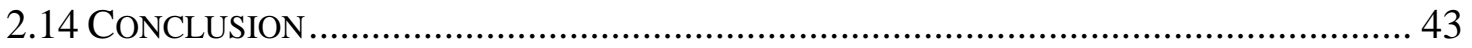

\section{CHAPTER 3}

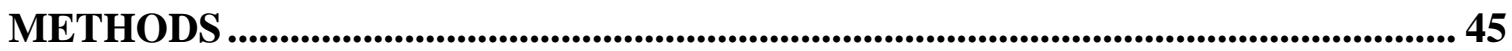

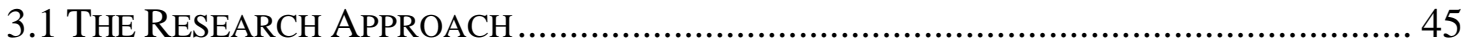

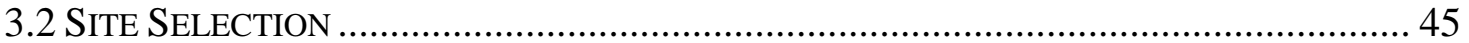

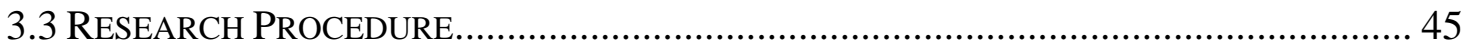

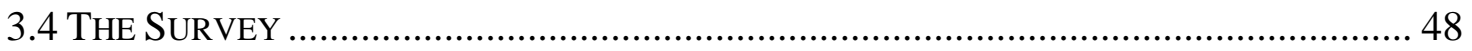

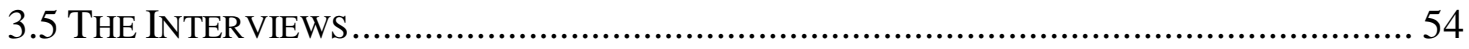

\section{CHAPTER 4}

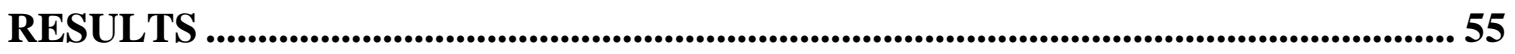

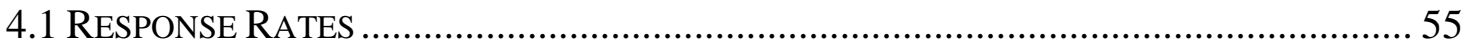

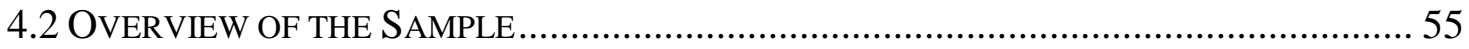

4.2.1 Demographic Characteristics ............................................................. 55

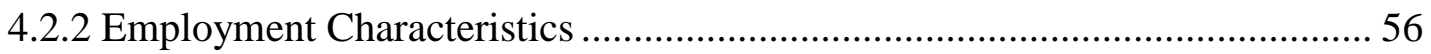

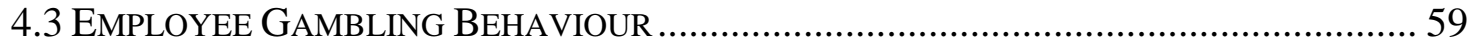

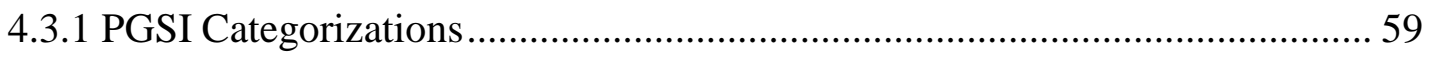

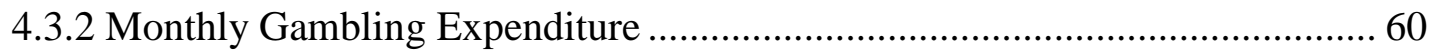

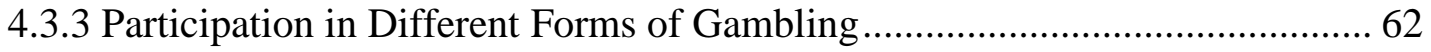

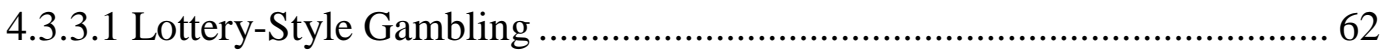




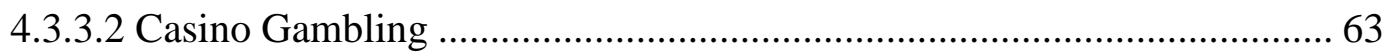

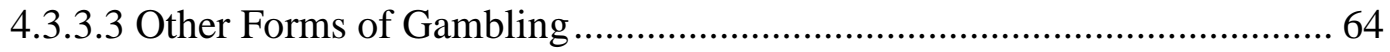

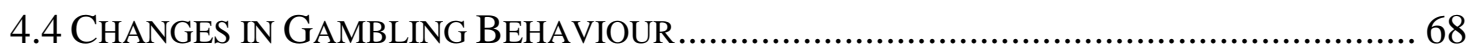

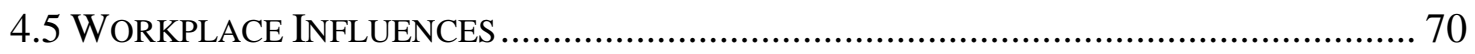

4.5.1 Exposure to Gambling ................................................................................ 70

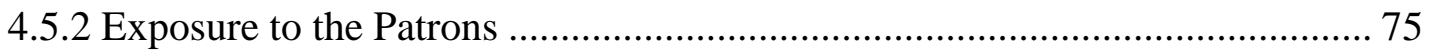

4.5.3 Exposure to the Work Environment ............................................................ 78

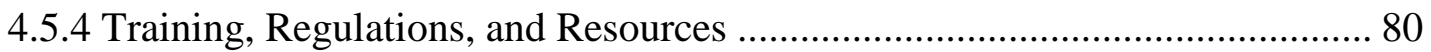

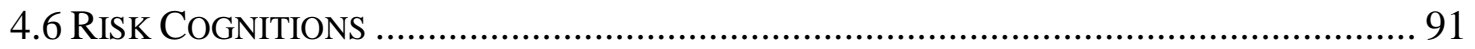

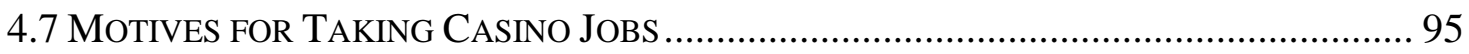

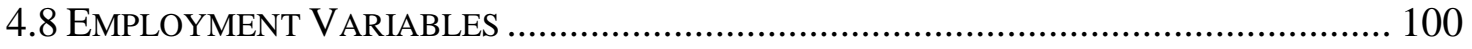

4.8.1 Length of Time Working in the Gambling Industry ..................................... 100

4.8.2 Previous Experience Working in the Gambling Industry ……....................... 105

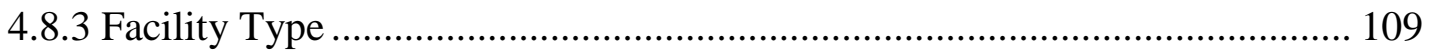

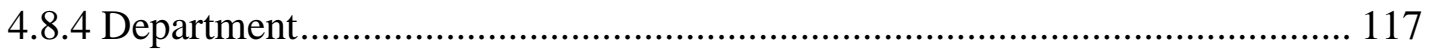

4.8.5 Percentage of Workday Spent Interacting with Patrons .................................. 134

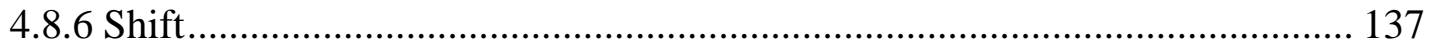

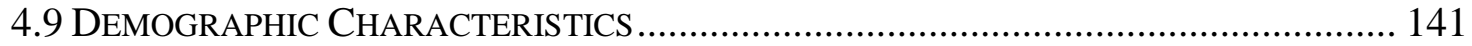

4.10 Explanations for Problem Gambling PreValence among Casino

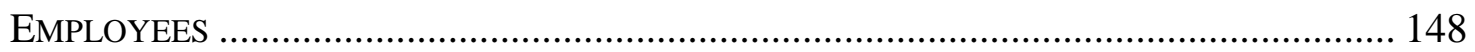

4.11 IDENTIFYING PATRON PROBLEM GAMBLERS …….......................................... 150

\section{CHAPTER 5}

DISCUSSION ........................................................................................................................... 153

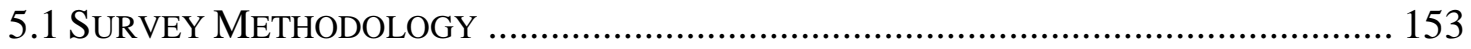

5.2 Gambling ANd Problem Gambling AmONG Ontario Casino EMPloyeES..... 153

5.3 CHANGES IN GAMBLING BEHAVIOUR AND THE IMPACTS OF WORKPLACE

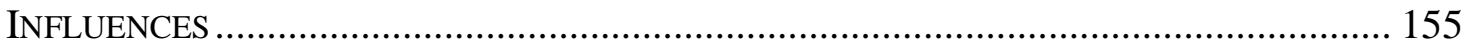

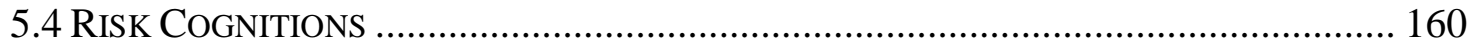

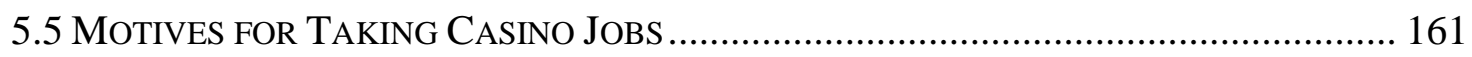

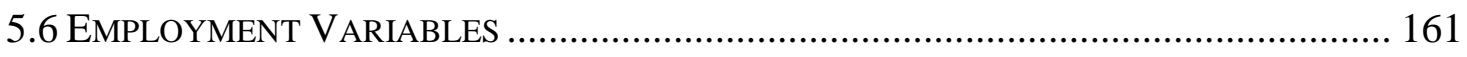




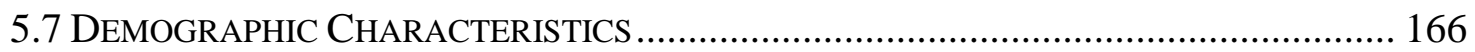

5.8 CASINo Benefits of REducing EMPLOYEe Problem GAMBLING ......................... 166

5.9 REASONS FOR THE High PROBLEM Gambling RATES AMONG CASINO

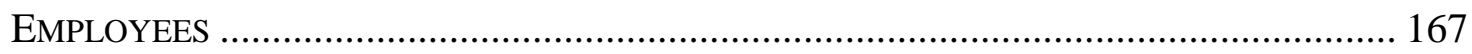

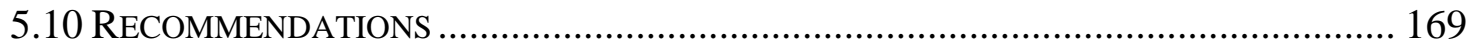

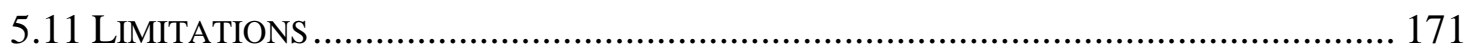

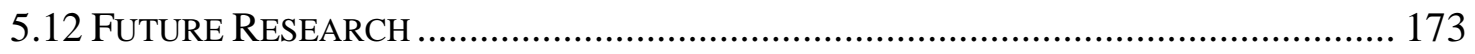

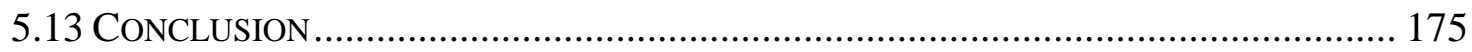

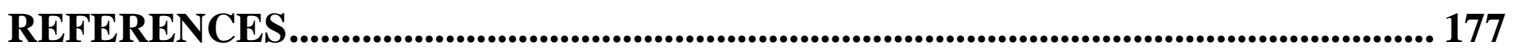

APPENDICES ............................................................................................................................ 187

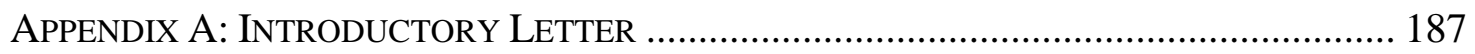

APPENDIX B: SURVEY COVER LETTER................................................................ 188

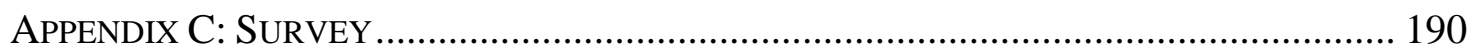

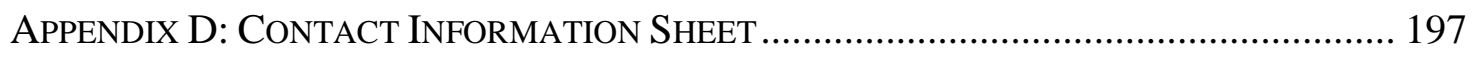

APPENDIX E: INTERVIEWEE CONTACT LETTER ………............................................. 198

APPENDIX F: LETTER FOR INTERVIEWEES AND CONSENT FORM .................................. 199

APPENDIX G: INTERVIEW GUIDE........................................................................ 202 


\section{List of Tables}

TABLE 1. Demographic characteristics of the survey sample ......................................... 56

TABLE 2. Employment characteristics of the survey sample ……………………….....58

TABLE 3. Percentage of individuals placed in the different PGSI categories ................. 60

TABLE 4. Estimated typical monthly gambling expenditures ........................................... 61

TABLE 5. PGSI results of employees with different monthly gambling expenditures ... 61

TABLE 6. Gambling participation during the previous 12 months................................... 67

TABLE 7. PGSI categorizations of employees who engaged in different forms of gambling at least once per month during the previous year

TABLE 8. Changes in employees' gambling since beginning work in an OLG or resort casino

TABLE 9. PGSI results of employees who had changed their gambling in different ways since beginning work in an OLG or resort casino

TABLE 10. Attitudes toward the impacts of exposure to gambling...... 71

TABLE 11. Relationships between PGSI categorizations and changes in gambling with perceived abilities to win money gambling

TABLE 12. Attitudes toward the impacts of exposure to the casino patrons 76

TABLE 13. During the previous 12 months, frequency with which employees saw patrons perceived to have gambling problems

TABLE 14. Attitudes toward the impacts of exposure to the work environment 78

TABLE 15. Percentage of employees who found jobs stressful 79

TABLE 16. PGSI results of employees feeling different amounts of job stress 80

TABLE 17. Changes in gambling experienced by employees feeling different amounts of job stress.

TABLE 18. Attitudes toward the impacts of RG training and employee gambling regulations 
TABLE 19. Distance from nearest unrestricted casino for employees perceiving different levels of difficulty posed by the employee gambling regulations 83

TABLE 20. PGSI results of employees living different distances from their nearest unrestricted casinos

TABLE 21. Changes in gambling experienced by employees living different distances from their nearest unrestricted casinos

TABLE 22. Past year gambling engaged in by employees living different distances from their nearest unrestricted casinos 85

TABLE 23. Agreement with the statement, "I am aware of employee outreach tools that OLG facility employees can use if concerned they may have a gambling problem" 88

TABLE 24. Most likely resource employees would use to seek assistance if they felt they had a gambling problem.

TABLE 25. PGSI results of employees who would and would not seek assistance for PG

TABLE 26. Employees' anticipated responses of their direct supervisors if approached about a personal gambling problem

TABLE 27. PGSI results of employees' who anticipated different responses from their direct supervisors if approached about a personal gambling problem

TABLE 28. Agreement with various risk cognitions

TABLE 29. Risk cognitions among employees in the different PGSI categories

TABLE 30. Risk cognitions among employees who had changed their gambling in different ways since beginning work in an OLG or resort casino

TABLE 31. Belief in risk cognitions among employees with different perceptions about their abilities to win money using their acquired gambling knowledge

TABLE 32. Agreement with the risk cognition, "My gambling wins on slot machines are evidence that I have skill and knowledge related to gambling," among employees who had and had not played an EGM in the previous year ....................................................... 95

TABLE 33. Reasons why employees sought their jobs.................................................. 98

TABLE 34. PGSI results of employees reporting different motives for choosing their jobs 
TABLE 35. Changes in gambling experienced by employees reporting different motives for choosing their jobs 100

TABLE 36. PGSI results of employees who had spent different amounts of time working in the gambling industry.... 100

TABLE 37. Changes in gambling experienced by employees who had spent different amounts of time working in the gambling industry

TABLE 38. The impacts of workplace influences on employees who had spent different amounts of time working in the gambling industry

TABLE 39. The impacts of workplace influences on employees who had spent different amounts of time working in the gambling industry

TABLE 40. Average level of belief in three risk cognitions by employees who had spent different amounts of time working in the gambling industry .....

TABLE 41. Average number of months worked in the gambling industry by employees exhibiting different levels of agreement that they were attracted to the employment because they were frequent gamblers

TABLE 42. PGSI results of employees who had and had not worked in the gambling industry prior to working in an OLG or resort casino

TABLE 43. Changes in gambling experienced by employees who had and had not worked in the gambling industry prior to working in an OLG or resort casino

TABLE 44. The impacts of workplace influences on employees who had and had not worked in the gambling industry prior to working in an OLG or resort casino

TABLE 45. The impacts of workplace influences on employees who had and had not worked in the gambling industry prior to working in an OLG or resort casino

TABLE 46. Average level of belief in three risk cognitions by employees who had and had not worked in the gambling industry prior to working in an OLG or resort casino 109

TABLE 47. Levels of agreement that they were attracted to the employment because they were frequent gamblers among employees who had and had not worked in the gambling industry prior to working in an OLG or resort casino 109

TABLE 48. PGSI results of employees from different facilities

TABLE 49. Changes in gambling experienced by employees from different types of facilities 
TABLE 50. Previous year participation and familiarity change with different forms of gambling by employees from different types of facilities

TABLE 51. Previous year participation and familiarity change with different forms of gambling by employees from different types of facilities

TABLE 52. The impacts of workplace influences on employees from different types of facilities

TABLE 53. The impacts of workplace influences on employees from different types of facilities

TABLE 54. Average level of belief in three risk cognitions by employees from different types of facilities

TABLE 55. Levels of agreement that they were attracted to the employment because they were frequent gamblers among employees from different types of facilities.

TABLE 56. PGSI results of the departments, grouped according to their proximity to the gambling floor.

TABLE 57. PGSI results of employees from different departments

TABLE 58. Changes in gambling experienced by employees from different departments

TABLE 59. Past year participation in different forms of gambling by employees from different departments

TABLE 60. Past year participation in different forms of gambling by employees from different departments

TABLE 61. Past year participation in different forms of gambling by employees from different departments

TABLE 62. Past year participation in different forms of gambling by employees from different departments

TABLE 63. The impacts of exposure to gambling on employees from different departments

TABLE 64. The impacts of exposure to the patrons on employees from different departments

TABLE 65. The impacts of exposure to the work environment on employees from different departments 
TABLE 66. The impacts of training and regulations on employees from different departments

TABLE 67. Agreement with the statement "I find my job stressful" among employees from different departments

TABLE 68. Average level of belief in three risk cognitions by employees from different departments

TABLE 69. Average level of belief in EGM-related risk cognition by employees from different departments

TABLE 70. Levels of agreement that they were attracted to the employment because they were frequent gamblers among employees from different departments

TABLE 71. PGSI results of employees who spent different percentages of their workdays interacting with patrons.

TABLE 72. Changes in gambling experienced by employees who spent different percentages of their workdays interacting with patrons

TABLE 73. The impacts of exposure to the patrons on employees who spent different percentages of their workdays interacting with the patrons......

TABLE 74. Average level of belief in three risk cognitions by employees who spent different percentages of their workdays interacting with patrons.

TABLE 75. Agreement with the statement, "Due to my shifts, casinos are some of the only entertainment venues open when I am not at work".

TABLE 76. PGSI results of employees who worked different shifts

TABLE 77. Changes in gambling experienced by employees who worked different shifts

TABLE 78. Impacts of exposure to the patrons among employees who work different shifts

TABLE 79. Average level of belief in three risk cognitions by employees who worked different shifts

TABLE 80. Levels of agreement that they were attracted to the employment because they were frequent gamblers among employees who worked different shifts

TABLE 81. Previous year participation in different forms of gambling by males and females. 
TABLE 82. PGSI results of employees in different demographic groups

TABLE 83. Changes in gambling experienced by employees in different demographic groups

TABLE 84. Average level of belief in three risk cognitions by employees in different demographic groups

TABLE 85. Levels of agreement that they were attracted to the employment because they were frequent gamblers among employees in different demographic groups

TABLE 86. Changes in gambling experienced by employees in different PGSI categories

TABLE 87. Levels of agreement that they were attracted to the employment because they were frequent gamblers among employees in different PGSI categories

TABLE 88. Amount of time spent working in the gambling industry by employees placed in different PGSI categories.

TABLE 89. Confidence in responding to patron problem gamblers and knowledge of OLG's RG policies and procedures among employees in different PGSI categories .... 150

TABLE 90. Frequency with which employees in different PGSI categories saw patrons believed to have a gambling problem in the previous 12 months.

TABLE 91. Frequency with which non-Table Games employees in different PGSI categories saw patrons believed to have a gambling problem in the previous 12 months 


\section{List of Abbreviations}

CGA - Canadian Gaming Association

CPGI - Canadian Problem Gambling Index

EAP - Employee assistance plan/program

EGM - Electronic gaming machine

GBQ - Gamblers' Belief Questionnaire

OLG - Ontario Lottery and Gaming Corporation

PG - Problem gambling

PGF - Problem Gambling Framework

PGSI - Problem Gambling Severity Index

RG - Responsible gambling

SOGS - South Oaks Gambling Screen

VLT - Video lottery terminal 


\section{Chapter 1}

\section{Introduction}

Tens of thousands of employees work in casinos located all across Canada. Not long ago none of this employment existed, but during the past several decades casino gambling has undergone rapid expansion in Canada, much like in many other parts of the world. In Ontario alone, there are now 27 casino facilities and the casino industry employs approximately 19,000 people. The promise of such jobs has been a significant factor in motivating Canada's acceptance of casino gambling, and job creation continues to be perceived and touted as one of the casino industry's most important benefits. However, while the creation of so many new jobs is certainly laudable, past research has suggested that casino employees, who represent such a clear benefit of the casino industry, also ironically represent one of its major costs, as the employees themselves appear to exhibit particularly high rates of problem gambling (PG) (e.g., Dangerfield, 2004; Duquette, 1999; Shaffer, Bilt, \& Hall, 1999).

These high PG rates obviously may be a result of the unique environment in which casino employees work. Environmental conditions are recognized as sometimes playing a role in the development of gambling problems (Ontario Problem Gambling Research Centre, 2009), and researchers have identified numerous workplace influences that could encourage casino employees to increase their gambling (e.g., Hing and Breen, 2007, 2008a, 2008b). Nevertheless, it should not simply be assumed that casino employees are invariably attracted to gambling as a result of their work, as there exist other workplace influences that actually may discourage employees from gambling. In fact, some influences even may encourage gambling among some employees while discouraging it among others, partly as a result of employment variables that affect how the different workplace influences are experienced. Also, it is possible that working in a casino has minimal impact on employees' gambling, and the apparent prevalence of PG among casino employees might exist because the work disproportionately attracts or retains individuals who are already heavily involved with gambling.

Achieving a better understanding of the gambling behaviours of casino employees and the factors influencing or associated with these behaviours clearly is necessary in 
order to formulate policies that can effectively promote responsible gambling (RG) among this group. Promoting RG among casino employees may even benefit casino patrons, as employees' gambling involvement may influence their likelihood of responding to patrons exhibiting gambling problems. It also is essential to comprehend how employees are impacted by their jobs in order to properly assess the value of creating these jobs. These topics, therefore, are of great importance in regions all around the world, and because so many Ontarians are employed by casinos, Ontario is a place where these issues are particularly germane.

\subsection{The Research Problem}

Existing research has indicated that PG may be particularly prevalent among casino employees, yet none of this research has focussed specifically on casino employees in Ontario. Also, it remains unclear whether the apparent prevalence of PG among casino employees results from various influences of the employment or whether it results from the jobs attracting or retaining heavy gamblers. Moreover, greater understanding is needed regarding how different workplace influences affect changes in employee gambling and how different employment variables may relate to different types of gambling involvement.

\subsection{The Research Purpose}

The purpose of this study was to better understand the gambling behaviours of Ontario casino employees, with a specific focus on the prevalence of PG, the impacts of workplace influences, and the significance of employment variables.

\subsection{The Research Objectives}

This study had seven research objectives:

1. To identify the gambling behaviours and estimate the prevalence of PG among Ontario casino employees.

2. To compare gambling by Ontario casino employees with gambling by the general Ontario population. 
3. To determine how Ontario casino employees' gambling is affected by different workplace influences.

4. To determine whether and why different employment variables and demographic characteristics may be associated with different types of gambling involvement.

5. To assess the validity of different potential explanations for the possible existence of PG among casino employees.

6. To determine whether casino employees who are problem gamblers are more or less likely than their co-workers to detect PG among casino patrons.

7. To provide policy recommendations which casinos in Ontario and elsewhere can use to promote RG among their workforces.

\subsection{Implications of the Research}

It was hoped that accomplishing these different research objectives could offer casinos and policymakers a better understanding of casino employment and its impacts on the workers, thereby allowing the casinos to promote RG within their workforces more effectively. Even though regional and jurisdictional differences must be considered when generalizing this study's findings, it was hoped that these findings could provide useful insights for casinos worldwide. This study, therefore, provides an important addition to the existing literature and contributes to the Reno Model of conducting empirical research that can assist key stakeholders in promoting RG (Blaszczynski, Ladouceur, \& Shaffer, 2004). 


\section{Chapter 2}

\section{Literature Review}

\subsection{Introduction}

The research objectives guiding this study were based on previous research that has been conducted on casino employee gambling and gambling behaviour in general. However, before examining these studies it is important to first understand the evolution of the casino industry and the central role that employment has played in this evolution. When looking back in time, one finds that gambling has been virtually ubiquitous in human history, but also that it is a fairly controversial activity that has been regulated in a variety of ways by different societies. Without question, the past few decades have been characterized by a rapid increase in casino gambling throughout many parts of the world, including Ontario. This increase primarily has resulted from three chief goals that governments have hoped to achieve with gambling expansion: an increase in government revenue, an increase in tourism, and an increase in employment. The promise of new employment opportunities has played a prominent role in Canada's embrace of legalized casino gambling, but while these job opportunities should be applauded, any possible consequences of these jobs also must be considered.

In fact, several studies have found that PG is particularly prevalent among casino employees (e.g., Dangerfield, 2004; Duquette, 1999; Shaffer et al., 1999). PG is a topic that has been researched and conceptualized for many decades, yet much debate still continues regarding what it is and what causes it. Nowadays, PG is often conceptualized as relating to a variety of risk factors, and there exist numerous influences in the unique, gambling-intensive setting where casino employees spend their workdays that could impact the employees' gambling behaviours and possibly explain the employees' high rates of PG. Some of these influences have been considered previously in existing studies on casino employees (e.g., Dangerfield; Duquette; Shaffer et al.), and this topic also has been significantly advanced by Hing and Breen (2007, 2008a, 2008b), whose qualitative studies have identified myriad workplace influences that may impact casino employee gambling. 
For the purposes of this study, those workplace influences being considered have been divided into four categories: the employees' exposure to gambling; the employees' exposure to the casino patrons; the employees' exposure to the casino work environment; and the existence of training, regulations, and resources. These workplace influences may affect employees' gambling behaviour directly, or they may affect it indirectly by leading the employees to either accept or refute certain erroneous gambling cognitions, some of which will be discussed. Also, the motives that prompt individuals to work in the casino industry will be examined as possibly relating to employee PG rates. Furthermore, considering casino employees as a uniform population overlooks many potentially significant variables, so several employment variables that may relate to employee gambling will be discussed: the length of time employees have been working in the industry, their departments, and the shifts they work. Different demographic characteristics also will be examined for similar reasons. Past studies that have investigated casino employee gambling have produced different explanations regarding the prevalence of PG among casino employees, and these explanations will be presented. Finally, it will be shown that reducing PG among casino workers may provide direct benefits to the casinos that employee these workers.

\subsection{The History of Casinos and the Recent Worldwide Casino Boom}

Gambling is evident in the early histories of cultures from all around the globe, ranging from the ancient Greeks, who bet on dice, cockfights, sporting events, and other games, to the early Aztecs, who wagered everything from corn to palaces on a dice game called patolli. The roots of gambling lie in ancient divination rituals that involved games like "odds and evens" and the interpretation of patterns that resulted when objects were tossed. The distinction between games used for divination rituals, simple diversion, and gambling was often blurred, but as civilizations progressed their games became more sophisticated and genuine gambling became more apparent. The earliest six-sided dice date back about 5,000 years and were uncovered in the Middle East, while the first playing cards emerged in East Asia and spread across Asia and into Europe in the early parts of the second millennium A.D. Early gambling primarily involved social games, in which bettors gambled against one another, while sometimes playing in specialized 
gambling houses. However, in sixteenth century Venice, gambling developed into a more mercantile activity as members of the nobility began charging a portion of the money staked in their gambling houses, called ridotti, and offering recently created "bank games" in which gamblers bet against an impersonal house rather than one another. Despite municipal anti-gambling laws, the Venetian gambling houses flourished, which prompted the government to ease its regulations and permit the opening of Europe's first state-sanctioned, public gambling house, the Ridotto, in 1638. Professional gambling houses eventually spread throughout Europe and stimulated a European gambling craze that lasted from about 1650 to 1800 (Schwartz, 2006).

As casinos emerged throughout Europe and gambling's popularity grew, casino gambling quickly became a popular tourism attraction. During the late eighteenth and early nineteenth centuries, casinos were established in numerous health resorts in Germany and other parts of Europe, and gambling quickly became an important - and sometimes primary - attraction for many vacationers' spa holidays (Hutchinson, 1999; Schwartz, 2006). For example, in describing Wiesbaden, a German spa resort on the banks of the Rhine, Schwartz wrote, "During the resort's nineteenth-century glory years, visitors to the more than twenty baths usually ended their day at the casino. Often, they began it there as well” (p. 203). In order to attract tourist gamblers, these spa resorts used marketing strategies that were remarkably similar to those still used by gambling destinations today. For instance, when competition from nearby towns increased, the German spa resort of Baden-Baden "opened a new theatre... and attracted the brightest stars of the musical world to better lure gamblers to the Conversation House [casino], located conveniently near the theatre" (p. 198). Baden-Baden also benefitted from its location near the French border, where gambling clubs had been closed by legislation enacted in 1837 (Schwartz). Consequently, in Baden-Baden, "French was the lingua franca, and Baden-Baden became, quite by design, a virtual suburb of Paris" (p. 193). This strategy of attracting casino tourists from nearby jurisdictions where casinos are outlawed has since been replicated in destinations ranging from Macao to Swaziland (Leiper, 1989).

The pervasiveness of this phenomenon is a direct result of the stringent regulations that have restricted and continued to restrict legal gambling in many countries 
throughout the world. Gambling has attracted the attention of governments for thousands of years, and these governments have taken various approaches toward permitting, regulating, or prohibiting the activity. For example, even in ancient Egypt laws existed that prohibited gambling, although they apparently were mostly ineffective at curbing the activity (Schwartz, 2006). Rather than fully prohibit gambling, many societies have chosen to regulate the activity and exploit it as an easy source of revenue, which is what occurred in Venice when the Ridotto was opened (Schwartz). In other examples of this approach, France's Louis XIV used a lottery to build the Paris General Hospital (Hutchinson, 1999) and state lotteries in Britain were exploited in the sixteenth and seventeenth centuries to raise funds for London's water supply, to pay civil servant salaries, and to finance the colonization of America (McMillen, 1996).

The prospect of easy gambling revenue has continued to influence governments to this day and it has contributed to a dramatic worldwide expansion of casino gambling that has occurred in recent years. As Wynne and Shaffer (2003) described, "During the last two decades of the twentieth century, the growth of legal gambling around the world has been phenomenal" (p.111), and one can find numerous examples to illustrate this trend. For instance, when Resorts International opened Atlantic City's first casino in May 1978, it was the only casino in the United States located outside of Nevada (Morse \& Goss, 2007; Sternlieb \& Hughes, 1983), yet in 2009 the American Gaming Association reported that the U.S. was home to 445 land-based and riverboat casinos, 423 tribal casinos, and 44 racetrack casinos, with Nevada accounting for only about $30 \%$ of that total (American Gaming Association, 2009). Similarly, in Australia only two casinos existed in 1984 (Wall \& Mathieson, 2006), but by 1997 they had been established in several tourism centres and every one of the country's major cities (Eadington, 2001).

Although casino gambling has expanded rapidly in recent decades, it certainly remains a "controversial industry" (Eadington, 2001, p. 135). The "legislative explosion permitting casino gaming from the mid-1980s onward" (p. 135) has likely been facilitated by an increase in the public's approval of gambling, but in many cases governments have simply decided to permit gambling "as a means to achieve broader ends" (p. 135). As one Senator sponsoring the bill that eventually permitted gambling in Atlantic City explained, "The end is not the casino industry. The end is the tourism, resort and convention 
industry of Atlantic City in particular, and the State of New Jersey" (Sternlieb \& Hughes, 1983, p. 59). By 1976, when New Jersey passed its referendum to permit gambling in Atlantic City, the city had become a "fading seaside resort" (p. ix) and wished to recover some of its lost lustre (Sternlieb \& Hughes). These circumstances clearly influenced New Jersey's embrace of casino gambling, and the state is far from alone in its decision to exploit gambling as an opportunity to earn revenue and encourage economic growth. As Sternlieb and Hughes summarized, "The quest for a quick and painless, that is, politically popular, means of raising funds and stimulating economic development never ends," and legalized casino gambling has sometimes been perceived as a "magic bullet" (p. ix).

Governments have three primary motives to permit gambling. Firstly, governments are essentially able to use casinos as vehicles for tax collection (Grinols, 2004), and as a form of revenue-generation gambling is often accepted far more favourably than simply increasing taxes (Morse \& Goss, 2007). The significance of this motive was clearly demonstrated during the financial crisis of 2007-2009, which prompted politicians in various U.S. states to expand or at least propose expanding their states' gambling industries (e.g., The Economist, 2009; Hanna, 2009; Neuman, 2009; Reid, 2009). Governments also frequently influence public sentiment by earmarking revenue generated from gambling for popular causes, such as health care, education, and social services (Wynne \& Shaffer, 2003). Secondly, casinos have been promoted as tools for producing economic stimulation, particularly through tourism (Eadington, 2001). In Colorado, for instance, a Senator in the eventually successful campaign to legalize gambling wrote in a newspaper column, "The primary purpose of the resolution... is not to promote gambling...It is hoped that tourists will come to these towns year-round, not only to engage in limited gambling, but to stay in hotels, eat in restaurants, and shop in the stores" (Stokowski, 1996, p. 61). Similarly, stimulating the economy with tourism was a primary objective behind the establishment of casinos in places ranging from Deadwood, South Dakota (Blevins \& Jensen, 1998; Nickerson, 1995) to Darwin, Australia (Hall \& Hamon, 1996). Thirdly, the lure of additional employment opportunities has been an important factor in many governments' acceptance of gambling (Eadington; Morse \& Goss). For instance, Sternlieb and Hughes (1983) claimed that in New Jersey, "The promise of increased employment played the largest part in winning 
endorsement for casino gaming" (p.79). Likewise, the desire to generate jobs for unemployed tribal members has convinced many Native American tribes to embrace gambling (Morse \& Goss).

\subsection{The Gambling Industry in Canada}

\subsubsection{The Emergence of Casinos in Canada}

The growth of the gambling industry in Canada has mirrored the industry's growth in other parts of the world. Gambling in Canada preceded Europe's colonization of the area, as many indigenous groups, such as the Hurons, gambled on a variety of games.

Nevertheless, gambling was soon prohibited in the early colonial area of New France, with only occasional lotteries being held. By the early nineteenth century, both Upper and Lower Canada had established laws forbidding all forms of gambling, and this complete prohibition was maintained when the two areas unified in 1840. In 1892, Canada established its Criminal Code, which included legislation pertaining to gambling, and this code still regulates gambling in Canada today. The original Criminal Code forbade all types of gambling, although illegal gambling remained rampant. Since its establishment, the Criminal Code has been periodically amended to gradually permit various forms of gambling. For example, in 1900 small raffles were permitted for church and charitable fundraising, in 1910 on-track horse betting was legalized, and in 1925 an exemption was made to permit games of chance in summer fairs and exhibitions. However, during the Great Depression, when many countries around the world instituted lotteries, various lottery proposals in Canada were defeated (Campbell \& Smith, 1998; Hutchinson, 1999; Smith \& Hinch, 1996).

Nevertheless, in 1969 the Canadian government passed an amendment that decreased restrictions on charity gambling and granted the federal and provincial governments the right to conduct lotteries (Campbell \& Smith, 1998; Hutchinson, 1999; Smith \& Hinch, 1996). The sanction of lotteries has often preceded the establishment of casinos, as the lotteries give governments a taste of the revenue that they can earn from gambling, while simultaneously improving the public's perception of gambling (Eadington, 2001). Canada was no exception to this trend and, as Hutchinson summarized, "The floodgates had opened" (p. 68). During the 1970s some western 
provinces hosted temporary charity casinos, where small-stakes games were used to raise funds for charitable organizations (Eadington). Then, on December 29, 1989, Canada's first permanent, government-run casino, known as the Crystal, opened its doors in Winnipeg (Hutchinson). Many other cities and towns followed suit, and between 1990 and 1997 casinos were introduced in cities including Montreal, Halifax, Hull, Niagara Falls, Regina, and Windsor (Eadington). By 2008, Canada was home to 66 casinos, 6,683 electronic gaming machine $\left(\mathrm{EGM}^{1}\right)$ venues, 62 horseracing tracks, 186 teletheatres (for off-track betting), 423 bingo facilities, and 30,466 ticket lottery outlets (Canadian Partnership for Responsible Gambling, 2008). Not surprisingly, the total amount of revenue earned from gambling has increased dramatically as the industry has expanded. In fact, between 1992 and 2008 the net revenue generated from government-run casinos, lotteries, and EGMs increased from \$2.7 billion (Marshall \& Wynne, 2003) to \$13.67 billion (Statistics Canada, 2009).

The primary distinction between the gambling industry in Canada and its counterparts in many other countries, such as the U.S. and Australia, is the Canadian government's direct role in the nation's gambling industry (Cosgrave \& Klassen, 2009; Eadington, 2001; Williams \& Wood, 2004b). Legislation enacted in 1985 gave provincial governments exclusive control over gambling, making them "the primary owners and beneficiaries of these enterprises" (Campbell \& Smith, 1998, p. 25). Hutchinson (1999) dubbed this exclusive control the "most lucrative monopoly of any kind in the nation" ( $p$. 73). Nevertheless, the actual role the provincial governments play differs slightly between the provinces. For instance, Quebec's and Manitoba's casinos and lotteries are fully owned and operated by government-owned Crown corporations, whereas the daily operation of some casinos in Ontario is managed by private companies (Campbell, 2009).

In Ontario, which generates nearly twice as much gambling revenue as any other province (Statistics Canada, 2009), the Ontario Lottery and Gaming Corporation (OLG) is the Crown corporation responsible for the bulk of the province's gambling (with the exception of horseracing and some charity-run gambling), which includes casino facilities, lotteries, sports betting, and electronic bingo venues. The province is home to

\footnotetext{
1 "EGMs" is a general term for "high-intensity gaming machines," which include slot machines, video poker machines, fruit machines, and video lottery terminals (VLTs) (Dowling, Smith, \& Thomas, 2005).
} 
27 casino facilities, which OLG divides into three categories: "resort casinos," "casinos," and "slots facilities." There are four resort casinos - Casino Niagara, Casino Rama, Caesars Windsor, and Fallsview Casino Resort - and these are both the largest facilities and the ones with their day-to-day operations managed by private businesses. There are also six casinos, which are smaller than the resort casinos, but still offer both slot machines and table games. Finally, there are 17 slots facilities, which offer slot machines but no table games, and are connected to horseracing tracks. In the 12 month period that ended on March 31, 2007, OLG generated just over $\$ 6$ billion in revenue, with the casino facilities accounting for slightly over half of that total (Ontario Lottery and Gaming, 2007).

The emergence of this massive industry in Ontario and the rest of Canada was precipitated by the same influences that precipitated gambling expansion in other countries: the potential for more revenue, more tourism, and more employment. As Campbell and Smith (1998) explained, "Gambling in Canada has not been advocated for its own sake...Rather, the activity has successfully been linked to serving the greater good" (p. 24). For example, Room, Turner, and Ialomiteanu (1999) argued, "The increase in the availability of gambling has been fuelled to a large extent by the search by various levels of government for new sources of revenue" (p. 1450). Also, the decision to locate casinos in cities such as Windsor, Niagara Falls, and Hull that are situated near the U.S. border exemplifies a deliberate attempt to attract foreign tourists, while casinos in places like Montreal and Halifax were established partly to give their cities additional tourist attractions (Eadington, 2001). Finally, in explaining Canada's embrace of gambling, Mandal and Doelen (1999) stated, "When it comes to job creation, no industry is more alluring than gambling, which promises good wages after only a few weeks of training" (p. 2).

Even today, one finds that these same three factors are mentioned repeatedly to promote Canada's gambling industry. For instance, the OLG website states:

OLG creates jobs and stimulates tourism. Proceeds from OLG Slots and Casinos assist the provincial government in the support of hospitals, amateur sport, recreational and cultural activities, provincial priority programs such as health 
care and education, and local and provincial charities and non-profit organizations through the Ontario Trillium Foundation. (Ontario Lottery and Gaming, 2009a) As another example, the President and CEO of the Canadian Gaming Association (CGA), which “publicly represents Canada's gambling industry” (Canadian Gaming Association, 2009), advocated the legalization of single event sports betting (as only multiple event sports betting is currently permitted) in a Canadian gaming business trade magazine by writing, "And let's not forget about the economic benefits. With more than 100 million Americans within a six-hour drive of a Canadian casino, allowing single event sports betting will foster tourism." He then discussed the revenue generated by visitors attracted to Las Vegas casinos on Super Bowl weekend and stated, "These kinds of tourist visitations and economic activities support literally thousands of jobs" (Rutsey, 2008, p. $6)$.

\subsubsection{Canadian Casinos and the Employment Factor}

Approximately 19,000 people are currently employed by Ontario's casino industry (J. Berkovitz, personal communication, January 6, 2010), and many more are employed by the province's more extensive, general gambling industry. The gambling industry's ability to create jobs in Ontario and other parts of Canada has received considerable attention and it seems to often be perceived as an especially important benefit that the industry provides. For example, the CGA recently released an "Economic Impact Study" boasting that Canada's gambling industry directly sustains over 135,000 full-time jobs nationwide, with nearly 50,000 of them in Ontario (Canadian Gaming Association, 2008). Such figures were subsequently relayed to the public through various newspaper stories about the report (e.g., Macleod, 2008; Wilson, 2008; Windsor Star, 2008). A story in Victoria's Times Colonist, for example, was particularly enthusiastic about the report, headlining its article, "Gambling Creates 16,400 Jobs in Province" (Wilson, 2008).

It is easy to understand such enthusiasm when considering the need for new employment opportunities in many communities. For instance, an article in Chatelaine magazine stated that when Sydney, Nova Scotia's casino opened in August 1995 it provided 300 well-paying jobs "in a community where jobs of any sort are as rare as a royal flush" (Kimber, 1997, p. 41). Apparently, the official unemployment rate at the 
time was $27 \%$ and nearly 5,000 people showed up for the casino's job fair (Kimber). Similarly, when explaining Windsor residents' widespread approval toward their local casino, Hutchinson (1999) stated:

This isn't surprising: the casino is Windsor's third-largest employer, with 5,200 full-time and part-time workers. Most Casino Windsor employees are unionized and make good money, more than they would in the up-and-down automotive industry, which still dominates the regional economy. (p. 135)

As Henriksson and Lipsey (1999) highlighted, "Employment is a matter of great public concern and it is not surprising that those who would push for increased gambling use increased employment as an argument to buttress their case” (p. 263).

The importance of new employment opportunities also was illustrated in a telling study by Room et al. (1999) on the real and perceived impacts of Niagara Falls' first casino. The researchers conducted short telephone interviews with hundreds of Niagara region residents just before the casino opened and then again one year later. The researchers found over $70 \%$ approval for the casino in both study intervals, and this approval appeared to result in large part from a perception held by over $85 \%$ of the respondents that the number of jobs would and did increase with the casino's establishment. The benefit of job creation seemed to outweigh other concerns, including expected increases in serious crimes, traffic congestion, and PG within the community.

Nevertheless, the employment benefits that casinos offer have sometimes been viewed with scepticism. One common question that critics raise is whether casinos actually generate job growth or whether they simply create new jobs while cannibalizing existing ones (e.g., Grinols, 2004). This phenomenon, known as "displacement," is caused by gamblers spending their money in casinos instead of other existing establishments, such as restaurants or movie theatres, that the gamblers would have otherwise patronized (Persky, 1995). For instance, in Room et al.'s (1999) study of the Niagara region, they found "a net increase in jobs did not occur at the levels which had been projected" (p. 1461), and reasoned that this failure was a result of displacement spending, which was detected among the respondents. Morse and Goss (2007) looked at data from numerous U.S. states and determined that casinos did seem to cannibalize jobs in some states, but not in others. Such incongruity is actually quite logical because overall 
job growth will depend on numerous factors, including casino location, as urban casinos naturally should receive more displacement spending than more isolated casinos (Eadington, 1998). Aside from displacement, casino employment also has received criticism for involving primarily menial jobs (Henriksson \& Lipsey, 1999), submitting employees to abuse from gamblers, causing hearing loss, (Hutchinson, 1999), offering poor shifts, and providing too much seasonal work (Blevins \& Jensen, 1998). Moreover, various studies have found that PG may be particularly prevalent among casino employees (e.g., Dangerfield, 2004; Duquette, 1999; Shaffer et al., 1999).

\subsection{Problem Gambling and Its Prevalence in Ontario}

A fairly simple definition of PG is offered by the Canadian Problem Gambling Index (CPGI), which is an instrument used to measure PG rates. The CPGI defines PG as "gambling behaviour that creates negative consequences for the gambler, others in his or her social network, or for the community" (Ferris \& Wynne, 2001, p. 7). However, despite the simplicity of that definition, conceptualizations of PG and gambling behaviour in general are far more complex and have been studied and explained with various theories for more than a century. For example, in the late 19th century, psychoanalytic theory stipulated that individuals were attracted to gambling by subconscious motivations, and excessive gambling resulted from a disease of the mind. Behavioural psychology theories that then emerged in the 1950s rationalized gambling behaviour primarily as a function of conditional learning from gamblers' external environments and stimuli. Modern cognitive-behavioural theories have somewhat combined the two approaches by explaining gambling behaviour with a recognition of both internal psychological factors and external environmental factors (Aasved, 2002). However, conceptualizations of PG continue to evolve and much debate over the topic persists. For instance, it remains unclear whether PG is most comparable to substance abuse disorders, such as alcoholism, or impulse control disorders, such as obsessive shopping (Blaszczynski, 2005).

Despite such remaining uncertainty, a current and fairly comprehensive conceptualization of PG is provided by the Ontario Problem Gambling Research Centre's Problem Gambling Framework (PGF). This framework suggests that PG is best 
understood as a dynamic continuum in which individuals' PG behaviour, or lack of, may vary over time. The PGF states that PG is closely related to different "direct" and "indirect" risks that influence each individual. Direct risks are those that can directly lead to PG and they involve both "risk practices," such as frequently betting more than one had planned or borrowing money to gamble, and "risk cognitions," such as a belief in gambling superstitions or a severe misunderstanding of probability. Indirect risks are the secondary factors that influence one's susceptibility to the direct risks. These indirect risks include one's social, emotional, and biological predispositions, which can make someone either more or less likely to adopt direct risks. Moreover, one's environmental conditions serve as a contextual indirect risk. For instance, greater access to gambling may impact the likelihood of someone becoming a problem gambler. Naturally, as an individual experiences a higher quantity of risk factors and risk factors in greater severity, the probability increases that PG will result. However, the relationship is not completely direct, which helps to explain why some people experiencing many or severe risk factors never become problem gamblers, while other people experiencing few risk factors do become problem gamblers. Furthermore, risk factors can be offset by protective factors, such as one's personal commitment to health or perception of social support. Also, in addition to negative consequences, the PGF suggests that PG can be partially defined by one's psychological or physiological dependence on gambling (Ontario Problem Gambling Research Centre, 2009).

The prevalence of PG in Ontario has been investigated in two fairly recent studies (i.e., Wiebe, Mun, \& Kauffman, 2006; Williams \& Wood, 2004a) using the CPGI, which categorizes each individual as a "non-gambler," "non-problem gambler," "low risk gambler," "moderate risk gambler," or "problem gambler" (Ferris \& Wynne, 2001). Williams and Wood classified $1.00 \%$ of their respondents $(n=6,554)$ as problem gamblers and $3.76 \%$ of their respondents as moderate risk gamblers, while Wiebe et al. classified $0.8 \%$ and $2.6 \%$ of their respondents $(n=3,604)$ in the two categories respectively. ${ }^{2}$

\footnotetext{
2 These two studies labelled "moderate risk gamblers" as "moderate problem gamblers" and "problem gamblers" as "severe problem gamblers."
} 


\subsection{Gambling by Casino Employees}

\subsubsection{Problem Gambling Rates}

Numerous existing studies have investigated PG among different population groups, including employees at a university health centre (Petry \& Mallya, 2004), employees in the transportation sector (Revheim \& Buvik, 2009), individuals in drug and alcohol treatment programs (Orford et al., 2003), and prison inmates (Walters, 1997). A small number of studies have investigated PG among casino employees, who represent a particularly interesting group due to the unique environment in which they work. As Hing and Breen (2008a) stated, “One occupational group with a distinctive work environment that could reasonably be expected to influence gambling behaviour is gaming venue employees" (p. 11). Moreover, given that increased employment is a common rationale for expanding the casino industry, it is important to understand the impacts of these jobs on the individuals who hold them.

The various studies that have investigated PG among casino employees have generally found that PG was, in fact, quite prevalent among these workers. The only one of these studies conducted in Canada is an unpublished study undertaken by Dangerfield (2004), who surveyed 123 employees from two Alberta casinos using the CPGI. Her findings classified $6.3 \%$ of the sample as problem gamblers and $18.9 \%$ as moderate risk gamblers, which were rates several times higher than had been detected by other studies involving the general Alberta population and workforce. In a U.S. study, Shaffer et al. (1999) surveyed 3,841 employees from four casinos using the South Oaks Gambling Screen (SOGS), which classifies individuals as either non-gamblers or as level 1, 2, or 3 gamblers, with level 3 signifying the most severe level of PG. The researchers classified $2.1 \%$ of the employees as exhibiting level 3 gambling behaviour, which was nearly double the stated rate for the U.S. population at the time, and 1.4\% as exhibiting level 2 gambling behaviour, which was actually less than the $2.2 \%$ stated for the general population. In another U.S. study, which is unpublished and used the SOGS to investigate employee gambling at a single Las Vegas casino, Duquette (1999) found extremely high levels of PG, with $20.3 \%$ of the sample classifying as level 3 gamblers and $44.6 \%$ classifying as level 2 gamblers. In South Korea, Lee, LaBrie, Rhee, and Shaffer (2008) 
used the SOGS to survey 388 employees in two casinos and the authors classified $3 \%$ of the employees as level 3 gamblers, which was identical to prevalence rates for the country's general population. Finally, Wu and Wong (2008) surveyed 119 casino dealers in Macao using a stricter interpretation of SOGS results, yet still classified $6.7 \%$ of the dealers as level 3 gamblers, although the authors did not provide comparative PG rates for Macao's general population.

\subsubsection{Forms of Gambling}

Even though PG appears to be relatively prevalent among casino employees, their preferences toward different games appear to be fairly similar to preferences exhibited by the general population. For example, Dangerfield (2004) found that the employee gamblers she surveyed were most likely to play the lottery, and EGMs were the most popular form of casino gambling. Duquette (1999) did not investigate lottery gambling, but she found that EGMs were easily the most popular form of gambling among her sample. Even though neither of these two studies was conducted in Ontario, it is still worth noting that the preferences the studies detected are quite similar to the preferences that Wiebe et al. (2006) found in the general Ontario population, for whom ticket lottery games and EGMs were the most common forms of past-year gambling.

The apparent popularity of EGMs among casino employees is noteworthy because numerous studies have suggested that EGM players may be particularly susceptible to PG. For instance, Breen and Zimmerman (2002) determined that the onset of PG occurred faster in gamblers who favoured machine games over other forms of gambling, and EGMs have been identified as the most common form of gambling among PG treatment seekers in both Ontario (Rush, Moxam, \& Urbanoski, 2002) and Winnipeg (Wiebe \& Cox, 2001). Numerous potential reasons have been offered to explain this apparent association between EGMs and PG. For example, Griffiths $(1990,1999)$ has argued that EGMs" "structural characteristics," such as buttons that give players control over certain functions and the games' rapid play frequencies, can induce a false perception of control and promote PG via basic psychological conditioning. Furthermore, modern slot machines are based on computerized random-number generators that distort the genuine chances of winning by displaying near misses and winning combinations on 
non-paying lines at disproportionately high frequencies, and these characteristics also may be related to PG (Harrigan, 2007, 2009).

\subsection{Changes in Gambling by Casino Employees}

Despite the high rates of PG that have been detected among casino employees, past research actually has found that casino employees are more likely to decrease than increase their gambling after beginning their jobs. For example, in Shaffer et al.'s (1999) study of U.S. casino employees, the authors asked the employees directly how their gambling had changed since they began working in a casino, and 55.4\% claimed their gambling had remained the same, $29.3 \%$ claimed it had decreased, and only $15.2 \%$ claimed it had increased. Similarly, Shaffer and Hall (2002) surveyed 6,067 employees from six different U.S. casinos, with two follow-up questionnaires administered one and two years later, and determined that over the two-year span of the study $22.6 \%$ of the sample had shifted to a more improved gambling status on the SOGS scale, while only $11.6 \%$ had shifted to a more disordered status. Additionally, in Dangerfield's (2004) study of Alberta casino employees she asked the employees directly how their employment had affected their gambling, and $51.1 \%$ claimed it had not affected their gambling, 28.9\% claimed it had decreased their gambling, and $20.2 \%$ claimed it had increased their gambling.

\subsection{Workplace Influences}

Working in a casino inevitably subjects casino employees to a variety of influences that potentially could precipitate such increases or decreases in gambling participation. Much of the research into these workplace influences has been conducted by Hing and Breen (2007, 2008a, 2008b), who identified a litany of such influences in a series of qualitative studies undertaken in Australian casinos. One study involved interviews with several dozen managers of gambling facilities (2007); one involved interviews with nearly 200 casino employees, gambling venue managers, and gambling counsellors (2008b); and one involved six case studies of employees who had become problem gamblers while working in casinos (2008a). The authors divided the influences they identified into nine categories: close interaction with gamblers, frequent exposure to gambling, the influence 
of fellow employees, the influence of management, the nature of the work, the hours of the work, the frequent exposure to gambling marketing and promotions, RG training of the staff, and other RG strategies in the venue (2007, 2008a, 2008b). For the purposes of this study, these nine categories have been further condensed into four categories of workplace influences: the employees' exposure to gambling; the employees' exposure to the casino patrons; the employees' exposure to the casino work environment; and the existence of training, regulations, and resources. Some of these influences have already been analyzed in prior research on casino employees, while insights on some of the other influences must be derived from general research on gambling behaviour.

\subsubsection{Exposure to Gambling}

Many casino employees experience high levels of exposure to gambling and some employees are completely immersed in it throughout their workdays. This exposure naturally increases the employees' familiarity with and knowledge about gambling. In fact, some employees must become highly knowledgeable about certain games simply to perform their jobs. For instance, a blackjack dealer must know the rules and strategies of

blackjack in order to deal it properly and a surveillance worker must know the nuances of the game in order to monitor it properly. As one supervisor explained to Hing and Breen (2008a), "My staff are so much better if they know how to [gamble]. I suggest to my staff that they sit down and learn - spend a day (learning). You need to know your product” (p. 17).

As casino employees acquire such gambling knowledge they naturally should learn that the house maintains a clear edge in virtually every game (excluding games like poker in which players bet against one another instead of the house), meaning gambling will usually result in losing one's money. As Hing and Breen (2008b) explained:

Staff sometimes hear about losses from patrons, see how much people spend and see the venue's takings during machine clearances, when change booth tills are cleared, in count rooms and during banking. Staff can therefore have better knowledge of the poor odds of gambling than the general public. (p. 14) This acquired knowledge consequently may serve to dissuade casino employees from gambling. Furthermore, employees simply may become bored or uninterested with 
gambling after spending so much time surrounded by it. In fact, throughout their interviews Hing and Breen found, "For some staff, any glamour, excitement and appeal of gambling had long been dispelled by virtue of their work experiences. They referred to gambling as boring, were sick of being around gambling... During their time off, the last environment they wanted to be in was a gaming room" (p. 14).

On the other hand, it is also possible that the gambling knowledge that employees acquire will actually encourage them to gamble. As Hing and Breen (2008b) explained, "Staff may feel well equipped to gamble as increased knowledge enhances ease of product use" (p. 11). In fact, as casino employees familiarize themselves with different games it is even possible that they will develop a false sense of overconfidence in their abilities to win at the games. This overconfidence can be characterized by an "illusion of control," which is "the perception of control over objectively chance-determined events" (Langer \& Roth, 1975, p. 951). In one of the earliest experiments on this topic, Langer (1975) studied a genuine office lottery that randomly gave buyers a ticket with either a normal letter or an unfamiliar symbol. Each player was then contacted before the drawing and offered an opportunity to exchange his or her ticket for a ticket in another lottery where the chances of winning were greater, and it was found that a much lower percentage of those individuals with normal letters on their tickets were willing to exchange their tickets. In a second experiment, subjects were asked to rate their confidence in correctly choosing one of three copper wire paths that could be touched with a stylus to sound a buzzer. Half of the subjects were given two minutes to inspect the device, while the other half were not, and although the subjects were told that the correct wire would be selected at random, those subjects given two minutes to familiarize themselves with the apparatus rated their confidence at choosing the correct wire significantly higher than did the other subjects. Inspired by Langer, Burger (1986) and Bouts and Van Avermaet (1992) conducted experiments in which subjects were asked to wager on very basic card games involving either traditional or unfamiliar cards. In both experiments, the subjects were willing to wager more when playing with traditional playing cards. Furthermore, based on his research of PG EGM players, Griffiths (1990) determined, "The fact that most of them had 'favourite machines' reflected the belief that 
they were better (through familiarity) on one particular fruit machine than other less familiar ones" (p. 36).

As casino employees familiarize themselves with various forms of gambling, it therefore is possible that the employees will develop an illusion of control regarding their abilities to win the games. In fact, several of the PG employees interviewed by Hing and Breen (2008a) made comments consistent with this phenomenon. For example, one employee stated, "[The employees] know that higher turnover machines have a higher rate of pay...If you were to... watch someone pump a machine for 2 hours with $\$ 5$, you'd be mad not to get on it and have a go. So they'll watch, watch, watch, and then jump on something that has been played" (p. 20). Some machines do, in fact, offer higher payout rates than others (Delfabbro, 2004; Harrigan \& Dixon, 2009a), but this employee was mistaken in her belief that it is advantageous to play a machine that has been played previously without paying out (Dowling, Smith, \& Thomas, 2005). In other words, the employee's familiarity with the machines has actually resulted in an illusion of control giving her a false sense of confidence.

\subsubsection{Exposure to the Patrons}

Much like casino employees theoretically should learn that the rules and design of gambling games dictates that gamblers generally will lose money, many employees also should be able to observe this losing among the patrons. Moreover, employees may witness the behaviours of patrons who appear to have gambling problems. Therefore, exposure to the patrons also may discourage some employees from gambling. As Hing and Breen (2008b) explained:

Close interaction with and frequent exposure to heavy and problem gamblers deter some staff from gambling or from gambling heavily. Many interviewees had an aversion to heavy gamblers and did not want to be like them. Some were turned off by the distress, rudeness, anger and mood volatility accompanying gambling losses. Some had witnessed the effects of gambling problems among patrons. (p. 14)

Similarly, to explain the decreases in gambling that many of their respondents claimed to have experienced, Shaffer et al. (1999) reasoned, "Like ice cream lovers who seek jobs in 
ice cream shops and soon tire of ice cream, casino employees may learn from their direct observations, and more indirect opportunities for social learning, about the 'downside' of gambling” (p. 374).

As an example of such observations, one of the employees surveyed by Dangerfield (2004) noted, "I think it is very sad to see some people enter the building right at opening at 10 a.m. and they are still here when I leave at 6 or 7 p.m.” (p. 58). In fact, such experiences may be relatively common among employees--a survey conducted several years ago by the British Columbia Lottery Corporation "found that one quarter of casino staff reported being approached at least once a month by people with concerns about their gambling" (Canadian Press, 2007). Moreover, slot machine attendants sometimes must clean up plastic cups filled with urine because slot machine players are unwilling to abandon their machines to visit a bathroom (Hutchinson, 1999), and casino employees sometimes even see gamblers wear diapers so they can remain at machines for prolonged periods of time (Canadian Press; Hutchinson). Such experiences with the patrons clearly could dissuade some employees from gambling.

On the other hand, even though employees may see many patrons losing, the employees also may observe patrons winning, and be enticed toward gambling by such observations. As one employee interviewed by Hing and Breen (2008a) stated, "If you see someone else winning the big one, you always think your time might come" (p. 12). Even though employees inevitably should see fewer wins than losses, the employees may recall the wins they observe better than the losses they observe, or simply be more impacted by those wins, just like gamblers sometimes exhibit selective memory biases in which they recall wins better than losses (Toneatto, 1999). As another employee interviewed by Hing and Breen explained, "When you see people winning, it affects you. It's amazing that the losing doesn't' (p. 17). In fact, with regards to EGMs such a phenomenon easily could result from the machines themselves, as the sound and light effects that typically are built into the machines (Griffiths, 1999) could make it appear as though the machines were generating more wins than they really were. Additionally, the patrons may give the casino employees gambling tips that the employees then want to follow. As the previous employee quoted from Hing and Breen's study also claimed, "Many patrons say 'I've got a hot tip,' which is ' $100 \%$ tempting”' (p. 17). 


\subsubsection{Exposure to the Work Environment}

In addition to possibly being influenced by the patrons, casino employees also may be influenced by one another. In some cases, employees may be discouraged from gambling by their co-workers. As Hing and Breen (2008b) found, "In some workplaces, a prevailing attitude of gambling as 'a mug's game' or that the staff member 'should know better' deterred staff from gambling" (p. 15). Nevertheless employees also may be drawn toward gambling by one another. In Hing and Breen's (2007) interviews with facility managers they found that most of the mangers felt fellow employees would exert little influence over their co-workers, but when such influences existed they would probably involve encouraging employees to gamble. Also, Hing and Breen (2008a) found that such social influence was a significant issue among the six PG casino employees the authors interviewed. As Hing and Breen summarized, "Five problem gamblers experienced some peer endorsement of gambling, where it is the 'norm' to gamble with colleagues after work and on days off, to gamble while waiting for others to finish work, or to gamble at other venues where they know the staff' (p. 24). In fact, the authors also found that some casino managers were "keen gamblers and so set a poor example for staff, nurture a gambling culture in the organisation, and allow staff to gamble in the workplace" (p. 24). As one of the interviewees explained, "All our managers like to gamble as well. So there is $100 \%$ influence there" (p. 17).

The influence of one's peers has been noted in general gambling research as well. For instance, when Griffiths (1990) questioned 50 PG EGM players about their behaviours, $44 \%$ claimed that one of the reasons they started playing was because their friends did it, and 58\% gave the same response to explain why they continued playing. Gamblers sometimes even bet in teams, such as when buying lottery tickets, and Hraba and Lee (1996) found this activity to be a predictor of PG among females. As the authors explained, "Team play connotes a special support for women who gamble, they gamble with others, and this can lead to problem gambling" (pp. 98-99). Also, in a telephone survey of 900 adult gamblers in Western Canada, Walker, Hinch, and Weighill (2005) found that "communing" was the most important gambling motivator identified by both males and females. Similarly, Neighbors, Lostutter, Cronce, and Larimer (2002) asked 
134 undergraduate student gamblers in the U.S. to list and rank their top five reasons for gambling, and when the authors grouped these responses into 16 different motivational categories, the "social reasons" category was the third most frequently identified, behind only "money" and "enjoyment/fun."

Aside from possibly being influenced by their co-workers, casino employees also comprise a captive audience that is exposed to the gambling marketing and promotions that are present throughout casinos. Such exposure naturally could attract the employees toward gambling. As one of the employees interviewed by Hing and Breen (2008a) stated, "Keno promotions are a real good one, because they do extensive in-house advertising... so people...put a bet on that game, because they think it is good odds" (p. 22). Very little research has been conducted on the relationship between advertising and gambling behaviour (Griffiths, 2005), but some limited evidence exists regarding the impact of such influences. For example, Grant and Kim (2001) investigated gambling triggers among 136 problem gamblers and found that gambling advertisements were the most commonly cited trigger, having been mentioned by $45.8 \%$ of the sample.

Working in a casino also may result in job stress, which in turn may induce employees to gamble. In fact, Keith et al. (2001) conducted focus groups with gambling industry employees from Ontario and Manitoba and found that stress was one of the most common health and safety concerns the employees mentioned, and slot machine workers described their work areas as particularly stressful. Also, Dangerfield (2004) investigated job stress in her Alberta study and found that $10.7 \%$ of the casino employees she surveyed rated their jobs as "extremely stressful," $61.5 \%$ as "somewhat stressful," and $27.9 \%$ as "not at all stressful," although these stress levels were actually less than those found in a previous survey on job stress in the general Alberta population.

Job stress is an important factor to consider because various studies have detected a positive relationship between job stress among casino employees and their gambling. For instance, Wu and Wong (2008), who examined casino employees in Macao, found PG scores to be positively correlated with job stress at significant levels. Also, Shaffer and Hall (2002) found that those employees who exhibited level 3 gambling behaviour in the final interval of the two-year study expressed significantly greater job stress in the first interval. Moreover, several of the PG employees interviewed by Hing and Breen 
(2008a) noted stress as a factor influencing their gambling. For example, one employee said that her gambling had increased after she received a promotion to a higher position that resulted in increased stress. Another employee claimed, "Workplace stress 'influences me. If I've had a hard day, I'll...play the pokies... it is an elation feeling, a good feeling...to forget about work for however long the money lasts for and to escape...it is just zoning out"' (p. 20). The relationship between stress and gambling has also been researched in studies that did not focus on casino employees. For instance, data taken from an Australian PG helpline in 1996 found that stress reduction was one of the most common reasons callers gave to explain their gambling (Coman, Burrows, \& Evans, 1997).

\subsubsection{Training, Regulations, and Resources}

Many casino facilities proactively strive to reduce PG and promote RG among their workforces through RG training programs. For example, in 2005 the Las Vegas Sands Corporation, which owns the Venetian and several other casinos, began a program that was developed in conjunction with the Harvard University Medical School Division on Addictions to teach all of its employees about PG (Stutz, 2005). Likewise, most of the employee problem gamblers interviewed by Hing and Breen (2008a) had received some sort of RG training, and although the employees' opinions on the training's effectiveness were quite varied, the nature of the sample leads one to expect responses doubting the training's efficacy. In fact, in Hing and Breen's (2007) interviews with facility managers, the authors found that the managers tended to believe the RG training their facilities provided would serve as the most significant factor discouraging employees from gambling.

Such training programs are used in Ontario as well. In 2005, OLG began "employee and management training programs to increase awareness of potential gambling-related problems and understanding of best practices in Responsible Gaming" (Ontario Lottery and Gaming, 2006, p. 13). Every OLG employee (resort casino employees are not employees of OLG) had received this training by early 2006 and OLG also incorporated RG training into the orientation program for new employees. Furthermore, "Responsible-gaming messages are reinforced through a variety of 
employee communication vehicles" (p. 13). The OLG conducted an internal study of this RG training program and claimed the results "indicated that the program had been highly successful as employees noted an increased understanding of appropriate practices" (Ontario Lottery and Gambing, 2007, p. 10). Although all OLG employees receive some RG training, more advanced levels of training are provided to higher-level personnel, such as managers and supervisors. Reinforcement training currently is managed independently by the different facilities, but OLG intends to implement a standardized schedule of reinforcement training in 2010. All resort casino employees receive RG training as well, but at some of the resort casinos this training differs from the OLG training (J. Berkovitz, personal communications, November 18 and 19, 2009; January 13, 2010).

The usefulness of such training is further supported by Giroux, Boutin, Ladouceur, Lachance, and Dufour's (2008) study on the impact of a RG training session on 1,615 employees from three Quebec casinos. The authors surveyed the employees immediately before and after the training session and found that $89.6 \%$ "were either very or entirely satisfied with the training session" and $77.1 \%$ "indicated that the training was very or entirely relevant and useful for their job" (p. 5). The employees also exhibited a clearer understanding of chance, less acceptance of risk cognitions, and a better understanding of PG. Moreover, the employees expressed greater confidence in their ability to identify "gamblers in crisis," exhibited greater clarity about the procedures established to help such gamblers, and attached greater value to such intervention. Six months later, $32 \%$ of the respondents completed a follow-up questionnaire and the results suggested that the employees had maintained their improved understanding of chance and risk cognitions. However, the employees also exhibited decreased confidence in their ability to identify gamblers in crisis, they indicated less clarity about the procedures established to help such gamblers, and they attached less value to such intervention. In other words, even though training programs seem to offer some benefits for casino employees, these benefits appear to wane over time. Giroux et al. noted that a "loss of knowledge" could have been responsible for the results found in the follow-up study and consequently advised, "If this is the case, it appears to be necessary to remind the 
employees about problem gambling on a regular basis, through various means, such as brochures, videos, additional training sessions or booster sessions" (p.7).

Casino facilities in many jurisdictions complement such training with regulations that restrict their employees' gambling options. Different jurisdictions and individual facilities have established a variety of such regulations, and even among Ontario casinos there are different regulations for employees in the OLG facilities and employees in the resort casinos. OLG stipulates essentially that its non-supervisory employees are allowed to gamble in an Ontario casino only if it is one of the four resort casinos, and supervisory employees cannot gamble in any Ontario casino [Gaming Control Act, 1992 - O. Reg. 385/99, Sec 32 (1), (2) and (2.1)]. On the other hand, resort casino employees can gamble at any casino in Ontario aside from the one where they work, with the exception of employees at Niagara's two resort casinos, who are prohibited from gambling in either of the two facilities (J. Berkowitz, personal communications, November 18, 2009; January 6, 2010). Also, on April 1, 2009, OLG instituted a new rule prohibiting all OLG employees from playing Ontario's ticket lottery games, which includes the governmentrun sports betting games (Loriggio \& Benzie, 2009; Ontario Lottery and Gaming, 2009b). Nonetheless, Ontario casino employees are permitted to bet on horse races, including at facilities in which they work, and participate in non-OLG affiliated forms of gambling in the province, such as betting in bingo halls.

In Alberta, Dangerfield (2004) encountered policies identical to those in Ontario's resort casinos, as employees simply were prohibited from gambling at the casinos where they worked. New Jersey, on the other hand, once had especially stringent regulations that prohibited employees from gambling in any of the state's casinos (Romano, 1991), but these restrictions have since loosened and the state now allows employees without high-level positions to gamble in casinos except for those where they work or those that are owned by the same company (New Jersey Casino Control Act, Article 7, Section n). In Australia, Hing and Breen (2008a) found that the rules regarding employee gambling varied by facility, and some of the facilities even allowed their employees to gamble on premises when not working. At the time of her study, Duquette (1999) found that in Las Vegas, "Gambling by casino employees is permitted and even encouraged by casinos 
through various incentives, such as paycheck cashing drawings and free drink tickets" (p. $33)$.

Such disparate regulations obviously can have varying influences, but it also should be recognized that even identical regulations can have quite different ramifications depending on the characteristics of the area where the regulations are enforced. For instance, the Alberta employees studied by Dangerfield (2004) had to travel over 400 kilometres to reach the next closest casino where they could gamble, and Dangerfield speculated that these regulations therefore contributed significantly to the decrease in gambling that many of the employees claimed to have experienced. She further supported this conjecture in part by highlighting that of the $4.2 \%$ of the sample who claimed to have quit gambling, $60 \%$ claimed they did so because it was prohibited by their jobs. In a city like Las Vegas or Atlantic City, on the other hand, being barred from gambling in a small number of casinos would be far less meaningful. In Ontario, most casino employees would need to make a concerted effort to visit an unrestricted casino, but few would need to travel over 400 kilometres like the employees in Dangerfield's study. Additionally, it should be noted that the impact of casino employee gambling regulations is limited because employees can engage in substitute forms of gambling, such as with friends or online.

Despite such limitations, there is reason to believe that regulations can significantly influence employee gambling. For example, one of Hing and Breen's (2008a) interviewees explained, "In one hotel I worked, we were allowed to gamble, and I gambled. And here we are not allowed... and I don't find myself gambling as much" (p. 19). Additionally, past research on gambling proximity and gambling behaviour offers indirect evidence supporting the notion that employees may be dissuaded from gambling as regulations force the employees to travel further to gamble. For example, Adams, Sullivan, Horton, Menna, and Guilmette (2007) surveyed about 1,500 students at four different Ontario universities and found that level 3 gambling was far more common among students enrolled in the two universities that were located near casinos. Likewise, one can analyze the impact of regulations by examining the changes in gambling behaviour that occur when gambling proximity increases through the establishment of a new casino in a community. Questions remain as to whether gambling expansion creates 
demand or fulfills existing demand, but there is little question that an expansion of gambling leads to more gambling (Marshall, 2005). For instance, Room et al. (1999) found that a year after the first casino opened in Niagara Falls, the percentage of Niagara region residents participating in casino gambling in the past year nearly quadrupled.

When gambling participation increases, it also may be complemented by an increase in PG. As Eadington (1996) stated, "There are certainly significant correlations between the proliferation of commercial gaming and compulsive gambling" (p. 5). For instance, Ladouceur, Jacques, Ferland, and Giroux (1999) found that in Quebec between 1989 and 1996, during which time gambling availability increased dramatically, the prevalence of level 2 gambling behaviour remained mostly unchanged but the prevalence of level 3 gambling behaviour nearly doubled from $1.2 \%$ to $2.1 \%$. In fact, Blaszczynski and Nower (2002) even call "availability and access to gambling" the "starting block" for their frequently cited "pathways model of problem and pathological gambling" (p. 491).

One can further analyze the impact of regulations on casino employees by examining how gambling regulations impact the general population. In one revealing study on this topic, Lund (2009) investigated a 2007 Norwegian ban on EGMs by surveying 1,293 EGM players on their gambling behaviours several months before and after the ban. Lund found that after the ban the respondents had not only decreased their EGM play, but also their participation in all eight of the other gambling games that were considered. As the author concluded:

This result suggests that the disappearance of one significant game can make even other games less appealing for (some) gamblers, almost as if...gambling loses some of its force of attraction or the gambling behaviour somehow loses momentum. This highlights the importance, not just of single games, but of the whole gambling environment that people exist within, and points in the direction of a possible synergetic effect between games. (p. 223)

In other words, these results suggest that when casino employees obtain their jobs and suddenly have their gambling options limited by regulations, the employees may decrease their involvement with all forms of gambling and not just those forms of gambling that have been restricted. 
However, Lund (2009) also found that participation in internet gambling significantly increased during the period of her study. Lund argued that this increase did not appear to be the result of substitution, pointing out that gambling substitution should have resulted in increases in the overall gambling on different games instead of just the online versions, and an increase in participation rates for games only found online. Nevertheless, her explanation that the significant increase in online gambling participation was simply the result of a general shift towards online gambling unrelated to the EGM ban is certainly questionable, and the possibility that a substitution effect occurred should not be fully discounted. In fact, Dangerfield (2004) found that the casino employees she surveyed engaged in non-casino forms of gambling with family and friends overwhelmingly more than the general population, and this finding led her to surmise, "It is possible that casino employees attempt to compensate for prohibited gambling activities such as slots and casino table games by increasing participation in those activities that are accessible such as lotteries, and cards with family and friends" ( $\mathrm{p}$. 57).

Despite the potentially dissuading influences of regulations and training, it is clear that PG can still be an issue for some casino employees. Consequently, some facilities offer various resources that employees can utilize to seek assistance. For example, Shaffer et al. (1999) found that the facilities they studied provided employee assistance programs (EAPs) that the employees could use for gambling problems or any other potential issues. However, the authors found that some of those employees who could have most benefitted from the program were actually the most hesitant to use it. As the authors explained, "Level 3 gamblers seem to be reluctant to use the EAP not because of concerns about confidentiality within the EAP staff/employee relationship, but because of concerns that their boss or co-workers may find out by other means" (p. 375).

\subsection{Risk Cognitions}

The various workplace influences that may affect employees' gambling directly may also affect their endorsement of risk cognitions. For example, employees may adopt or refute certain erroneous gambling beliefs through the gambling knowledge the employees acquire, through the employees' observations of patrons, through the employees' 
interactions with co-workers, or through the RG training the employees receive. Risk cognitions are important to consider because they can encourage the use of risky gambling practices and possibly catalyze the development of PG (Ontario Problem Gambling Research Centre, 2009). The link between risk cognitions and PG has been demonstrated by a variety of studies. For instance, Joukhador, Blaszczynski, and Maccallum (2004) assessed the acceptance of common gambling superstitions among 56 PG EGM players, 22 non-PG EGM players, and 23 individuals who were neither problem gamblers nor played EGMs. The authors found that the problem gamblers tended to espouse more superstitious beliefs than the other subjects, and levels of superstition acceptance were positively correlated with higher levels of gambling. Similarly, Mitrovic and Brown (2009) found that risk cognitions were positively related to PG levels among social poker players. Additionally, Miller and Currie (2008) aggregated data from five large Canadian gambling prevalence surveys and determined that irrational gambling beliefs were positively related to risky gambling practices. ${ }^{3}$

Research into gambling behaviour has identified a wide variety of risk cognitions, including the illusion of control; a "biased evaluation of outcomes" in which "successful outcomes are attributed to factors internal to the person... whereas failures are attributed to factors beyond personal control" (Walker, 1992b, p. 142); "Type I" and "Type II" gambler's fallacies, in which an observed frequency of a certain random result is expected to change or continue, respectively (Keren \& Lewis, 1994); superstition, which is "a strong conviction based on the erroneous perception of a cause-effect association between two independent events" (Joukhador et al., 2004, p. 171); and basic misunderstandings about probability and the laws of chance (Aasved, 2002). Risk cognitions are not only quite varied, but they are also fairly common. For example, Walker (1992a) asked 27 regular gamblers to verbalize all of their thoughts when playing EGMs, and the author classified $38 \%$ of the total statements and $80 \%$ of the strategic statements as irrational.

\footnotetext{
${ }^{3}$ The reliability of this study is questionable because one of the two risk cognitions considered - "You could win more if you used a certain system or strategy" - is actually a valid statement for some games. For example, in blackjack the "basic strategy" system of betting gives gamblers optimal probabilities of winning.
} 
Nevertheless, risk cognitions also appear to be quite vulnerable to corrective teaching. For example, Boutin, Tremblay, and Ladouceur (2009) conducted a study involving individuals who voluntarily visited an onsite casino information centre before entering a Montreal casino. The subjects spent approximately 10 minutes inside the information centre and during this time they were told about common misconceptions of randomness and presented with RG strategies. The authors found that, compared to a control group, the subjects had fewer misconceptions about gambling and randomness immediately after the visit and also three months later. In a second example, Williams and Connolly (2006) conducted a study involving several hundred university students who were divided into three different groups: students in a statistics class that involved extensive gambling examples, students receiving basic instruction on probability without gambling examples, and students enrolled in no math classes. In a questionnaire distributed six months after the courses concluded, the authors found that the students in the statistics class that involved extensive gambling examples had improved their ability to calculate gambling odds and were more resistant to certain irrational beliefs.

Therefore, it is reasonable to expect that casino employees would hold relatively few risk cognitions due to the gambling knowledge they acquire and the RG training they receive. In fact, Dangerfield (2004) investigated Alberta casino employees' attitudes toward the risk cognition, "When gambling, after losing many times in a row, you are more likely to win," and found that none of her respondents "strongly agreed" with this risk cognition and only $2.5 \%$ "agreed" with it. In comparison, Dangerfield cited a study of Alberta's general population in which $1.0 \%$ of the sample had "strongly agreed" and $9.9 \%$ had "agreed" with the same risk cognition.

As employees or other gamblers have their risk cognitions corrected, it logically should help them become more responsible gamblers. As Bersabé and Arias (2000) stated, "The correction of mistaken perceptions of chance would appear to be a measure capable of significantly reducing pathological gambling" (p. 33). This statement was based in part on findings from a variety of relevant studies. For instance, research by Ladouceur, Sylvain, Letarte, Giroux, and Jacques (1998) found that correcting risk cognitions produced a significant decrease in the urge to gamble among four of five PG subjects. Similarly, in study by Ladouceur et al. (2003), a group of 34 problem gamblers 
was given treatment primarily focused on correcting their risk cognitions and at the end of the ten week treatment period only $12 \%$ of the subjects were still categorized as problem gamblers, while $80 \%$ of a 25 -person control group were still categorized as such.

However, the studies by Ladouceur et al. $(1998,2003)$ focused on treating PG instead of preventing it, and the results of some other studies actually question what impact correcting risk cognitions has on individuals' gambling behaviours. For example, Dangerfield (2004) found that PG was particularly common among Alberta casino employees even though risk cognitions were particularly uncommon. Also, in Boutin et al.'s (2009) study involving the Montreal casino information centre, even though the centre's visitors appeared to have had their risk cognitions corrected, it was not found that the visitors had altered their gambling behaviours or adopted more RG strategies. Similarly, in Williams and Connolly's (2006) study involving university students, even though the students who received gambling-specific statistics lessons had reduced their risk cognitions, the authors detected no significant changes in the gambling behaviours or attitudes expressed by these students. In other words, even though various workplace influences may teach casino employees to reject risk cognitions, an associated change in gambling behaviour may not necessarily occur.

It is uncertain why gamblers who become more knowledgeable about risk cognitions do not tend to change their gambling behaviours, but a study on this topic by Sévigny and Ladouceur (2003) is somewhat illuminating. They found that VLT players often exhibited irrational behaviours based on risk cognitions when gambling, despite reporting that the games were governed solely by chance both before and after playing. These observations prompted the researchers to propose the "double switching" concept, which essentially states that gamblers who normally perceive events rationally may temporarily espouse risk cognitions when gambling. Whether or not the "double switching" concept is valid, it seems that although correcting risk cognitions may be a useful component in the long-term treatment of PG, the benefits of correcting risk cognitions in other situations are less obvious. As Delfabbro (2004) stated in his review of this topic, "It appears that common educational strategies, such as displaying the odds, telling gamblers that there is no skill involved, or that events are random is probably going to have little impact upon heavy gambling” (p. 17). Nonetheless, such findings do 
not necessarily indicate that correcting risk cognitions is useless in the prevention of PG. For instance, Williams and Connolly (2006) claimed, “Although knowledge may not directly lead to behavior change, it would seem to be a necessary precursor" (p. 67), and it may be effective in conjunction with other initiatives.

\subsection{Motives for Taking Casino Jobs}

The workplace influences that may impact employees' beliefs in risk cognitions or otherwise impact the employees' gambling behaviours may explain much of the PG prevalence that has been found among casino employee populations. Nevertheless, these patterns also may exist simply because casino employment naturally may attract individuals who are already problem gamblers or are especially likely to become problem gamblers. In fact, in Hing and Breen's (2008b) interviews they found, "Some interviewees suggested the industry attracts outgoing, less risk-averse people, and gamblers and problem gamblers" (p. 11). In Dangerfield's (2004) study she asked her respondents to mark all applicable statements in a list of possible explanations describing why they had chosen to work in the casino industry. Although the most commonly marked statement was "I needed a job and knew they were hiring," the next three most commonly marked statements suggested that the respondents were attracted to different aspects of the work: $36.6 \%$ marked "I thought I would enjoy the nature of the work (i.e., dealing cards, attending slots, etc.);" 32.5\% marked "I thought I would enjoy the atmosphere;" and 30.9\% marked "I thought I would enjoy interacting with the players

and/or customers." Respondents' agreement with these statements could have been based more on romantic notions about the jobs than a high level of prior involvement with gambling, but the answers do appear to highlight some level of attraction toward the activity. Unfortunately, Dangerfield did not examine how respondents' agreement with these statements was directly related to their gambling behaviours.

\subsection{Employment Variables}

Even if casino employment does attract a disproportionately large quantity of individuals with prior gambling involvement, it should not be assumed that these individuals will be equally attracted to all types of casino employment. Likewise, the various workplace 
influences that may precipitate changes in casino employee gambling probably will not affect all employees equally. Rather, numerous employment variables may be closely related to different types of gambling involvement among the employees.

For example, the length of time an employee has worked in the gambling industry may be related to his or her gambling, either as a function of the different workplace influences or as an indicator of his or her attitudes toward gambling. In fact, this possibility has been considered in several studies on casino employee gambling, although the findings have varied considerably. For instance, Duquette (1999) found that the amount of time employees had worked in the industry was positively correlated with PG behaviour and Shaffer et al. (1999) found some noteworthy, but nonlinear, trends showing an increase in level 2 and level 3 gambling problems as length of employment time increased. On the other hand, Dangerfield (2004) examined length of employment and did not find that it exhibited any significant relationship with PG. She also failed to detect significant differences between the employees' gambling behaviours as expressed in an initial survey and a second survey distributed to the same employees six months later. Moreover, Shaffer and Hall (2002), who surveyed employees about their gambling three times over a two-year period, actually detected a negative relationship between employment duration and PG. When only considering the $19.4 \%$ of the original sample who completed all three questionnaires, Shaffer and Hall found that the rate of level 3 gambling decreased from $4.4 \%$ in the initial survey to $2.0 \%$ in the second survey and $1.8 \%$ in the final survey, while level 2 gambling decreased from $18.4 \%$ to $11.8 \%$ to $13.0 \%$.

Even casino employees who have worked for the same amount of time may have very different work experiences if the employees work in different departments. Casino workforces often include a broad range of different departments, and each department may involve unique types of exposure to different workplace influences. For example, some workers, such as slot machine attendants or card dealers, are fully immersed in the gambling action, while other workers, such as human resources personnel, are fully removed from the gambling action. Past studies on this topic have found that employees who work closer to the gambling action tend to exhibit higher rates of PG. For example, Duquette (1999) found that those employees whose jobs entailed the direct delivery of 
gambling services exhibited over double the rate of level 3 gambling as those employees whose jobs had little direct involvement with gambling. Shaffer et al. (1999) also found that employees whose job duties directly related to gambling exhibited slightly higher rates of level 3 gambling, although the differences were not statistically significant. Furthermore, an assistant manager interviewed by Hing and Breen (2008a) contended: Most back-of-house people don't gamble, because they deal with the issues, the complaints, the money, the profit. I think that that deters people. But front of house [staff]... are continually talking to people who win...I find that staff that work in gaming rooms, if they are the gambling sort...will spend a lot of money gambling at the gaming machines. (p. 21)

Employee gambling behaviours may also relate to the different shifts employees work. As Hing and Breen (2008a) explained, "Having time off when family and friends are unavailable means that they can experience social isolation and need to find solitary leisure activities...For those who finish work in the evenings, there are few other entertainment options away from gambling venues" (p. 25). One of the employees the authors interviewed explained this influence by stating, "If staff want to...go out after work, a lot of the time the gaming venues are the only ones open" (p. 20), while another employee describing her personal gambling remarked, "When you work shift work there is not too much to do, no entertainment when you finish and need to unwind" (p. 17).

\subsection{Demographic Characteristics}

In addition to employment variables, several demographic characteristics may be useful in better understanding casino employee gambling behaviour. For instance, numerous gambling studies have looked at differences between the sexes and the most common conclusion seems to be that males gamble more frequently and exhibit higher PG rates than females. For example, Williams and Wood's (2004a) study of PG prevalence in Ontario found that $61.6 \%$ of their sample's problem gamblers were male, even though only $43.6 \%$ of the non-gamblers and non-problem gamblers were male. Similarly, in Wiebe et al.'s (2006) study of PG prevalence in Ontario, they found that the rates of moderate risk and problem gambling were more than double among males as among females. Additionally, Ladouceur (1996) analyzed PG prevalence studies from six 
Canadian provinces to create a demographic profile of the "typical problem gambler" within each province, and he determined that this gambler would be a male in five of the six provinces, while in the sixth there was simply no sex attribution. These patterns are relatively consistent with studies of casino employee problem gambling as well. For example, Duquette (1999) found that $11.3 \%$ of the male casino employees she surveyed gambled "almost everyday," whereas only $6.1 \%$ of the females did so. Likewise, Lee et al. (2008), who studied casino employees in South Korea, found, "Employees who reported gambling problems included disproportionately more men than those who did not" (p. 195).

Past gambling research also has detected differences between the more detailed characteristics of male and female gambling. For instance, studies by Hraba and Lee (1996) and Walker et al. (2005) both found that the social aspect of gambling was more important for females than males. Also, Hing and Breen (2001) found that female EGM players, when compared to male EGM players, tended to play lower-denomination machines and wager less per session. The authors identified these behaviours as "tactics evidently used to lengthen playing time" (p. 76), in support of their hypothesis that "escape and relaxation in a familiar venue may be motivators for female gaming machine players" (p. 69). Moreover, evidence exists to suggest that males and females prefer different games. As Aasved (2002) summarized, "Certain forms of gambling such as electronic gaming machines attract high-frequency gamblers in equal numbers from both sexes while bingo and video poker machines appear to be particularly attractive to women" (pp. 14-15). This statement is consistent with Wiebe et al.'s (2006) findings that gambling on the lottery and EGMs was quite similar between the sexes, but males were much more likely to play casino table games, bet on sports, bet on horse races, and wager on card or board games outside of a casino, while females were more than twice as likely to play bingo. Duquette (1999) found similar patterns in her casino employee study, claiming, "Males tended to play craps, blackjack, live poker, and wager on race and sports, while females preferred bingo" (p. 22). She also found that males and females exhibited relatively similar levels of gambling on EGMs, although slot machines and video poker machines were both slightly more popular with females. Comparable findings also were made by Toneatto, Blitz-Miller, Calderwood, Dragonetti, and Tsanos 
(1997), who interviewed 38 Canadian "regular and heavy gamblers" and found that the females exhibited a strong preference for chance games while the males exhibited a strong preference for skill games.

Although sex has been the demographic variable most frequently considered in past gambling research, various studies also have detected significant relationships between age and gambling, often finding that gambling problems are most prevalent in young adults. In Wiebe et al.'s (2006) study, for example, their youngest age group - 18 to 24 year olds - exhibited the highest rate of moderate risk and problem gambling (6.7\%), while 25 to 34 year olds exhibited the next highest rate (4.0\%). Similarly, Welte, Barnes, Wieczorek, Tidwell, and Hoffman (2007) conducted a telephone survey of over 2,500 U.S. adults that revealed, "Those 30 or older gambled slightly more than younger adults, but younger adults had considerably more problems" (p. 189). Additionally, in a PG prevalence study conducted in Switzerland, individuals 28 years old and younger were far more likely to be problem gamblers than individuals who where at least 29 years old (Bondolfi, Osiek, \& Ferrero, 2000).

These patterns have been somewhat evident in studies of casino employees as well. For instance, in their interviews with managers of numerous gambling establishments, Hing and Breen (2007) found, "Some managers noted that older, mature staff have a better understanding of the odds of losing, are deterred from gambling in their leisure time due to family responsibilities and treated gambling as part of their normal hospitality workload" (p. 358). Also, Shaffer et al. (1999), who divided their sample into six different age groups, found level 3 gambling prevalence was second highest among 21 to 30 years olds (3.1\%), although no statistically significant differences between the age groups were detected. Interestingly, however, level 3 gambling was most common among the casino employees who were 61 to 75 years old (3.2\%), and it was lowest among 17 to 20 year olds $(0.9 \%)$. Although these results may appear surprising, the popularity of gambling and the prevalence of PG among seniors have been noted in numerous studies devoted to the age group (e.g., Hope \& Havir, 2002; Levens, Dyer, Zubritsky, Knott, \& Oslin, 2005; McNeilly \& Burke, 2000, 2001), and the low prevalence of level 3 gambling detected among the 17 to 20 year olds is likely explained by the fact that individuals under the age of 21 were not legally permitted to gamble in the 
jurisdiction where Shaffer et al. conducted their study (H. Shaffer, personal communication, September, 19, 2008).

Age likely explains some of the variance that has been found between the gambling behaviours of individuals with different marital statuses, but marital status is nonetheless a variable worth considering on its own. Most studies that have considered this variable have found that single individuals are the most likely to exhibit gambling problems. For instance, Williams and Wood (2004a) found that people who were single and never married comprised $21 \%$ of their sample's non-gamblers and non-problem gamblers, but they comprised $30 \%$ of their sample's problem gamblers. Similarly, Wiebe et al. (2006) found that the rates of moderate risk and problem gambling were highest among individuals who were single and never married. Furthermore, Young, Stevens, and Morris (2008) found that PG behaviour among non-Indigenous adults in Northern Territory, Australia was about twice as common among single adults as among those who were married or in common-law relationships. Additionally, Volberg, Abbott, Rönnberg, and Munck (2001) found that single adults in Sweden were significantly more likely than married adults to be problem gamblers.

Ethnicity is another variable that that has been shown to be related to gambling behaviour. In their review of the relationship between culture and gambling, Raylu and Oei (2004) determined, "Evidence does suggest certain cultural groups are more vulnerable to begin gambling and to develop PG" (p. 1087). The authors argued that such differences in PG may be at least partly explained by factors such as cultural values and beliefs, although the differences may also simply be a function of correlated socioeconomic variables. As an example of such differences, in Ontario Williams and Wood (2004a) found that Aboriginals accounted for 1.6\% of the surveyed non-gamblers and non-problem gamblers, but $7.0 \%$ of the problem gamblers. In a U.S. study for which over 2,000 adults were surveyed, Welte, Barnes, Wieczorek, Tidwell, and Parker (2004) determined that African Americans, Hispanics, and Asians all exhibited particularly high levels of PG. Among American casino employees, Shaffer et al. (1999) similarly found that Native Americans, Hispanics, African Americans, and Asians all exhibited disproportionately high rates of level 3 gambling. 
Finally, education is an additional variable that may be associated with gambling behaviour, and most studies have detected negative relationships between education level and PG prevalence. For example, Williams and Wood (2004a) found that $61.4 \%$ of their sample's non-gamblers and non-problem gamblers had some education beyond high school, but only $35.1 \%$ of the problem gamblers had obtained a similar level of education. Similarly, Wiebe et al. (2006) found that PG was least prevalent among individuals who had completed post-secondary or post-graduate education, although the patterns were not quite as clear. In research from the U.S., Scherrer et al. (2007) looked at over 7,000 pairs of American male twins in two study intervals, spaced ten years apart, and determined, "Attainment of education beyond high school was associated with decreased odds of PG at follow-up, suggesting that higher education may be a protective factor against the development of PG” (p. 975). Additionally, in Young et al.'s (2008) Australian study they found, "Non-gamblers tended to be more educated" (p. 83).

\subsection{Explanations for Problem Gambling Prevalence among Casino Employees}

Although demographic characteristics and employment variables may be useful in better understanding casino employee gambling, the high PG rates that have been detected among casino employees must be explained by at least one of three basic factors: Being employed in a casino somehow induces employees to gamble more, casinos attract individuals who are already problem gamblers, or problem gamblers remain in the industry for longer periods of time (Dangerfield, 2004; Shaffer et al., 1999). Based on the results from her study in Alberta, Dangerfield concluded, "There is very little evidence that the high rates of problem gambling among casino employees are a result of their casino employment. Rather, it appears the gaming industry actually attracts problem gamblers" (p. 57). Dangerfield discounted the impacts of workplace influences in part because of her finding that employees were more likely to have decreased than increased their gambling. Additionally, she did not find that length of employment in the industry positively related with gambling, nor did gambling participation increase during the six months between her first and second study intervals. On the other hand, she discovered a fairly high percentage of her respondents were attracted to the employment because they 
thought they would enjoy it, and she interpreted this finding as an indication that many of the employees may have already been problem gamblers when their employment began.

Shaffer et al. (1999) similarly found that casino employees were more likely to have decreased than increased their gambling, yet the authors also pointed out that the problem gamblers were especially likely to have claimed their gambling had increased since they became casino workers. In fact, $74.4 \%$ of the level 3 gamblers claimed to have increased their gambling, while only $15.2 \%$ of the total sample had made the same claim. The authors suggested that such increases in gambling could have been the cause of the gambling problems or a result of pre-existing problems. The authors also pointed out that the highest level 3 gambling rates were detected among those employees who had worked in their facilities for several years, and that this finding could indicate that "working in a casino may facilitate a gambling problem among employees who gamble and are at risk of problem gambling" or that "workers with gambling problems may be more likely to choose to remain employed in a setting that offers ready access to gambling" (p. 374).

\subsection{Why Preventing Employee Problem Gambling Is Beneficial for Casinos}

Regardless of why PG seems to be particularly prevalent among casino employees, there is no question that preventing employee PG is in a casino's own best interests. PG can lead to a wide variety of consequences, including difficulty maintaining personal relationships and financial hardship that may induce crime (Bergh \& Kühlhorn, 1994), which may decrease an individual's value as an employee. In fact, Bergh and Kühlhorn interviewed several dozen problem gamblers in Sweden and found that $74 \%$ of the subjects experienced work-related problems, including a lack of concentration (57\%); frequent sick-leave (46\%); continually borrowing money at work (11\%); and workrelated theft, fraud, and embezzlement (14\%). Twelve percent of the subjects were eventually fired from their jobs while $29 \%$ had left on their own accord. This study did not focus specifically on casino employees, but there is no reason to doubt that such problems would exist in the casino industry as well. In fact, one shift manager of a tribal casino in San Diego stated about his employees, "You know they're gambling when they start missing work" (Williams, 2005). 
When Harrah's Casino Hotels, which owns numerous casinos around the world, instituted its first official program in the late 1980s to combat PG among employees and customers it had been noted, "From Harrah's corporate perspective, problem gambling also seriously affects the health and growth of its business organization and, more importantly, its employees" (Sherman, 1991, p. 675). The company’s program was considered a success and it led to "real bottom-line savings in improved employee performance and morale, and reduced incidence of undesirable behaviour among...employees" (p. 677). The importance to casinos of maintaining a quality workforce should not be understated, as employees should be "brand ambassadors" (Kale, 2007, p. 5) who promote customer satisfaction (Kale). This importance also was highlighted in a recent article titled, "Even the Greatest Ad Campaign can't Overcome a Crabby Dealer," which appeared in a Canadian gaming business trade magazine. This article advised readers:

Make sure you deliver your end of the bargain with outstanding customer service, from the burly security guard at the entrance, to the cashier in the cage...Ad campaigns are a much easier sell if the level of service portrayed in the ads accurately reflects what guests can actually expect when they sit down at the tables. (Jones, 2008, p. 18)

Additionally, preventing employee PG may help decrease employee turnover. In fact, one of Harrah's specific goals in instituting its PG prevention program was to combat employee turnover (Sherman, 1991). Such turnover can be quite costly for casinos due to the resources needed to train each new worker (Stedham \& Mitchell, 1996). As Argusa and Lema (2007) summarized, "With less employee turnover, the cost of training new employees is lower and thus has a direct positive impact on the casino's bottom line" (p. 24). Furthermore, "Turnover in the service industries, such as gaming, has additional costs because employees develop relationships with specific customers" (Stedham \& Mitchell, p. 270). Decreasing employee turnover also is important because the rapid expansion of casino gambling has led to an unmet demand for qualified casino employees in locations ranging from Mississippi (Argusa \& Lema) to Macao (Kale, 2007). 
Moreover, employee RG training programs often are not meant solely to prevent PG among employees, but also to teach the employees how to respond to PG they may observe among the patrons. For instance, in describing its RG training program, OLG explained:

The training aims to build awareness of problem gambling, dispel myths and enable OLG employees to respond appropriately to customer requests for help and information. Employees are trained to recognize problem behaviors that may indicate customers at risk and are provided with guidelines for bringing issues to designated managers, while managers are given the tools for responding to these situations. (Ontario Lottery and Gaming, 2006, p. 13)

Such a responsibility is obviously quite important, yet an employee's own gambling could hinder his or her ability to handle this responsibility effectively. In fact, Lee et al. (2008) found that casino employees with gambling problems were significantly less likely than their co-workers to support a greater focus on PG by the public health system. The authors explained these results by pointing to a psychological phenomenon known as the "false consensus effect," which is a cognitive bias in which people tend to assume that their beliefs and opinions are more common than they really are (Ross, Greene, \& House, 1977). Lee et al. applied this phenomenon to gambling and concluded:

Consequently, people who experience gambling problems tend to view their gambling problems as more common and a consequence of the social setting; therefore, projecting less need to develop a public education system directed towards gambling problems than will those who do not experience any gambling problems. (p. 195)

Taken one step further, this finding implies that employees who are problem gamblers may rationalize PG behaviour observed among patrons rather than responding to it appropriately.

\subsection{Conclusion}

As the casino industry continues to expand, it will create many new jobs in Ontario and elsewhere. The employees who hold these jobs will find themselves working in an environment with numerous workplace influences that may impact the employees' 
gambling behaviours. Some of these influences may encourage the employees to gamble, while other influences may actually discourage the employees from gambling, and these influences will be felt differently by different employees. In general, it seems as though these influences actually will do more to push employees away from gambling than to draw them towards the activity, but casino employee populations in numerous jurisdictions nonetheless have been found to exhibit relatively high rates of PG. A small number of existing studies have investigated these issues, but many uncertainties remain. A better understanding of these issues will provide a more critical assessment of the genuine benefits of casino employment and it will assist casinos in their efforts to reduce the rates of PG within their workforces. Fortunately, the casinos, which are the institutions most capable of lowering the rates of casino employee PG, will benefit directly from such efforts. 


\section{Chapter 3}

\section{Methods}

\subsection{The Research Approach}

This study used a mixed methods research approach that involved both a quantitative survey and qualitative interviews. Comparatively greater attention was devoted toward the survey portion of this study, which provided an abundance of data describing a large sample of employees. Nonetheless, the interviews were included to provide greater richness to these findings and to reveal relevant issues that were overlooked in the survey (Creswell, 2003). Existing research on casino employee gambling includes both survey studies (e.g., Dangerfield, 2004; Duquette, 1999; Lee et al., 2008; Shaffer et al., 1999; Shaffer \& Hall, 2002; Wu \& Wong, 2008) and interview studies (e.g., Hing \& Breen, 2007, 2008a, 2008b), but this study will be the first to combine the two approaches.

\subsection{Site Selection}

This study involved five Ontario casino facilities, consisting of one "resort casino," two "casinos," and two "slots facilities." All three types of facilities were included in order to produce a reasonably representative sample of Ontario casino employees and to permit facility type to be considered as an analyzable variable. Only one resort casino was included because these facilities employ a disproportionately high quantity of workers, so including two resort casinos would have led to an extreme overrepresentation of resort casino employees in the final sample. The five participating facilities were selected by OLG based on their willingness to participate and their general proximity to the region where the researcher was based.

\subsection{Research Procedure}

In mid-April of 2009, the survey was distributed to essentially all of the nearly 4,700 employees of the five participating facilities. The only exceptions were those slots facility employees whose jobs were associated only with horseracing, ${ }^{4}$ although some of the

\footnotetext{
${ }^{4}$ These workers are not employed by OLG, but rather by private entities that own and operate the racetracks.
} 
participating employees held jobs indirectly associated with horseracing, such as employees who worked at food stands near the racetracks. The survey was preceded by an introductory letter (see Appendix A), which summarized the study and guaranteed anonymity to the respondents. This letter was distributed to the employees in early April, two weeks before the surveys were distributed. Also, the survey was accompanied by a cover letter (see Appendix B) that reiterated the points discussed in the introductory letter. The survey (see Appendix C) and all of the other study materials were distributed by attaching them to employee pay cheques, which are issued every two weeks. This distribution strategy had already been used successfully by Dangerfield (2004) in her Alberta study.

Participation in this study was completely voluntary. Nevertheless, in numerous cases casino managers or shift managers encouraged their employees to participate. Also, the resort casino distributes a biweekly employee newsletter, and two of the April issues included a small section describing the survey and reminding employees to participate. However, the employees were not allotted work time to complete the survey, but rather had to complete it in their free time either at work or outside of work.

Depending on the number of employees working at the different facilities, each facility was provided with at least two secure and clearly marked collection boxes in which employees could return their completed surveys. These boxes were placed in locations frequented by employees and recommended by the facilities. Each of these locations was under camera surveillance in order to prevent tampering. Every employee also was given a prepaid envelope which he or she could use to return the survey by mail. This latter option was offered to provide an alternative return method for employees who may have been reluctant to return their surveys at their workplaces. The employees were asked to return their surveys within two weeks. The collection boxes were retrieved from the facilities in early May.

When the surveys were distributed they were accompanied by a separate "contact information sheet" (see Appendix D) with which the employees could volunteer to participate in the personal interviews. This contact information sheet included a summary of the interview process and guaranteed the confidentiality of the interviewees. To volunteer for an interview, employees were required to give their name and contact 
information, either in the form of a phone number or email address. The contact information sheets were distributed unattached to the surveys so that when the two items were returned there would be no way to link one's survey with one's contact information sheet. Also, the employees were given the option of returning their surveys using one of the return methods (the collection boxes and the mail) and their contact information sheets using the other. Participation in an interview was not contingent on survey completion, so employees had the option of doing one and not the other.

In the days preceding the selected interview date of each facility, the employees who had volunteered to participate in an interview were contacted to select the actual interviewees. Employees could not participate in interviews during work hours, so the interviews were scheduled primarily at the beginning or end of employees' shifts, or with employees who had the day off from work. The interview volunteers who gave email addresses were contacted using a uniform email letter (see Appendix E). A full interview schedule was easily created for each facility from this group of employees, so the employees who provided only their phone numbers were not contacted. The participants were selected simply based on scheduling, as no information was available to create a purposive sample consisting of employees with different characteristics, such as being from different departments or having spent different quantities of time working in the industry.

The interviews were conducted in a ten-day period beginning in mid-June. A total of 21 interviews were conducted, with four to six interviews held at four of the five participating facilities. Interviews were not conducted at one of the two "casino" facilities due to its lack of proximity to the researcher. The interviews were held in private board rooms or conference rooms on the facilities' premises, and the interviews were all audiorecorded. Prior to the interviews each participant was given a letter (see Appendix F) that provided an overview of what would be discussed and guaranteed the interviewee complete confidentiality. Moreover, each participant signed a form acknowledging his or her willingness to participate in the study, his or her willingness to be audio-recorded, and his or her willingness to have selected statements anonymously quoted in the study. At the beginning of the interview the researcher further reiterated the guarantee of confidentiality. 
The various efforts made to guarantee anonymity in the surveys and confidentiality in the interviews were deemed necessary due to ethical considerations and the potentially sensitive nature of the research topic. Sensitive research topics can discourage participation or lead to misreporting (Tourangeau \& Yan, 2007), and gamblers frequently exhibit biases, such as social desirability bias (Parke \& Griffiths, 2002). Consequently, it was hoped that the explicit and repeated guarantees of anonymity and confidentiality would increase participation in the study, reduce non-response bias, and minimize misreporting (Singer, Von Thurn, \& Miller, 1995; Tourangeau \& Yan).

To encourage participation in both the survey and the interviews, eight $\$ 40 \mathrm{gift}$ certificates valid at a variety of restaurants were offered as incentives. The prizes were given away in raffle drawings, with five of the gift certificates given to employees who had completed a survey and three of the gift certificates given to employees who had participated in an interview. Incentives had been used successfully in prior studies on casino employees (e.g., Dangerfield, 2004; Shaffer et al., 1999; Shaffer \& Hall, 2002), and Parke and Griffiths (2002) recommended the use of incentives in their paper on the challenges associated with researching slot machine gamblers and potential strategies for overcoming these challenges. Because the surveys were completely anonymous, the contact information sheets that employees could use to volunteer for the interviews also included a separate space for employees to enter the survey prize draws by indicating they had completed a survey and providing their names and mailing addresses. Consequently, no measure existed to prevent employees from entering the survey prize draws by falsely claiming to have completed a survey, but this shortcoming was trumped by the importance of guaranteeing full anonymity to the respondents.

\subsection{The Survey}

During the survey creation process, input was offered by various personnel from OLG and the different participating facilities. This input included suggested re-wordings and terminology to make the survey as understandable as possible for the respondents. Additionally, this input entailed the inclusion of several new items about topics that had been overlooked or about which OLG wished to obtain information. 
In late March, a preliminary version of the survey was tested with six employees at one of the participating facilities. The employees were asked to complete the survey in the company of the researcher and as they completed the surveys the employees were asked to voice any questions, confusions, or general issues they encountered. However, due to the nature of the survey topic, the employees were instructed to not answer the survey honestly, but rather to provide random answers. After completing the survey, each employee was asked a series of questions regarding some specific items that had been deemed potentially confusing or problematic during the survey creation process.

The final survey was seven pages long and required approximately ten to fifteen minutes to complete. It consisted of exclusively multiple-choice and single-answer questions, with a few opportunities for respondents to fill in written responses if the available options were not adequate. On the front page of the survey in capitalized, bold letters the respondents were instructed not to write their names on the surveys, in order to protect their anonymity. Moreover, the surveys were not numbered, nor did they contain any other marking that could differentiate one from another. Many of the survey items were borrowed or adapted from previous studies of casino employee gambling or gambling behaviour in general, although other items were generated uniquely for this study.

The survey items pertaining to gambling behaviour borrowed heavily from the CPGI (Ferris \& Wynne, 2001). Development of the CPGI began in 1996 and was led by a research team sponsored by the Canadian Centre for Substance Abuse with a goal "to develop a new, more meaningful measure of problem gambling for use in general population surveys, one that reflected a more holistic view of gambling, and included more indicators of social context" (p. 6). The CPGI development process involved a battery of tests that found it to be both reliable and valid (Ferris \& Wynne), and the CPGI has been widely used to measure PG prevalence in every Canadian province and numerous other nations (McCready \& Adlaf, 2006). In fact, the CPGI appears to have supplanted the SOGS as the instrument of choice for many gambling researchers. This change has occurred in part because the CPGI was developed to measure gambling behaviour in general populations, whereas the SOGS was designed for use in a clinical setting and has been found to suffer from a false-positive bias (Eadington, 2001; 
Thompson, Walker, Milton, \& Djukic, 2005; Williams \& Wood, 2004b). Furthermore, independent studies conducted in both Australia (McMillen \& Wenzel, 2006) and Singapore (Arthur et al., 2008) have compared the CPGI, the SOGS, and other gambling measures, and concluded that the CPGI was a better measure of PG than any of the other measures considered. The CPGI items used in this study's survey were occasionally altered slightly to better accommodate the sample or to follow similar changes made by Williams and Wood (2004a) and Wiebe et al. (2006), so as to facilitate comparison with their results.

The CPGI involves a total of 31 items, but nine of these items specifically are used to identify PG. This nine-item scale, known as the Problem Gambling Severity Index (PGSI), was used in its entirety and without changes in this study's survey for the purpose of PG classification. The nine PGSI items focus on gambling behaviours (e.g., "How often have you gone back another day to try to win back the money you lost?") and consequences (e.g., "How often has your gambling caused any financial problems for you or your household?"). Each item is answered with a four-point scale where "never" $=0$, "sometimes" $=1$, "most of the time" $=2$, and "almost always" $=3$. A final score is calculated by summing responses to all nine items, meaning total scores can range from zero to 27 , with higher scores indicating a greater severity of gambling problems (Ferris \& Wynne, 2001; Wynne, 2003). Ferris and Wynne suggested that the scores can be used to classify individuals as "non-problem gamblers" (a score of zero), "low risk gamblers" (scores of one or two), "moderate risk gamblers" (scores between three and seven), and "problem gamblers" (scores of eight and higher).

To determine how much money respondents typically spent gambling each month, they were asked about this expenditure directly. Because this type of question can be confusing for respondents, the wording was based partly on recommendations made by various studies that have analyzed how best to clarify this question (i.e., Blaszczynski, Dumlao, \& Lange, 1997; Blaszczynski, Ladouceur, Goulet, \& Savard, 2006; Williams \& Wood, 2004a). If employees gave an expenditure range, then the mean of the two amounts defining this range was used. Also, some employees wrote two separate amounts to denote expenditures before and after the April 1 lottery ban, and in such situations the 
amount associated with expenditure before the April 1 ban was used. For many analyses the expenditure amounts were collapsed into different expenditure categories.

Participation in different forms of gambling was measured by asking how frequently each respondent had participated in the forms of gambling during the previous year. Eight possible responses were provided, ranging from "daily" to "never." These eight responses were taken from the CPGI, as were many of the forms of gambling considered. Nevertheless, these forms of gambling were supplemented by some additional forms of gambling that seemed relevant to this study. For all analyses the eight categories were collapsed into broader categories of gambling frequency. An identical approach was used to determine how frequently respondents observed patrons with apparent gambling problems.

The change in gambling that employees had experienced since beginning their jobs was measured by asking respondents directly how their gambling behaviour had changed since they began working in an OLG or resort casino. Five possible responses were offered: "decreased significantly," "decreased a little," "remained the same," "increased a little," and "increased significantly." The design of this item was based on approaches to the same topic taken by Shaffer et al. (1999) and Dangerfield (2004).

The change in familiarity with different forms of gambling that employees had experienced was measured with two identical, seven-point scales ranging from "very unfamiliar" (1) to "very familiar" (7). One scale represented a respondent's familiarity with a particular form of gambling on his or her first day of work, and the second scale represented his or her familiarity with the same form of gambling on the day the survey was completed. Consequently, the levels of familiarity change were calculated by subtracting the score on the first day scale from the score on survey completion date scale, meaning scores could range from zero to six. Negative scores (indicating a decrease in familiarity over time) were omitted if they constituted more than half of a respondent's non-zero scores.

The survey included 18 items associated with the various workplace influences that could affect employee gambling (e.g., "I spend so much time surrounded by gambling that it is no longer interesting"). These items were based primarily on the workplace influences identified by Hing and Breen (2007, 2008a, 2008b). Respondents 
marked their agreement with the different statements on a five-point scale: "strongly disagree"=1, "disagree"=2, "neutral"=3, "agree"=4, and "strongly agree"=5. Perceived job stress was measured with an identical scale, which was marked based on the statement, "I find my job stressful."

The same scale also was used to measure endorsement of three risk cognitions. One of the three risk cognitions was taken from the CPGI and the other two were taken directly or closely adapted from the Gamblers' Belief Questionnaire (GBQ), which is a validated, 21-item questionnaire designed to measure gamblers' belief in risk cognitions (Steenbergh, Meyers, May, \& Whelan, 2002). The 21 GBQ items correspond with two risk cognition factors - luck/perseverance and illusion of control - and this study's survey included one item relating to each of these two factors. The two items were selected based on a combination of high factor loadings and relevance to this study's research focus. For numerous analyses respondents' mean levels of agreement with the three risk cognitions were used.

The respondents' motives for choosing to work in a casino also were measured with the same five-point agreement scale. Thirteen possible motives were included in the survey. These motives included several items examined by Dangerfield (2004) in her Alberta study, in addition to common responses employees gave when asked about this topic in a study on Louisiana casino employees (i.e., Ryan \& Speyrer, 1999). Furthermore, some of the motive items were generated uniquely for this study.

Whether or not respondents had been attracted to their jobs by a pre-existing gambling affinity was determined through their levels of agreement with two items: "I thought I would enjoy the atmosphere" and "I thought I would enjoy the nature of the work (e.g., dealing cards, attending slots, etc.)." Respondents who agreed with both of these items were considered to have chosen their jobs in part due to pre-existing gambling affinities, and were compared with their co-workers who had not agreed with both items.

Whether or not respondents had been attracted to their jobs by prior gambling involvement was determined by their agreement with the statement, "I was a frequent gambler so I thought I would enjoy the work." Using only responses to this item to identify employees who had chosen their jobs due to prior gambling involvement 
possibly excluded some employees who belonged in the category. For example, there may be employees who chose their jobs because of prior gambling involvement, but not because this involvement led the employees to believe they would enjoy their jobs. Nevertheless, it was felt that broadening the category would have produced less reliable groupings. For instance, if the survey simply had asked whether or not employees chose their jobs due to prior gambling involvement, then respondents may have answered whether they gambled prior to obtaining their jobs, and not whether this gambling actually influenced their decision to choose their jobs, which was the primary focus of the question.

The respondents' potential reaction to personal gambling problems was examined by asking how respondents would most likely seek assistance if they felt they may have a gambling problem. Eight possible responses were offered: "calling a helpline," "seeking help through work," "going to a counselling centre," "using the employee assistance plan," "seeking help from family and friends," "I don't know anywhere to seek assistance for problem gambling," and "I wouldn't seek assistance anywhere." For one analysis, those respondents who claimed they would not seek assistance anywhere were compared with those who specified a way they would seek assistance.

The respondents' attitudes toward their direct supervisors' potential reaction if approached about a personal gambling problem were examined by asking about this topic directly. Five possible supervisor reactions were offered: "do nothing," "simply advise you to stop gambling," "show you where to get help," "show you where to get help, but also terminate you," and "terminate you without providing any assistance." For two analyses, those respondents who believed their jobs would be terminated and then those respondents who believed no help would be offered were compared with the other respondents.

Data from the completed surveys was entered into SPSS. The gambling patterns exhibited by the respondents were analyzed independently and also by comparing them with results from past gambling studies that have focused on Ontario's general population (i.e., Wiebe et al., 2006; Williams \& Wood, 2004a) or other casino employees (e.g., Dangerfield, 2004; Duquette, 1999; Shaffer et al., 1999; Shaffer \& Hall, 2002). The significance of the various workplace influences, employment variables, and 
demographic characteristics was further analyzed with a variety of statistical tests, primarily including t-tests, one-way ANOVA tests, correlation coefficiency tests, and chi square tests.

\subsection{The Interviews}

Each interview lasted approximately 30 minutes. During the interviews, participants were asked to provide broad insights on the casino employee population based on the interviewees' observations and experiences. This approach differed considerably from the surveys, which primarily asked the respondents to answer questions about themselves. It was felt that asking interviewees to discuss their own gambling behaviours would discourage participation, particularly by employees who gambled frequently. The interviews were semi-structured and involved the use of an interview guide (see Appendix G). This approach ensured that fairly similar questions were asked of each interviewee, but it also permitted the flexibility to explore relevant topics more thoroughly with each interviewee (Patton, 1990). The topics featured in the interview guide were very similar to those included in the survey. The interview guide was derived in part from the existing casino employee gambling research, and most predominately the studies by Hing and Breen (2007, 2008a, 2008b). However, basic analyses on this study's survey data were conducted prior to the beginning of the interviews, so these preliminary results also were used to create the interview guide. This process allowed the interviews to function as a tool to delve deeper into the nuances of the survey findings. Moreover, some new issues were introduced by the employees during the interviews and these issues were then added to the interview guide for the subsequent interviews.

Some basic notes were taken during the course of the interviews, but, more importantly, detailed summary transcriptions of the audio recordings were composed following the completion of the interviews. These transcriptions were then analyzed using content analysis, in which the different individual interview texts were reorganized into a variety of topic categories. Some of these categories were predetermined, based on prior casino employee research and the survey findings, and some other categories were created during the course of the analysis (Flick, 2002; Mayring, 2000). 


\section{Chapter 4}

\section{Results}

\subsection{Response Rates}

Surveys were distributed to 4,698 employees and 934 of these surveys were returned, resulting in an overall response rate of $19.9 \%$. The response rates for the individual facilities varied between $13.5 \%$ and $45.3 \%$, with higher response rates generally associated with facilities with lower employee numbers. A total of 759 contact information sheets were returned, resulting in an overall return rate of $16.2 \%$. Therefore, roughly $80 \%$ of the employees who returned a survey also returned a contact information sheet, although this number should be viewed as an approximate figure because some employees might have returned contact information sheets to enter the prize draws without having actually completed a survey.

Of the returned surveys, $89.9 \%$ were returned using the collection boxes and the other $10.1 \%$ were returned using the mail. Essentially no differences existed with regards to the PGSI categorizations of employees who gave back their surveys using the different return methods, and this finding was strongly confirmed with a t-test comparing the two groups' mean PGSI scores ( $\mathrm{t}=0.257, \mathrm{p}=0.798, \mathrm{n}=887$ ). Nevertheless, older employees seemed more likely to return their surveys using the mail, as $11.5 \%$ of the employees aged 31 or over used the mail, whereas only $4.2 \%$ of the employees aged 30 or younger used the mail. A chi square test confirmed the statistical significance of this disparity $\left(\mathrm{X}^{2}=8.740, \mathrm{p}=0.003, \mathrm{n}=931\right)$.

\subsection{Overview of the Sample}

\subsubsection{Demographic Characteristics}

The demographic characteristics of the survey sample are presented in Table 1. ${ }^{5}$ As can be observed, nearly two-thirds of the sample (64.4\%) was female, which is notable because females did not seem to genuinely constitute such a clear majority of the staff at the participating facilities, although females did constitute a small majority in some of the

\footnotetext{
${ }^{5}$ The totals for the variables do not all add up to 934 because of missing cases.
} 
facilities. It also can be seen that almost three-fifths of the sample (58.4\%) were aged between 31 and 50, nearly two-thirds of the sample (64.7\%) were married or living with a partner, over $85 \%$ of the sample identified their ethnicity as Canadian, and a little less than half of the sample (45.4\%) had completed some form of post-secondary school.

TABLE 1. Demographic characteristics of the survey sample

\begin{tabular}{|c|c|c|}
\hline $\begin{array}{l}\text { Variable } \\
\text { Characteristic }\end{array}$ & Pct. & $\mathbf{n}$ \\
\hline \multicolumn{3}{|l|}{ Sex } \\
\hline Female & 64.4 & 597 \\
\hline Male & 35.6 & 330 \\
\hline \multicolumn{3}{|l|}{ Age group } \\
\hline$\leq 20$ years & 1.0 & 9 \\
\hline 21-30 years & 19.3 & 180 \\
\hline $31-40$ years & 32.0 & 298 \\
\hline $41-50$ years & 26.4 & 246 \\
\hline $51-60$ years & 17.0 & 158 \\
\hline$\geq 61$ years & 4.3 & 40 \\
\hline \multicolumn{3}{|l|}{ Marital status } \\
\hline Married or living with partner & 64.7 & 601 \\
\hline Single and never married & 20.9 & 194 \\
\hline Divorced or separated & 13.2 & 123 \\
\hline Widowed & 1.2 & 11 \\
\hline \multicolumn{3}{|l|}{ Ethnic group } \\
\hline Canadian & 87.6 & 808 \\
\hline Aboriginal & 5.1 & 47 \\
\hline European & 4.0 & 37 \\
\hline Asian & 2.0 & 18 \\
\hline Caribbean & 0.2 & 2 \\
\hline Other & 1.1 & 10 \\
\hline \multicolumn{3}{|l|}{ Highest level of education } \\
\hline Some high school / junior high or less & 4.5 & 42 \\
\hline Completed high school & 23.4 & 217 \\
\hline Some post-secondary school & 26.7 & 248 \\
\hline Completed post-secondary school & 41.2 & 383 \\
\hline Completed post-graduate education & 4.2 & 39 \\
\hline
\end{tabular}

\subsubsection{Employment Characteristics}

The employment characteristics of the survey sample are presented in Table 2. As can be observed, approximately half of the survey respondents (49.1\%) worked in the single resort casino involved in the study, while the other respondents worked in the four OLG 
casinos and slots facilities. The average amount of time spent working in the gambling industry was 86.8 months ( $\mathrm{SD}=49.58)$, which equals just over seven years. Approximately $85 \%$ of the respondents had worked in the industry for at least two years and about two-thirds of the respondents $(67.9 \%)$ had worked in the industry for more than five years. Only about one of every 20 respondents (5.8\%) had worked in the gambling industry prior to taking a job at an OLG or resort casino. Of those few employees who did possess such prior experience, a relatively large portion $(41.5 \%)$ had worked in roving charity casinos in Ontario, and about half of the respondents (54.2\%) who marked "other" had worked in bingo halls. The five departments most highly represented among the respondents were Cashiering, Security, Marketing, Table Games, and Food \& Beverage. When estimating the percentage of their workdays spent interacting with patrons, over $70 \%$ of the respondents placed themselves in one of the two extreme categories - "0 to $20 \%$ " or "81 to $100 \%$ " - and over $40 \%$ of the total sample claimed to spend over $80 \%$ of their workday interacting with patrons. Finally, the morning shift was the one most commonly worked by the respondents (38.1\%). 
TABLE 2. Employment characteristics of the survey sample

\begin{tabular}{|c|c|c|}
\hline $\begin{array}{l}\text { Variable } \\
\text { Characteristic } \\
\end{array}$ & Pet. & $\mathbf{n}$ \\
\hline \multicolumn{3}{|l|}{ Facility type } \\
\hline Resort Casino (1) & 49.1 & 459 \\
\hline Casino (2) & 34.5 & 322 \\
\hline Slots facility (2) & 16.4 & 153 \\
\hline \multicolumn{3}{|l|}{ Months employed in gaming industry } \\
\hline$\leq 6$ & 2.3 & 21 \\
\hline $7-12$ & 5.4 & 50 \\
\hline $13-24$ & 7.4 & 69 \\
\hline $25-60$ & 17.0 & 158 \\
\hline $61-120$ & 45.1 & 419 \\
\hline$\geq 121$ & 22.8 & 212 \\
\hline \multicolumn{3}{|c|}{$\begin{array}{l}\text { Gambling industry experience prior to working in an OLG or } \\
\text { resort casino }\end{array}$} \\
\hline None & 94.2 & 867 \\
\hline Roving charity casino in Ontario & 2.4 & 22 \\
\hline Land-based casino outside of Ontario & 0.5 & 5 \\
\hline Cruise ship & 0.2 & 2 \\
\hline Other & 2.6 & 24 \\
\hline \multicolumn{3}{|l|}{ Department } \\
\hline Administration & 1.4 & 13 \\
\hline Cashiering & 15.9 & 147 \\
\hline Finance & 5.7 & 53 \\
\hline Food \& Beverage & 11.1 & 103 \\
\hline Human Resources & 2.0 & 19 \\
\hline $\begin{array}{l}\text { Maintenance / Housekeeping / } \\
\text { Hotel operations }\end{array}$ & 9.8 & 91 \\
\hline Marketing & 12.1 & 112 \\
\hline Security & 13.7 & 127 \\
\hline Slots & 7.2 & 67 \\
\hline Surveillance & 4.3 & 40 \\
\hline Table Games & 11.3 & 105 \\
\hline Other & 5.4 & 50 \\
\hline \multicolumn{3}{|c|}{ Percentage of workday spent interacting with patrons } \\
\hline $0-20 \%$ & 28.4 & 265 \\
\hline $21-40 \%$ & 7.4 & 69 \\
\hline $41-60 \%$ & 7.3 & 68 \\
\hline $61-80 \%$ & 13.7 & 128 \\
\hline $81-100 \%$ & 43.1 & 402 \\
\hline \multicolumn{3}{|l|}{ Most frequently worked shift } \\
\hline Morning & 38.1 & 351 \\
\hline Afternoon & 22.0 & 203 \\
\hline Night-time & 14.1 & 130 \\
\hline Rotating & 25.8 & 238 \\
\hline
\end{tabular}




\subsection{Employee Gambling Behaviour}

\subsubsection{PGSI Categorizations}

The PGSI categorization of this study's sample is presented in Table 3, along with comparative categorizations derived from relevant past research. As can be observed, this study found that low risk gambling, moderate risk gambling, and PG were all approximately two to three times more prevalent among Ontario casino employees as among the general Ontario population. Also, only $3.0 \%$ of the employees were determined to be non-gamblers ${ }^{6}$ (these employees were grouped in the non-problem gambler category), whereas Williams and Wood (2004a) classified $40.9 \%$ of the Ontario population as non-gamblers and Weibe et al. (2006) classified 36.6\% as non-gamblers. On the other hand, the rates of moderate risk and problem gambling that this study detected were only about half of what Dangerfield (2004) detected in her Alberta casino employee study, although Dangerfield's results may have been skewed by her small sample size.

PGSI results are not perfectly comparable with SOGS results, but the two measures are fairly correlated (Ferris \& Wynne, 2001), so comparing results obtained with the two measures can provide an inexact but general picture of existing patterns. If such comparisons are made, this study's results are fairly similar to those of Lee et al. (2008), who classified 3\% of their sample $(n=388)$ in two South Korean casinos as level 3 gamblers. Nevertheless, this study's sample appeared to exhibit far less PG than was detected by Duquette (1999), who classified $20.3 \%$ of her sample in a single Las Vegas casino ( $\mathrm{n}=279)$ as level 3 gamblers and $44.6 \%$ as level 2 gamblers. Finally, this study's sample appeared to demonstrate slightly more PG than was found by Shaffer et al. (1999), who classified $2.1 \%$ of their sample $(n=3,841)$ in four U.S. casinos as level 3 gamblers and $1.4 \%$ as level 2 gamblers.

\footnotetext{
6 "Non-gamblers" were those survey respondents who stated that in the previous year they had not participated in any of the various forms of gambling listed in the survey.
} 
TABLE 3. Percentage of individuals placed in the different PGSI categories

\begin{tabular}{|l|c|c|c|c|}
\hline $\begin{array}{l}\text { Sample group } \\
\text { Study }\end{array}$ & $\begin{array}{c}\text { Non- } \\
\text { problem } \\
(\mathbf{\%})\end{array}$ & $\begin{array}{c}\text { Low risk } \\
(\mathbf{\%})\end{array}$ & $\begin{array}{c}\text { Moderate } \\
\text { risk (\%) }\end{array}$ & $\begin{array}{c}\text { Problem } \\
\text { gambler } \\
(\%)\end{array}$ \\
\hline $\begin{array}{l}\text { Ontario casino employees (n=887) } \\
\text { This study }\end{array}$ & 73.6 & 14.3 & 8.9 & 3.2 \\
\hline $\begin{array}{c}\text { General Ontario population (n=3,604) } \\
\text { Wiebe et al., 2006 }\end{array}$ & 90.7 & 5.8 & 2.6 & 0.8 \\
\hline $\begin{array}{l}\text { General Ontario population (n=6,654) } \\
\text { Williams \& Wood, 2004a }\end{array}$ & 87.8 & 7.5 & 3.8 & 1.0 \\
\hline $\begin{array}{c}\text { Alberta casino employees (n=113) } \\
\text { Dangerfield, 2004 }\end{array}$ & 60.7 & 14.3 & 18.9 & 6.3 \\
\hline \hline
\end{tabular}

During the interview portion of this study, when participants were asked whether PG existed among the employee population, many claimed that PG most likely existed but probably only among a fairly small group. For instance, one interviewee stated, “[The] majority [of employee gambling], I would say it's responsible...I really don't think that there is a lot of employees that have that problem. I'm sure there are some, as with the general population, but I haven't really heard of it being a very predominate problem at work." Another interviewee similarly claimed, "I'm sure there are exceptions to what I'm saying, but from what I can see and from what I can tell when employees go to [casinos] it's purely entertainment and there doesn't seem to be any kind of addiction at all." Moreover, some of the other interviewees were even less convinced that PG existed. As, one of these interviewees stated, "If there's anyone with problems I haven't seen it. I haven't seen anybody with red flags," and another claimed, "I can't think of anybody that goes [gambling] regularly." Nevertheless, there were also some interviewees who were quite convinced that the problem existed. As one interviewee surmised, "I bet you [there is] a good 10 or 15 percent [of employees] that really gamble a lot. Whether they know it's a problem or not, I don't know." Similarly, another employee remarked, "Some people do have [problems]. Definitely, definitely."

\subsubsection{Monthly Gambling Expenditure}

The mean monthly gambling expenditure of the survey respondents was $\$ 54.67$ $(\mathrm{SD}=\$ 162.83)$ and the median monthly expenditure was $\$ 13.75$, which indicates an 
extremely skewed sample characterized by a small number employees with very high mean monthly expenditures. The percentage of respondents who spent different amounts is presented in Table 4 and, as can be observed, about two-thirds (67.4\%) spent $\$ 25$ or less per month and about one-tenth (8.4\%) spent more than $\$ 100$ per month. Such estimates are fairly unreliable (Blaszczynski et al., 1997, 2006; Williams \& Wood, 2004a), and should be interpreted as such, but they nevertheless offer a useful picture of some general patterns.

TABLE 4. Estimated typical monthly gambling expenditures

\begin{tabular}{|l|c|c|}
\hline Amount & Pct. & n \\
\hline$\$ 0$ & 20.3 & 186 \\
\hline$\$ 1-25$ & 47.1 & 431 \\
\hline$\$ 26-100$ & 23.1 & 212 \\
\hline$\$ 101-250$ & 4.7 & 43 \\
\hline$\$ 251-500$ & 3.8 & 35 \\
\hline$\geq \$ 501$ & 1.0 & 9 \\
\hline \hline
\end{tabular}

As Table 5 illustrates, employees who spent greater amounts of money on gambling reported far greater rates of moderate risk and problem gambling. In fact, well over half of the respondents $(63.5 \%)$ who claimed to spend over $\$ 100$ each month on gambling were categorized as either moderate risk or problem gamblers. Predictably, a significant, positive correlation was detected between typical monthly gambling expenditure and PGSI scores $(\mathrm{R}=0.541, \mathrm{p}<0.001)$.

TABLE 5. PGSI results of employees with different monthly gambling expenditures

\begin{tabular}{|c|c|c|c|c|c|c|c|}
\hline $\begin{array}{l}\text { Typical } \\
\text { monthly } \\
\text { expenditure }\end{array}$ & $\begin{array}{c}\begin{array}{c}\text { Non- } \\
\text { problem } \\
(\%)\end{array} \\
\end{array}$ & $\begin{array}{c}\text { Low risk } \\
(\%)\end{array}$ & $\begin{array}{c}\text { Moderate } \\
\text { risk (\%) }\end{array}$ & $\begin{array}{c}\text { Problem } \\
\text { gambler } \\
(\%)\end{array}$ & $\begin{array}{l}\text { Mean } \\
\text { PGSI } \\
\text { score* }\end{array}$ & SD & $\mathbf{n}$ \\
\hline$\$ 0$ & 92.5 & 4.6 & 2.9 & 0.0 & 0.21 & 0.88 & 174 \\
\hline$\$ 1-25$ & 84.6 & 11.2 & 3.7 & 0.5 & 0.34 & 1.12 & 410 \\
\hline$\$ 26-100$ & 60.9 & 26.2 & 11.9 & 1.0 & 0.97 & 1.82 & 202 \\
\hline$\$ 101-250$ & 26.2 & 23.8 & 28.6 & 21.4 & 4.07 & 4.56 & 42 \\
\hline$\geq \$ 251$ & 2.3 & 20.9 & 41.9 & 34.9 & 6.56 & 5.57 & 43 \\
\hline
\end{tabular}




\subsubsection{Participation in Different Forms of Gambling}

\subsubsection{Lottery-Style Gambling}

Table 6 presents the frequency with which the respondents gambled in certain ways and on certain games during the 12 months preceding the survey. As the table clearly illustrates, lottery-style gambling was by far the most common form of gambling in which the employees engaged, with over $25 \%$ of the employees playing at least once per week and over $90 \%$ having played at least once in the previous year. However, it should be remembered that participation in this form of gambling undoubtedly has since declined considerably due to the recently enacted restriction banning OLG employees from playing OLG lottery games. ${ }^{7}$

The overwhelming popularity of lottery-style games, as compared to other forms of gambling, parallels the findings of both Wiebe et al. (2006) and Dangerfield (2004), although the respondents in this study seemed to play lottery-style games even more than the respondents in either of those studies. For instance, Wiebe et al. found that in the general Ontario population $52.4 \%$ had gambled on lottery tickets in the past 12 months (Wiebe et al. differentiated between "lottery tickets," "raffle tickets," and "scratch tickets," but lottery tickets had the most participation). Nevertheless, Wiebe et al. also found that $35.7 \%$ of those people who had played the lottery in the past 12 months had done so at least once per week, while in this study the proportion was $29.3 \%$. In her study of Alberta casino employees, Dangerfield found that in the previous six months $21.4 \%$ had played lottery-style games at least once per week, and $21.5 \%$ had played them between one and three times per month.

During this study's interviews, many of the participants corroborated the apparent overwhelming popularity of lottery-style games among Ontario casino employees. Moreover, several interviewees remarked that, prior to April 1, employees frequently purchased tickets during the workday and on their work premises, often pooling their money together in groups. For example, one interviewee claimed:

\footnotetext{
${ }^{7}$ The survey was distributed two weeks after the ban took effect. Nevertheless, because the survey asked about previous year gambling the employees clearly seem to have answered the lottery items by referring to their lottery gambling prior to April 1.
} 
[Before April 1, lottery] was very common...Every group...of different team members, they would all have their own little pool going...Every department, they would all have their money in on it. That was a huge thing for us, that was our excitement. We'd all bring two dollars in and instead of doing the coffee run we'd all throw in for [the lottery].

Another interviewee similarly remarked:

[OLG has] lost so much business from us not purchasing, it's not funny. I mean we have it... and I know that I was there every week buying tickets. I know my boss, people - I see them in line buying tickets all the time... on our breaks or whatever...purchasing, going checking their tickets and things like that.

\subsubsection{Casino Gambling}

Following lottery-style gambling, casino gambling appears to be the second most popular form of gambling for Ontario's casino employees. Over half of the sample (55.4\%) claimed to have gambled in a casino during the previous year, although only $6.5 \%$ claimed to have done so more than once per month during that period. According to this study's interviews, it appears as though Ontario casino employees gamble in a variety of casinos, primarily in Ontario and in U.S. border casinos. Moreover, numerous interviewees remarked that vacationing in Las Vegas is relatively common amongst the employees.

When gambling in a casino, it seems as though the employees tend to play EGMs much more than any of the table games, with $34.7 \%$ having played an EGM at least once in the previous year. In comparison, Wiebe et al. (2006) found that only $16.5 \%$ of their sample had played an EGM in an Ontario casino during the previous year (Wiebe et al. differentiated between EGMs in Ontario casinos, in Ontario slots facilities, and in establishments outside of Ontario, but the first category was the most popular). On the other hand, Wiebe et al. found that of those people who had played an EGM in an Ontario casino during the previous year, $17.1 \%$ had played at least once per month, while in this study the corresponding figure was 12.5\%. Dangerfield's (2004) Alberta study found that $42.3 \%$ of the respondents had played a slot machine and $53.5 \%$ had played a VLT in the previous six months. 
Ontario casino employees appear to play the various casino table games somewhat sparingly, but still more than the general Ontario population. Wiebe et al. (2006) found that during the previous year $6.5 \%$ of their sample had gambled on table games in Ontario and 5.2\% had gambled on anything in a non-Ontario casino, while this study found that during the previous year $12.8 \%$ of the respondents had played casino blackjack - the most popular of the table games. On the other hand, the casino employees surveyed in this study appeared to gamble on table games less than the Alberta casino employees who Dangerfield (2004) surveyed. Dangerfield did not look at blackjack, but did find that $20.2 \%$ of her sample had played roulette in the past 6 months, in comparison with the $11.3 \%$ past year participation found in this study. Similarly, Dangerfield found that $12.5 \%$ of her sample had played craps or other dice games in the past six months, in comparison with the $3.9 \%$ past year participation in casino craps found in this study.

\subsubsection{Other Forms of Gambling}

In addition to lottery and casino gambling, Ontario casino employees also engage in various other forms of betting. Among these different types of betting, the most popular seems to be gambling with friends or family outside of a casino, which about one-third of the sample (33.4\%) had done during the previous year. Also, among those employees who gambled in this way, a relatively high percentage appeared to do it on a weekly basis. For example, $9.8 \%$ of these individuals stated that in the previous year they had engaged in this form of gambling at least once per week, while among those respondents who had gambled in a casino at least once in the past year, the corresponding figure was only $1.8 \%$.

Based on comments made during the interviews, and consistent with the game's recent explosion in popularity (e.g., Kirn \& Ressner, 2004), it seems as though much of this non-casino gambling with friends and family revolves around poker games. According to the interviewees, these poker games often involve co-workers playing amongst one another. In fact, some of the interviewees even viewed poker as the most popular form of employee gambling. As one interviewee remarked, "I would say probably the largest group is poker. It may not be at an OLG facility, but there's a lot of poker that goes on in little leagues here and there or people put it on in their houses." In 
the survey, betting on poker in house games was additionally included in the larger category of "betting on card or board games played outside of a casino," and approximately one-fifth of the sample $(20.1 \%)$ claimed to have engaged in this form of gambling during the past year. This figure is over double the $8.5 \%$ rate of participation found by Wiebe et al. (2006). On the other hand, these participation rates are far lower than those detected by Dangerfield (2004), who found that in the previous six months $67.0 \%$ of her sample had engaged in that form of gambling at least once, and $15.0 \%$ had participated at least once per week.

Nevertheless, Ontario casino employees seem to invest in stocks, options, and commodities even more frequently than they gamble on non-casino card and board games with family and friends. The survey found that $27.3 \%$ of the respondents had spent money in such a way during the previous year, and about one-third of this group $(36.0 \%)$ had done so at least once per month. This overall participation level was notably higher than what was detected by either Wiebe et al. (2006), who found a previous year participation rate of $1.9 \%$ (Wiebe et al. asked only about short-term speculative stock or commodity purchases), or Dangerfield (2004), who found participation in the previous six months to be $13.5 \%$.

Bingo and horseracing were each wagered on in the previous year by just under one-fifth of this study's respondents (17.5\% and $16.8 \%$ respectively). However, among those employees who had gambled on bingo in the past year, $27.5 \%$ had done so at least once per month, while among the horserace bettors the corresponding figure was only $7.1 \%$. Overall participation in these forms of gambling was greater than in the general Ontario population, as Wiebe et al. (2006) found that $4.8 \%$ of their sample had wagered on bingo and $4.1 \%$ had wagered on horseracing during the previous year. Ontario casino employees also seem more likely to gamble on horseracing than Alberta casino employees, as Dangerfield (2004) found that only $6.2 \%$ of her sample had wagered on horseracing in the previous six months. On the other hand, Dangerfield also found that a comparatively higher percentage of her sample wagered on bingo, as $29.0 \%$ had gambled on the game during the previous six months.

Sports betting and online betting (which for some may be one and the same) each seem to be less popular among Ontario casino employees than gambling on either bingo 
or horseracing, as in the previous year $12.6 \%$ of the respondents had gambled on sports and $11.4 \%$ had gambled online. However, aside from lottery-style gambling, these were the only two forms of gambling in which more respondents had gambled at least once per week than between one and three times per month. In fact, of the employees who had wagered on sports at least once in the previous year, $23.3 \%$ had done so at least once per week, and of the employees who had wagered online at least once in the past year, 30.8\% had done so at least once per week. The overall levels of participation revealed in this study were greater than those detected by Wiebe et al. (2006), who found that in the previous year $4.3 \%$ of their sample had participated in government-run sports betting (Wiebe et al. differentiated between different types of sports betting, but the governmentrun games were the most popular), and $1.7 \%$ had gambled online. Nonetheless, Wiebe et al. similarly found that individuals who gambled over the internet were especially likely to do so on a weekly basis, although the same finding was not made for individuals who participated in government-run sports betting. The levels of participation in sports and online betting found in this study also were somewhat greater than those detected by Dangerfield (2004), who found that in the past six months $9.4 \%$ of her sample had wagered on government-run sports betting and $6.2 \%$ had wagered online. 
TABLE 6. Gambling participation during the previous 12 months

\begin{tabular}{|c|c|c|c|c|c|}
\hline Forms of Gambling & Never $(\%)$ & $\begin{array}{l}1-11 \text { times } \\
\text { / year }(\%)\end{array}$ & $\begin{array}{c}1-3 \text { times / } \\
\text { month } \\
(\%)\end{array}$ & $\begin{array}{c}\text { At least } \\
\text { once / } \\
\text { week (\%) }\end{array}$ & $\mathbf{n}$ \\
\hline \multicolumn{6}{|l|}{ Location / Companions } \\
\hline At a lottery outlet & 15.5 & 39.0 & 21.9 & 23.6 & 921 \\
\hline In any casino & 44.6 & 48.9 & 5.5 & 1.0 & 922 \\
\hline $\begin{array}{l}\text { With friends or family members outside of a } \\
\text { casino (e.g., betting on poker in a house game) }\end{array}$ & 66.6 & 24.5 & 5.7 & 3.3 & 918 \\
\hline $\begin{array}{l}\text { Inside or outside of a casino with friends or } \\
\text { family members who are also co-workers }\end{array}$ & 72.1 & 20.5 & 4.8 & 2.6 & 919 \\
\hline Online & 88.6 & 6.2 & 1.6 & 3.5 & 913 \\
\hline \multicolumn{6}{|l|}{ Game } \\
\hline $\begin{array}{l}\text { Lottery, instant win, scratch, raffle, or } \\
\text { fundraising tickets }\end{array}$ & 7.7 & 39.7 & 25.6 & 27.1 & 927 \\
\hline EGMs & 65.3 & 30.4 & 3.6 & 0.8 & 925 \\
\hline $\begin{array}{l}\text { Personal investment in stocks, options, or } \\
\text { commodities markets }\end{array}$ & 72.7 & 17.4 & 7.6 & 2.2 & 917 \\
\hline $\begin{array}{l}\text { Betting on card games or board games played } \\
\text { outside of a casino }\end{array}$ & 79.9 & 14.5 & 3.6 & 2.0 & 922 \\
\hline Bingo & 82.5 & 12.7 & 3.0 & 1.9 & 915 \\
\hline Horse races (live at the track and/or off-track) & 83.2 & 15.6 & 0.9 & 0.3 & 923 \\
\hline Blackjack in a casino & 87.2 & 11.7 & 1.0 & 0.1 & 923 \\
\hline Sports betting & 87.4 & 7.2 & 2.5 & 2.9 & 922 \\
\hline Roulette in a casino & 88.7 & 10.3 & 1.0 & 0.0 & 922 \\
\hline $\begin{array}{l}\text { Betting on games of skill (e.g., pool, bowling, } \\
\text { darts) }\end{array}$ & 91.1 & 7.0 & 1.1 & 0.8 & 923 \\
\hline Poker in a casino & 91.6 & 7.3 & 1.0 & 0.2 & 924 \\
\hline Craps in a casino & 96.1 & 3.5 & 0.3 & 0.1 & 922 \\
\hline Betting on arcade or video games & 96.6 & 2.9 & 0.3 & 0.1 & 917 \\
\hline $\begin{array}{l}\text { Betting on tile games (e.g., mahjong, } \\
\text { dominoes) }\end{array}$ & 97.2 & 2.3 & 0.3 & 0.2 & 924 \\
\hline
\end{tabular}

Table 7 presents the PGSI categorizations of those survey respondents who engaged in different forms of gambling at least once per month during the previous year. ${ }^{8}$ As can be observed, the rates of moderate risk and problem gambling were highest among the monthly casino gamblers. In contrast, such rates were the lowest among employees who regularly played lottery-style games or engaged in different forms of investment. In between these two groups, one finds the other forms of gambling: horseracing, bingo, skill games, card or board games played outside of casinos, and

\footnotetext{
${ }^{8}$ Forms of gambling that were engaged in monthly by five or fewer employees were excluded.
} 
sports. However, it should be noted that only tenuous conclusions can be drawn about those forms of gambling that were played on a monthly basis by a very small number of employees.

TABLE 7. PGSI categorizations of employees who engaged in different forms of gambling at least once per month during the previous year

\begin{tabular}{|c|c|c|c|c|c|}
\hline Forms of Gambling & $\begin{array}{l}\text { Non- } \\
\text { problem } \\
(\%)\end{array}$ & $\begin{array}{c}\text { Low risk } \\
(\%)\end{array}$ & $\begin{array}{l}\text { Moderate } \\
\text { risk }(\%)\end{array}$ & $\begin{array}{l}\text { Problem } \\
\text { gambler } \\
(\%)\end{array}$ & $\mathbf{n}$ \\
\hline \multicolumn{6}{|l|}{ Location / Companions } \\
\hline In any casino & 13.8 & 27.6 & 31.0 & 27.6 & 58 \\
\hline Online & 25.5 & 17.0 & 38.3 & 19.1 & 47 \\
\hline $\begin{array}{l}\text { Inside or outside of a casino with friends } \\
\text { or family members who are also co- } \\
\text { workers }\end{array}$ & 44.1 & 19.1 & 23.5 & 13.2 & 68 \\
\hline $\begin{array}{l}\text { With friends or family members outside of } \\
\text { a casino (e.g., betting on poker in a house } \\
\text { game) }\end{array}$ & 44.4 & 19.8 & 23.5 & 12.3 & 81 \\
\hline At a lottery outlet & 64.1 & 17.8 & 12.1 & 6.0 & 398 \\
\hline \multicolumn{6}{|l|}{ Game } \\
\hline Roulette in a casino & 0.0 & 37.5 & 25.0 & 37.5 & 8 \\
\hline Poker in a casino & 9.1 & 27.3 & 27.3 & 36.4 & 11 \\
\hline Blackjack in a casino & 10.0 & 20.0 & 20.0 & 50.0 & 10 \\
\hline EGMs & 12.8 & 25.6 & 30.8 & 30.8 & 39 \\
\hline $\begin{array}{l}\text { Horse races (live at the track and/or off- } \\
\text { track) }\end{array}$ & 18.2 & 18.2 & 27.3 & 36.4 & 11 \\
\hline Bingo & 23.8 & 28.6 & 35.7 & 11.9 & 42 \\
\hline $\begin{array}{l}\text { Betting on games of skill (e.g., pool, } \\
\text { bowling, darts) }\end{array}$ & 35.3 & 17.6 & 23.5 & 23.5 & 17 \\
\hline $\begin{array}{l}\text { Betting on card games or board games } \\
\text { played outside of a casino }\end{array}$ & 49.0 & 20.4 & 20.4 & 10.2 & 49 \\
\hline Sports betting & 55.1 & 12.2 & 18.4 & 14.3 & 49 \\
\hline $\begin{array}{l}\text { Lottery, instant win, scratch, raffle, or } \\
\text { fundraising tickets }\end{array}$ & 64.6 & 17.6 & 12.4 & 5.4 & 466 \\
\hline $\begin{array}{l}\text { Personal investment in stocks, options, or } \\
\text { commodities markets }\end{array}$ & 69.8 & 12.8 & 9.3 & 8.1 & 86 \\
\hline
\end{tabular}

\subsection{Changes in Gambling Behaviour}

Ontario casino employees clearly seem to gamble more frequently and exhibit more PG than Ontario's general population. Nevertheless, as Table 8 presents, when the employees were asked directly how their gambling had changed since they began working in an OLG or resort casino, only $12.2 \%$ claimed their gambling had increased. Moreover, $28.4 \%$ claimed their gambling had actually decreased, and the bulk of these employees 
claimed the decrease had been significant. Also, the majority of the employees stated their gambling had remained the same (it should be noted that this group would include those employees who never gambled either before or since their casino employment began). These findings are relatively consistent with those made by Shaffer et al. (1999) in the U.S. and Dangerfield (2004) in Alberta. Shaffer et al. found that $15.2 \%$ of their sample claimed their gambling had increased, 29.3\% claimed it had decreased, and $55.4 \%$ claimed it had remained the same. Dangerfield posed the question slightly differently by asking how the employment had affected the respondents' gambling activities, and $20.2 \%$ of her sample claimed the employment had resulted in an increase in gambling, 28.9\% claimed it had resulted in a decrease, and 50.9\% claimed it had exerted no effect.

TABLE 8. Changes in employees' gambling since beginning work in an OLG or resort casino

\begin{tabular}{|l|c|c|}
\hline Gambling change & Pct. & n \\
\hline Decreased significantly & 17.9 & 162 \\
\hline Decreased a little & 10.5 & 95 \\
\hline Remained the same & 59.4 & 537 \\
\hline Increased a little & 8.8 & 80 \\
\hline Increased significantly & 3.3 & 30 \\
\hline \hline
\end{tabular}

When asked in this study's interviews how employees tended to change their gambling after beginning their jobs, the participants offered a variety of answers. Some of the interviewees claimed that the job had little impact on employees' gambling, so their gambling generally remained the same. For instance, one interviewee claimed, "I don't really think [employees' gambling] would [go up]. It would probably just kind of stay the same but shift to the sites you're allowed to go to." Another interviewee similarly opined, "I don't think there's really much impact. The people that come here that gambled before still gamble. The people that come here just for a job are not really interested in playing cards after their shift is over." Nevertheless, some of the other interviewees believed the work typically caused the employees to gamble less. As one interviewee remarked, "I think, if anything, from just what I've seen, [the work] makes people gamble less if they did [gamble before]." On the other hand, some other interviewees felt the work typically 
caused the employees to gamble more. As one of these interviewees stated, "I think probably most of [the employees] start gambling more."

Table 9 shows the PGSI categorizations of employees who claimed to have experienced different changes in their gambling since beginning their work. The table demonstrates that a clear, positive relationship exists between PG rates and increases in one's gambling. In fact, even though only a tiny portion of the respondents claimed that their gambling had increased significantly, over three-quarters of these respondents (76.7\%) were categorized as moderate risk or problem gamblers. A one-way ANOVA test confirmed that significant differences existed between the different groups' mean PGSI scores $(\mathrm{F}=62.775, \mathrm{p}<0.001)$ and a Scheffé post-hoc test further confirmed the existence of significant differences between the groups.

TABLE 9. PGSI results of employees who had changed their gambling in different ways since beginning work in an OLG or resort casino

\begin{tabular}{|c|c|c|c|c|c|c|c|}
\hline Gambling Change & $\begin{array}{c}\begin{array}{c}\text { Non- } \\
\text { problem } \\
(\%)\end{array} \\
\end{array}$ & $\begin{array}{c}\text { Low risk } \\
(\%)\end{array}$ & $\begin{array}{c}\text { Moderate } \\
\text { risk }(\%)\end{array}$ & $\begin{array}{c}\text { Problem } \\
\text { gambler } \\
(\%)\end{array}$ & $\begin{array}{c}\text { Mean } \\
\text { PGSI } \\
\text { score* }\end{array}$ & SD & $\mathbf{n}$ \\
\hline Decreased significantly & 75.5 & 13.9 & 8.6 & 2.0 & $0.80^{\mathrm{a}}$ & 1.99 & 151 \\
\hline Decreased a little & 62.9 & 24.7 & 9.0 & 3.4 & $1.06^{\mathrm{ab}}$ & 2.08 & 89 \\
\hline Remained the same & 81.6 & 12.0 & 5.4 & 1.0 & $0.49^{\mathrm{a}}$ & 1.74 & 515 \\
\hline Increased a little & 50.0 & 21.1 & 22.4 & 6.6 & $2.08^{\mathrm{b}}$ & 3.48 & 76 \\
\hline Increased significantly & 6.7 & 16.7 & 40.0 & 36.7 & $6.80^{\mathrm{c}}$ & 5.17 & 30 \\
\hline
\end{tabular}

Note: Superscripts indicate groups that are significantly different based on Scheffé test $(\mathrm{p}<.05)$

\subsection{Workplace Influences}

\subsubsection{Exposure to Gambling}

The employees' exposure to gambling appears to be one workplace influence that explains some of the gambling changes the employees claimed to have experienced after beginning their jobs. As can be observed in Table 10, the survey respondents generally expressed clear agreement that their exposure to gambling had not led to an increase in their interest toward the activity, nor had their increased knowledge of the games caused the employees to believe they could profit from playing the games. Such attitudes were further confirmed in statements made in numerous interviews. For instance, regarding a 
diminished interest in gambling, one interviewee stated, "It seems like once you're out of here you don't want to go to a facility that has the same noise, same ringing bells and spend you're time off sitting there." Another interviewee similarly remarked, "I wasn't big into [gambling] when I started here, but now, seeing it every time I work, it's not exciting now... [it] definitely doesn't have an entertainment factor to me. If I'm on my day off, I definitely don't want to spend it in a casino again." Also, regarding employees' increased knowledge of the games, one interviewee stated, "We know the house wins, you just see it. We're not about to use our hard-earned money to go do the same thing." Another interviewee similarly claimed:

The more you know about [slot machines] the more you realize that they are completely random, and playing more doesn't mean you're going to win more and all that kind of stuff. And we all know that...I think just observing, without our training, you'd still be able to see slot machines are completely random. There's no way to win really, the house always wins.

TABLE 10. Attitudes toward the impacts of exposure to gambling

\begin{tabular}{|c|c|c|c|c|c|c|c|c|}
\hline $\begin{array}{l}\text { Impacts of Exposure to } \\
\text { Gambling }\end{array}$ & $\begin{array}{l}\text { Strongly } \\
\text { Disagree } \\
(\%)\end{array}$ & $\begin{array}{c}\text { Disagree } \\
(\%)\end{array}$ & $\begin{array}{l}\text { Neutral } \\
(\%)\end{array}$ & $\begin{array}{c}\text { Agree } \\
(\%)\end{array}$ & $\begin{array}{c}\text { Strongly } \\
\text { Agree } \\
(\%)\end{array}$ & Mean* & SD & $\mathbf{n}$ \\
\hline $\begin{array}{l}\text { After work I want to avoid } \\
\text { spending even more time in a } \\
\text { casino or involved with } \\
\text { gambling }\end{array}$ & 4.9 & 7.7 & 17.9 & 27.4 & 42.1 & 3.94 & 1.16 & 894 \\
\hline $\begin{array}{l}\text { As I have become more } \\
\text { knowledgeable about the } \\
\text { games I have realized that I } \\
\text { cannot overcome the house } \\
\text { odds in most games }\end{array}$ & 8.2 & 4.5 & 15.7 & 34.2 & 37.5 & 3.88 & 1.20 & 822 \\
\hline $\begin{array}{l}\text { I spend so much time } \\
\text { surrounded by gambling that it } \\
\text { is no longer interesting }\end{array}$ & 7.6 & 15.2 & 26.8 & 22.9 & 27.4 & 3.47 & 1.25 & 853 \\
\hline $\begin{array}{l}\text { I have become more interested } \\
\text { in gambling so I wanted to } \\
\text { participate }\end{array}$ & 56.7 & 27.8 & 9.1 & 5.7 & 0.7 & 1.66 & 0.91 & 864 \\
\hline $\begin{array}{l}\text { I believe I can win money } \\
\text { because I have become more } \\
\text { knowledgeable about casino } \\
\text { games }\end{array}$ & 64.9 & 24.0 & 6.2 & 3.8 & 1.0 & 1.52 & 0.85 & 870 \\
\hline
\end{tabular}


Nevertheless, numerous interviewees also claimed that it is not uncommon for employees to believe their acquired gambling knowledge gives them a gambling edge, particularly with respect to the table games. For instance, one interviewee remarked:

There's the people that work here that I know they figure they know the games better. They figure they know what's going on, they know basic strategy, whatever it is that they know. So they go to other casinos that they can gamble at...because they think that they can win now because they have the tools. A second interviewee expressed a similar sentiment in claiming, "Some people that started dealing poker thought, 'Yeah, I can do this, this is easy'... They deal a lot of hands in an hour, in a day, in a week. I'm sure they pick up a lot of skill by dealing, knowing when to bet and what hands are winning." Although poker does involve a genuine element of skill (Parke, Griffiths, \& Parke, 2005), such confidence can even be associated with EGMs. As one interviewee explained, "Even though it's ingrained into us that it's all random...I've definitely heard some slot attendants say, like, that they've been on the floor so much that they've figured it out."

A small number of employees apparently have even quit their jobs to focus entirely on using their acquired gambling knowledge to earn money gambling. As one interviewee recalled:

[One employee] was extremely successful. Four or five guys followed him. I don't know for sure, but the rumour was he made a hundred thousand dollars on online poker, playing in tournaments throughout the States and Las Vegas, and that was his goal, if he had a bankroll that high he was going to resign.

However, not all of the employees who have dedicated themselves to gambling have enjoyed as much success. For instance, an interviewee from a different facility stated:

There have actually been dealers who have been stupid enough to quit to gamble professionally. One left who played poker because he had won a few times and he was going to make money. He is now working at Tim Horton's...Another guy also, he dealt a game all the time and he figured he had the strategy figured out so he quit...[He] figured he could make a killing on craps because he now knew the strategy. 
Table 11 examines respondents' beliefs that they can or cannot use their acquired gambling knowledge to win money by analyzing how these beliefs relate to the respondents' PGSI classifications and changes in gambling behaviour. As the table illustrates, those employees who were categorized as moderate risk or problem gamblers and those employees who claimed their gambling had increased since they began working at an OLG or resort casino were more likely to agree that their acquired gambling knowledge permitted them to win money gambling. One-way ANOVA tests found significant differences between the groups for both variables (PGSI categories: $\mathrm{F}=23.028, \mathrm{p}<0.001$; gambling change categories: $\mathrm{F}=32.407, \mathrm{p}<0.001)$. A Scheffé posthoc test analyzing the PGSI categories found that moderate risk gamblers reported significantly higher levels of agreement than the non-problem and low risk gamblers, and the problem gamblers reported significantly higher levels of agreement than the moderate risk gamblers. A Scheffé post-hoc test analyzing the gambling change categories found that levels of agreement were significantly highest among those employees whose gambling had increased. However, moderate risk gamblers, problem gamblers, and employees who claimed their gambling had increased also paradoxically seemed slightly more likely to agree that that their acquired gambling knowledge had convinced them they could not win money gambling, although one-way ANOVA tests did not find significant differences between the groups in this case (PGSI categories: $F=1.325$, $\mathrm{p}=0.265$; gambling change categories: $\mathrm{F}=2.597, \mathrm{p}=0.075$ ). 
TABLE 11. Relationships between PGSI categorizations and changes in gambling with perceived abilities to win money gambling

\begin{tabular}{|c|c|c|c|c|c|c|c|c|}
\hline $\begin{array}{l}\text { Variable } \\
\text { Group }\end{array}$ & $\begin{array}{c}\text { Strongly } \\
\text { disagree } \\
(\%)\end{array}$ & $\begin{array}{l}\text { Disagree } \\
(\%)\end{array}$ & $\begin{array}{c}\text { Neutral } \\
(\%)\end{array}$ & $\begin{array}{c}\text { Agree } \\
(\%)\end{array}$ & $\begin{array}{c}\text { Strongly } \\
\text { agree } \\
(\%)\end{array}$ & Mean* & SD & $\mathbf{n}$ \\
\hline & \multicolumn{8}{|c|}{$\begin{array}{c}\text { I believe I can win money because I have become more knowledgeable about casino } \\
\text { games }\end{array}$} \\
\hline \multicolumn{9}{|l|}{ PGSI category } \\
\hline Non-problem & 70.3 & 22.1 & 4.5 & 2.2 & 1.0 & $1.41^{\mathrm{a}}$ & 0.76 & 603 \\
\hline Low risk & 59.7 & 30.6 & 4.8 & 4.8 & 0.0 & $1.55^{\mathrm{a}}$ & 0.80 & 124 \\
\hline Moderate risk & 41.6 & 35.1 & 13.0 & 7.8 & 2.6 & $1.95^{\mathrm{b}}$ & 1.05 & 77 \\
\hline Problem gambler & 28.6 & 21.4 & 25.0 & 25.0 & 0.0 & $2.46^{\mathrm{c}}$ & 1.17 & 28 \\
\hline \multicolumn{9}{|l|}{ Gambling change } \\
\hline Decreased & 67.8 & 23.3 & 6.4 & 2.1 & 0.4 & $1.44^{\mathrm{a}}$ & 0.74 & 236 \\
\hline Remained the same & 69.3 & 23.1 & 4.4 & 2.4 & 0.8 & $1.42^{\mathrm{a}}$ & 0.76 & 498 \\
\hline \multirow[t]{2}{*}{ Increased } & 38.5 & 31.2 & 14.7 & 12.8 & 2.8 & $2.10^{\mathrm{b}}$ & 1.14 & 109 \\
\hline & \multicolumn{8}{|c|}{$\begin{array}{l}\text { As I have become more knowledgeable about the games I have realized that I cannot } \\
\text { overcome the house odds in most games }\end{array}$} \\
\hline \multicolumn{9}{|l|}{ PGSI category } \\
\hline Non-problem & 10.4 & 4.7 & 14.9 & 31.3 & 38.7 & 3.83 & 1.28 & 569 \\
\hline Low risk & 2.5 & 4.2 & 18.5 & 42.9 & 31.9 & 3.97 & 0.95 & 119 \\
\hline Moderate risk & 1.3 & 5.3 & 13.3 & 45.3 & 34.7 & 4.07 & 0.91 & 75 \\
\hline Problem gambler & 4.0 & 0.0 & 20.0 & 40.0 & 36.0 & 4.04 & 0.98 & 25 \\
\hline \multicolumn{9}{|l|}{ Gambling change } \\
\hline Decreased & 7.2 & 5.0 & 12.2 & 33.3 & 42.3 & 3.99 & 1.18 & 222 \\
\hline Remained the same & 9.0 & 4.7 & 17.7 & 32.5 & 36.1 & 3.82 & 1.23 & 468 \\
\hline Increased & 3.6 & 2.7 & 12.7 & 46.4 & 34.5 & 4.05 & 0.96 & 110 \\
\hline
\end{tabular}

Note: Superscripts indicate groups that are significantly different based on Scheffé test $(\mathrm{p}<.05)$

These contradictions are primarily explained by irrational thinking that somehow permits the gamblers to hold entirely contradictory beliefs. In fact, of the 15 moderate risk and problem gamblers who agreed with the first statement, 12 also agreed with the second statement, and only one disagreed with it (while two marked "doesn't apply"). Likewise, of the 17 employees who had increased their gambling and agreed with the first statement, 15 also agreed with the second statement, while only one disagreed and one marked the "neutral" response.

Such irrational thinking is further exemplified by analyzing employees' gambling expenses. Those employees who agreed with the statement "I typically win when I gamble" claimed to spend an average of $\$ 251.48(\mathrm{SD}=\$ 564.72, \mathrm{n}=41)$ gambling each 
month, those who were neutral toward the statement claimed to spend an average of $\$ 79.71(\mathrm{SD}=\$ 150.13, \mathrm{n}=147)$ gambling each month, and those who disagreed with the statement claimed to spend an average of $\$ 47.57$ gambling each month $(\mathrm{SD}=\$ 106.10$, $\mathrm{n}=534)$. A one-way ANOVA test found significant differences between these groups $(\mathrm{F}=26.406, \mathrm{p}<0.001)$ and a Scheffé post-hoc test distinguished the employees who agreed with the statement from the other two groups.

However, several interviewees also pointed out that employees may increase their gambling not because they believe they can win, but rather because they are now simply familiar with the games and feel comfortable playing them. As one interviewee explained, "Being an employee in a gambling establishment, they develop more of a comfort zone to go to another place, they feel comfortable gambling. It's not unfamiliar to them...Y You're more comfortable walking into a gambling establishment once you've worked in one." Similarly, another interviewee remarked, "I do think [gambling] would increase [for employees] just for the fact that you know how to use those games. If you never were around them before you walk into a casino and you're like, 'I don't know what I'm doing,' you know, you have no idea how to use them."

\subsubsection{Exposure to the Patrons}

Just as casino employees' gambling may be influenced by their exposure to gambling itself, it also may be influenced by their exposure to the casino patrons. As can be seen in Table 12, the survey respondents clearly expressed that they were typically dissuaded from gambling by their observations of casino patrons, and only a very small fraction of the employees felt they had been drawn to gambling by these observations. In fact, as Table 13 illustrates, over $60 \%$ of the survey respondents claimed that they observed patron PG at least once per week. 
TABLE 12. Attitudes toward the impacts of exposure to the casino patrons

\begin{tabular}{|c|c|c|c|c|c|c|c|c|}
\hline $\begin{array}{l}\text { Impacts of exposure to } \\
\text { patrons }\end{array}$ & $\begin{array}{c}\begin{array}{c}\text { Strongly } \\
\text { disagree } \\
(\%)\end{array} \\
\end{array}$ & $\begin{array}{c}\text { Disagree } \\
(\%)\end{array}$ & $\begin{array}{c}\text { Neutral } \\
(\%)\end{array}$ & $\begin{array}{c}\text { Agree } \\
(\%)\end{array}$ & $\begin{array}{c}\text { Strongly } \\
\text { agree } \\
(\%)\end{array}$ & Mean* & SD & $\mathbf{n}$ \\
\hline $\begin{array}{l}\text { I see patrons losing money and } \\
\text { do not want to do the same }\end{array}$ & 5.0 & 3.8 & 14.0 & 34.2 & 43.1 & 4.07 & 1.08 & 845 \\
\hline $\begin{array}{l}\text { I see some negative } \\
\text { consequences of gambling } \\
\text { among patrons and I do not } \\
\text { want to be like them }\end{array}$ & 4.6 & 5.0 & 15.8 & 38.0 & 36.6 & 3.97 & 1.07 & 866 \\
\hline $\begin{array}{l}\text { I see how much fun patrons are } \\
\text { having and I want to participate } \\
\text { too }\end{array}$ & 38.2 & 28.9 & 22.4 & 9.1 & 1.4 & 2.07 & 1.05 & 866 \\
\hline $\begin{array}{l}\text { I have seen many patrons win so } \\
\text { I think I have a good chance of } \\
\text { winning money }\end{array}$ & 58.7 & 30.6 & 7.4 & 2.3 & 0.9 & 1.56 & 0.80 & 862 \\
\hline $\begin{array}{l}\text { I receive gambling tips from } \\
\text { patrons that I feel are worth } \\
\text { following }\end{array}$ & 71.4 & 22.1 & 4.1 & 1.3 & 1.1 & 1.39 & 0.73 & 786 \\
\hline
\end{tabular}

TABLE 13. During the previous 12 months, frequency with which employees saw patrons perceived to have gambling problems $(n=924)$

\begin{tabular}{|c|c|c|c|c|}
\hline Never (\%) & $\begin{array}{c}\text { 1-11 times / } \\
\text { yr (\%) }\end{array}$ & $\begin{array}{c}\mathbf{1 - 3} \text { times / } \\
\text { month (\%) }\end{array}$ & $\begin{array}{c}\mathbf{1 - 6} \text { times / } \\
\text { week (\%) }\end{array}$ & Daily (\%) \\
\hline 14.7 & 11.9 & 10.7 & 21.6 & 41.0 \\
\hline \hline
\end{tabular}

The impact of witnessing such patron behaviour was described in numerous interviews as having an especially significant dissuasive impact on the employees' own gambling. For instance, one interviewee stated:

You see everything [the patrons] are losing. You see what it does to them-it ends up being the only thing in their life... 'Gosh,' you think to yourself, 'there's more to life, why would you spend your time here?'... So I think it makes [employees] even more determined not to [gamble].

Similar sentiments were expressed by another interviewee, who claimed:

[Working here] made me realize how silly [gambling] really is and you see people out on the gaming floor and you watch them and they're rubbing down machines and they have all these good luck charms and they do the strangest things and you see people wasting their money when they don't have any and it's sad, and, to me, I'm like, I never want to be in that situation. 
Moreover, several interviewees claimed that casino employees often become acquainted with patrons, even in the larger facilities, so such familiarity may amplify the impacts of the employees' patron observations. As one interviewee explained, "The patrons on our floor, we know well, and we do want to know how they're doing, to be honest."

The survey made no specific mention of complaints, but during the interviews numerous participants commented on the large number of complaints or generally poor treatment the employees felt they frequently received from the patrons. As one interviewee explained, "We have a unique customer here [in this industry]... They're sometimes short with us because they are losing money." Another interviewee further described:

[Complaints are] very common: 'The machines are too tight, you need to loosen them, you never win at this place, I'm going to go to [another facility].' There's tons of complaints, even on the comment cards, because patrons, I think no matter what you tell them, they still believe that we can do something to help them win and that's not true.

Receiving such complaints and poor treatment appears to play a significant role in diminishing gambling's appeal to many employees. As one interviewee stated:

A lot of the negativity that we often hear is, you know, the machines don't pay out...A lot of that we hear all day. Every time you walk around the corner and you go down to see someone else and you congratulate them on a win, you see their light and you're like, 'Oh, congratulations, that's awesome,' they turn around and they're like, 'No, it's not awesome I just spent three grand in the machine'...You're trying to be happy with them and bring the whole thing up and they bring you back down...I think it has an impact. I think it completely deters us [from gambling] because I don't want to go. After hearing that I don't want any part of it...I think we're all equally susceptible to hearing it... Whatever person they come into contact with that is wearing a uniform, if a patron's upset they will tell everybody...It's constant. 


\subsubsection{Exposure to the Work Environment}

Table 14 illustrates how the survey respondents felt their gambling was impacted by certain factors related to the casino work environment. As can be observed, the employees did not generally perceive either co-workers, marketing, or job stress as major factors that had influenced the employees to gamble. Nevertheless, numerous interviewees noted that employees frequently gambled with one another, including on lottery games or sports pools, in house games, or in casinos. As one employee explained, "We go as a group of employees that go down to the States or wherever to go [gambling]." Moreover, the facilities' social clubs sometimes organize social outings that involve visiting other casinos, and one interviewee claimed that, at the facility where the interviewee worked, "[The bus] usually sells out every time." Also, even though the interviewees did not generally feel stress was a significant factor associated with employee gambling, one interviewee stated, “[Gambling's] actually de-stressing for me because I listen to it day in and day out so when I go to [another casino] I don't even hear the noise."

TABLE 14. Attitudes toward the impacts of exposure to the work environment

\begin{tabular}{|c|c|c|c|c|c|c|c|c|}
\hline $\begin{array}{l}\text { Impacts of exposure to work } \\
\text { environment }\end{array}$ & $\begin{array}{l}\text { Strongly } \\
\text { disagree } \\
(\%)\end{array}$ & $\begin{array}{c}\text { Disagree } \\
(\%)\end{array}$ & $\begin{array}{c}\text { Neutral } \\
(\%)\end{array}$ & $\begin{array}{c}\text { Agree } \\
(\%)\end{array}$ & $\begin{array}{l}\text { Strongly } \\
\text { agree } \\
(\%)\end{array}$ & Mean* & SD & $\mathbf{n}$ \\
\hline $\begin{array}{l}\text { My friends who also work in } \\
\text { the facility rarely or never } \\
\text { gamble so I rarely or never } \\
\text { gamble }\end{array}$ & 16.1 & 19.5 & 26.4 & 22.2 & 15.8 & 3.02 & 1.30 & 799 \\
\hline $\begin{array}{l}\text { My friends who also work in } \\
\text { the facility gamble a lot so I } \\
\text { gamble with them }\end{array}$ & 61.8 & 27.0 & 7.0 & 3.3 & 0.9 & 1.54 & 0.83 & 812 \\
\hline $\begin{array}{l}\text { The marketing and advertising } \\
\text { that I see at work tempts me to } \\
\text { gamble }\end{array}$ & 68.1 & 23.7 & 4.5 & 2.5 & 1.1 & 1.45 & 0.79 & 872 \\
\hline $\begin{array}{l}\text { Gambling relieves the stress } \\
\text { from my job }\end{array}$ & 69.8 & 22.1 & 4.6 & 2.6 & 0.8 & 1.43 & 0.77 & 839 \\
\hline
\end{tabular}

Although very few employees agreed that they gambled to relieve job stress, a much larger percentage agreed that they found their jobs stressful, as is illustrated in Table 15. These levels of agreement are somewhat comparable to those found by 
Dangerfield (2004) in Alberta, where 10.7\% of her respondents called their jobs "extremely stressful," $61.5 \%$ called their jobs "somewhat stressful," and $27.9 \%$ called their jobs "not at all stressful." Consistent with the fairly disparate opinions regarding job stress that were expressed in this study's survey findings, a variety of contrasting opinions were voiced about this topic during the interviews. For example, one interviewee claimed that working at the casino facility was "less stressful than a restaurant, say, position, for those people who are in that kind of service role." On the other hand, another interviewee stated, "It's a stressful job...for the dealers, like, they get abused by the patrons... Those games are pretty intense."

TABLE 15. Percentage of employees who found jobs stressful $(n=905)$

\begin{tabular}{|l|c|}
\hline I find my job stressful... & Pct. \\
\hline Strongly Disagree & 19.0 \\
\hline Disagree & 24.3 \\
\hline Neutral & 25.4 \\
\hline Agree & 22.0 \\
\hline Strongly Agree & 9.3 \\
\hline \hline
\end{tabular}

As Table 16 illustrates, mean PGSI scores were somewhat related to respondents' levels of agreement that they found their jobs stressful. A one-way ANOVA test found significant differences between the groups' mean PGSI scores $(F=2.467, p=0.044)$ and a Scheffé post-hoc test confirmed that some significant differences existed between the groups. It also should be noted that those employees who strongly agreed that their jobs were stressful exhibited PG rates over four times greater than any of the other groups. 
TABLE 16. PGSI results of employees feeling different amounts of job stress $(n=868)$

\begin{tabular}{|c|c|c|c|c|c|c|c|}
\hline $\begin{array}{l}\text { I find my job } \\
\text { stressful... }\end{array}$ & $\begin{array}{c}\begin{array}{c}\text { Non- } \\
\text { problem } \\
(\%)\end{array} \\
\end{array}$ & $\begin{array}{c}\text { Low risk } \\
(\%)\end{array}$ & $\begin{array}{c}\text { Moderate } \\
\text { risk }(\%)\end{array}$ & $\begin{array}{c}\text { Problem } \\
\text { gambler } \\
(\%)\end{array}$ & $\begin{array}{l}\text { Mean } \\
\text { PGSI } \\
\text { score* }\end{array}$ & SD & $\mathbf{n}$ \\
\hline Strongly disagree & 75.9 & 15.1 & 6.0 & 3.0 & $0.88^{\mathrm{ab}}$ & 2.58 & 166 \\
\hline Disagree & 78.0 & 10.6 & 7.3 & 4.1 & $0.96^{\mathrm{ab}}$ & 2.91 & 218 \\
\hline Neutral & 75.6 & 14.6 & 8.0 & 1.9 & $0.70^{\mathrm{a}}$ & 1.74 & 213 \\
\hline Agree & 66.8 & 19.2 & 11.4 & 2.6 & $1.04^{\mathrm{ab}}$ & 2.30 & 193 \\
\hline Strongly agree & 62.8 & 14.1 & 16.7 & 17.9 & $1.73^{\mathrm{b}}$ & 3.35 & 78 \\
\hline
\end{tabular}

Note: Superscripts indicate groups that are significantly different based on Scheffé test $(p<.05)$

As can be observed in Table 17, the employees who strongly agreed that their jobs were stressful also were the most likely to have claimed that their gambling had increased since they began working in an OLG or resort casino, although a chi square test failed to detect any significant differences between the groups in this case $\left(X^{2}=18.194, p=0.313\right)$. Furthermore, a significant, positive correlation was found between respondents' stated levels of agreement with the statements "I find my job stressful" and "Gambling relives the stress from my job" $(\mathrm{R}=0.106, \mathrm{p}=0.002)$.

TABLE 17. Changes in gambling experienced by employees feeling different amounts of job stress $(\mathrm{n}=879)$

\begin{tabular}{|l|c|c|c|c|c|c|}
\hline $\begin{array}{l}\text { I find my job } \\
\text { stressful... }\end{array}$ & $\begin{array}{c}\text { Decreased } \\
\text { significantly } \\
(\mathbf{\%})\end{array}$ & $\begin{array}{c}\text { Decreased a } \\
\text { little (\%) }\end{array}$ & $\begin{array}{c}\text { Remained } \\
\text { the same } \\
(\mathbf{\% )}\end{array}$ & $\begin{array}{c}\text { Increased a } \\
\text { little (\%) }\end{array}$ & $\begin{array}{c}\text { Increased } \\
\text { significantly } \\
(\boldsymbol{\%})\end{array}$ & n \\
\hline Strongly disagree & 19.2 & 13.2 & 55.7 & 7.8 & 4.2 & 167 \\
\hline Disagree & 19.2 & 13.1 & 56.1 & 8.9 & 2.8 & 214 \\
\hline Neutral & 15.8 & 9.9 & 64.0 & 8.6 & 1.8 & 222 \\
\hline Agree & 13.4 & 7.2 & 65.5 & 9.8 & 4.1 & 194 \\
\hline Strongly agree & 23.2 & 7.3 & 52.4 & 11.0 & 6.1 & 82 \\
\hline \hline
\end{tabular}

\subsubsection{Training, Regulations, and Resources}

Table 18 displays the casino employees' attitudes toward how their gambling had been impacted by their RG training and their facilities' employee gambling regulations. As can be observed, the survey respondents tended to agree that the training is useful in preventing PG, although they did not generally feel that the training had discouraged them from gambling. During the interviews, opinions about the RG training were more 
varied, but most of the interviewees had fairly positive perceptions of the training. For instance, in discussing the RG training, one interviewee stated, "It has changed a lot of how I look at things." Another interviewee similarly claimed, "It's very beneficial. It debunks a lot of the myths out there. It's a real eye-opener...It's helped [employees] explain this to the patrons as much as themselves."

However, numerous interviewees also claimed that the RG training focused predominately on the patrons and very little attention was paid toward the employees themselves. As one interviewee described:

I would say the majority of the program is based on recognizing the signs of other people and, you know, what to look for, how to approach, how to notify your supervisor, what to do in the case of, what information you can provide the patron. That type of thing. I don't recall it being too much based on us as employees. I don't recall that at all.

Another interviewee similarly explained, "I don't really think that the casino is educating us enough...I just think that there really should be better training in the responsible gambling area. We do get training to recognize it in customers and that sort of thing, but I don't think that there's a lot of looking at ourselves."

Some of the interviewees nonetheless felt that employees could easily apply the patron-based RG lessons to themselves. For instance, one interviewee claimed, "I think it's more directed on detecting it on the patron level, it's not really for you. But, I mean, all those signs can reflect on yourself too, you know what I mean? You know, like, you can say, 'OK, this person's done this, this, and this. Am I doing this, this and this too?'” Nevertheless, other interviewees felt as though the training possibly would be more beneficial if it devoted more attention to the employees themselves. As one of these interviewees stated, "It's mainly just about looking for signs among the patrons...it never really relates to employee problems and gambling... It might be something that would be good to have. It might change some people, I'm not sure."

The survey results also indicated that a large percentage of employees do not feel that the regulations limiting employee casino gambling make it particularly difficult to gamble at a casino. During the interviews, however, a wide variety of contrasting opinions were voiced regarding the impact of these regulations. For instance, one 
interviewee stated, "If they lifted that ban or if they changed the Gaming Control Act, where OLG employees could gamble at an OLG facility, there'd be a dramatic increase in employee gambling I would say." A second interviewee similarly claimed, "If [the employees] could come here [to gamble], I think they would gamble more, for sure. I think a lot of them would come here." In fact, as one interviewee explained from personal experience, "I used to come to [my facility] and gamble... at least maybe once or twice a month, and now that I've been working here...I don't gamble very often at all. It's because...I really don't want to gamble so badly that I want to drive an hour and a half / two hours to the next gaming facility." Nevertheless, several other interviewees believed that employees who were interested in gambling would not be deterred by the regulations. For instance, one of these interviewees opined, "I think if someone is the type of person who likes to gamble, they're going to go where they need to go to gamble, right? I think those rules and regulations are a lot more for the public perception.” Likewise, another interviewee stated, "I think [the regulations are] irrelevant...If someone's really interested in playing they're going to make that trek."

TABLE 18. Attitudes toward the impacts of RG training and employee gambling regulations

\begin{tabular}{|c|c|c|c|c|c|c|c|c|}
\hline $\begin{array}{l}\text { Impacts of regulations and } \\
\text { resources }\end{array}$ & $\begin{array}{c}\text { Strongly } \\
\text { disagree } \\
(\%)\end{array}$ & $\begin{array}{c}\text { Disagree } \\
(\%)\end{array}$ & $\begin{array}{c}\text { Neutral } \\
(\%)\end{array}$ & $\begin{array}{c}\text { Agree } \\
(\%)\end{array}$ & $\begin{array}{l}\text { Strongly } \\
\text { agree } \\
(\%)\end{array}$ & Mean* & SD & $\mathrm{n}$ \\
\hline $\begin{array}{l}\text { My facility's problem gambling } \\
\text { training course was useful in } \\
\text { teaching me about problem } \\
\text { gambling }\end{array}$ & 3.5 & 6.0 & 19.8 & 50.6 & 20.0 & 3.78 & 0.95 & 828 \\
\hline $\begin{array}{l}\text { My facility's problem gambling } \\
\text { training course has reduced the } \\
\text { chances that I will ever become } \\
\text { a problem gambler }\end{array}$ & 7.2 & 13.3 & 27.8 & 31.7 & 20.0 & 3.44 & 1.16 & 774 \\
\hline $\begin{array}{l}\text { My job's regulations about } \\
\text { employee gambling make it } \\
\text { difficult for me to visit a casino } \\
\text { where I am allowed to gamble }\end{array}$ & 29.1 & 20.6 & 15.6 & 19.5 & 15.2 & 2.71 & 1.45 & 853 \\
\hline $\begin{array}{l}\text { My facility's training about } \\
\text { problem gambling convinced } \\
\text { me to gamble less }\end{array}$ & 25.1 & 23.6 & 32.0 & 13.5 & 5.9 & 2.52 & 1.17 & 798 \\
\hline
\end{tabular}

The survey respondents lived an average of 76.1 minutes $(\mathrm{SD}=54.83)$ from the nearest casino facility where they were allowed to gamble. Even though the majority of 
the survey respondents did not agree that the employee gambling regulations made it difficult to visit an unrestricted casino, the stated levels of agreement were significantly, positively related to the number of minutes the employees had to travel to reach their nearest unrestricted casino $(\mathrm{R}=0.350, \mathrm{p}<0.001, \mathrm{n}=820)$. A simple regression test revealed that the number of minutes explained $12.2 \%$ of the variance in the employees' levels of agreement $\left(\mathrm{R}^{2}=0.122\right)$. This pattern is also made apparent by considering the average number of minutes to reach the nearest casino needed by employees who expressed different attitudes toward the difficulties posed by the casino restrictions, as is presented in Table 19.

TABLE 19. Distance from nearest unrestricted casino for employees perceiving different levels of difficulty posed by the employee gambling regulations

\begin{tabular}{|l|c|c|c|}
\hline $\begin{array}{l}\text { My job's regulations about } \\
\text { employee gambling make it } \\
\text { difficult for me to visit a casino } \\
\text { where I am allowed to gamble }\end{array}$ & $\begin{array}{c}\text { Average number of } \\
\text { minutes from nearest } \\
\text { unrestricted casino }\end{array}$ & SD & n \\
\hline Strongly disagree & 58.1 & 43.90 & 239 \\
\hline Disagree & 61.7 & 40.46 & 173 \\
\hline Neutral & 77.2 & 49.78 & 129 \\
\hline Agree & 97.5 & 49.71 & 157 \\
\hline Strongly agree & 110.1 & 80.11 & 122 \\
\hline \hline
\end{tabular}

Nevertheless, as Tables 20 and 21 illustrate, employees who lived further from their nearest unrestricted casinos neither showed lower rates of moderate risk and problem gambling, nor were they more likely to have decreased their gambling since they began working in an OLG or resort casino. No correlation was found between the distances employees needed to travel and their PGSI scores $(R=0.004, p=0.901)$ and a chi square test failed to detect any differences between the different groups' changes in gambling $\left(\mathrm{X}^{2}=14.338, \mathrm{p}=0.280\right)$. 
TABLE 20. PGSI results of employees living different distances from their nearest unrestricted casinos

\begin{tabular}{|c|c|c|c|c|c|c|c|}
\hline $\begin{array}{l}\text { Minutes from } \\
\text { nearest } \\
\text { unrestricted casino }\end{array}$ & $\begin{array}{c}\text { Non- } \\
\text { problem } \\
(\%)\end{array}$ & $\begin{array}{c}\text { Low risk } \\
(\%)\end{array}$ & $\begin{array}{c}\text { Moderate } \\
\text { risk }(\%)\end{array}$ & $\begin{array}{c}\text { Problem } \\
\text { gambler } \\
(\%)\end{array}$ & $\begin{array}{l}\text { Mean } \\
\text { PGSI } \\
\text { score* }\end{array}$ & SD & $\mathrm{n}$ \\
\hline$\leq 20$ & 82.7 & 11.2 & 5.1 & 1.0 & 0.54 & 1.59 & 98 \\
\hline $21-60$ & 71.4 & 14.8 & 10.2 & 3.6 & 1.04 & 2.49 & 364 \\
\hline $61-120$ & 73.9 & 13.8 & 8.3 & 4.0 & 1.07 & 3.06 & 253 \\
\hline$\geq 121$ & 68.2 & 19.4 & 9.3 & 3.1 & 0.96 & 2.17 & 129 \\
\hline
\end{tabular}

TABLE 21. Changes in gambling experienced by employees living different distances from their nearest unrestricted casinos

\begin{tabular}{|l|c|c|c|c|c|c|}
\hline $\begin{array}{l}\text { Minutes from } \\
\text { nearest unrestricted } \\
\text { casino }\end{array}$ & $\begin{array}{c}\text { Decreased } \\
\text { significantly } \\
(\boldsymbol{\%})\end{array}$ & $\begin{array}{c}\text { Decreased a } \\
\text { little (\%) }\end{array}$ & $\begin{array}{c}\text { Remained } \\
\text { the same } \\
(\boldsymbol{\%})\end{array}$ & $\begin{array}{c}\text { Increased a } \\
\text { little (\%) }\end{array}$ & $\begin{array}{c}\text { Increased } \\
\text { significantly } \\
(\boldsymbol{\%})\end{array}$ & $\mathbf{n}$ \\
\hline$\leq 20$ & 19.4 & 6.1 & 69.4 & 3.1 & 2.0 & 98 \\
\hline $21-60$ & 17.8 & 10.8 & 58.5 & 9.4 & 3.5 & 371 \\
\hline $61-120$ & 14.9 & 11.1 & 59.0 & 11.1 & 3.8 & 261 \\
\hline$\geq 121$ & 22.7 & 12.9 & 52.3 & 9.1 & 3.0 & 132 \\
\hline \hline
\end{tabular}

As Table 22 illustrates, employees who lived further from unrestricted casinos did not even engage in significantly less casino gambling during the previous year, and a chi square test confirmed that no statistically significant differences existed between the groups $\left(\mathrm{X}^{2}=10.254, \mathrm{p}=0.114\right)$. Moreover, these same employees did not appear to engage in alternative forms of gambling - such as gambling with family and friends outside of a casino or online gambling - at much higher rates. A chi square test found no significant differences between the groups for gambling with family and friends outside of a casino $\left(\mathrm{X}^{2}=4.729, \mathrm{p}=0.579\right)$, but it did find significant differences between the groups for online gambling $\left(\mathrm{X}^{2}=13.047, \mathrm{p}=0.042\right)$. In each case the data hint that perhaps employees living further away from unrestricted casinos may be more likely to engage in alternative forms of gambling, but in neither case are the patterns abundantly clear. These results, therefore, contrast with Dangerfield's (2004) finding that Alberta casino employees gambled outside of casinos on card and board games with friends and family at extremely high rates, which she theorized resulted from the restrictions on casino gambling. It is worth repeating, however, that the employees she studied were more severely limited by their 
restrictions because the employees had to travel over 400 kilometres to reach their nearest unrestricted casinos.

TABLE 22. Past year gambling engaged in by employees living different distances from their nearest unrestricted casinos

\begin{tabular}{|l|c|c|c|c|}
\hline $\begin{array}{l}\text { Minutes from } \\
\text { nearest } \\
\text { unrestricted casino }\end{array}$ & Never (\%) & \multicolumn{1}{|c|}{$\begin{array}{c}\text { 1-11 times / } \\
\text { year (\%) }\end{array}$} & $\begin{array}{c}\text { At least once / } \\
\text { month (\%) }\end{array}$ & n \\
\hline & \multicolumn{3}{|c|}{ Casino gambling } \\
\hline$\leq 20$ & 54.0 & 41.0 & 5.0 & 100 \\
\hline $21-60$ & 39.9 & 52.5 & 7.6 & 383 \\
\hline $61-120$ & 43.3 & 48.7 & 8.0 & 263 \\
\hline$\geq 121$ & 45.9 & 51.1 & 3.0 & 133 \\
\hline & Gambling with friends/family outside of a casino & \\
\hline$\leq 20$ & 66.3 & 27.7 & 5.9 & 101 \\
\hline $21-60$ & 67.1 & 22.9 & 10.0 & 380 \\
\hline $61-120$ & 67.9 & 24.0 & 8.0 & 262 \\
\hline$\geq 121$ & 60.6 & 28.8 & 10.6 & 132 \\
\hline & \multicolumn{4}{|c|}{ Online gambling } \\
\hline$\leq 20$ & 94.0 & 1.0 & 5.0 & 100 \\
\hline $21-60$ & 90.5 & 5.0 & 4.5 & 380 \\
\hline $61-120$ & 84.8 & 8.4 & 6.8 & 263 \\
\hline$\geq 121$ & 85.3 & 10.1 & 4.7 & 129 \\
\hline \hline
\end{tabular}

The Ontario regulations' apparent lack of a major impact on employees' casino gambling does not seem to be the result of employees disregarding the regulations and gambling in restricted casino facilities, as all of this study's interviewees seemed to agree that the regulations were followed and employees would not jeopardize their jobs by gambling in a restricted facility. For instance, one interviewee stated, "Those rules, like, about gambling at different sites, I think are followed. I really don't think that people would risk their job for that." Another interviewee similarly agreed, "The [rules] with the casinos [are followed] because it's pretty much a threat of losing your job."

Moreover, the interviewees generally indicated that they saw the logic of these regulations and did not oppose them. For instance, one employee remarked, "I personally think that it's a good idea that the employees can only game at certain facilities...I feel like if we could game [closer] they'd be gaming more for sure." A second interviewee 
similarly stated, "I think [the rule] does [decrease employee gambling], and I think it's probably a good thing because I think you would see more people, you know, getting off a shift here and sitting down at a table and maybe playing table games when they're done, and plus it doesn't look very good."

On the other hand, the interviewees indicated that many OLG employees were extremely aggravated by the newly imposed ban on OLG lottery-style games. As different interviewees explained, "The general reaction, from what I've heard, is everyone's really pissed;" "[Employees are] very upset, outraged actually, some of them;" "[Employees] are extremely frustrated;" "There was a lot of grumbling about that;" and, "I think there was a lot of people pretty annoyed."

The first reason why employees seemed to be so angry was that they had played the banned games so frequently. As one interviewee remarked:

[Employees have reacted with] anger, complete anger. There was quite a few groups, you know, from different departments especially, and we would do the Sunday, you know, the 6/49 draw and the Super 7s. So we would all collect our two dollars, put it in together and that was our fun. We would all sit there and wait for it, you know. That was our thing and they took it away from us. Similarly, another interviewee explained, "I always bought a lottery ticket, you know once a week, for that long shot...I think most people did...I guess, like anybody else, we want to make a quick buck. I think everybody was upset over that. It's something that was taken away that you always had."

The second reason why employees were so angered by the ban was that they felt they were being punished for a retailer scandal with which the employees were uninvolved (see Bowden, 2009; CBC News, 2009; Marin, 2007). As one interviewee vented:

That is a nasty topic...I'm very frustrated with that policy...I feel like we, as employees, are paying for the retailers' fraudulent behaviours...I really am upset that they've taken that away from us...I feel like we're paying for those retailers who aren't employed by OLG and they're the ones spoiling it for us.

Another interviewee similarly explained: 
[Among] my peers at work, the general consensus is, sort of like, that's pretty dumb. Nobody really is a big fan of that, just because the whole like, I guess, the scandals that were going on, they all had to do with more the retailers, but then it was almost like we were being punished for things the retailers were doing. ${ }^{9}$

Even though the new lottery regulations undoubtedly have eliminated some lottery playing, such as the lottery gambling done in the workplaces, many of the interviewees felt that employees would continue to play the lottery through friends and family members (which is not prohibited). For instance, one interviewee stated, "People that honestly want to play, whatever, their spouses are going out on Friday night, stopping at the corner store, and picking up a ticket. That's what their doing...It's just made it a little tougher." Another interviewee agreed, "If you want to buy a lotto 6/49 ticket your husband can do it, or whoever. If you really want to do it you can...I don't think it would stop somebody who has always done it before, they'd just get someone else to do it for them."

Despite these possibilities, some of the interviewees claimed that employees were already substituting other forms of gambling for the various gambling opportunities that had been taken away. As one interviewee explained, "Now that I've been restricted, now I'm playing the hospital lotteries because that's the only other thing that I can do...Those types of things that I had never purchased before but now I've purchased because the OLG has nothing to do with that." Similarly, with regards to the sports betting that was also restricted, a second interviewee claimed:

A lot of people are now doing the hockey pools for charity kind of thing. So they're taking their ten bucks a week they were playing on [government-run sports betting] and they're putting into like a hundred dollar hockey pool where they have the chance of winning like thirty thousand...They're usually fundraisers of some kind.

Nevertheless, there are certainly other employees who have not adopted new substitute forms of gambling. As one interviewee explained, "I've just put [the money] elsewhere,

\footnotetext{
${ }^{9}$ A few months after the interviews were conducted it was announced that OLG was soon going to institute new rules banning lottery retailers from purchasing tickets within their own stores, although the retailers would still be permitted to purchase tickets at other locations (SooToday.com, 2009; The Canadian Press, 2009).
} 
that I'll use for entertainment when I go away, but I haven't heard of anyone that's switched from one gambling way...to another."

In addition to the various regulations that limit employee gambling, Ontario casinos also offer various resources that employees can use if they feel they are experiencing gambling problems. In such a situation, as Table 23 illustrates, the clear majority of the survey respondents indicated that they were cognizant of resources they could use to seek assistance. Of these resources, the Employee Assistance Plan (EAP) is clearly the most popular option, as can be observed in Table 24. However, even though nearly $95 \%$ of the respondents named a specific place where they would seek PG assistance if needed, the small percentage of respondents who claimed they would not seek assistance anywhere were far more likely to be moderate risk and problem gamblers, as is illustrated in Table 25. A t-test found significant differences between the two groups' mean PGSI scores $(\mathrm{t}=2.802, \mathrm{p}=0.008)$.

TABLE 23. Agreement with the statement, "I am aware of employee outreach tools that OLG facility employees can use if concerned they may have a gambling problem" $(n=892)$

\begin{tabular}{|c|c|c|c|c|}
\hline $\begin{array}{c}\text { Strongly } \\
\text { disagree (\%) }\end{array}$ & Disagree (\%) & Neutral (\%) & Agree (\%) & $\begin{array}{c}\text { Strongly } \\
\text { agree (\%) }\end{array}$ \\
\hline 2.6 & 7.8 & 11.8 & 53.9 & 23.9 \\
\hline \hline
\end{tabular}

TABLE 24. Most likely resource employees would use to seek assistance if they felt they had a gambling problem

\begin{tabular}{|l|c|c|}
\hline Resource & Pct. & n \\
\hline Using the Employee Assistance Plan (EAP) & 52.1 & 447 \\
\hline Seeking help from family or friends & 17.6 & 151 \\
\hline Seeking help through work & 14.1 & 121 \\
\hline Calling a helpline & 7.5 & 64 \\
\hline Wouldn't seek assistance anywhere & 5.0 & 43 \\
\hline Going to a counselling centre & 3.3 & 28 \\
\hline $\begin{array}{l}\text { Don't know of anywhere to seek assistance } \\
\text { for problem gambling }\end{array}$ & 0.5 & 4 \\
\hline \hline
\end{tabular}


TABLE 25. PGSI results of employees who would and would not seek assistance for PG

\begin{tabular}{|l|c|c|c|c|c|c|c|c|}
\hline $\begin{array}{l}\text { Whether or not } \\
\text { employees would } \\
\text { seek assistance }\end{array}$ & $\begin{array}{c}\text { Non- } \\
\text { problem } \\
(\mathbf{\%})\end{array}$ & $\begin{array}{c}\text { Low risk } \\
(\boldsymbol{\%})\end{array}$ & $\begin{array}{c}\text { Moderate } \\
\text { risk } \mathbf{( \% )}\end{array}$ & $\begin{array}{c}\text { Problem } \\
\text { gambler } \\
(\mathbf{\%})\end{array}$ & $\begin{array}{c}\text { Mean } \\
\text { PGSI } \\
\text { score* }\end{array}$ & SD & n \\
\cline { 1 - 4 } Yes & 74.2 & 14.3 & 8.5 & 3.0 & & 0.90 & 2.46 & 774 \\
\hline No & 45.2 & 21.4 & 23.8 & 9.5 & & 2.48 & 3.59 & 42 \\
\hline
\end{tabular}

The value of the EAP was emphasized throughout the interviews as well, as the program was repeatedly described as a useful resource that employees could utilize to deal with gambling problems or any other issues. As one employee stated, "Until recently I didn't think a lot of people used the Employee Assistance Program, but I feel like I've been hearing about it a lot, so a lot of people do use it. Or they put you in touch with the right people and they help you. As far as I know, it's a very good program." Another interviewee likewise claimed:

We have an Employee Assistance Program that's totally confidential. It is really great. I've used it for other things [aside from gambling]... They're excellent... They were great with me...I know quite a few employees have used it for a lot of different things and I have not heard a negative thing about our system at all.

Nevertheless, several of the interviewees voiced concerns regarding the program's confidentiality, feeling that any problems exposed to the program may be disclosed to OLG or resort casino staff who should not be aware of the problems. For instance, one interviewee stated:

There is a 1-800 number, but a lot of people are afraid it's going to come back, or that, you know, when you put a claim in to our benefit program it's going to come back to the company and the company's going to see that you're getting help for whatever and it's going to come back to you and you're going to get fired because of whatever the problem is.

Another interviewee concurred in claiming:

I don't know how many people would call [about a gambling problem]...If it were me with that problem I would not want to dare seek anything that had anything to do with work just because, they say it's confidential, but really is 
something going to happen and am I going to lose my job? And I think that would be people's natural concern.

Aside from the EAP, the results presented in Table 24 show that only a small fraction of the survey respondents claimed they would seek help through work. Nonetheless, as Table 26 indicates, the vast majority of the respondents believed that if they approached their direct supervisors about a gambling problem, these supervisors would show the employees where to get help without terminating their contracts. During the interviews, employees also indicated that they believed supervisors would be relatively supportive if approached regarding a gambling problem, although the interviewees also pointed out that many employees may nonetheless feel uncomfortable approaching their supervisors with such issues and it may be pointless because a supervisor would simply refer the employee to the EAP. For example, one interviewee stated, "I guess it depends on who your supervisor is, if you feel that they're approachable. And I think if you do go to a supervisor basically what they'll do is tell you to go to the Employee Assistance Program." Another interviewee similarly remarked:

I think it depends on the department, really. Like, we have a small, pretty intimate department, so probably not, you probably wouldn't go because everybody knows everything about everybody...But, I mean, in a really large department if you had, you know, 15 different supervisors and one of them you liked and respected, I could see them being comfortable going to that person... But probably I could see most people leaving the personal and professional separate.

TABLE 26. Employees' anticipated responses of their direct supervisors if approached about a personal gambling problem

\begin{tabular}{|l|c|c|}
\hline Response & Pct. & n \\
\hline Show you where to get help & 87.4 & 801 \\
\hline Do nothing & 4.6 & 42 \\
\hline Simply advise you to stop gambling & 3.9 & 36 \\
\hline Show you where to get help, but also terminate you & 3.4 & 31 \\
\hline Terminate you without providing any assistance & 0.7 & 7 \\
\hline \hline
\end{tabular}

As Table 27 details, those employees who believed they would lose their jobs if they approached their direct supervisor about a personal gambling problem did not 
exhibit comparatively high rates of moderate risk or problem gambling. A t-test confirmed that no significant differences existed between the groups' mean PGSI scores $(\mathrm{t}=0.285, \mathrm{p}=0.777)$. On the other hand, those employees who believed their direct supervisors would offer no assistance did exhibit comparatively high rates of moderate risk and problem gambling. In this case, a t-test found significant differences between the groups' mean PGSI scores $(\mathrm{t}=2.799, \mathrm{p}=0.006)$.

TABLE 27. PGSI results of employees' who anticipated different responses from their direct supervisors if approached about a personal gambling problem

\begin{tabular}{|c|c|c|c|c|c|c|c|c|}
\hline \multicolumn{2}{|l|}{ Type of response } & $\begin{array}{c}\begin{array}{c}\text { Non- } \\
\text { problem } \\
(\%)\end{array} \\
\end{array}$ & $\begin{array}{c}\text { Low risk } \\
(\%)\end{array}$ & $\begin{array}{l}\text { Moderate } \\
\text { risk }(\%)\end{array}$ & $\begin{array}{c}\text { Problem } \\
\text { gambler } \\
(\%)\end{array}$ & $\begin{array}{c}\text { Mean } \\
\text { PGSI } \\
\text { score* }\end{array}$ & SD & $\mathbf{n}$ \\
\hline \multirow{2}{*}{$\begin{array}{l}\text { Whether or not response } \\
\text { would involve losing job }\end{array}$} & Yes & 70.6 & 17.6 & 8.8 & 2.9 & 0.85 & 2.25 & 34 \\
\hline & $\mathrm{No}$ & 73.6 & 14.1 & 9.0 & 3.2 & 0.97 & 2.53 & 842 \\
\hline \multirow{2}{*}{$\begin{array}{l}\text { Whether or not response } \\
\text { would involve offering help }\end{array}$} & Yes & 74.8 & 14.2 & 8.5 & 2.5 & 0.83 & 2.16 & 797 \\
\hline & No & 60.8 & 15.2 & 13.9 & 10.1 & 2.30 & 4.64 & 79 \\
\hline
\end{tabular}

\subsection{Risk Cognitions}

The various workplace influences that seem to impact employees' gambling also appear to impact their beliefs in risk cognitions. As is illustrated in Table 28, the vast majority of the survey respondents demonstrated marked disagreement with the three risk cognition statements included in the survey. This pattern is consistent with the findings of Dangerfield (2004), whose survey included the first risk cognition concerning winning after numerous consecutive losses. She found that no respondents strongly agreed with it and $2.5 \%$ agreed with it (she did not offer a "neutral" option). On the other hand, Wiebe, Single, and Falkowski-Ham (2001) included this same item in a study of Ontario's general population and found that $0.9 \%$ of their sample strongly agreed with it and $12.7 \%$ agreed with it (they also did not offer a "neutral" option). It also should be noted that correlation between the casino employees' levels of agreement toward the three risk cognition items was tested and found to be highly positive for all three pairings (first and second items: $\mathrm{R}=0.544, \mathrm{p}<0.001$; first and third items: $\mathrm{R}=0.632, \mathrm{p}<0.001$; second and third items: $\mathrm{R}=0.758, \mathrm{p}<0.001$ ), indicating that many of the same employees endorsed the different risk cognitions. 
TABLE 28. Agreement with various risk cognitions

\begin{tabular}{|c|c|c|c|c|c|c|c|c|}
\hline Risk Cognition & $\begin{array}{c}\text { Strongly } \\
\text { Disagree } \\
(\%)\end{array}$ & $\begin{array}{c}\text { Disagree } \\
(\%)\end{array}$ & $\begin{array}{c}\text { Neutral } \\
(\%)\end{array}$ & $\begin{array}{c}\text { Agree } \\
(\%)\end{array}$ & $\begin{array}{c}\text { Strongly } \\
\text { Agree } \\
(\%)\end{array}$ & Mean* & SD & $\mathbf{n}$ \\
\hline $\begin{array}{l}\text { When I am gambling, after } \\
\text { losing many times in a row I } \\
\text { am more likely to win }\end{array}$ & 65.3 & 27.6 & 4.9 & 1.0 & 1.2 & 1.45 & 0.74 & 778 \\
\hline $\begin{array}{l}\text { There are certain things I do } \\
\text { when I am betting (for } \\
\text { example, tapping a certain } \\
\text { number of times, holding a } \\
\text { lucky coin in my hand, } \\
\text { crossing my fingers, etc.) } \\
\text { which increase the chances } \\
\text { that I will win }\end{array}$ & 71.0 & 22.0 & 4.5 & 1.5 & 1.0 & 1.39 & 0.73 & 718 \\
\hline $\begin{array}{l}\text { My gambling wins on slot } \\
\text { machines are evidence that I } \\
\text { have skill and knowledge } \\
\text { related to gambling }\end{array}$ & 75.1 & 21.2 & 2.5 & 0.6 & 0.7 & 1.31 & 0.62 & 727 \\
\hline
\end{tabular}

Table 29 illustrates that endorsement of the risk cognitions was positively associated with low risk, moderate risk, and problem gambling. For all three risk cognitions, higher levels of agreement corresponded with higher levels of severity on the PGSI. Also, one-way ANOVA tests detected significant differences between the different groups' levels of agreement with first two risk cognitions (first item: $F=7.279, \mathrm{p}<0.001$; second item: $F=11.480, \mathrm{p}<0.001)$ and nearly significant differences for the third risk cognition $(\mathrm{F}=2.195, \mathrm{p}=0.087)$. A Scheffé post-hoc test on the first risk cognition differentiated the problem gamblers from the non-problem and low risk gamblers, and a Scheffé post-hoc test on the second risk cognition differentiated the moderate risk and problem gamblers from the non-problem gamblers. 
TABLE 29. Risk cognitions among employees in the different PGSI categories

\begin{tabular}{|c|c|c|c|c|c|c|c|c|}
\hline PGSI category & $\begin{array}{l}\text { Strongly } \\
\text { disagree } \\
(\%)\end{array}$ & $\begin{array}{l}\text { Disagree } \\
(\%)\end{array}$ & $\begin{array}{l}\text { Neutral } \\
(\%)\end{array}$ & $\begin{array}{l}\text { Agree } \\
(\%)\end{array}$ & $\begin{array}{l}\text { Strongly } \\
\text { agree } \\
(\%)\end{array}$ & Mean* & SD & $\mathbf{n}$ \\
\hline & \multicolumn{8}{|c|}{ When I am gambling, after losing many times in a row I am more likely to win } \\
\hline Non-problem & 69.7 & 25.5 & 3.1 & 0.4 & 1.3 & $1.38^{\mathrm{a}}$ & 0.69 & 522 \\
\hline Low risk & 57.9 & 36.5 & 5.6 & 0.0 & 0.0 & $1.48^{\mathrm{a}}$ & 0.60 & 126 \\
\hline Moderate risk & 58.4 & 27.3 & 9.1 & 2.6 & 2.6 & $1.64^{\mathrm{ab}}$ & 0.95 & 77 \\
\hline \multirow[t]{2}{*}{ Problem gambler } & 50.0 & 21.4 & 14.3 & 14.3 & 0.0 & $1.93^{\mathrm{b}}$ & 1.12 & 28 \\
\hline & \multicolumn{8}{|c|}{$\begin{array}{l}\text { There are certain things I do when I am betting (for example, tapping a certain number } \\
\text { of times, holding a lucky coin in my hand, crossing my fingers, etc.) which increase the } \\
\text { chances that I will win }\end{array}$} \\
\hline Non-problem & 76.8 & 19.2 & 3.2 & 0.2 & 0.6 & $1.29^{\mathrm{a}}$ & 0.60 & 475 \\
\hline Low risk & 66.7 & 27.5 & 1.7 & 3.3 & 0.8 & $1.44^{\mathrm{ab}}$ & 0.77 & 120 \\
\hline Moderate risk & 57.9 & 22.4 & 11.8 & 5.3 & 2.6 & $1.72^{\mathrm{b}}$ & 1.04 & 76 \\
\hline \multirow[t]{2}{*}{ Problem gambler } & 46.4 & 39.3 & 10.7 & 3.6 & 0.0 & $1.71^{\mathrm{b}}$ & 0.81 & 28 \\
\hline & \multicolumn{8}{|c|}{$\begin{array}{l}\text { My gambling wins on slot machines are evidence that I have skill and knowledge } \\
\text { related to gambling }\end{array}$} \\
\hline Non-problem & 77.8 & 19.8 & 1.6 & 0.2 & 0.6 & 1.26 & 0.56 & 486 \\
\hline Low risk & 70.8 & 26.7 & 2.5 & 0.0 & 0.0 & 1.32 & 0.52 & 120 \\
\hline Moderate risk & 71.1 & 22.4 & 3.9 & 2.6 & 0.0 & 1.38 & 0.69 & 76 \\
\hline Problem gambler & 69.2 & 19.2 & 7.7 & 0.0 & 3.8 & 1.50 & 0.95 & 26 \\
\hline
\end{tabular}

Note: Superscripts indicate groups that are significantly different based on Scheffé test $(\mathrm{p}<.05)$

Similarly, Table 30 illustrates that endorsement of risk cognitions also appeared to be greatest among employees who claimed their gambling had increased significantly since they began their work. For all three items the percentage of employees who agreed with the risk cognitions was at least twice as high among those employees who had increased their gambling significantly as any other group. However, a one-way ANOVA test only found significant differences between the groups' mean levels of agreement with the first risk cognition $(\mathrm{F}=3.622, \mathrm{p}=0.006)$, and for this item a Scheffé post-hoc test confirmed the distinction between the employees who had increased their gambling significantly and the other groups of employees. On the other hand, one-way ANOVA tests on the mean levels of agreement with the other two items failed to detect significant differences between the groups (second item: $\mathrm{F}=0.221, \mathrm{p}=0.932$; third item: $\mathrm{F}=0.533$, $\mathrm{p}=0.711)$. 
TABLE 30. Risk cognitions among employees who had changed their gambling in different ways since beginning work in an OLG or resort casino

\begin{tabular}{|c|c|c|c|c|c|c|c|c|}
\hline Change in gambling & $\begin{array}{l}\text { Strongly } \\
\text { disagree } \\
(\%)\end{array}$ & $\begin{array}{l}\text { Disagree } \\
(\%)\end{array}$ & $\begin{array}{l}\text { Neutral } \\
(\%)\end{array}$ & $\begin{array}{c}\text { Agree } \\
(\%)\end{array}$ & $\begin{array}{l}\text { Strongly } \\
\text { agree } \\
(\%)\end{array}$ & Mean* & SD & $\mathbf{n}$ \\
\hline & \multicolumn{8}{|c|}{ When I am gambling, after losing many times in a row I am more likely to win } \\
\hline Decreased significantly & 68.7 & 23.9 & 4.5 & 1.5 & 1.5 & $1.43^{\mathrm{a}}$ & 0.780 & 134 \\
\hline Decreased a little & 65.9 & 29.4 & 3.5 & 1.2 & 0.0 & $1.40^{\mathrm{a}}$ & 0.621 & 85 \\
\hline Remained the same & 67.1 & 26.9 & 4.4 & 0.2 & 1.4 & $1.42^{\mathrm{a}}$ & 0.717 & 431 \\
\hline Increased a little & 62.3 & 31.2 & 6.5 & 0.0 & 0.0 & $1.44^{\mathrm{a}}$ & 0.618 & 77 \\
\hline \multirow[t]{2}{*}{ Increased significantly } & 43.3 & 33.3 & 10.0 & 13.3 & 0.0 & $1.93^{\mathrm{b}}$ & 1.048 & 30 \\
\hline & \multicolumn{8}{|c|}{$\begin{array}{c}\text { There are certain things I do when I am betting (for example, tapping a certain number of } \\
\text { times, holding a lucky coin in my hand, crossing my fingers, etc.) which increase the } \\
\text { chances that I will win }\end{array}$} \\
\hline Decreased significantly & 71.3 & 19.7 & 5.7 & 1.6 & 1.6 & 1.43 & 0.812 & 122 \\
\hline Decreased a little & 69.7 & 23.7 & 3.9 & 2.6 & 0.0 & 1.39 & 0.694 & 76 \\
\hline Remained the same & 72.9 & 20.9 & 4.0 & 1.3 & 1.0 & 1.37 & 0.714 & 398 \\
\hline Increased a little & 64.9 & 29.7 & 5.4 & 0.0 & 0.0 & 1.41 & 0.595 & 74 \\
\hline \multirow[t]{2}{*}{ Increased significantly } & 70.0 & 23.3 & 0.0 & 6.7 & 0.0 & 1.43 & 0.817 & 30 \\
\hline & \multicolumn{8}{|c|}{$\begin{array}{l}\text { My gambling wins on slot machines are evidence that I have skill and knowledge related } \\
\text { to gambling }\end{array}$} \\
\hline Decreased significantly & 78.1 & 18.8 & 1.6 & 0.8 & 0.8 & 1.27 & 0.611 & 128 \\
\hline Decreased a little & 70.0 & 25.0 & 3.8 & 1.3 & 0.0 & 1.36 & 0.621 & 80 \\
\hline Remained the same & 76.4 & 20.8 & 1.8 & 0.5 & 0.5 & 1.28 & 0.574 & 394 \\
\hline Increased a little & 72.4 & 23.7 & 3.9 & 0.0 & 0.0 & 1.32 & 0.547 & 76 \\
\hline Increased significantly & 75.9 & 17.2 & 3.4 & 0.0 & 3.4 & 1.38 & 0.862 & 29 \\
\hline
\end{tabular}

Note: Superscripts indicate groups that are significantly different based on Scheffé test $(\mathrm{p}<.05)$

Table 31 demonstrates that those employees who thought they could win money using their acquired gambling knowledge were much more likely to endorse the different risk cognitions. One-way ANOVA tests detected significant differences between the groups for all three items (first item: $F=26.164$, $\mathrm{p}<0.001$; second item: $\mathrm{F}=6.649, \mathrm{p}=0.001$; third item: $F=15.291, \mathrm{p}<0.001)$. In each case a Scheffé post-hoc test found significant differences between those employees who agreed and disagreed that they could win money using their acquired gambling knowledge, and in each case the test failed to find a significant difference between those employees who agreed and expressed neutrality toward the belief. These findings suggest that the endorsement of risk cognitions possibly contributes toward the confidence that some employees have in their gambling abilities, which in turn may induce them to gamble more. Nevertheless, as Table 32 shows, those 
employees who had played an EGM in the previous year actually were slightly less likely to have agreed with the EGM-related risk cognition item, although a t-test did not detect any significant differences between the two groups $(\mathrm{t}=0.857, \mathrm{p}=0.392)$.

TABLE 31. Belief in risk cognitions among employees with different perceptions about their abilities to win money using their acquired gambling knowledge

\begin{tabular}{|c|c|c|c|c|c|c|c|c|}
\hline $\begin{array}{l}\text { I believe I can win } \\
\text { money because I have } \\
\text { become more } \\
\text { knowledgeable about } \\
\text { casino games }\end{array}$ & $\begin{array}{l}\text { Strongly } \\
\text { disagree } \\
(\%)\end{array}$ & $\begin{array}{l}\text { Disagree } \\
(\%)\end{array}$ & $\begin{array}{c}\text { Neutral } \\
(\%)\end{array}$ & $\begin{array}{l}\text { Agree } \\
(\%)\end{array}$ & $\begin{array}{l}\text { Strongly } \\
\text { agree } \\
(\%)\end{array}$ & Mean* & SD & $\mathbf{n}$ \\
\hline & \multicolumn{8}{|c|}{ When I am gambling, after losing many times in a row I am more likely to win } \\
\hline (Strongly) disagree & 68.2 & 27.5 & 3.2 & 0.5 & 0.8 & $1.38^{\mathrm{a}}$ & 0.65 & 663 \\
\hline Neutral & 36.7 & 40.8 & 20.4 & 2.0 & 0.0 & $1.88^{\mathrm{b}}$ & 0.81 & 49 \\
\hline \multirow[t]{2}{*}{ (Strongly) agree } & 46.3 & 24.4 & 14.6 & 9.8 & 4.9 & $2.02^{\mathrm{b}}$ & 1.21 & 41 \\
\hline & \multicolumn{8}{|c|}{$\begin{array}{l}\text { There are certain things I do when I am betting (for example, tapping a certain number } \\
\text { of times, holding a lucky coin in my hand, crossing my fingers, etc.) which increase } \\
\text { the chances that I will win }\end{array}$} \\
\hline (Strongly) disagree & 72.8 & 20.8 & 4.6 & 1.1 & 0.7 & $1.36^{\mathrm{a}}$ & 0.69 & 614 \\
\hline Neutral & 54.3 & 37.0 & 4.3 & 2.2 & 2.2 & $1.61^{\mathrm{ab}}$ & 0.86 & 46 \\
\hline \multirow[t]{2}{*}{ (Strongly) agree } & 56.4 & 28.2 & 5.1 & 7.7 & 2.6 & $1.72^{\mathrm{b}}$ & 1.05 & 39 \\
\hline & \multicolumn{8}{|c|}{$\begin{array}{l}\text { My gambling wins on slot machines are evidence that I have skill and knowledge } \\
\text { related to gambling }\end{array}$} \\
\hline (Strongly) disagree & 77.2 & 20.4 & 1.8 & 0.3 & 0.3 & $1.26^{\mathrm{a}}$ & 0.54 & 623 \\
\hline Neutral & 61.7 & 27.7 & 6.4 & 2.1 & 2.1 & $1.55^{\mathrm{b}}$ & 0.88 & 47 \\
\hline (Strongly) agree & 51.4 & 32.4 & 10.8 & 2.7 & 2.7 & $1.73^{\mathrm{b}}$ & 0.96 & 37 \\
\hline
\end{tabular}

Note: Superscripts indicate groups that are significantly different based on Scheffé test $(\mathrm{p}<.05)$

TABLE 32. Agreement with the risk cognition, "My gambling wins on slot machines are evidence that I have skill and knowledge related to gambling," among employees who had and had not played an EGM in the previous year

\begin{tabular}{|c|c|c|c|c|c|c|c|c|}
\hline $\begin{array}{l}\text { EGM } \\
\text { gambling in } \\
\text { previous year }\end{array}$ & $\begin{array}{c}\text { Strongly } \\
\text { disagree } \\
(\%)\end{array}$ & $\begin{array}{c}\text { Disagree } \\
(\%)\end{array}$ & $\begin{array}{c}\text { Neutral } \\
(\%)\end{array}$ & $\begin{array}{c}\text { Agree } \\
(\%)\end{array}$ & $\begin{array}{c}\text { Strongly } \\
\text { agree } \\
(\%)\end{array}$ & Mean* & SD & n \\
\hline No & 75.5 & 19.9 & 2.7 & 0.7 & 1.2 & 1.32 & 0.679 & 413 \\
\hline Yes & 74.5 & 22.9 & 2.3 & 0.3 & 0.0 & 1.28 & 0.518 & 310 \\
\hline
\end{tabular}

\subsection{Motives for Taking Casino Jobs}

Table 33 presents the survey respondents' levels of agreement with various statements describing why they decided to work in an OLG or resort casino, and the general patterns 
are fairly consistent with the findings made by Dangerfield (2004). As the table illustrates, the primary draw of employment at an OLG or resort casino clearly appears to be the basic need for a job and the feeling that the casinos offer good pay and benefits. In fact, slightly over $80 \%$ of the respondents agreed that they took the work because they needed a job, nearly $80 \%$ agreed that they were attracted by the good pay, and almost $75 \%$ agreed that they were attracted by the good benefits. These motives were confirmed during the interviews, in which essentially every interviewee noted the casinos' high wages as a primary attraction for the employees. Additionally, when discussing the casino facilities' wages, numerous interviewees pointed out that few other good employment opportunities exist in some of the areas where the facilities are located. For example, one interviewee remarked, "In this town...there pretty much isn't anywhere else to work. This is the only place...that offers the pay that they offer." Also, numerous interviewees noted that they felt the employment offered good job security, which was frequently mentioned as a benefit of working for the government. As one interviewee stated, "It's government [employment], so it's very steady work."

The next most common motives seemed to be employees' feelings that they would enjoy different aspects of working in a casino, which suggests a pre-existing affinity for gambling. In fact, over $70 \%$ of the respondents agreed that they chose to work in a casino at least in part because they thought they would enjoy the atmosphere, over $65 \%$ agreed they did so at least in part because they thought they would enjoy the nature of the work, and over $60 \%$ agreed that they did so at least in part because they thought they would enjoy interacting with the patrons. However, in the interviews a variety of contrasting opinions were voiced regarding these factors. For instance, one interviewee claimed, "I think most people aren't here because it's a casino, I think it's just because of the pay and what's offered," while another interviewee stated, "Not many people can say they work in a casino and people think of working here as really exciting - the lights, the money, and all those things."

On the other hand, the vast majority of the respondents did not appear to decide to work in a casino due to a prior familiarity or involvement with gambling, nor because they had prior experience working in the industry. In fact, only about $11 \%$ agreed that they chose to work in a casino at least in part because they were already familiar with 
most casino games and therefore thought the work would be easy, and only about $7 \%$ agreed that they had done so at least in part because they were frequent gamblers and therefore thought they would enjoy it. Moreover, the low number of scored responses for these items resulted in large part from an abundance of un-scored "doesn't apply" responses, which suggests the lack of agreement with these statements is even greater than Table 33 directly indicates. During this study's interviews the participants generally claimed that pre-existing gambling familiarity or involvement may attract some employees to the work, but it is not a factor for most employees. Moreover, some interviewees even believed that heavy gamblers would avoid the employment due to the regulations that limit employee gambling. As one interviewee claimed, "I don't think having an interest in gambling really has any relation to taking this job at all...If you were [an avid gambler] you wouldn't be working in a casino because you can't play there." 
TABLE 33. Reasons why employees sought their jobs

\begin{tabular}{|c|c|c|c|c|c|c|c|c|}
\hline $\begin{array}{l}\text { Why did you choose to work in an } \\
\text { OLG or resort casino? }\end{array}$ & $\begin{array}{c}\text { Strongly } \\
\text { disagree } \\
(\%)\end{array}$ & $\begin{array}{c}\text { Disagree } \\
(\%)\end{array}$ & $\begin{array}{c}\text { Neutral } \\
(\%)\end{array}$ & $\begin{array}{c}\text { Agree } \\
(\%)\end{array}$ & $\begin{array}{l}\text { Strongly } \\
\text { agree } \\
(\%)\end{array}$ & Mean* & SD & $\mathbf{n}$ \\
\hline I needed a job & 3.0 & 4.2 & 11.2 & 33.9 & 47.7 & 4.19 & 1.00 & 876 \\
\hline The pay was good & 1.4 & 3.0 & 15.7 & 47.5 & 32.4 & 4.06 & 0.85 & 864 \\
\hline It offered good benefits & 2.1 & 4.4 & 18.7 & 46.1 & 28.7 & 3.95 & 0.92 & 850 \\
\hline $\begin{array}{l}\text { I thought I would enjoy the } \\
\text { atmosphere }\end{array}$ & 0.8 & 2.1 & 24.6 & 53.0 & 19.5 & 3.88 & 0.76 & 862 \\
\hline $\begin{array}{l}\text { I thought I would enjoy the nature of } \\
\text { the work (e.g., dealing cards, } \\
\text { attending slots, etc.) }\end{array}$ & 1.6 & 4.6 & 28.1 & 47.1 & 18.6 & 3.76 & 0.86 & 797 \\
\hline $\begin{array}{l}\text { I thought I would enjoy interacting } \\
\text { with the players and/or other } \\
\text { customers }\end{array}$ & 1.3 & 6.2 & 29.4 & 45.8 & 17.3 & 3.72 & 0.87 & 839 \\
\hline $\begin{array}{l}\text { It provided an opportunity for career } \\
\text { advancement }\end{array}$ & 3.9 & 8.0 & 28.1 & 40.5 & 19.5 & 3.64 & 1.01 & 847 \\
\hline Another employee suggested I apply & 15.3 & 20.5 & 17.6 & 26.8 & 19.9 & 3.16 & 1.36 & 694 \\
\hline $\begin{array}{l}\text { I already knew and liked members of } \\
\text { the staff }\end{array}$ & 12.0 & 22.4 & 35.9 & 23.3 & 6.4 & 2.90 & 1.09 & 686 \\
\hline The hours appealed to me & 12.8 & 20.8 & 39.1 & 20.1 & 7.1 & 2.88 & 1.09 & 849 \\
\hline $\begin{array}{l}\text { I thought it would be easy because I } \\
\text { was already familiar with most } \\
\text { casino games }\end{array}$ & 29.7 & 32.3 & 26.9 & 6.8 & 4.3 & 2.24 & 1.08 & 677 \\
\hline $\begin{array}{l}\text { I was a frequent gambler so I } \\
\text { thought I would enjoy the work }\end{array}$ & 58.1 & 24.5 & 10.6 & 5.0 & 1.8 & 1.68 & 0.98 & 658 \\
\hline $\begin{array}{l}\text { I had previous experience working } \\
\text { in a casino }\end{array}$ & 61.3 & 25.7 & 5.6 & 2.1 & 5.4 & 1.65 & 1.06 & 573 \\
\hline
\end{tabular}

As Table 34 illustrates, a fairly large percentage of the respondents seemed attracted to their jobs by pre-existing gambling affinities, but these employees exhibited only slightly higher rates of moderate risk and problem gambling. A t-test analyzing mean PGSI scores confirmed that these employees did not differ significantly from their co-workers $(\mathrm{t}=0.790, \mathrm{p}=0.430)$. On the other hand, only a small fraction of the survey respondents agreed that they had chosen to work in a casino at least in part because of prior gambling involvement, but these employees exhibited very high rates of moderate risk and problem gambling. In this case, a one-way ANOVA test found significant differences between the different groups' mean PGSI scores $(F=77.609, \mathrm{p}<0.001)$ and a Scheffé post-hoc test differentiated all three groups from one another, suggesting that PGSI scores increase dramatically as agreement with the motive increases. 
TABLE 34. PGSI results of employees reporting different motives for choosing their jobs

\begin{tabular}{|l|c|c|c|c|c|c|c|c|}
\hline & $\begin{array}{c}\text { Non- } \\
\text { problem } \\
(\%)\end{array}$ & $\begin{array}{c}\text { Low risk } \\
(\%)\end{array}$ & $\begin{array}{c}\text { Moderate } \\
\text { risk (\%) }\end{array}$ & $\begin{array}{c}\text { Problem } \\
\text { gambler } \\
(\%)\end{array}$ & $\begin{array}{c}\text { Mean } \\
\text { PGSI } \\
\text { score* }\end{array}$ & SD & n \\
\hline Pre-existing gambling affinity (Agreement that thought would enjoy atmosphere and nature of work) \\
\hline No & 75.3 & 13.9 & 7.9 & 3.0 & 0.89 & 2.47 & 368 \\
\hline Yes & 71.7 & 14.9 & 10.0 & 3.4 & 1.03 & 2.57 & 410 \\
\hline Prior gambling involvement (I was a frequent gambler so I thought I would enjoy the work) \\
\hline (Strongly) Disagree & 77.4 & 14.1 & 7.2 & 1.3 & $0.63^{\mathrm{a}}$ & 1.73 & 526 \\
\hline Neutral & 47.0 & 22.7 & 19.7 & 10.6 & $2.42^{\mathrm{b}}$ & 3.74 & 66 \\
\hline (Strongly) Agree & 23.3 & 23.3 & 27.9 & 25.6 & $5.28^{\mathrm{c}}$ & 6.00 & 43 \\
\hline *0=Non-problem, 1-2=Low risk, 3-7=Moderate risk, 8+=Problem gambler (Max=27) \\
\hline
\end{tabular}

Note: Superscripts indicate groups that are significantly different based on Scheffé test $(\mathrm{p}<.05)$

Likewise, Table 35 illustrates that those respondents who were attracted by preexisting gambling affinities were not even much more likely to have increased their gambling after beginning their jobs. A chi-square test confirmed that no differences existed between the groups $\left(\mathrm{X}^{2}=2.793, \mathrm{p}=0.593\right)$. However, those employees who did not disagree that they had taken their jobs because of prior gambling involvement were much more likely to have increased their gambling since they began working in an OLG or resort casino. In other words, employees attracted to their jobs by pre-existing gambling affinities were not particularly predisposed to increase their gambling, whereas employees attracted to their jobs because they were already heavy gamblers were particularly predisposed to become heavier gamblers. Nevertheless, it also should be noted that nearly two-thirds (63.6\%) of those employees who chose their jobs because of prior gambling involvement actually claimed to have decreased their gambling since they began working in an OLG or resort casino, which was a proportion far greater than was found among the other groups. A chi square test confirmed that significant differences existed between the changes in gambling experienced by the different groups $\left(\mathrm{X}^{2}=77.927, \mathrm{p}<0.001\right)$. 
TABLE 35. Changes in gambling experienced by employees reporting different motives for choosing their jobs

\begin{tabular}{|l|c|c|c|c|c|c|}
\hline & $\begin{array}{c}\text { Decreased } \\
\text { significantly } \\
(\boldsymbol{\%})\end{array}$ & $\begin{array}{c}\text { Decreased } \\
\text { a little }(\boldsymbol{\%})\end{array}$ & $\begin{array}{c}\text { Remained } \\
\text { the same } \\
(\boldsymbol{\%})\end{array}$ & $\begin{array}{c}\text { Increased a } \\
\text { little (\%) }\end{array}$ & $\begin{array}{c}\text { Increased } \\
\text { significantly } \\
(\%)\end{array}$ & $\begin{array}{c}\text { n } \\
\text { n }\end{array}$ \\
\hline Pre-existing gambling affinity (Agreement that thought would enjoy atmosphere and nature of work) \\
\hline No & 18.3 & 10.8 & 60.1 & 7.3 & 3.5 & 371 \\
\hline Yes & 17.8 & 11.4 & 56.5 & 10.5 & 3.8 & 421 \\
\hline Prior gambling involvement (I was a frequent gambler so I thought I would enjoy the work) \\
\hline (Strongly) Disagree & 14.2 & 11.4 & 62.9 & 8.9 & 2.7 & 528 \\
\hline Neutral & 32.8 & 6.0 & 35.8 & 13.4 & 11.9 & 67 \\
\hline (Strongly) Agree & 43.2 & 20.5 & 13.6 & 9.1 & 13.6 & 44 \\
\hline \hline
\end{tabular}

\subsection{Employment Variables}

\subsubsection{Length of Time Working in the Gambling Industry}

The amount of time that employees had worked in the gambling industry did not appear to exhibit any linear relationship with PGSI scores, as no significant correlation was detected between the two variables $(\mathrm{R}=0.038, \mathrm{p}=0.257)$. Nevertheless, it is worth noting that those employees who had been in the industry for less than one year exhibited the lowest levels of moderate risk and problem gambling, as can be observed in Table 36. As can be seen in Table 37, these employees also were the least likely to have increased their gambling since they began working in an OLG or resort casino, and for this variable a chi square test did detect significant differences between the groups $\left(X^{2}=24.145, p=0.019\right)$.

TABLE 36. PGSI results of employees who had spent different amounts of time working in the gambling industry

\begin{tabular}{|c|c|c|c|c|c|c|c|}
\hline $\begin{array}{l}\text { Months } \\
\text { in } \\
\text { industry }\end{array}$ & $\begin{array}{c}\text { Non- } \\
\text { problem } \\
(\%)\end{array}$ & $\begin{array}{c}\text { Low risk } \\
(\%)\end{array}$ & $\begin{array}{c}\text { Moderate } \\
\text { risk }(\%)\end{array}$ & $\begin{array}{c}\text { Problem } \\
\text { gambler } \\
(\%)\end{array}$ & $\begin{array}{c}\text { Mean } \\
\text { PGSI } \\
\text { score* }\end{array}$ & SD & $\mathbf{n}$ \\
\hline$\leq 12$ & 80.0 & 14.3 & 4.3 & 1.4 & 0.46 & 1.36 & 70 \\
\hline $13-60$ & 75.6 & 13.6 & 6.1 & 4.7 & 1.04 & 3.06 & 213 \\
\hline $61-120$ & 72.1 & 14.9 & 10.4 & 2.5 & 0.97 & 2.41 & 402 \\
\hline$\geq 121$ & 72.5 & 14.0 & 10.5 & 3.0 & 0.95 & 2.23 & 200 \\
\hline
\end{tabular}


TABLE 37. Changes in gambling experienced by employees who had spent different amounts of time working in the gambling industry

\begin{tabular}{|l|c|c|c|c|c|c|}
\hline $\begin{array}{l}\text { Months in } \\
\text { industry }\end{array}$ & $\begin{array}{c}\text { Decreased } \\
\text { significantly } \\
(\boldsymbol{\%})\end{array}$ & $\begin{array}{c}\text { Decreased a } \\
\text { little (\%) }\end{array}$ & $\begin{array}{c}\text { Remained } \\
\text { the same } \\
(\boldsymbol{\%})\end{array}$ & $\begin{array}{c}\text { Increased } \\
\text { Increased a } \\
\text { little (\%) }\end{array}$ & $\begin{array}{c}\text { significantly } \\
(\boldsymbol{\%})\end{array}$ & n \\
\hline$\leq 12$ & 14.3 & 14.3 & 65.7 & 5.7 & 0.0 & 70 \\
\hline $13-60$ & 20.9 & 10.2 & 58.6 & 6.5 & 3.7 & 215 \\
\hline $61-120$ & 19.7 & 11.9 & 56.4 & 9.5 & 2.4 & 411 \\
\hline$\geq 121$ & 12.8 & 5.9 & 64.0 & 11.3 & 5.9 & 203 \\
\hline \hline
\end{tabular}

As Tables 38 and 39 illustrate, the impacts of most of the workplace influences were perceived quite similarly by employees who had spent different amounts of time working in the gambling industry. In fact, no significant correlations were found between the amount of time employees had been in the industry and any of the factors associated with exposure to gambling or exposure to the patrons. Nevertheless, with regards to the work environment, it appears as though employees who had been working in the industry for less time were more likely to claim they rarely or never gambled because their coworker friends rarely or never gambled. Also, with regards to the training and regulations, it is clear that employees who had spent less time in the industry were more likely to perceive their RG training as having impacted their gambling. Moreover, these same employees were more likely to feel as though the employee gambling regulations make it difficult to visit an unrestricted casino. 
TABLE 38. The impacts of workplace influences on employees who had spent different amounts of time working in the gambling industry

\begin{tabular}{|c|c|c|c|c|c|c|}
\hline Impacts of workplace influences & $\begin{array}{l}\text { Months in } \\
\text { industry }\end{array}$ & $\begin{array}{l}\text { Mean } \\
\text { Score* }\end{array}$ & SD & $\mathbf{R}$ & $\mathbf{p}$ & $\mathbf{n}$ \\
\hline \multicolumn{7}{|l|}{ Exposure to gambling } \\
\hline \multirow{4}{*}{$\begin{array}{l}\text { After work I want to avoid spending } \\
\text { even more time in a casino or } \\
\text { involved with gambling }\end{array}$} & $\leq 12$ & 3.78 & 1.06 & \multirow{4}{*}{0.045} & \multirow{4}{*}{0.183} & 67 \\
\hline & $13-60$ & 3.85 & 1.21 & & & 212 \\
\hline & $61-120$ & 4.01 & 1.13 & & & 406 \\
\hline & $\geq 121$ & 3.94 & 1.21 & & & 204 \\
\hline \multirow{4}{*}{$\begin{array}{l}\text { As I have become more } \\
\text { knowledgeable about the games I } \\
\text { have realized that I cannot overcome } \\
\text { the house odds in most games }\end{array}$} & $\leq 12$ & 3.78 & 1.23 & \multirow{4}{*}{0.045} & \multirow{4}{*}{0.197} & 55 \\
\hline & $13-60$ & 3.82 & 1.24 & & & 200 \\
\hline & $61-120$ & 3.93 & 1.18 & & & 381 \\
\hline & $\geq 121$ & 3.90 & 1.19 & & & 181 \\
\hline \multirow{4}{*}{$\begin{array}{l}\text { I have become more interested in } \\
\text { gambling so I wanted to participate }\end{array}$} & $\leq 12$ & 1.66 & 0.85 & \multirow{4}{*}{0.037} & \multirow{4}{*}{0.281} & 65 \\
\hline & $13-60$ & 1.66 & 0.91 & & & 209 \\
\hline & $61-120$ & 1.61 & 0.85 & & & 392 \\
\hline & $\geq 121$ & 1.75 & 1.04 & & & 193 \\
\hline \multirow{4}{*}{$\begin{array}{l}\text { I believe I can win money because I } \\
\text { have become more knowledgeable } \\
\text { about casino games }\end{array}$} & $\leq 12$ & 1.49 & 0.74 & \multirow{4}{*}{0.009} & \multirow{4}{*}{0.786} & 63 \\
\hline & $13-60$ & 1.56 & 0.94 & & & 209 \\
\hline & 61-120 & 1.50 & 0.82 & & & 402 \\
\hline & $\geq 121$ & 1.51 & 0.86 & & & 191 \\
\hline \multirow{4}{*}{$\begin{array}{l}\text { I spend so much time surrounded by } \\
\text { gambling that it is no longer } \\
\text { interesting }\end{array}$} & $\leq 12$ & 3.37 & 1.21 & \multirow{4}{*}{0.002} & \multirow{4}{*}{0.963} & 63 \\
\hline & $13-60$ & 3.46 & 1.27 & & & 204 \\
\hline & 61-120 & 3.52 & 1.26 & & & 395 \\
\hline & $\geq 121$ & 3.41 & 1.25 & & & 186 \\
\hline \multicolumn{7}{|l|}{ Exposure to patrons } \\
\hline \multirow{4}{*}{$\begin{array}{l}\text { I see some negative consequences of } \\
\text { gambling among patrons and I do not } \\
\text { want to be like them }\end{array}$} & $\leq 12$ & 4.14 & 0.83 & \multirow{4}{*}{-0.050} & \multirow{4}{*}{0.144} & 65 \\
\hline & $13-60$ & 4.01 & 1.00 & & & 210 \\
\hline & $61-120$ & 3.97 & 1.06 & & & 392 \\
\hline & $\geq 121$ & 3.88 & 1.22 & & & 194 \\
\hline \multirow{4}{*}{$\begin{array}{l}\text { I receive gambling tips from patrons } \\
\text { that I feel are worth following }\end{array}$} & $\leq 12$ & 1.61 & 0.93 & \multirow{4}{*}{-0.047} & \multirow{4}{*}{0.185} & 56 \\
\hline & $13-60$ & 1.42 & 0.79 & & & 189 \\
\hline & 61-120 & 1.35 & 0.65 & & & 365 \\
\hline & $\geq 121$ & 1.35 & 0.74 & & & 172 \\
\hline \multirow{4}{*}{$\begin{array}{l}\text { I see patrons losing money and do } \\
\text { not want to do the same }\end{array}$} & $\leq 12$ & 4.18 & 1.04 & & & 61 \\
\hline & $13-60$ & 4.11 & 1.08 & $-0,044$ & & 203 \\
\hline & $61-120$ & 4.08 & 1.06 & -0.044 & 0.201 & 388 \\
\hline & $\geq 121$ & 3.95 & 1.14 & & & 188 \\
\hline & $\leq 12$ & 2.24 & 1.08 & & & 66 \\
\hline I see how much fun patrons are & $13-60$ & 2.11 & 1.06 & 0032 & 0346 & 213 \\
\hline having and I want to participate too & $61-120$ & 2.04 & 1.03 & -0.032 & 0.340 & 391 \\
\hline & $\geq 121$ & 2.01 & 1.04 & & & 191 \\
\hline & $\leq 12$ & 1.50 & 0.67 & & & 64 \\
\hline I have seen many patrons win so I & $13-60$ & 1.59 & 0.83 & & & 211 \\
\hline $\begin{array}{l}\text { think I have a good chance of } \\
\text { winning money }\end{array}$ & $61-120$ & 1.53 & 0.73 & 0.013 & 0.695 & 391 \\
\hline & $\geq 121$ & 1.59 & 0.92 & & & 191 \\
\hline
\end{tabular}


TABLE 39. The impacts of workplace influences on employees who had spent different amounts of time working in the gambling industry

\begin{tabular}{|c|c|c|c|c|c|c|}
\hline Impacts of workplace influences & $\begin{array}{l}\text { Months in } \\
\text { industry }\end{array}$ & $\begin{array}{l}\text { Mean } \\
\text { Score* }\end{array}$ & SD & $\mathbf{R}$ & $\mathbf{p}$ & $\mathbf{n}$ \\
\hline \multicolumn{7}{|l|}{ Exposure to the work environment } \\
\hline \multirow{4}{*}{$\begin{array}{l}\text { My friends who also work in the } \\
\text { facility rarely or never gamble so I } \\
\text { rarely or never gamble }\end{array}$} & $\leq 12$ & 3.35 & 1.23 & \multirow{4}{*}{-0.076} & \multirow{4}{*}{0.033} & 54 \\
\hline & $13-60$ & 3.02 & 1.38 & & & 190 \\
\hline & $61-120$ & 3.07 & 1.27 & & & 367 \\
\hline & $\geq 121$ & 2.83 & 1.29 & & & 184 \\
\hline \multirow{4}{*}{$\begin{array}{l}\text { The marketing and advertising that I } \\
\text { see at work tempts me to gamble }\end{array}$} & $\leq 12$ & 1.44 & 0.71 & \multirow{4}{*}{-0.027} & \multirow{4}{*}{0.433} & 64 \\
\hline & $13-60$ & 1.47 & 0.90 & & & 211 \\
\hline & $61-120$ & 1.46 & 0.78 & & & 399 \\
\hline & $\geq 121$ & 1.39 & 0.71 & & & 193 \\
\hline \multirow{4}{*}{$\begin{array}{l}\text { Gambling relieves the stress from my } \\
\text { job }\end{array}$} & $\leq 12$ & 1.34 & 0.68 & \multirow{4}{*}{0.021} & \multirow{4}{*}{0.553} & 62 \\
\hline & $13-60$ & 1.40 & 0.79 & & & 198 \\
\hline & $61-120$ & 1.46 & 0.79 & & & 389 \\
\hline & $\geq 121$ & 1.39 & 0.73 & & & 185 \\
\hline \multirow{4}{*}{$\begin{array}{l}\text { My friends who also work in the } \\
\text { facility gamble a lot so I gamble with } \\
\text { them }\end{array}$} & $\leq 12$ & 1.47 & 0.73 & \multirow{4}{*}{0.019} & \multirow{4}{*}{0.600} & 59 \\
\hline & $13-60$ & 1.55 & 0.89 & & & 192 \\
\hline & $61-120$ & 1.55 & 0.80 & & & 376 \\
\hline & $\geq 121$ & 1.54 & 0.84 & & & 180 \\
\hline \multicolumn{7}{|l|}{ Training and regulations } \\
\hline \multirow{4}{*}{$\begin{array}{l}\text { My job's regulations about employee } \\
\text { gambling make it difficult for me to } \\
\text { visit a casino where I am allowed to } \\
\text { gamble }\end{array}$} & $\leq 12$ & 2.89 & 1.30 & \multirow{4}{*}{-0.088} & \multirow{4}{*}{0.010} & 66 \\
\hline & $13-60$ & 2.60 & 1.45 & & & 204 \\
\hline & $61-120$ & 3.01 & 1.46 & & & 387 \\
\hline & $\geq 121$ & 2.18 & 1.30 & & & 191 \\
\hline \multirow{4}{*}{$\begin{array}{l}\text { My facility's training about problem } \\
\text { gambling convinced me to gamble } \\
\text { less }\end{array}$} & $\leq 12$ & 3.03 & 1.18 & \multirow{4}{*}{-0.079} & \multirow{4}{*}{0.026} & 58 \\
\hline & $13-60$ & 2.45 & 1.15 & & & 194 \\
\hline & $61-120$ & 2.55 & 1.20 & & & 367 \\
\hline & $\geq 121$ & 2.34 & 1.11 & & & 175 \\
\hline \multirow{4}{*}{$\begin{array}{l}\text { My facility's problem gambling } \\
\text { training course has reduced the } \\
\text { chances that I will ever become a } \\
\text { problem gambler }\end{array}$} & $\leq 12$ & 3.71 & 1.07 & \multirow{4}{*}{-0.071} & \multirow{4}{*}{0.050} & 56 \\
\hline & $13-60$ & 3.35 & 1.17 & & & 187 \\
\hline & $61-120$ & 3.54 & 1.13 & & & 356 \\
\hline & $\geq 121$ & 3.23 & 1.21 & & & 171 \\
\hline \multirow{4}{*}{$\begin{array}{l}\text { My facility's problem gambling } \\
\text { training course was useful in } \\
\text { teaching me about problem gambling }\end{array}$} & $\leq 12$ & 4.05 & 0.72 & \multirow{4}{*}{-0.023} & \multirow{4}{*}{0.516} & 60 \\
\hline & $13-60$ & 3.72 & 0.96 & & & 200 \\
\hline & $61-120$ & 3.80 & 0.98 & & & 382 \\
\hline & $\geq 121$ & 3.71 & 0.95 & & & 182 \\
\hline
\end{tabular}

When asked in the interviews whether a relationship existed between employees' gambling behaviours and the amount of time they had spent working in the industry, some of the interviewees speculated that employees with more work experience would gamble more, while other employees said the exact opposite. For instance, one interviewee, who had started gambling occasionally after having begun working in the 
industry, claimed, "I think [gambling] would be more after a year, more after being there for a while. For me, anyway, it wasn't like an instantaneous thing." Another employee agreed in stating, "I see it as seasoned employees [who gamble more]...I think the more comfortable they were in their jobs or their experience, say, as table games handlers, they're the ones that probably went out to gamble." On the other hand, another employee opined:

I think [for] people that are new and fresh out of the first few years, [the employment] would probably have an effect, as in they would want to go and play, or they like the excitement, they've learned some things they want to try. People who have been here, after so many years, I think, aren't as naïve. Now they've seen the bad side, or the hard side, or the house side of things, and maybe they're less likely [to gamble].

Similarly, another interviewee explained, "If you've only worked here for a short time you might not be exposed to the negativity as long, you might not get sick of it, whereas if you're here for a lengthy part of time you're seeing it everyday."

As can be observed in Table 40, mean levels of belief in the three risk cognitions varied little between employees who had spent different quantities of time working in the gambling industry, and no significant correlation was found between the two variables ( $\mathrm{R}=-0.011, \mathrm{p}=0.761$ ). As can be seen in Table 41, the workers who were most attracted to the employment because of prior gambling involvement appeared to have remained in the industry for a relatively short period of time, but again no significant correlation was found between the two variables $(\mathrm{R}=-0.026, \mathrm{p}=0.506)$.

TABLE 40. Average level of belief in three risk cognitions by employees who had spent different amounts of time working in the gambling industry

\begin{tabular}{|l|c|c|c|}
\hline $\begin{array}{l}\text { Months in } \\
\text { industry }\end{array}$ & Mean* & SD & n \\
\hline$\leq 12$ & 1.40 & 0.62 & 63 \\
\hline $13-60$ & 1.37 & 0.66 & 192 \\
\hline $61-120$ & 1.38 & 0.58 & 365 \\
\hline$\geq 121$ & 1.37 & 0.62 & 178 \\
\hline $\begin{array}{l}\text { *Mean score of three items with scale: } 1=\text { Strongly disagree, } \\
\text { 2=Disagree, 3=Neutral, 4=Agree, 5=Strongly agree }\end{array}$ \\
\hline \hline
\end{tabular}


TABLE 41. Average number of months worked in the gambling industry by employees exhibiting different levels of agreement that they were attracted to the employment because they were frequent gamblers

\begin{tabular}{|l|c|c|c|}
\hline $\begin{array}{l}\text { Level of } \\
\text { agreement }\end{array}$ & $\begin{array}{c}\text { Mean } \\
\text { months }\end{array}$ & SD & n \\
\hline Strongly disagree & 88.5 & 48.53 & 382 \\
\hline Disagree & 86.5 & 45.36 & 160 \\
\hline Neutral & 89.6 & 61.04 & 69 \\
\hline Agree & 90.6 & 37.47 & 32 \\
\hline Strongly Agree & 64.3 & 28.82 & 12 \\
\hline \hline
\end{tabular}

\subsubsection{Previous Experience Working in the Gambling Industry}

Those respondents who had worked in the gambling industry prior to working at an OLG or resort casino exhibited far more moderate risk and problem gambling than their coworkers, as is shown in Table 42. A t-test found significant differences between the two groups' mean PGSI scores $(\mathrm{t}=2.615, \mathrm{p}=0.012)$. These individuals were also more likely to have either increased or decreased their gambling since they began working in an OLG or resort casino, as is illustrated in Table 43. Regarding these changes, a chi square test revealed significant differences between the groups $\left(\mathrm{X}^{2}=14.887, \mathrm{p}=0.005\right)$.

TABLE 42. PGSI results of employees who had and had not worked in the gambling industry prior to working in an OLG or resort casino

\begin{tabular}{|l|c|c|c|c|c|c|c|c|}
\hline $\begin{array}{l}\text { Previous } \\
\text { Experience }\end{array}$ & $\begin{array}{c}\text { Non- } \\
\text { problem } \\
(\mathbf{\%})\end{array}$ & $\begin{array}{c}\text { Low risk } \\
(\boldsymbol{\%})\end{array}$ & $\begin{array}{c}\text { Moderate } \\
\text { risk } \mathbf{( \% )}\end{array}$ & $\begin{array}{c}\text { Problem } \\
\text { gambler } \\
(\mathbf{\%})\end{array}$ & $\begin{array}{c}\text { Mean } \\
\text { PGSI } \\
\text { score* }\end{array}$ & SD & n \\
${$\cline { 1 - 5 }$} }$ & 74.5 & 14.4 & 8.5 & 2.5 & 0.86 & 2.31 & 825 \\
\hline Yes & 59.2 & 12.2 & 14.3 & 14.3 & 2.55 & 4.50 & 49 \\
\hline
\end{tabular}

TABLE 43. Changes in gambling experienced by employees who had and had not worked in the gambling industry prior to working in an OLG or resort casino

\begin{tabular}{|l|c|c|c|c|c|c|}
\hline $\begin{array}{l}\text { Previous } \\
\text { Experience }\end{array}$ & $\begin{array}{c}\text { Decreased } \\
\text { significantly } \\
(\boldsymbol{\%})\end{array}$ & $\begin{array}{c}\text { Decreased a } \\
\text { little (\%) }\end{array}$ & $\begin{array}{c}\text { Remained } \\
\text { the same } \\
(\boldsymbol{\%})\end{array}$ & $\begin{array}{c}\text { Increased a } \\
\text { little (\%) }\end{array}$ & $\begin{array}{c}\text { Increased } \\
\text { significantly } \\
(\boldsymbol{\%})\end{array}$ & $\mathbf{n}$ \\
\hline No & 17.5 & 10.1 & 60.7 & 8.6 & 3.1 & 839 \\
\hline Yes & 23.5 & 19.6 & 35.3 & 13.7 & 7.8 & 51 \\
\hline \hline
\end{tabular}


Nevertheless, as Tables 44 and 45 illustrate, the survey respondents who did and did not have experience working in the gambling industry prior to working in an OLG or resort casino expressed fairly similar levels of agreement toward most of the workplace influences that may have affected their gambling. A t-test did find that employees who possessed prior gambling industry experience were significantly less likely to want to avoid gambling after work, which is somewhat logical given that these employees had elected to remain in the gambling industry even when changing employers. The only other statistically significant difference between the two groups entailed the employees with previous gambling industry experience agreeing more strongly that the employee gambling regulations rendered casino gambling difficult. 
TABLE 44. The impacts of workplace influences on employees who had and had not worked in the gambling industry prior to working in an OLG or resort casino

\begin{tabular}{|c|c|c|c|c|c|c|}
\hline Impacts of workplace influences & $\begin{array}{l}\text { Previous } \\
\text { Experience }\end{array}$ & $\begin{array}{l}\text { Mean } \\
\text { score* }\end{array}$ & SD & $\mathbf{t}$ & $\mathbf{p}$ & $\mathbf{n}$ \\
\hline \multicolumn{7}{|l|}{ Exposure to gambling } \\
\hline \multirow{2}{*}{$\begin{array}{l}\text { After work I want to avoid spending even } \\
\text { more time in a casino or involved with } \\
\text { gambling }\end{array}$} & Yes & 3.46 & 1.36 & \multirow{2}{*}{2.569} & \multirow{2}{*}{0.013} & 50 \\
\hline & No & 3.96 & 1.14 & & & 830 \\
\hline \multirow{2}{*}{$\begin{array}{l}\text { I spend so much time surrounded by gambling } \\
\text { that it is no longer interesting }\end{array}$} & Yes & 3.20 & 1.40 & \multirow{2}{*}{1.392} & \multirow{2}{*}{0.170} & 50 \\
\hline & No & 3.48 & 1.24 & & & 790 \\
\hline \multirow{2}{*}{$\begin{array}{l}\text { I believe I can win money because I have } \\
\text { become more knowledgeable about casino } \\
\text { games }\end{array}$} & Yes & 1.67 & 0.97 & \multirow{2}{*}{1.142} & \multirow{2}{*}{0.259} & 49 \\
\hline & No & 1.51 & 0.84 & & & 808 \\
\hline \multirow{2}{*}{$\begin{array}{l}\text { As I have become more knowledgeable about } \\
\text { the games I have realized that I cannot } \\
\text { overcome the house odds in most games }\end{array}$} & Yes & 3.98 & 1.36 & \multirow{2}{*}{0.521} & \multirow{2}{*}{0.605} & 46 \\
\hline & No & 3.87 & 1.19 & & & 763 \\
\hline \multirow{2}{*}{$\begin{array}{l}\text { I have become more interested in gambling so } \\
\text { I wanted to participate }\end{array}$} & Yes & 1.68 & 1.00 & \multirow{2}{*}{0.135} & \multirow{2}{*}{0.893} & 50 \\
\hline & No & 1.66 & 0.91 & & & 801 \\
\hline \multicolumn{7}{|l|}{ Exposure to patrons } \\
\hline \multirow{2}{*}{$\begin{array}{l}\text { I see patrons losing money and do not want to } \\
\text { do the same }\end{array}$} & Yes & 3.88 & 1.20 & \multirow{2}{*}{1.111} & \multirow{2}{*}{0.272} & 48 \\
\hline & No & 4.07 & 1.08 & & & 784 \\
\hline \multirow{2}{*}{$\begin{array}{l}\text { I receive gambling tips from patrons that I feel } \\
\text { are worth following }\end{array}$} & Yes & 1.32 & 0.64 & \multirow{2}{*}{0.790} & \multirow{2}{*}{0.433} & 44 \\
\hline & No & 1.40 & 0.74 & & & 730 \\
\hline \multirow{2}{*}{$\begin{array}{l}\text { I have seen many patrons win so I think I have } \\
\text { a good chance of winning money }\end{array}$} & Yes & 1.65 & 0.99 & \multirow{2}{*}{0.645} & \multirow{2}{*}{0.522} & 49 \\
\hline & $\mathrm{No}$ & 1.56 & 0.79 & & & 800 \\
\hline \multirow{2}{*}{$\begin{array}{l}\text { I see some negative consequences of gambling } \\
\text { among patrons and I do not want to be like } \\
\text { them }\end{array}$} & Yes & 3.90 & 1.16 & \multirow{2}{*}{0.433} & \multirow{2}{*}{0.667} & 49 \\
\hline & No & 3.97 & 1.06 & & & 805 \\
\hline \multirow{2}{*}{$\begin{array}{l}\text { I see how much fun patrons are having and I } \\
\text { want to participate too }\end{array}$} & Yes & 2.12 & 1.21 & \multirow{2}{*}{0.303} & \multirow{2}{*}{0.763} & 50 \\
\hline & No & 2.07 & 1.04 & & & 804 \\
\hline
\end{tabular}


TABLE 45. The impacts of workplace influences on employees who had and had not worked in the gambling industry prior to working in an OLG or resort casino

\begin{tabular}{|c|c|c|c|c|c|c|}
\hline Impacts of workplace influences & $\begin{array}{l}\text { Previous } \\
\text { Experience }\end{array}$ & $\begin{array}{l}\text { Mean } \\
\text { score* }\end{array}$ & SD & $\mathbf{t}$ & $\mathbf{p}$ & $\mathbf{n}$ \\
\hline \multicolumn{7}{|l|}{ Exposure to the work environment } \\
\hline \multirow{2}{*}{$\begin{array}{l}\text { My friends who also work in the facility rarely } \\
\text { or never gamble so I rarely or never gamble }\end{array}$} & Yes & 2.72 & 1.28 & \multirow{2}{*}{1.638} & \multirow{2}{*}{0.107} & 47 \\
\hline & No & 3.04 & 1.30 & & & 740 \\
\hline \multirow{2}{*}{ Gambling relieves the stress from my job } & Yes & 1.55 & 0.98 & \multirow{2}{*}{0.912} & \multirow{2}{*}{0.366} & 49 \\
\hline & No & 1.42 & 0.76 & & & 777 \\
\hline \multirow{2}{*}{$\begin{array}{l}\text { The marketing and advertising that I see at } \\
\text { work tempts me to gamble }\end{array}$} & Yes & 1.50 & 0.79 & \multirow{2}{*}{0.435} & \multirow{2}{*}{0.665} & 50 \\
\hline & No & 1.45 & 0.80 & & & 809 \\
\hline \multirow{2}{*}{$\begin{array}{l}\text { My friends who also work in the facility } \\
\text { gamble a lot so I gamble with them }\end{array}$} & Yes & 1.58 & 0.82 & \multirow{2}{*}{0.284} & \multirow{2}{*}{0.778} & 48 \\
\hline & No & 1.55 & 0.84 & & & 751 \\
\hline \multicolumn{7}{|l|}{ Training and regulations } \\
\hline \multirow{2}{*}{$\begin{array}{l}\text { My job's regulations about employee } \\
\text { gambling make it difficult for me to visit a } \\
\text { casino where I am allowed to gamble }\end{array}$} & Yes & 3.22 & 1.50 & \multirow{2}{*}{2.522} & \multirow{2}{*}{0.015} & 49 \\
\hline & No & 2.67 & 1.43 & & & 792 \\
\hline \multirow{2}{*}{$\begin{array}{l}\text { My facility's problem gambling training } \\
\text { course has reduced the chances that I will ever } \\
\text { become a problem gambler }\end{array}$} & Yes & 3.13 & 1.23 & \multirow{2}{*}{1.810} & \multirow{2}{*}{0.076} & 47 \\
\hline & No & 3.46 & 1.16 & & & 716 \\
\hline \multirow{2}{*}{$\begin{array}{l}\text { My facility's training about problem gambling } \\
\text { convinced me to gamble less }\end{array}$} & Yes & 2.42 & 1.15 & \multirow{2}{*}{0.630} & \multirow{2}{*}{0.531} & 48 \\
\hline & No & 2.52 & 1.18 & & & 738 \\
\hline \multirow{2}{*}{$\begin{array}{l}\text { My facility's problem gambling training } \\
\text { course was useful in teaching me about } \\
\text { problem gambling }\end{array}$} & Yes & 3.78 & 0.92 & \multirow{2}{*}{0.014} & \multirow{2}{*}{0.989} & 49 \\
\hline & No & 3.78 & 0.96 & & & 768 \\
\hline
\end{tabular}


As can be observed in Table 46, those employees who had worked in the gambling industry prior to working in an OLG or resort casino also expressed lower levels of belief in risk cognitions, and a t-test detected statistically significant differences between the groups $(\mathrm{t}=2.122, \mathrm{p}=0.038)$. As Table 47 illustrates, these same individuals also were more likely to have been attracted to their jobs by prior gambling involvement, and a t-test found slightly less than statistically significant differences between the groups $(\mathrm{t}=1.878, \mathrm{p}=0.066)$.

TABLE 46. Average level of belief in three risk cognitions by employees who had and had not worked in the gambling industry prior to working in an OLG or resort casino

\begin{tabular}{|l|c|c|c|}
\hline $\begin{array}{l}\text { Previous } \\
\text { Experience }\end{array}$ & Mean* & SD & n \\
\hline No & 1.39 & 0.63 & 743 \\
\hline Yes & 1.26 & 0.41 & 48 \\
\hline $\begin{array}{l}\text { *Mean score of three items with scale: 1=Strongly disagree, } \\
\text { 2=Disagree, 3=Neutral, 4=Agree, 5=Strongly agree }\end{array}$ \\
\hline \hline
\end{tabular}

TABLE 47. Levels of agreement that they were attracted to the employment because they were frequent gamblers among employees who had and had not worked in the gambling industry prior to working in an OLG or resort casino

\begin{tabular}{|c|c|c|c|c|c|c|c|c|}
\hline $\begin{array}{l}\text { Previous } \\
\text { Experience }\end{array}$ & $\begin{array}{c}\text { Strongly } \\
\text { disagree } \\
(\%)\end{array}$ & $\begin{array}{c}\text { Disagree } \\
(\%)\end{array}$ & $\begin{array}{c}\text { Neutral } \\
(\%)\end{array}$ & $\begin{array}{c}\text { Agree } \\
(\%)\end{array}$ & $\begin{array}{c}\text { Strongly } \\
\text { agree } \\
(\%)\end{array}$ & Mean* & SD & $\mathbf{n}$ \\
\hline No & 58.3 & 25.3 & 10.4 & 4.5 & 1.5 & 1.65 & 0.94 & 605 \\
\hline Yes & 53.3 & 13.3 & 15.6 & 13.3 & 4.4 & 2.02 & 1.29 & 45 \\
\hline
\end{tabular}

\subsubsection{Facility Type}

Table 48 presents PGSI results of the survey respondents grouped by their individual facilities and by their types of facilities. As can be observed, PG was nonexistent among the survey respondents from the two slots facilities, it was somewhat prevalent among the respondents from the two casinos, and it was most prevalent among the respondents from the resort casino. A pair of one-way ANOVA tests detected statistically significant differences between the groups' mean PGSI scores in both cases (individual facilities: $\mathrm{F}=2.944, \mathrm{p}=0.020$; facility types: $\mathrm{F}=4.014, \mathrm{p}=0.018$ ). A Scheffé post-hoc test nevertheless failed to distinguish between any of the individual facilities, but a second test found 
significant differences between the mean PGSI scores reported by the slots facility employees and the resort casino employees.

TABLE 48. PGSI results of employees from different facilities $(n=887)$

\begin{tabular}{|c|c|c|c|c|c|c|}
\hline Facility & $\begin{array}{c}\text { Non- } \\
\text { problem } \\
(\%) \\
\end{array}$ & $\begin{array}{c}\text { Low risk } \\
(\%)\end{array}$ & $\begin{array}{c}\text { Moderate } \\
\text { risk }(\%)\end{array}$ & $\begin{array}{c}\text { Problem } \\
\text { gambler } \\
(\%)\end{array}$ & $\begin{array}{c}\text { Mean } \\
\text { PGSI } \\
\text { score* }^{*}\end{array}$ & SD \\
\hline Slots facility A & 73.8 & 19.0 & 7.1 & 0.0 & 0.56 & 1.24 \\
\hline Slots facility B & 80.3 & 12.1 & 7.6 & 0.0 & 0.48 & 1.22 \\
\hline Casino A & 78.9 & 12.2 & 7.5 & 1.4 & 0.57 & 1.53 \\
\hline Casino B & 73.4 & 15.2 & 7.6 & 3.8 & 1.12 & 3.36 \\
\hline Resort casino & 70.8 & 14.1 & 10.4 & 4.6 & 1.17 & 2.70 \\
\hline Slots facilities (2) & 76.7 & 16.0 & 7.3 & 0.0 & $0.53^{\mathrm{a}}$ & 1.22 \\
\hline Casinos (2) & 76.1 & 13.8 & 7.5 & 2.6 & $0.86^{\mathrm{ab}}$ & 2.65 \\
\hline Resort casino (1) & 70.8 & 14.1 & 10.4 & 4.6 & $1.17^{\mathrm{b}}$ & 2.70 \\
\hline
\end{tabular}

Note: Superscripts indicate groups that are significantly different based on Scheffé test $(\mathrm{p}<.05)$

A fairly similar pattern is apparent with regards to how employees from the different types of facilities changed their gambling after beginning work in an OLG or resort casino. As can be seen in Table 49, respondents from the slots facilities were the least likely to have increased their gambling, respondents from the casino facilities were comparably more likely to have done so, and employees from the resort casino were the most likely to have done so. Nevertheless, a chi square test failed to detect significant differences between the groups $\left(\mathrm{X}^{2}=9.555, \mathrm{p}=0.298\right)$.

TABLE 49. Changes in gambling experienced by employees from different types of facilities $(n=904)$

\begin{tabular}{|l|c|c|c|c|c|}
\hline Facility type & $\begin{array}{c}\text { Decreased } \\
\text { significantly } \\
(\boldsymbol{\%})\end{array}$ & $\begin{array}{c}\text { Decreased a } \\
\text { little }(\boldsymbol{\%})\end{array}$ & $\begin{array}{c}\text { Remained } \\
\text { the same } \\
(\boldsymbol{\%})\end{array}$ & $\begin{array}{c}\text { Increased a } \\
\text { little }(\boldsymbol{\%})\end{array}$ & $\begin{array}{c}\text { Increased } \\
\text { significantly } \\
(\boldsymbol{\%})\end{array}$ \\
\hline Slots facility & 20.4 & 15.6 & 55.1 & 6.8 & 2.0 \\
\hline Casino & 17.1 & 8.9 & 62.2 & 9.2 & 2.5 \\
\hline Resort casino & 17.6 & 10.0 & 58.8 & 9.3 & 4.3 \\
\hline \hline
\end{tabular}

Tables 50 and 51 present the frequency with which employees from the different types of facilities engaged in different forms of gambling during the previous year. As 
can be observed, employees from the different facilities seemed comparatively more likely to participate in the forms of gambling offered by their facilities--casino and resort casino employees were somewhat more likely to have gambled on most of the table games (i.e., poker, blackjack, roulette, and craps), and slots facility employees were far more likely to have gambled on horseracing. It is worth reiterating that this study did not involve employees who worked directly with horseracing, such as the employees who receive patrons' horse wagers, but it did include some slots facility employees who held responsibilities more loosely associated with horse racing, such as Food \& Beverage employees who worked in areas near the racetracks.

Somewhat more significant differences can be observed in the second part of Tables 50 and 51, which quantifies the increase in familiarity with different forms of gambling that the employees felt they had experienced since they began working in an OLG or resort casino. As can be seen, familiarity with the different forms of gambling increased far more among employees who worked in facilities that offered such forms of gambling, although less explicable significant differences were also found between the employees' scores for some of the games offered in all or none of the facilities. For example, a Scheffé post-hoc test found that familiarity with horseracing increased significantly more among the slots facility employees, while familiarity with the table games increased significantly less. The greater increase in table game familiarity experienced by casino and resort casino employees was mostly expected because this group included Table Games employees who must familiarize themselves with at least some of these games simply in order to perform their jobs. Consequently, the data were re-analyzed with the Table Games employees omitted from the sample, and this omission predictably led to reductions in the average table game familiarity increases among the casino and resort casino employees. Nevertheless, a series of t-tests comparing the slots facility employees with the casino and resort casino employees still found significant differences in the familiarity changes associated with these games (poker: $t=3.830$, $\mathrm{p}<0.001$; blackjack: $\mathrm{t}=7.009, \mathrm{p}<0.001$; roulette: $\mathrm{t}=8.469, \mathrm{p}<0.001$; and craps: $\mathrm{t}=7.488$, $\mathrm{p}<0.001)$. 
TABLE 50. Previous year participation and familiarity change with different forms of gambling by employees from different types of facilities

\begin{tabular}{|c|c|c|c|c|c|c|c|c|}
\hline $\begin{array}{l}\text { Gambling } \\
\text { Game }\end{array}$ & $\begin{array}{l}\text { Facility } \\
\text { type }\end{array}$ & $\operatorname{Never}(\%)$ & $\begin{array}{c}\text { 1-11 times } \\
\text { per year } \\
(\%)\end{array}$ & $\begin{array}{c}\text { At least } \\
\text { once per } \\
\text { month }(\%)\end{array}$ & $\begin{array}{c}\text { Mean } \\
\text { familiarity } \\
\text { change* }\end{array}$ & SD & $\mathbf{F}$ & $\mathbf{p}$ \\
\hline \multicolumn{9}{|c|}{ Games offered only in casinos and resort casinos } \\
\hline \multirow{3}{*}{$\begin{array}{l}\text { Casino } \\
\text { poker }\end{array}$} & Slots & 90.1 & 9.9 & 0.0 & $0.77^{\mathrm{a}}$ & 1.47 & \multirow{3}{*}{20.327} & \multirow{3}{*}{$<0.001$} \\
\hline & Casino & 89.3 & 9.7 & 0.9 & $1.87^{\mathrm{c}}$ & 1.97 & & \\
\hline & Resort & 93.6 & 4.6 & 1.8 & $1.26^{\mathrm{b}}$ & 1.87 & & \\
\hline \multirow{3}{*}{$\begin{array}{l}\text { Casino } \\
\text { blackjack }\end{array}$} & Slots & 90.1 & 9.9 & 0.0 & $0.41^{\mathrm{a}}$ & 1.04 & \multirow{3}{*}{29.525} & \multirow{3}{*}{$<0.001$} \\
\hline & Casino & 83.7 & 15.0 & 1.3 & $1.76^{\mathrm{c}}$ & 1.94 & & \\
\hline & Resort & 88.7 & 9.9 & 1.3 & $1.21^{\mathrm{b}}$ & 1.88 & & \\
\hline \multirow{3}{*}{$\begin{array}{l}\text { Casino } \\
\text { roulette }\end{array}$} & Slots & 90.7 & 8.6 & 0.7 & $0.37^{\mathrm{a}}$ & 1.08 & \multirow{3}{*}{38.481} & \multirow{3}{*}{$<0.001$} \\
\hline & Casino & 85.8 & 12.9 & 1.3 & $2.00^{\mathrm{c}}$ & 2.07 & & \\
\hline & Resort & 90.1 & 9.1 & 0.9 & $1.34^{\mathrm{b}}$ & 1.99 & & \\
\hline \multirow{3}{*}{$\begin{array}{l}\text { Casino } \\
\text { craps }\end{array}$} & Slots & 97.4 & 2.0 & 0.7 & $0.28^{\mathrm{a}}$ & 0.93 & \multirow{3}{*}{31.089} & \multirow{3}{*}{$<0.001$} \\
\hline & Casino & 94.0 & 5.3 & 0.6 & $1.60^{\mathrm{c}}$ & 2.04 & & \\
\hline & Resort & 97.1 & 2.6 & 0.2 & $0.95^{\mathrm{b}}$ & 1.75 & & \\
\hline \multicolumn{9}{|c|}{ Games offered only in slots facilities } \\
\hline \multirow{3}{*}{ Horse races } & Slots & 73.3 & 24.7 & 2.0 & $1.17^{\mathrm{b}}$ & 1.42 & \multirow{3}{*}{38.117} & \multirow{3}{*}{$<0.001$} \\
\hline & Casino & 88.1 & 11.3 & 0.6 & $0.39^{\mathrm{a}}$ & 0.98 & & \\
\hline & Resort & 83.0 & 15.7 & 1.3 & $0.32^{\mathrm{a}}$ & 0.95 & & \\
\hline \multicolumn{9}{|c|}{ Games offered in all facilities } \\
\hline \multirow{3}{*}{$\begin{array}{l}\text { Lottery- } \\
\text { style games }\end{array}$} & Slots & 7.9 & 40.1 & 52.0 & $0.63^{\mathrm{b}}$ & 1.20 & \multirow{3}{*}{10.056} & \multirow{3}{*}{$<0.001$} \\
\hline & Casino & 10.7 & 43.3 & 46.1 & $0.67^{\mathrm{b}}$ & 1.24 & & \\
\hline & Resort & 5.5 & 37.1 & 57.5 & $0.33^{\mathrm{a}}$ & 0.96 & & \\
\hline \multirow{3}{*}{ EGMs } & Slots & 63.2 & 32.9 & 3.9 & $2.49^{\mathrm{b}}$ & 1.94 & \multirow{3}{*}{18.012} & \multirow{3}{*}{$<0.001$} \\
\hline & Casino & 70.9 & 26.6 & 2.5 & $2.20^{\mathrm{b}}$ & 1.95 & & \\
\hline & Resort & 62.0 & 32.2 & 5.7 & $1.54^{\mathrm{a}}$ & 1.96 & & \\
\hline
\end{tabular}

Note: Superscripts indicate groups that are significantly different based on Scheffé test $(\mathrm{p}<.05)$ 
TABLE 51. Previous year participation and familiarity change with different forms of gambling by employees from different types of facilities

\begin{tabular}{|c|c|c|c|c|c|c|c|c|}
\hline $\begin{array}{l}\text { Gambling } \\
\text { Game }\end{array}$ & $\begin{array}{l}\text { Facility } \\
\text { type }\end{array}$ & Never $(\%)$ & $\begin{array}{c}\text { 1-11 times } \\
\text { per year } \\
(\%)\end{array}$ & $\begin{array}{c}\text { At least } \\
\text { once per } \\
\text { month }(\%)\end{array}$ & $\begin{array}{c}\text { Mean } \\
\text { familiarity } \\
\text { change* }\end{array}$ & SD & $\mathbf{F}$ & p \\
\hline \multicolumn{9}{|c|}{ Non-casino gambling games } \\
\hline \multirow{3}{*}{ Bingo } & Slots & 85.4 & 10.6 & 4.0 & 0.19 & 0.65 & \multirow{3}{*}{1.004} & \multirow{3}{*}{0.367} \\
\hline & Casino & 77.7 & 14.7 & 7.5 & 0.17 & 0.93 & & \\
\hline & Resort & 84.9 & 11.9 & 3.1 & 0.10 & 0.75 & & \\
\hline \multirow{3}{*}{$\begin{array}{l}\text { Sports } \\
\text { betting }\end{array}$} & Slots & 88.1 & 6.0 & 6.0 & $0.20^{\mathrm{a}}$ & 0.65 & \multirow{3}{*}{8.911} & \multirow{3}{*}{$<0.001$} \\
\hline & Casino & 85.0 & 8.2 & 6.9 & $0.68^{\mathrm{b}}$ & 1.34 & & \\
\hline & Resort & 88.9 & 6.9 & 4.2 & $0.48^{\mathrm{b}}$ & 1.17 & & \\
\hline \multirow{3}{*}{$\begin{array}{l}\text { Non-casino } \\
\text { card or } \\
\text { board } \\
\text { games }\end{array}$} & Slots & 75.5 & 19.9 & 4.6 & & & & \\
\hline & Casino & 80.9 & 14.1 & 5.0 & & & & \\
\hline & Resort & 80.8 & 13.1 & 6.2 & & & & \\
\hline \multirow{3}{*}{ Tile games } & Slots & 98.7 & 1.3 & 0.0 & & & & \\
\hline & Casino & 97.2 & 1.9 & 0.9 & & & & \\
\hline & Resort & 96.7 & 2.9 & 0.4 & & & & \\
\hline \multirow{3}{*}{ Skill games } & Slots & 90.0 & 8.0 & 2.0 & & & & \\
\hline & Casino & 88.4 & 8.4 & 3.1 & & & & \\
\hline & Resort & 93.4 & 5.7 & 0.9 & & & & \\
\hline \multirow{3}{*}{$\begin{array}{l}\text { Arcade } \\
\text { games }\end{array}$} & Slots & 99.3 & 0.7 & 0.0 & & & & \\
\hline & Casino & 96.5 & 2.8 & 0.6 & & & & \\
\hline & Resort & 95.8 & 3.8 & 0.4 & & & & \\
\hline \multirow{3}{*}{$\begin{array}{l}\text { Personal } \\
\text { investments }\end{array}$} & Slots & 69.3 & 18.0 & 12.7 & & & & \\
\hline & Casino & 74.1 & 18.0 & 7.9 & & & & \\
\hline & Resort & 72.9 & 16.9 & 10.2 & & & & \\
\hline
\end{tabular}

Note: Superscripts indicate groups that are significantly different based on Scheffé test $(\mathrm{p}<.05)$ 
Tables 52 and 53 illustrate how employees from the different types of facilities felt their gambling had been affected by different workplace influences. As can be observed, the greatest differences are associated with the factors relating to training and regulations. The resort casino employees exhibited far less agreement that their facility's regulations made casino gambling difficult, but this finding is quite unsurprising given the less strict regulations imposed on the resort casino employees. It is also clear that the resort casino employees felt they were the least impacted by their RG training, particularly in comparison with the OLG casino employees. This finding is noteworthy because the resort casino's RG training differed from the training offered in the OLG facilities. With regards to the other impacts that showed statistically significant differences between the groups, resort casino employees agreed least strongly that their acquired gambling knowledge had convinced them they could not profit from most games, they agreed most strongly that they could win money using their acquired gambling knowledge, they agreed most strongly that their interest in gambling had increased, and they agreed least strongly that they observed negative gambling consequences among patrons and wanted to avoided being like them. 
TABLE 52. The impacts of workplace influences on employees from different types of facilities

\begin{tabular}{|c|c|c|c|c|c|}
\hline Impacts of workplace influences & $\begin{array}{l}\text { Facility } \\
\text { type }\end{array}$ & $\begin{array}{l}\text { Mean } \\
\text { Score* }\end{array}$ & SD & $\mathbf{F}$ & $\mathbf{p}$ \\
\hline \multicolumn{6}{|l|}{ Exposure to gambling } \\
\hline \multirow{3}{*}{$\begin{array}{l}\text { As I have become more knowledgeable about the } \\
\text { games I have realized that I cannot overcome the } \\
\text { house odds in most games }(n=822)\end{array}$} & Slots & 3.99 & 1.15 & \multirow{3}{*}{3.445} & \multirow{3}{*}{0.032} \\
\hline & Casino & 3.98 & 1.18 & & \\
\hline & Resort & 3.77 & 1.22 & & \\
\hline \multirow{3}{*}{$\begin{array}{l}\text { I believe I can win money because I have } \\
\text { become more knowledgeable about casino games } \\
(\mathrm{n}=870)\end{array}$} & Slots & $1.36^{\mathrm{a}}$ & 0.71 & \multirow{3}{*}{3.312} & \multirow{3}{*}{0.037} \\
\hline & Casino & $1.54^{\mathrm{ab}}$ & 0.87 & & \\
\hline & Resort & $1.56^{\mathrm{b}}$ & 0.88 & & \\
\hline \multirow{3}{*}{$\begin{array}{l}\text { I have become more interested in gambling so I } \\
\text { wanted to participate }(n=864)\end{array}$} & Slots & $1.51^{\mathrm{a}}$ & 0.72 & \multirow{3}{*}{3.207} & \multirow{3}{*}{0.041} \\
\hline & Casino & $1.64^{\mathrm{ab}}$ & 0.91 & & \\
\hline & Resort & $1.73^{\mathrm{b}}$ & 0.97 & & \\
\hline \multirow{3}{*}{$\begin{array}{l}\text { I spend so much time surrounded by gambling } \\
\text { that it is no longer interesting }(n=853)\end{array}$} & Slots & 3.46 & 1.26 & \multirow{3}{*}{0.323} & \multirow{3}{*}{0.724} \\
\hline & Casino & 3.52 & 1.26 & & \\
\hline & Resort & 3.44 & 1.24 & & \\
\hline \multirow{3}{*}{$\begin{array}{l}\text { After work I want to avoid spending even more } \\
\text { time in a casino or involved with gambling } \\
(\mathrm{n}=894)\end{array}$} & Slots & 3.98 & 1.13 & \multirow{3}{*}{0.145} & \multirow{3}{*}{0.865} \\
\hline & Casino & 3.95 & 1.17 & & \\
\hline & Resort & 3.92 & 1.17 & & \\
\hline \multicolumn{6}{|l|}{ Exposure to patrons } \\
\hline \multirow{3}{*}{$\begin{array}{l}\text { I see some negative consequences of gambling } \\
\text { among patrons and I do not want to be like them } \\
(\mathrm{n}=866)\end{array}$} & Slots & $4.14^{\mathrm{b}}$ & 0.96 & \multirow{3}{*}{3.744} & \multirow{3}{*}{0.02} \\
\hline & Casino & $4.01^{\mathrm{ab}}$ & 1.02 & & \\
\hline & Resort & $3.88^{\mathrm{a}}$ & 1.13 & & \\
\hline \multirow{3}{*}{$\begin{array}{l}\text { I receive gambling tips from patrons that I feel } \\
\text { are worth following }(n=786)\end{array}$} & Slots & 1.30 & 0.61 & \multirow{3}{*}{2.334} & \multirow{3}{*}{0.098} \\
\hline & Casino & 1.36 & 0.66 & & \\
\hline & Resort & 1.44 & 0.81 & & \\
\hline \multirow{3}{*}{$\begin{array}{l}\text { I see how much fun patrons are having and I } \\
\text { want to participate too }(n=866)\end{array}$} & Slots & 1.98 & 0.98 & \multirow{3}{*}{0.605} & \multirow{3}{*}{0.546} \\
\hline & Casino & 2.08 & 1.06 & & \\
\hline & Resort & 2.09 & 1.06 & & \\
\hline \multirow{3}{*}{$\begin{array}{l}\text { I have seen many patrons win so I think I have a } \\
\text { good chance of winning money }(\mathrm{n}=862)\end{array}$} & Slots & 1.51 & 0.71 & \multirow{3}{*}{0.347} & \multirow{3}{*}{0.707} \\
\hline & Casino & 1.56 & 0.81 & & \\
\hline & Resort & 1.58 & 0.83 & & \\
\hline \multirow{3}{*}{$\begin{array}{l}\text { I see patrons losing money and do not want to do } \\
\text { the same }(n=845)\end{array}$} & Slots & 4.10 & 1.16 & & \\
\hline & Casino & 4.09 & 1.05 & 0.239 & 0.787 \\
\hline & Resort & 4.04 & 1.08 & & \\
\hline
\end{tabular}

Note: Superscripts indicate groups that are significantly different based on Scheffé test $(\mathrm{p}<.05)$ 
TABLE 53. The impacts of workplace influences on employees from different types of facilities

\begin{tabular}{|c|c|c|c|c|c|}
\hline Impacts of workplace influences & $\begin{array}{l}\text { Facility } \\
\text { type }\end{array}$ & $\begin{array}{l}\text { Mean } \\
\text { Score* }\end{array}$ & SD & $\mathbf{F}$ & $\mathbf{p}$ \\
\hline \multicolumn{6}{|l|}{ Exposure to the work environment } \\
\hline \multirow{3}{*}{$\begin{array}{l}\text { My friends who also work in the facility rarely or } \\
\text { never gamble so I rarely or never gamble } \\
(\mathrm{n}=799)\end{array}$} & Slots & 3.09 & 1.31 & \multirow{3}{*}{2.066} & \multirow{3}{*}{0.127} \\
\hline & Casino & 3.12 & 1.28 & & \\
\hline & Resort & 2.92 & 1.31 & & \\
\hline \multirow{3}{*}{$\begin{array}{l}\text { Gambling relieves the stress from my job } \\
(\mathrm{n}=839)\end{array}$} & Slots & 1.32 & 0.60 & \multirow{3}{*}{1.680} & \multirow{3}{*}{0.187} \\
\hline & Casino & 1.45 & 0.77 & & \\
\hline & Resort & 1.45 & 0.82 & & \\
\hline \multirow{3}{*}{$\begin{array}{l}\text { My friends who also work in the facility gamble } \\
\text { a lot so I gamble with them }(n=812)\end{array}$} & Slots & 1.45 & 0.73 & \multirow{3}{*}{1.672} & \multirow{3}{*}{0.188} \\
\hline & Casino & 1.53 & 0.78 & & \\
\hline & Resort & 1.59 & 0.90 & & \\
\hline \multirow{3}{*}{$\begin{array}{l}\text { The marketing and advertising that I see at work } \\
\text { tempts me to gamble }(\mathrm{n}=872)\end{array}$} & Slots & 1.38 & 0.74 & \multirow{3}{*}{0.706} & \multirow{3}{*}{0.494} \\
\hline & Casino & 1.47 & 0.80 & & \\
\hline & Resort & 1.46 & 0.80 & & \\
\hline \multicolumn{6}{|l|}{ Training and regulations } \\
\hline \multirow{3}{*}{$\begin{array}{l}\text { My job's regulations about employee gambling } \\
\text { make it difficult for me to visit a casino where I } \\
\text { am allowed to gamble }(n=853)\end{array}$} & Slots & $3.41^{\mathrm{b}}$ & 1.42 & \multirow{3}{*}{150.480} & \multirow{3}{*}{$<0.001$} \\
\hline & Casino & $3.43^{\mathrm{b}}$ & 1.34 & & \\
\hline & Resort & $1.94^{\mathrm{a}}$ & 1.10 & & \\
\hline \multirow{3}{*}{$\begin{array}{l}\text { My facility's problem gambling training course } \\
\text { was useful in teaching me about problem } \\
\text { gambling }(\mathrm{n}=828)\end{array}$} & Slots & $3.88^{\mathrm{b}}$ & 0.88 & \multirow{3}{*}{15.445} & \multirow{3}{*}{$<0.001$} \\
\hline & Casino & $3.96^{\mathrm{b}}$ & 0.82 & & \\
\hline & Resort & $3.58^{\mathrm{a}}$ & 1.05 & & \\
\hline \multirow{3}{*}{$\begin{array}{l}\text { My facility's problem gambling training course } \\
\text { has reduced the chances that I will ever become a } \\
\text { problem gambler }(n=774)\end{array}$} & Slots & $3.45^{\mathrm{ab}}$ & 1.17 & \multirow{3}{*}{10.468} & \multirow{3}{*}{$<0.001$} \\
\hline & Casino & $3.67^{\mathrm{b}}$ & 1.10 & & \\
\hline & Resort & $3.25^{\mathrm{a}}$ & 1.18 & & \\
\hline \multirow{3}{*}{$\begin{array}{l}\text { My facility's training about problem gambling } \\
\text { convinced me to gamble less }(n=798)\end{array}$} & Slots & $2.58^{\mathrm{ab}}$ & 1.26 & \multirow{3}{*}{5.631} & \multirow{3}{*}{0.004} \\
\hline & Casino & $2.67^{\mathrm{b}}$ & 1.19 & & \\
\hline & Resort & $2.37^{\mathrm{a}}$ & 1.11 & & \\
\hline
\end{tabular}

Note: Superscripts indicate groups that are significantly different based on Scheffé test $(\mathrm{p}<.05)$ 
As can be observed in Table 54, the resort casino employees also expressed the greatest levels of belief in risk cognitions. A one-way ANOVA test confirmed that significant differences existed between the three groups of employees $(F=3.943, p=0.020$, $\mathrm{n}=802$ ), and a Scheffé post-hoc test differentiated between the slots facility employees and the resort casino employees. On the other hand, as is illustrated in Table 55, employees from the different types of facilities were quite equally likely to agree that they sought their jobs at least in part because of prior gambling involvement. A one-way ANOVA test confirmed that no significant differences existed between the groups $(\mathrm{F}=0.19, \mathrm{p}=0.981)$.

TABLE 54. Average level of belief in three risk cognitions by employees from different types of facilities

\begin{tabular}{|l|c|c|}
\hline Facility type & Mean* & SD \\
\hline Slots facility & $1.28^{\mathrm{a}}$ & 0.51 \\
\hline Casino & $1.34^{\mathrm{ab}}$ & 0.56 \\
\hline Resort casino & $1.44^{\mathrm{b}}$ & 0.68 \\
\hline $\begin{array}{l}\text { Mean score of three items with scale: } 1=\text { Strongly disagree, } \\
\text { 2=Disagree, 3=Neutral, 4=Agree, 5=Strongly agree }\end{array}$ \\
\hline \hline
\end{tabular}

Note: Superscripts indicate groups that are significantly different based on Scheffé test $(\mathrm{p}<.05)$

TABLE 55. Levels of agreement that they were attracted to the employment because they were frequent gamblers among employees from different types of facilities

\begin{tabular}{|l|c|c|c|c|c|c|c|c|}
\hline Facility type & $\begin{array}{c}\text { Strongly } \\
\text { disagree } \\
(\mathbf{\%})\end{array}$ & $\begin{array}{c}\text { Disagree } \\
(\mathbf{\%})\end{array}$ & $\begin{array}{c}\text { Neutral } \\
(\mathbf{\%})\end{array}$ & $\begin{array}{c}\text { Agree } \\
(\mathbf{\%})\end{array}$ & $\begin{array}{c}\text { Strongly } \\
\text { agree } \\
(\mathbf{\%})\end{array}$ & Mean* & SD \\
\hline Slots facility & 54.5 & 29.5 & 9.8 & 4.5 & 1.8 & 1.70 & 0.948 \\
\hline Casino & 58.1 & 25.6 & 9.3 & 4.5 & 2.4 & 1.67 & 0.986 \\
\hline Resort casino & 59.3 & 21.7 & 12.0 & 5.7 & 1.3 & 1.68 & 0.980 \\
\hline
\end{tabular}

\subsubsection{Department}

Based on input from facility and personnel managers from the participating facilities, the different casino departments were divided into four groups according to their involvement with gambling and proximity to the gambling floor: those departments that are directly involved with the games (Slots and Table Games), those other departments that frequently work on the gambling floor (Security and Cashiering), those departments 
that typically work close to but not on the gambling floor (Food \& Beverage, Marketing, and Maintenance / Housekeeping / Hotel operations), and those departments that generally work away from the gambling floor (Administration, Finance, Human Resources, and Surveillance). As can be observed in Table 56, those departments most directly involved with gambling exhibited the highest rates of moderate risk and problem gambling, although those departments typically working close to the gambling floor exhibited higher rates of moderate risk and problem gambling than those departments other than Slots and Table Games that generally work on the gambling floor. A one-way ANOVA test confirmed that significant differences existed between the groups' mean PGSI scores $(\mathrm{F}=6.881, \mathrm{p}<0.001)$ and a Scheffé post-hoc test further confirmed these distinctions. These results, therefore, are fairly consistent with the findings of Shaffer et al. (1999) and Duquette (1999), who also detected patterns indicating that PG was most prevalent among employees whose jobs were closely related to the gambling action.

TABLE 56. PGSI results of the departments, grouped according to their proximity to the gambling floor

\begin{tabular}{|c|c|c|c|c|c|c|c|}
\hline Department Group & $\begin{array}{c}\begin{array}{c}\text { Non- } \\
\text { problem } \\
(\%)\end{array} \\
\end{array}$ & $\begin{array}{c}\text { Low risk } \\
(\%)\end{array}$ & $\begin{array}{c}\text { Moderate } \\
\text { risk }(\%)\end{array}$ & $\begin{array}{c}\text { Problem } \\
\text { gambler } \\
(\%)\end{array}$ & $\begin{array}{c}\text { Mean } \\
\text { PGSI } \\
\text { score* }\end{array}$ & SD & $\mathbf{n}$ \\
\hline Involved in gambling & 63.1 & 16.3 & 13.1 & 7.5 & $1.66^{\mathrm{b}}$ & 3.33 & 160 \\
\hline On floor & 77.4 & 14.2 & 7.3 & 1.1 & $0.64^{\mathrm{a}}$ & 1.80 & 261 \\
\hline Close to floor & 71.8 & 15.6 & 9.2 & 3.4 & $1.05^{\mathrm{ab}}$ & 2.83 & 294 \\
\hline Removed from floor & 81.5 & 11.8 & 5.9 & 0.8 & $0.52^{\mathrm{a}}$ & 1.48 & 119 \\
\hline
\end{tabular}

Note: Superscripts indicate groups that are significantly different based on Scheffé test $(p<.05)$

Nevertheless, as can be seen in Table 57, considering the PGSI results of each department individually ${ }^{10}$ reveals notable differences between some of the departments that were grouped together in Table 56, indicating that it may be preferable to analyze each department independently. As can also be noticed in Table 57, the different departments' means PGSI scores varied considerably, and a one-way ANOVA test confirmed these differences to be significant $(\mathrm{F}=3.981, \mathrm{p}<0.001)$. A Scheffé post-hoc test only differentiated employees from the Table Games department and employees from the

\footnotetext{
${ }^{10}$ The Administration and Human Resources departments were combined because their gambling behaviours appeared fairly similar and there were relatively few respondents from each department.
} 
Administration / Human Resources departments, but the lack of other significant differences likely results in part from issues related to the small group sizes and the high skewness of the PGSI scores. Looking at the PGSI categorizations, it is clear that the Table Games department exhibited far higher rates of PG than any other department. Likewise, as can be observed in Table 58, employees in the Table Games department also were far more likely to have increased their gambling after having begun their jobs.

TABLE 57. PGSI results of employees from different departments

\begin{tabular}{|c|c|c|c|c|c|c|c|}
\hline Department & $\begin{array}{c}\begin{array}{c}\text { Non- } \\
\text { problem } \\
(\%)\end{array} \\
\end{array}$ & $\begin{array}{c}\text { Low risk } \\
(\%)\end{array}$ & $\begin{array}{l}\text { Moderate } \\
\text { risk }(\%)\end{array}$ & $\begin{array}{c}\text { Problem } \\
\text { gambler } \\
(\%)\end{array}$ & $\begin{array}{l}\text { Mean } \\
\text { PGSI } \\
\text { score* }\end{array}$ & SD & $\mathbf{n}$ \\
\hline Table Games & 58.0 & 15.0 & 16.0 & 11.0 & $2.12^{\mathrm{b}}$ & 3.67 & 100 \\
\hline $\begin{array}{l}\text { Maintenance / Housekeeping / } \\
\text { Hotel operations }\end{array}$ & 62.9 & 19.1 & 13.5 & 4.5 & $1.38^{\mathrm{ab}}$ & 2.89 & 89 \\
\hline Food \& Beverage & 75.5 & 13.3 & 7.1 & 4.1 & $1.17^{\mathrm{ab}}$ & 3.66 & 98 \\
\hline Surveillance & 71.8 & 15.4 & 10.3 & 2.6 & $0.90^{\mathrm{ab}}$ & 2.01 & 39 \\
\hline Slots & 71.7 & 18.3 & 8.3 & 1.7 & $0.88^{\mathrm{ab}}$ & 2.52 & 60 \\
\hline Security & 80.6 & 10.5 & 7.3 & 1.6 & $0.70^{\mathrm{ab}}$ & 2.18 & 124 \\
\hline Marketing & 75.7 & 15.0 & 7.5 & 1.9 & $0.67^{\mathrm{ab}}$ & 1.65 & 107 \\
\hline Cashiering & 74.5 & 17.5 & 7.3 & 0.7 & $0.58^{\mathrm{ab}}$ & 1.38 & 137 \\
\hline Finance & 91.8 & 2.0 & 6.1 & 0.0 & $0.37^{\mathrm{ab}}$ & 1.35 & 49 \\
\hline Administration / HR & 77.4 & 22.6 & 0.0 & 0.0 & $0.29^{\mathrm{a}}$ & 0.59 & 31 \\
\hline
\end{tabular}

Note: Superscripts indicate groups that are significantly different based on Scheffé test $(\mathrm{p}<.05)$

TABLE 58. Changes in gambling experienced by employees from different departments

\begin{tabular}{|l|c|c|c|c|c|c|}
\hline & $\begin{array}{c}\text { Decreased } \\
\text { significantly } \\
\mathbf{( \% )}\end{array}$ & $\begin{array}{c}\text { Decreased } \\
\text { a little (\%) }\end{array}$ & $\begin{array}{c}\text { Remained } \\
\text { the same } \\
(\boldsymbol{\%})\end{array}$ & $\begin{array}{c}\text { Increased } \\
\text { Iittle (\%) }\end{array}$ & $\begin{array}{c}\text { significantly } \\
(\boldsymbol{\%})\end{array}$ & $\mathbf{n}$ \\
\hline Administration / HR & 6.3 & 9.4 & 84.4 & 0.0 & 0.0 & 32 \\
\hline Cashiering & 19.4 & 9.7 & 59.7 & 9.0 & 2.1 & 144 \\
\hline Finance & 20.0 & 20.0 & 56.0 & 4.0 & 0.0 & 50 \\
\hline Food \& Beverage & 16.8 & 8.4 & 65.3 & 7.4 & 2.1 & 95 \\
\hline $\begin{array}{l}\text { Maintenance / House- } \\
\text { keeping / Hotel operations }\end{array}$ & 25.3 & 6.9 & 56.3 & 6.9 & 4.6 & 87 \\
\hline Marketing & 16.0 & 10.4 & 58.5 & 12.3 & 2.8 & 106 \\
\hline Security & 12.7 & 11.1 & 65.9 & 7.9 & 2.4 & 126 \\
\hline Slots & 23.1 & 7.7 & 55.4 & 10.8 & 3.1 & 65 \\
\hline Surveillance & 15.0 & 12.5 & 57.5 & 10.0 & 5.0 & 40 \\
\hline Table Games & 19.4 & 9.7 & 44.7 & 15.5 & 10.7 & 103 \\
\hline \hline
\end{tabular}


Tables 59, 60, 61, and 62 illustrate the frequency with which survey respondents from the various departments participated in different forms of gambling during the previous year. Consistent with the other findings regarding the Table Games department, employees from this department appeared to engage in numerous forms of gambling more frequently than employees from the other departments, particularly on the table games themselves. Likewise, the Slots department employees seemed to gamble relatively often on EGMs, although this pattern was not nearly as pronounced as with the Table Games employees gambling on table games. It is also apparent that employees from the Surveillance department engaged in various forms of gambling at relatively high rates. 
TABLE 59. Past year participation in different forms of gambling by employees from different departments

\begin{tabular}{|c|c|c|c|c|}
\hline Department & $\operatorname{Never}(\%)$ & $\begin{array}{l}\text { 1-11 times per } \\
\text { year }(\%)\end{array}$ & $\begin{array}{l}\text { At least once } \\
\text { per month }(\%)\end{array}$ & $\mathbf{n}$ \\
\hline \multicolumn{5}{|l|}{ In a casino } \\
\hline Table Games & 35.2 & 51.4 & 13.3 & 105 \\
\hline Marketing & 37.5 & 56.3 & 6.3 & 112 \\
\hline Administration / HR & 43.8 & 56.3 & 0.0 & 32 \\
\hline Security & 44.8 & 49.6 & 5.6 & 125 \\
\hline Slots & 45.5 & 47.0 & 7.6 & 66 \\
\hline Food \& Beverage & 46.1 & 49.0 & 4.9 & 102 \\
\hline Cashiering & 46.9 & 46.9 & 6.1 & 147 \\
\hline $\begin{array}{l}\text { Maintenance / Housekeeping / } \\
\text { Hotel operations }\end{array}$ & 48.8 & 41.9 & 9.3 & 86 \\
\hline Surveillance & 50.0 & 50.0 & 0.0 & 40 \\
\hline Finance & 58.5 & 37.7 & 3.8 & 53 \\
\hline \multicolumn{5}{|c|}{ With friends or family members outside of a casino } \\
\hline Surveillance & 50.0 & 30.0 & 20.0 & 40 \\
\hline Table Games & 56.7 & 26.9 & 16.3 & 104 \\
\hline Slots & 60.0 & 27.7 & 12.3 & 65 \\
\hline Security & 61.6 & 33.6 & 4.8 & 125 \\
\hline Finance & 62.3 & 28.3 & 9.4 & 53 \\
\hline Food \& Beverage & 65.7 & 25.5 & 8.8 & 102 \\
\hline $\begin{array}{l}\text { Maintenance / Housekeeping / } \\
\text { Hotel operations }\end{array}$ & 66.7 & 23.8 & 9.5 & 84 \\
\hline Administration / HR & 71.9 & 25.0 & 3.1 & 32 \\
\hline Marketing & 75.0 & 18.8 & 6.3 & 112 \\
\hline Cashiering & 79.6 & 15.6 & 4.8 & 147 \\
\hline \multicolumn{5}{|c|}{ Inside or outside of a casino with friends or family members who are also co-workers } \\
\hline Table Games & 59.2 & 26.2 & 14.6 & 103 \\
\hline Food \& Beverage & 69.6 & 20.6 & 9.8 & 102 \\
\hline Slots & 70.8 & 20.0 & 9.2 & 65 \\
\hline Security & 72.8 & 22.4 & 4.8 & 125 \\
\hline $\begin{array}{l}\text { Maintenance / Housekeeping / } \\
\text { Hotel operations }\end{array}$ & 74.4 & 18.6 & 7.0 & 86 \\
\hline Finance & 75.5 & 18.9 & 5.7 & 53 \\
\hline Cashiering & 75.5 & 21.8 & 2.7 & 147 \\
\hline Marketing & 76.6 & 17.0 & 6.3 & 112 \\
\hline Administration / HR & 78.1 & 15.6 & 6.3 & 32 \\
\hline Surveillance & 80.0 & 12.5 & 7.5 & 40 \\
\hline \multicolumn{5}{|l|}{ Online } \\
\hline Table Games & 77.5 & 11.8 & 10.8 & 102 \\
\hline Surveillance & 77.5 & 12.5 & 10.0 & 40 \\
\hline Slots & 83.1 & 7.7 & 9.2 & 65 \\
\hline Food \& Beverage & 86.0 & 6.0 & 8.0 & 100 \\
\hline Security & 89.5 & 6.5 & 4.0 & 124 \\
\hline $\begin{array}{l}\text { Maintenance / Housekeeping / } \\
\text { Hotel operations }\end{array}$ & 90.6 & 2.4 & 7.1 & 85 \\
\hline Cashiering & 91.8 & 5.5 & 2.7 & 146 \\
\hline Marketing & 92.0 & 5.4 & 2.7 & 112 \\
\hline Finance & 100.0 & 0.0 & 0.0 & 53 \\
\hline Administration / HR & 100.0 & 0.0 & 0.0 & 32 \\
\hline
\end{tabular}


TABLE 60. Past year participation in different forms of gambling by employees from different departments

\begin{tabular}{|c|c|c|c|c|}
\hline Department & Never $(\%)$ & $\begin{array}{l}\text { 1-11 times per } \\
\text { year }(\%)\end{array}$ & $\begin{array}{c}\text { At least once } \\
\text { per month }(\%)\end{array}$ & $\mathbf{n}$ \\
\hline \multicolumn{5}{|l|}{ Lottery-style games } \\
\hline Administration / HR & 3.1 & 43.8 & 53.1 & 32 \\
\hline Marketing & 5.4 & 45.5 & 49.1 & 112 \\
\hline Finance & 5.7 & 50.9 & 43.4 & 53 \\
\hline Slots & 6.1 & 37.9 & 56.1 & 66 \\
\hline Cashiering & 7.5 & 41.5 & 51.0 & 147 \\
\hline Security & 8.2 & 44.3 & 47.5 & 122 \\
\hline Table Games & 8.6 & 27.6 & 63.8 & 105 \\
\hline Food \& Beverage & 8.7 & 42.7 & 48.5 & 103 \\
\hline $\begin{array}{l}\text { Maintenance / Housekeeping / } \\
\text { Hotel operations }\end{array}$ & 11.1 & 31.1 & 57.8 & 90 \\
\hline Surveillance & 15.0 & 32.5 & 52.5 & 40 \\
\hline \multicolumn{5}{|l|}{ EGMs } \\
\hline Marketing & 54.5 & 39.3 & 6.3 & 112 \\
\hline Slots & 54.5 & 39.4 & 6.1 & 66 \\
\hline Table Games & 65.4 & 29.8 & 4.8 & 104 \\
\hline $\begin{array}{l}\text { Maintenance / Housekeeping / } \\
\text { Hotel operations }\end{array}$ & 65.9 & 27.3 & 6.8 & 88 \\
\hline Food \& Beverage & 66.0 & 28.2 & 5.8 & 103 \\
\hline Cashiering & 66.0 & 31.3 & 2.7 & 147 \\
\hline Security & 69.0 & 26.2 & 4.8 & 126 \\
\hline Finance & 71.7 & 26.4 & 1.9 & 53 \\
\hline Administration / HR & 71.9 & 28.1 & 0.0 & 32 \\
\hline Surveillance & 72.5 & 27.5 & 0.0 & 40 \\
\hline \multicolumn{5}{|l|}{ Horse races } \\
\hline Finance & 69.8 & 30.2 & 0.0 & 53 \\
\hline Administration / HR & 78.1 & 21.9 & 0.0 & 32 \\
\hline Marketing & 81.3 & 18.8 & 0.0 & 112 \\
\hline Table Games & 81.7 & 17.3 & 1.0 & 104 \\
\hline Slots & 83.1 & 16.9 & 0.0 & 65 \\
\hline Food \& Beverage & 83.5 & 12.6 & 3.9 & 103 \\
\hline Surveillance & 85.0 & 10.0 & 5.0 & 40 \\
\hline $\begin{array}{l}\text { Maintenance / Housekeeping / } \\
\text { Hotel operations }\end{array}$ & 85.2 & 12.5 & 2.3 & 88 \\
\hline Cashiering & 85.7 & 14.3 & 0.0 & 147 \\
\hline Security & 87.2 & 12.0 & 0.8 & 125 \\
\hline
\end{tabular}


TABLE 61. Past year participation in different forms of gambling by employees from different departments

\begin{tabular}{|c|c|c|c|c|}
\hline Department & Never $(\%)$ & $\begin{array}{l}\text { 1-11 times per } \\
\text { year }(\%)\end{array}$ & $\begin{array}{l}\text { At least once } \\
\text { per month }(\%)\end{array}$ & $\mathbf{n}$ \\
\hline \multicolumn{5}{|l|}{ Casino blackjack } \\
\hline Table Games & 69.2 & 25.0 & 5.8 & 104 \\
\hline Surveillance & 72.5 & 27.5 & 0.0 & 40 \\
\hline Slots & 80.0 & 20.0 & 0.0 & 65 \\
\hline Food \& Beverage & 87.4 & 11.7 & 1.0 & 103 \\
\hline Administration / HR & 87.5 & 12.5 & 0.0 & 32 \\
\hline Security & 89.7 & 10.3 & 0.0 & 126 \\
\hline Marketing & 90.2 & 8.0 & 1.8 & 112 \\
\hline $\begin{array}{l}\text { Maintenance / Housekeeping / } \\
\text { Hotel operations }\end{array}$ & 92.0 & 6.9 & 1.1 & 87 \\
\hline Finance & 94.3 & 5.7 & 0.0 & 53 \\
\hline Cashiering & 94.6 & 5.4 & 0.0 & 147 \\
\hline \multicolumn{5}{|l|}{ Casino roulette } \\
\hline Table Games & 72.1 & 24.0 & 3.8 & 104 \\
\hline Surveillance & 85.0 & 15.0 & 0.0 & 40 \\
\hline Security & 87.3 & 12.7 & 0.0 & 126 \\
\hline Marketing & 87.5 & 9.8 & 2.7 & 112 \\
\hline Slots & 87.7 & 10.8 & 1.5 & 65 \\
\hline Administration / HR & 90.6 & 9.4 & 0.0 & 32 \\
\hline $\begin{array}{l}\text { Maintenance / Housekeeping / } \\
\text { Hotel operations }\end{array}$ & 91.9 & 8.1 & 0.0 & 86 \\
\hline Cashiering & 92.5 & 7.5 & 0.0 & 147 \\
\hline Finance & 94.3 & 5.7 & 0.0 & 53 \\
\hline Food \& Beverage & 95.1 & 3.9 & 1.0 & 103 \\
\hline \multicolumn{5}{|l|}{ Casino poker } \\
\hline Table Games & 71.4 & 21.0 & 7.6 & 105 \\
\hline Surveillance & 87.5 & 12.5 & 0.0 & 40 \\
\hline Slots & 89.2 & 10.8 & 0.0 & 65 \\
\hline Food \& Beverage & 91.3 & 7.8 & 1.0 & 103 \\
\hline $\begin{array}{l}\text { Maintenance / Housekeeping / } \\
\text { Hotel operations }\end{array}$ & 93.1 & 5.7 & 1.1 & 87 \\
\hline Marketing & 93.8 & 6.3 & 0.0 & 112 \\
\hline Cashiering & 94.6 & 4.8 & 0.7 & 147 \\
\hline Finance & 96.2 & 3.8 & 0.0 & 53 \\
\hline Security & 97.6 & 2.4 & 0.0 & 126 \\
\hline Administration / HR & 100.0 & 0.0 & 0.0 & 32 \\
\hline \multicolumn{5}{|l|}{ Casino craps } \\
\hline Table Games & 83.7 & 14.4 & 1.9 & 104 \\
\hline Surveillance & 90.0 & 10.0 & 0.0 & 40 \\
\hline Slots & 95.4 & 4.6 & 0.0 & 65 \\
\hline Security & 96.8 & 2.4 & 0.8 & 126 \\
\hline Food \& Beverage & 98.1 & 1.0 & 1.0 & 103 \\
\hline Finance & 98.1 & 1.9 & 0.0 & 53 \\
\hline Marketing & 98.2 & 1.8 & 0.0 & 112 \\
\hline Cashiering & 98.6 & 1.4 & 0.0 & 147 \\
\hline $\begin{array}{l}\text { Maintenance / Housekeeping / } \\
\text { Hotel operations }\end{array}$ & 100.0 & 0.0 & 0.0 & 86 \\
\hline Administration / HR & 100.0 & 0.0 & 0.0 & 32 \\
\hline
\end{tabular}


TABLE 62. Past year participation in different forms of gambling by employees from different departments

\begin{tabular}{|c|c|c|c|c|}
\hline Department & $\operatorname{Never}(\%)$ & $\begin{array}{l}\text { 1-11 times per } \\
\text { year }(\%)\end{array}$ & $\begin{array}{l}\text { At least once } \\
\text { per month }(\%)\end{array}$ & $\mathbf{n}$ \\
\hline \multicolumn{5}{|c|}{ Personal investment in stocks, options, or commodities markets } \\
\hline Finance & 50.9 & 34.0 & 15.1 & 53 \\
\hline Slots & 67.2 & 26.6 & 6.3 & 64 \\
\hline Administration / HR & 68.8 & 15.6 & 15.6 & 32 \\
\hline Table Games & 71.8 & 17.5 & 10.7 & 103 \\
\hline Food \& Beverage & 72.5 & 16.7 & 10.8 & 102 \\
\hline Surveillance & 72.5 & 17.5 & 10.0 & 40 \\
\hline Security & 73.8 & 19.0 & 7.1 & 126 \\
\hline $\begin{array}{l}\text { Maintenance / Housekeeping / } \\
\text { Hotel operations }\end{array}$ & 76.1 & 14.8 & 9.1 & 88 \\
\hline Cashiering & 76.6 & 13.8 & 9.7 & 145 \\
\hline Marketing & 80.2 & 12.6 & 7.2 & 111 \\
\hline \multicolumn{5}{|c|}{ Betting on card games or board games played outside of a casino } \\
\hline Surveillance & 62.5 & 25.0 & 12.5 & 40 \\
\hline Slots & 72.3 & 18.5 & 9.2 & 65 \\
\hline Security & 75.4 & 21.4 & 3.2 & 126 \\
\hline Finance & 75.5 & 18.9 & 5.7 & 53 \\
\hline Marketing & 76.8 & 17.0 & 6.3 & 112 \\
\hline Table Games & 77.7 & 14.6 & 7.8 & 103 \\
\hline Food \& Beverage & 82.5 & 11.7 & 5.8 & 103 \\
\hline $\begin{array}{l}\text { Maintenance / Housekeeping / } \\
\text { Hotel operations }\end{array}$ & 83.9 & 10.3 & 5.7 & 87 \\
\hline Cashiering & 87.8 & 10.2 & 2.0 & 147 \\
\hline Administration / HR & 90.6 & 6.3 & 3.1 & 32 \\
\hline \multicolumn{5}{|l|}{ Bingo } \\
\hline Table Games & 76.0 & 14.4 & 9.6 & 104 \\
\hline $\begin{array}{l}\text { Maintenance / Housekeeping / } \\
\text { Hotel operations }\end{array}$ & 77.6 & 16.5 & 5.9 & 85 \\
\hline Slots & 78.5 & 15.4 & 6.2 & 65 \\
\hline Food \& Beverage & 79.4 & 14.7 & 5.9 & 102 \\
\hline Cashiering & 81.4 & 12.4 & 6.2 & 145 \\
\hline Finance & 82.7 & 13.5 & 3.8 & 52 \\
\hline Administration / HR & 84.4 & 9.4 & 6.3 & 32 \\
\hline Marketing & 86.4 & 10.9 & 2.7 & 110 \\
\hline Security & 87.3 & 11.9 & 0.8 & 126 \\
\hline Surveillance & 95.0 & 5.0 & 0.0 & 40 \\
\hline \multicolumn{5}{|l|}{ Sports betting } \\
\hline Surveillance & 70.0 & 10.0 & 20.0 & 40 \\
\hline Security & 77.8 & 12.7 & 9.5 & 126 \\
\hline Marketing & 83.8 & 9.9 & 6.3 & 111 \\
\hline Food \& Beverage & 87.4 & 5.8 & 6.8 & 103 \\
\hline Slots & 87.7 & 6.2 & 6.2 & 65 \\
\hline Table Games & 88.5 & 4.8 & 6.7 & 104 \\
\hline Finance & 90.6 & 7.5 & 1.9 & 53 \\
\hline $\begin{array}{l}\text { Maintenance / Housekeeping / } \\
\text { Hotel operations }\end{array}$ & 90.8 & 5.7 & 3.4 & 87 \\
\hline Cashiering & 95.2 & 4.8 & 0.0 & 147 \\
\hline Administration / HR & 100.0 & 0.0 & 0.0 & 32 \\
\hline
\end{tabular}


These general patterns were identified and described by numerous interviewees. For example, one interviewee stated, "When you understand the games a lot better, you play them. So table game staff will go to another casino and play table games because they are confident that they are going to beat the dealer." Likewise, an interviewee from one of the slots facilities claimed:

The majority of people that I know that work here that go gamble go to the slots...It's games that [are] in their head and they want to try them. And I know that when you go... you still look for the same kinds of machines. And it's like, okay, you know what, we have that one, let's try that one, we know how that works. You go to something you know.

Another interviewee similarly remarked:

Most card dealers are not interested in slots, only because [they] deal cards...that's [their] interest—slots [would be] very boring...Slot attendants probably are interested in slots...I would say there's very little crossover-you know, slot attendants like to play slots, card dealers like to play cards. The relative popularity of gambling among Table Games employees also was acknowledged by numerous interviewees. As one interviewee stated:

I feel like [Table Games employees] do [gamble] more. I know of them getting together more often to play cards or going to other casinos. I just know that that happens more often - [although] it could be because it's more employees. Also, when we were allowed to play lottery...you'd see them more often purchasing lottery tickets, too.

In explaining the Table Games employees' propensity toward gambling, several of the interviewees cited the employees' acquired comfort with and knowledge about the activity. For example, one employee explained:

[Table Games employees] are more familiar [with] the game, they're more exposed to it. They're drive could be, 'I want to be on the other side of the table,' or the other drive might be, 'I have a better understanding of the game, so I think I've got that edge,' so, yeah, I think naturally Table Games would be the ones that would do the more gambling than any other department. 
A second interviewee similarly claimed:

My perception would be...the [employees] that have access to the gaming floor are more inclined to gamble...probably [because of] just knowledge — maybe they have a confidence that they understand the way a casino works. They would be maybe less intimidated to go up to a gaming table to play.

Tables 63, 64, 65, and 66 illustrate how employees from the different departments felt their gambling had been impacted by various workplace influences. As some of the interviewees had believed, the Table Games employees agreed relatively strongly that they could win money using their acquired gambling knowledge. Nevertheless, in another apparent example of irrational thinking, these same employees also agreed the most strongly that they had learned they could not beat the house odds in most games. It is also noteworthy that the Surveillance employees agreed most strongly that they had wanted to gamble due to an increased interest in the activity and that they believed they could win using their acquired gambling knowledge. On the other hand, employees from the Security department agreed very strongly that they wanted to avoid gambling after work and that the activity was no longer interesting to them. Regarding exposure to the patrons, it should be noted that the Table Games, Slots, and Security departments all agreed most strongly with the items about not wanting to be like the patrons. Nevertheless, the Table Games and Slots employees also expressed comparably high levels of agreement that they had been motivated to gamble by observing the patrons having fun, while the Security employees disagreed with this motive more strongly than any other department. It is also worth mentioning that the Surveillance employees most strongly believed that they could win because they saw patrons winning. With regards to exposure to the work environment, it is worth noting that the Table Games employees expressed the strongest agreement that they were motivated to gamble by other co-workers. Moreover, with regards to the training and regulations, the Table Games employees expressed the least agreement that they had been impacted by their RG training. 
TABLE 63. The impacts of exposure to gambling on employees from different departments

\begin{tabular}{|c|c|c|c|c|c|c|c|}
\hline Department & Mean* & SD & $\mathbf{n}$ & Department & Mean* & SD & n \\
\hline \multicolumn{4}{|c|}{$\begin{array}{l}\text { As I have become more knowledgeable about the games } \\
\text { I have realized that I cannot overcome the house odds in } \\
\text { most games }\end{array}$} & \multicolumn{4}{|c|}{$\begin{array}{l}\text { I have become more interested in gambling so I wanted } \\
\text { to participate }\end{array}$} \\
\hline Table Games & $4.34^{\mathrm{b}}$ & 0.87 & 102 & Surveillance & 1.95 & 1.01 & 38 \\
\hline Finance & $4.16^{\mathrm{ab}}$ & 1.08 & 38 & Table Games & 1.85 & 1.10 & 102 \\
\hline Slots & $4.14^{\mathrm{ab}}$ & 0.83 & 64 & Maintenance / Housekeeping / & & & \\
\hline Security & $4.12^{\mathrm{ab}}$ & 1.09 & 116 & Hotel operations & 1.71 & 0.92 & 82 \\
\hline Surveillance & $4.10^{\mathrm{ab}}$ & 0.87 & 40 & Slots & 1.70 & 0.95 & 64 \\
\hline Cashiering & $3.80^{\mathrm{ab}}$ & 1.27 & 134 & Marketing & 1.65 & 0.90 & 110 \\
\hline Marketing & $3.70^{\mathrm{ab}}$ & 1.32 & 101 & Security & 1.61 & 0.91 & 118 \\
\hline Food \& Beverage & $3.53^{\mathrm{ab}}$ & 1.30 & 88 & Food \& Beverage & 1.59 & 0.87 & 92 \\
\hline Administration / HR & $3.52^{\mathrm{ab}}$ & 1.45 & 25 & Administration / HR & 1.57 & 0.79 & 28 \\
\hline \multirow{2}{*}{$\begin{array}{l}\text { Maintenance / Housekeeping / } \\
\text { Hotel operations }\end{array}$} & \multirow{2}{*}{$3.33^{\mathrm{a}}$} & \multirow{2}{*}{1.42} & \multirow{2}{*}{76} & Cashiering & 1.57 & 0.78 & 143 \\
\hline & & & & Finance & 1.44 & 0.70 & 43 \\
\hline \multicolumn{4}{|c|}{$\mathrm{F}=6.355, \mathrm{p}<0.001$} & \multicolumn{4}{|c|}{$\mathrm{F}=1.564, \mathrm{p}=0.122$} \\
\hline \multicolumn{4}{|c|}{$\begin{array}{l}\text { I believe I can win money because I have become more } \\
\text { knowledgeable about casino games }\end{array}$} & \multicolumn{4}{|c|}{$\begin{array}{l}\text { After work I want to avoid spending even more time in } \\
\text { a casino or involved with gambling }\end{array}$} \\
\hline Surveillance & $2.26^{\mathrm{b}}$ & 1.21 & 39 & Administration / HR & 4.21 & 0.83 & 28 \\
\hline \multirow{2}{*}{$\begin{array}{l}\text { Maintenance / Housekeeping / } \\
\text { Hotel operations }\end{array}$} & \multirow{2}{*}{$1.69^{\mathrm{ab}}$} & \multirow{2}{*}{0.94} & \multirow{2}{*}{83} & Security & 4.10 & 1.11 & 125 \\
\hline & & & & Cashiering & 4.01 & 1.09 & 143 \\
\hline Table Games & $1.65^{\mathrm{ab}}$ & 1.04 & 103 & Slots & 3.98 & 1.14 & 65 \\
\hline Food \& Beverage & $1.58^{\mathrm{a}}$ & 0.85 & 93 & Food \& Beverage & 3.96 & 1.14 & 95 \\
\hline Security & $1.54^{\mathrm{a}}$ & 0.93 & 122 & Marketing & 3.96 & 1.13 & 108 \\
\hline Slots & $1.44^{\mathrm{a}}$ & 0.76 & 62 & Maintenance / Housekeeping / & 3.92 & 1.18 & 86 \\
\hline Marketing & $1.39^{\mathrm{a}}$ & 0.64 & 105 & Hotel operations & 3.92 & 1.18 & 80 \\
\hline Cashiering & $1.32^{\mathrm{a}}$ & 0.66 & 142 & Finance & 3.78 & 1.22 & 51 \\
\hline Finance & $1.27^{\mathrm{a}}$ & 0.54 & 48 & Surveillance & 3.67 & 1.18 & 39 \\
\hline Administration / HR & $1.22^{\mathrm{a}}$ & 0.42 & 27 & Table Games & 3.67 & 1.36 & 102 \\
\hline \multicolumn{4}{|c|}{$\mathrm{F}=6.183, \mathrm{p}<0.001$} & \multicolumn{4}{|c|}{$\mathrm{F}=1.477, \mathrm{p}=0.152$} \\
\hline \multicolumn{4}{|c|}{$\begin{array}{l}\text { I spend so much time surrounded by gambling that it is } \\
\text { no longer interesting }\end{array}$} & & & & \\
\hline Security & 3.80 & 1.14 & 123 & & & & \\
\hline Slots & 3.76 & 1.16 & 63 & & & & \\
\hline Cashiering & 3.56 & 1.13 & 141 & & & & \\
\hline Food \& Beverage & 3.50 & 1.28 & 90 & & & & \\
\hline $\begin{array}{l}\text { Maintenance / Housekeeping / } \\
\text { Hotel operations }\end{array}$ & 3.36 & 1.40 & 85 & & & & \\
\hline Marketing & 3.34 & 1.24 & 106 & & & & \\
\hline Finance & 3.27 & 1.19 & 37 & & & & \\
\hline Table Games & 3.25 & 1.44 & 103 & & & & \\
\hline Administration / HR & 3.14 & 1.24 & 21 & & & & \\
\hline Surveillance & 3.10 & 1.12 & 39 & & & & \\
\hline \multicolumn{4}{|c|}{$\mathrm{F}=2.653, \mathrm{p}=0.005$} & & & & \\
\hline
\end{tabular}

Note: Superscripts indicate groups that are significantly different based on Scheffé test $(\mathrm{p}<.05)$ 
TABLE 64. The impacts of exposure to the patrons on employees from different departments

\begin{tabular}{|c|c|c|c|c|c|c|c|}
\hline Department & Mean* & SD & $\mathbf{n}$ & Department & Mean* & SD & n \\
\hline \multicolumn{4}{|c|}{$\begin{array}{l}\text { I see some negative consequences of gambling among } \\
\text { patrons and I do not want to be like them }\end{array}$} & \multicolumn{4}{|c|}{$\begin{array}{l}\text { I receive gambling tips from patrons that I feel are } \\
\text { worth following }\end{array}$} \\
\hline Table Games & 4.21 & 0.94 & 101 & Food \& Beverage & 1.53 & 0.87 & 87 \\
\hline Slots & 4.19 & 0.85 & 64 & \multirow{2}{*}{$\begin{array}{l}\text { Maintenance / Housekeeping / } \\
\text { Hotel operations }\end{array}$} & \multirow{2}{*}{1.49} & \multirow{2}{*}{0.73} & \multirow{2}{*}{80} \\
\hline Security & 4.12 & 1.02 & 123 & & & & \\
\hline \multirow{2}{*}{$\begin{array}{l}\text { Maintenance / Housekeeping / } \\
\text { Hotel operations }\end{array}$} & \multirow{2}{*}{3.95} & \multirow{2}{*}{1.10} & \multirow{2}{*}{83} & Slots & 1.45 & 0.89 & 60 \\
\hline & & & & Security & 1.42 & 0.84 & 114 \\
\hline Cashiering & 3.94 & 1.14 & 145 & Table Games & 1.39 & 0.79 & 97 \\
\hline Marketing & 3.88 & 1.06 & 109 & Cashiering & 1.28 & 0.56 & 138 \\
\hline Food \& Beverage & 3.86 & 1.19 & 92 & Marketing & 1.28 & 0.50 & 95 \\
\hline Surveillance & 3.84 & 1.03 & 38 & Surveillance & 1.28 & 0.61 & 25 \\
\hline Administration / HR & 3.68 & 1.18 & 25 & Finance & 1.19 & 0.48 & 31 \\
\hline Finance & 3.53 & 1.20 & 40 & Administration / HR & 1.18 & 0.39 & 17 \\
\hline \multicolumn{4}{|c|}{$\mathrm{F}=2.367, \mathrm{p}=0.012$} & \multicolumn{4}{|c|}{$\mathrm{F}=1.668, \mathrm{p}=0.093$} \\
\hline \multicolumn{4}{|c|}{$\begin{array}{l}\text { I see how much fun patrons are having and I want to } \\
\text { participate too }\end{array}$} & \multicolumn{4}{|c|}{$\begin{array}{l}\text { I have seen many patrons win so I think I have a good } \\
\text { chance of winning money }\end{array}$} \\
\hline Table Games & 2.32 & 1.10 & 100 & Surveillance & 1.82 & 0.89 & 39 \\
\hline Slots & 2.23 & 1.11 & 64 & Slots & 1.69 & 0.91 & 64 \\
\hline Administration / HR & 2.11 & 0.93 & 27 & Table Games & 1.63 & 0.98 & 100 \\
\hline $\begin{array}{l}\text { Maintenance / Housekeeping / } \\
\text { Hotel operations }\end{array}$ & 2.10 & 1.09 & 84 & $\begin{array}{l}\text { Maintenance / Housekeeping / } \\
\text { Hotel operations }\end{array}$ & 1.56 & 0.73 & 81 \\
\hline Food \& Beverage & 2.07 & 1.13 & 94 & Marketing & 1.55 & 0.80 & 108 \\
\hline Cashiering & 2.06 & 1.07 & 143 & Food \& Beverage & 1.54 & 0.73 & 93 \\
\hline Surveillance & 2.05 & 0.99 & 38 & Administration / HR & 1.52 & 0.71 & 25 \\
\hline Marketing & 2.04 & 1.00 & 108 & Cashiering & 1.51 & 0.76 & 145 \\
\hline Finance & 1.97 & 0.84 & 39 & \begin{tabular}{|l|} 
Security \\
\end{tabular} & 1.47 & 0.74 & 121 \\
\hline Security & 1.78 & 0.94 & 121 & Finance & 1.44 & 0.59 & 41 \\
\hline \multicolumn{4}{|c|}{$\mathrm{F}=1.941, \mathrm{p}=0.043$} & \multicolumn{4}{|c|}{$F=1.086, p=0.371$} \\
\hline \multicolumn{4}{|c|}{$\begin{array}{l}\text { I see patrons losing money and do not want to do the } \\
\text { same }\end{array}$} & & & & \\
\hline Slots & 4.23 & 0.94 & 64 & & & & \\
\hline Security & 4.21 & 1.00 & 121 & & & & \\
\hline Table Games & 4.21 & 0.92 & 101 & & & & \\
\hline Cashiering & 4.18 & 0.95 & 142 & & & & \\
\hline Marketing & 4.01 & 1.07 & 104 & & & & \\
\hline Finance & 3.94 & 1.26 & 35 & & & & \\
\hline Food \& Beverage & 3.94 & 1.14 & 90 & & & & \\
\hline $\begin{array}{l}\text { Maintenance / Housekeeping / } \\
\text { Hotel operations }\end{array}$ & 3.94 & 1.24 & 86 & & & & \\
\hline Surveillance & 3.74 & 1.19 & 39 & & & & \\
\hline Administration / HR & 3.63 & 1.38 & 19 & & & & \\
\hline \multicolumn{4}{|c|}{$\mathrm{F}=1.928, \mathrm{p}=0.045$} & & & & \\
\hline
\end{tabular}


TABLE 65. The impacts of exposure to the work environment on employees from different departments

\begin{tabular}{|c|c|c|c|c|c|c|c|}
\hline Department & Mean* & SD & $\mathbf{n}$ & Department & Mean* & SD & $\mathbf{n}$ \\
\hline \multicolumn{4}{|c|}{ Gambling relieves the stress from my job } & \multicolumn{4}{|c|}{$\begin{array}{l}\text { My friends who also work in the facility gamble a lot so } \\
\text { I gamble with them }\end{array}$} \\
\hline \multirow{2}{*}{$\begin{array}{l}\text { Maintenance / Housekeeping / } \\
\text { Hotel operations }\end{array}$} & \multirow{2}{*}{1.67} & \multirow{2}{*}{0.92} & \multirow{2}{*}{79} & Table Games & 1.74 & 1.03 & 99 \\
\hline & & & & \multirow{2}{*}{$\begin{array}{l}\text { Maintenance / Housekeeping / } \\
\text { Hotel operations }\end{array}$} & \multirow{2}{*}{1.69} & \multirow{2}{*}{0.91} & \multirow{2}{*}{77} \\
\hline Slots & 1.66 & 1.00 & 61 & & & & \\
\hline Surveillance & 1.49 & 0.61 & 37 & Slots & 1.66 & 0.85 & 61 \\
\hline Food \& Beverage & 1.47 & 0.75 & 87 & Surveillance & 1.63 & 0.84 & 35 \\
\hline Table Games & 1.47 & 0.84 & 99 & Marketing & 1.57 & 0.92 & 97 \\
\hline Marketing & 1.45 & 0.89 & 101 & Food \& Beverage & 1.57 & 0.78 & 86 \\
\hline Cashiering & 1.31 & 0.64 & 139 & Security & 1.53 & 0.87 & 116 \\
\hline Security & 1.31 & 0.65 & 118 & Cashiering & 1.41 & 0.65 & 134 \\
\hline Finance & 1.25 & 0.57 & 48 & Finance & 1.21 & 0.41 & 43 \\
\hline Administration / HR & 1.12 & 0.33 & 25 & Administration / HR & 1.18 & 0.40 & 22 \\
\hline \multicolumn{4}{|c|}{$\mathrm{F}=3.006, p=0.002$} & \multicolumn{4}{|c|}{$\mathrm{F}=2.686, p=0.004$} \\
\hline \multicolumn{4}{|c|}{$\begin{array}{l}\text { My friends who also work in the facility rarely or never } \\
\text { gamble so I rarely or never gamble }\end{array}$} & \multicolumn{4}{|c|}{$\begin{array}{l}\text { The marketing and advertising that I see at work tempts } \\
\text { me to gamble }\end{array}$} \\
\hline Administration / HR & $3.81^{\mathrm{b}}$ & 1.11 & 27 & Surveillance & 1.72 & 1.19 & 39 \\
\hline Security & $3.19^{\mathrm{ab}}$ & 1.38 & 108 & \multirow{2}{*}{$\begin{array}{l}\text { Maintenance / Housekeeping / } \\
\text { Hotel operations }\end{array}$} & \multirow{2}{*}{1.59} & \multirow{2}{*}{0.79} & \multirow{2}{*}{85} \\
\hline Slots & $3.17^{\mathrm{ab}}$ & 1.11 & 60 & & & & \\
\hline Cashiering & $3.12^{\mathrm{ab}}$ & 1.22 & 130 & Food \& Beverage & 1.56 & 0.88 & 93 \\
\hline Surveillance & $3.06^{\mathrm{ab}}$ & 1.15 & 34 & Slots & 1.52 & 0.80 & 64 \\
\hline Finance & $3.05^{\mathrm{ab}}$ & 1.48 & 44 & Security & 1.45 & 0.84 & 122 \\
\hline Food \& Beverage & $2.96^{\mathrm{ab}}$ & 1.28 & 84 & Administration / HR & 1.44 & 0.85 & 27 \\
\hline \multirow{2}{*}{$\begin{array}{l}\text { Maintenance / Housekeeping / } \\
\text { Hotel operations }\end{array}$} & \multirow{2}{*}{$2.88^{\mathrm{ab}}$} & \multirow{2}{*}{1.33} & \multirow{2}{*}{77} & Table Games & 1.43 & 0.75 & 101 \\
\hline & & & & Marketing & 1.42 & 0.82 & 106 \\
\hline Marketing & $2.81^{\mathrm{a}}$ & 1.25 & 97 & Cashiering & 1.29 & 0.54 & 139 \\
\hline Table Games & $2.66^{\mathrm{a}}$ & 1.36 & 95 & Finance & 1.22 & 0.55 & 50 \\
\hline \multicolumn{4}{|c|}{$\mathrm{F}=2.761, \mathrm{p}=0.003$} & \multicolumn{4}{|c|}{$\mathrm{F}=2.201, \mathrm{p}=0.020$} \\
\hline
\end{tabular}

Note: Superscripts indicate groups that are significantly different based on Scheffé test $(\mathrm{p}<.05)$ 
TABLE 66. The impacts of training and regulations on employees from different departments

\begin{tabular}{|c|c|c|c|c|c|c|c|}
\hline Department & Mean* & SD & $\mathbf{n}$ & Department & Mean* & SD & $\mathbf{n}$ \\
\hline \multicolumn{4}{|c|}{$\begin{array}{l}\text { My job's regulations about employee gambling make it } \\
\text { difficult for me to visit a casino where I am allowed to } \\
\text { gamble }\end{array}$} & \multicolumn{4}{|c|}{$\begin{array}{l}\text { My facility's problem gambling training course has } \\
\text { reduced the chances that I will ever become a problem } \\
\text { gambler }\end{array}$} \\
\hline Surveillance & $3.58^{\mathrm{b}}$ & 1.29 & 38 & Food \& Beverage & 3.66 & 1.19 & 86 \\
\hline Slots & $3.05^{\mathrm{ab}}$ & 1.50 & 64 & Administration / HR & 3.63 & 1.17 & 24 \\
\hline Cashiering & $2.89^{\mathrm{ab}}$ & 1.51 & 138 & \multirow{2}{*}{$\begin{array}{l}\text { Maintenance / Housekeeping / } \\
\text { Hotel operations }\end{array}$} & \multirow{2}{*}{3.55} & \multirow{2}{*}{1.04} & \multirow{2}{*}{76} \\
\hline Food \& Beverage & $2.84^{\mathrm{ab}}$ & 1.42 & 91 & & & & \\
\hline Security & $2.81^{\mathrm{ab}}$ & 1.44 & 117 & Marketing & 3.54 & 1.04 & 90 \\
\hline Table Games & $2.65^{\mathrm{ab}}$ & 1.46 & 99 & Cashiering & 3.48 & 1.17 & 129 \\
\hline Administration / HR & $2.56^{\mathrm{ab}}$ & 1.42 & 27 & Finance & 3.45 & 1.06 & 31 \\
\hline \multirow{2}{*}{$\begin{array}{l}\text { Maintenance / Housekeeping / } \\
\text { Hotel operations }\end{array}$} & \multirow{2}{*}{$2.46^{\mathrm{a}}$} & \multirow{2}{*}{1.40} & \multirow{2}{*}{81} & Security & 3.45 & 1.24 & 109 \\
\hline & & & & Surveillance & 3.37 & 1.31 & 35 \\
\hline Marketing & $2.45^{\mathrm{a}}$ & 1.40 & 100 & Slots & 3.31 & 1.21 & 62 \\
\hline Finance & $2.22^{\mathrm{a}}$ & 1.39 & 50 & Table Games & 3.02 & 1.18 & 94 \\
\hline \multicolumn{4}{|c|}{$F=3.633, p<0.001$} & \multicolumn{4}{|c|}{$\mathrm{F}=2.054, \mathrm{p}=0.031$} \\
\hline \multicolumn{4}{|c|}{$\begin{array}{l}\text { My facility's problem gambling training course was } \\
\text { useful in teaching me about problem gambling }\end{array}$} & \multicolumn{4}{|c|}{$\begin{array}{l}\text { My facility's training about problem gambling } \\
\text { convinced me to gamble less }\end{array}$} \\
\hline Food \& Beverage & 3.97 & 0.94 & 95 & Administration / HR & 2.93 & 1.09 & 28 \\
\hline Cashiering & 3.91 & 0.75 & 138 & Food \& Beverage & 2.72 & 1.24 & 86 \\
\hline Finance & 3.91 & 0.82 & 35 & Slots & 2.63 & 1.31 & 62 \\
\hline Marketing & 3.89 & 0.91 & 97 & \multirow{2}{*}{$\begin{array}{l}\text { Maintenance / Housekeeping / } \\
\text { Hotel operations }\end{array}$} & \multirow{2}{*}{2.62} & \multirow{2}{*}{1.24} & \multirow{2}{*}{77} \\
\hline Administration / HR & 3.88 & 1.05 & 25 & & & & \\
\hline Surveillance & 3.86 & 0.92 & 37 & Surveillance & 2.60 & 0.95 & 35 \\
\hline \multirow{2}{*}{$\begin{array}{l}\text { Maintenance / Housekeeping / } \\
\text { Hotel operations }\end{array}$} & \multirow{2}{*}{3.81} & \multirow{2}{*}{0.85} & \multirow{2}{*}{83} & Cashiering & 2.50 & 1.11 & 128 \\
\hline & & & & Marketing & 2.48 & 1.18 & 102 \\
\hline Slots & 3.72 & 0.98 & 64 & Security & 2.40 & 1.22 & 106 \\
\hline Security & 3.60 & 1.12 & 117 & Finance & 2.37 & 1.11 & 41 \\
\hline Table Games & 3.48 & 1.08 & 99 & Table Games & 2.29 & 1.12 & 94 \\
\hline \multicolumn{4}{|c|}{$\mathrm{F}=2.545, \mathrm{p}=0.007$} & \multicolumn{4}{|c|}{$\mathrm{F}=1.435, \mathrm{p}=0.169$} \\
\hline
\end{tabular}

Note: Superscripts indicate groups that are significantly different based on Scheffé test $(\mathrm{p}<.05)$

The varying levels of impact that different workplace influences may have on employees from different departments was mentioned by some of the interview participants. For example, one interviewee explained, "[Security] sees the problem gamblers, [does] the trespasses, [does] the self-exclusions. I think [that] department will tend to shy away from gambling more than the average department." Another employee remarked, "A lot of the Table Games employees and Surveillance department are trained in card counting and that sort of thing, and basic strategy in blackjack, and so I really do 
think that a lot of them think they have an edge because of that." Similarly, another interviewee claimed:

I would say in the Surveillance department you see people that play table games at other casinos because they think they understand the game a little bit better. So I do know that they do play, you know, table games, because that's what [they] do, [they] watch table games and slot machines and things.

Even though employees from all of the departments tended to disagree that they gambled to reduce job stress, the amount of job stress perceived by employees from the different departments appeared to vary, as can be observed in Table 67. A one-way ANVOA test found significant differences between the departments $(F=3.311, p=0.001)$, which was further confirmed with a Scheffé post-hoc test. Keith et al. (2001) had found that Slots employees perceived their jobs as particularly stressful, but this study found that the Slots employees exhibited, on average, a basically neutral attitude toward the idea that their jobs were stressful, and employees from two other departments agreed more strongly that their jobs were stressful.

TABLE 67. Agreement with the statement "I find my job stressful" among employees from different departments

\begin{tabular}{|l|c|c|c|}
\hline Department & Mean* & SD & n \\
\hline Food \& Beverage & $3.08^{\mathrm{b}}$ & 1.28 & 98 \\
\hline Finance & $3.04^{\mathrm{b}}$ & 1.08 & 52 \\
\hline Slots & $2.95^{\mathrm{ab}}$ & 1.17 & 64 \\
\hline $\begin{array}{l}\text { Maintenance / Housekeeping / } \\
\text { Hotel operations }\end{array}$ & $2.94^{\mathrm{ab}}$ & 1.30 & 86 \\
\hline Administration / HR & $2.87^{\mathrm{ab}}$ & 1.09 & 31 \\
\hline Cashiering & $2.80^{\mathrm{ab}}$ & 1.25 & 143 \\
\hline Table Games & $2.80^{\mathrm{ab}}$ & 1.31 & 104 \\
\hline Marketing & $2.76^{\mathrm{ab}}$ & 1.22 & 110 \\
\hline Security & $2.48^{\mathrm{ab}}$ & 1.29 & 126 \\
\hline Surveillance & $2.10^{\mathrm{a}}$ & 1.07 & 39 \\
\hline $\begin{array}{l}\text { *Based on scale: 1=Strongly disagree, 2=Disagree, 3=Neutral, } \\
\text { 4=Agree, 5=Strongly agree }\end{array}$ & \\
\hline \hline
\end{tabular}

Note: Superscripts indicate groups that are significantly different based on Scheffé test $(\mathrm{p}<.05)$

In addition to feeling different amounts of job stress, employees in the different departments also exhibited different levels of belief in risk cognitions, as is illustrated in 
Table 68. As can be observed, the Table Games employees expressed the second highest levels of belief in risk cognitions, although employees in the Maintenance /

Housekeeping / Hotel operations department expressed much more belief than workers from any other department. It is also worth noting that the Surveillance employees, who most strongly agreed that they could win money using their acquired gambling knowledge, actually exhibited comparatively low levels of belief in the risk cognitions. A one-way ANOVA test found significant differences between the various departments $(\mathrm{F}=3.608, \mathrm{p}<0.001)$ and a Scheffé post-hoc test further confirmed these differences.

TABLE 68. Average level of belief in three risk cognitions by employees from different departments

\begin{tabular}{|l|c|c|c|}
\hline Department & Mean* & SD & n \\
\hline $\begin{array}{l}\text { Maintenance / Housekeeping / } \\
\text { Hotel operations }\end{array}$ & $1.66^{\mathrm{b}}$ & 0.84 & 79 \\
\hline Table Games & $1.46^{\mathrm{ab}}$ & 0.79 & 94 \\
\hline Slots & $1.36^{\mathrm{ab}}$ & 0.60 & 58 \\
\hline Cashiering & $1.36^{\mathrm{ab}}$ & 0.51 & 126 \\
\hline Food \& Beverage & $1.35^{\mathrm{ab}}$ & 0.55 & 87 \\
\hline Finance & $1.34^{\mathrm{ab}}$ & 0.47 & 42 \\
\hline Surveillance & $1.30^{\mathrm{ab}}$ & 0.44 & 38 \\
\hline Marketing & $1.26^{\mathrm{ab}}$ & 0.47 & 98 \\
\hline Security & $1.26^{\mathrm{ab}}$ & 0.45 & 108 \\
\hline Administration / HR & $1.19^{\mathrm{a}}$ & 0.39 & 27 \\
\hline $\begin{array}{l}\text { *Average score of three items with scale: } 1=\text { Strongly disagree, } \\
\text { 2=Disagree, 3=Neutral, 4=Agree, 5=Strongly agree }\end{array}$ \\
\hline \hline
\end{tabular}

Note: Superscripts indicate groups that are significantly different based on Scheffé test $(\mathrm{p}<.05)$

The EGM-related risk cognition was analyzed independently, and once again a one-way ANOVA test found significant differences between the departments $(\mathrm{F}=3.747$, $\mathrm{p}<0.001)$ that were further confirmed with a Scheffé post-hoc test. As can be observed in Table 69, the Slots employees actually exhibited more belief in this EGM-related risk cognition than employees from any other department besides the Maintenance / Housekeeping / Hotel operations department. 
TABLE 69. Average level of belief in EGM-related risk cognition by employees from different departments

\begin{tabular}{|l|c|c|c|}
\hline Department & Mean* & SD & n \\
\hline $\begin{array}{l}\text { Maintenance / Housekeeping / } \\
\text { Hotel operations }\end{array}$ & $1.59^{\mathrm{b}}$ & 0.84 & 74 \\
\hline Slots & $1.36^{\mathrm{ab}}$ & 0.67 & 56 \\
\hline Table Games & $1.34^{\mathrm{ab}}$ & 0.78 & 79 \\
\hline Cashiering & $1.31^{\mathrm{ab}}$ & 0.53 & 119 \\
\hline Food \& Beverage & $1.30^{\mathrm{ab}}$ & 0.54 & 79 \\
\hline Surveillance & $1.23^{\mathrm{ab}}$ & 0.43 & 35 \\
\hline Finance & $1.19^{\mathrm{ab}}$ & 0.40 & 37 \\
\hline Security & $1.19^{\mathrm{ab}}$ & 0.40 & 89 \\
\hline Marketing & $1.18^{\mathrm{ab}}$ & 0.49 & 92 \\
\hline Administration / HR & $1.04^{\mathrm{a}}$ & 0.20 & 26 \\
\hline $\begin{array}{l}\text { *Based on scale: 1=Strongly disagree, 2=Disagree, 3=Neutral, } \\
\text { 4=Agree, 5=Strongly agree }\end{array}$ & \multicolumn{4}{|l}{} \\
\hline \hline
\end{tabular}

Note: Superscripts indicate groups that are significantly different based on Scheffé test $(\mathrm{p}<.05)$

As can be seen in Table 70, employees from the different departments showed fairly varied levels of agreement that they had been attracted to their jobs by prior gambling involvement. A one-way ANOVA test confirmed that significant differences existed between the departments $(\mathrm{F}=3.892, \mathrm{p}<0.001)$, although a Scheffé post-hoc test failed to distinguish between any of the departments. As can be observed, the data indicated that Table Games employees were the most likely to have been attracted to their jobs by prior gambling involvement, and some of the interviewees speculated that such a pattern existed. As one interviewee stated, "I definitely think it would be Table Games and Slots [that gamble most]...I think especially in Table Games you're there because you enjoy it, you enjoy the games and that." Another interviewee claimed Table Games was the only department in which gambling was particularly popular, and similarly explained, "I think the reason they chose the Table Games department was because they liked to gamble and to play cards...You want to do something you enjoy." 
TABLE 70. Levels of agreement that they were attracted to the employment because they were frequent gamblers among employees from different departments

\begin{tabular}{|c|c|c|c|c|c|c|c|c|}
\hline Department & $\begin{array}{c}\text { Strongly } \\
\text { disagree } \\
(\%)\end{array}$ & $\begin{array}{c}\text { Disagree } \\
(\%)\end{array}$ & $\begin{array}{c}\text { Neutral } \\
(\%)\end{array}$ & $\begin{array}{c}\text { Agree } \\
(\%)\end{array}$ & $\begin{array}{c}\text { Strongly } \\
\text { agree } \\
(\%)\end{array}$ & Mean* & SD & $\mathbf{n}$ \\
\hline Table Games & 45.5 & 23.9 & 10.2 & 12.5 & 8.0 & 2.14 & 1.33 & 88 \\
\hline $\begin{array}{l}\text { Maintenance / Housekeeping } \\
\text { / Hotel operations }\end{array}$ & 39.0 & 32.2 & 22.0 & 6.8 & 0.0 & 1.97 & 0.95 & 59 \\
\hline Surveillance & 54.3 & 28.6 & 5.7 & 11.4 & 0.0 & 1.74 & 1.01 & 35 \\
\hline Food \& Beverage & 53.9 & 27.6 & 14.5 & 2.6 & 1.3 & 1.70 & 0.91 & 76 \\
\hline Slots & 61.5 & 19.2 & 13.5 & 3.8 & 1.9 & 1.65 & 0.99 & 52 \\
\hline Cashiering & 59.2 & 27.6 & 8.2 & 4.1 & 1.0 & 1.60 & 0.88 & 98 \\
\hline Marketing & 63.3 & 21.5 & 11.4 & 3.8 & 0.0 & 1.56 & 0.84 & 79 \\
\hline Security & 67.1 & 22.4 & 7.1 & 2.4 & 1.2 & 1.48 & 0.83 & 85 \\
\hline Finance & 71.4 & 20.0 & 5.7 & 0.0 & 2.9 & 1.43 & 0.85 & 35 \\
\hline Administration / HR & 75.0 & 20.0 & 0.0 & 5.0 & 0.0 & 1.35 & 0.75 & 20 \\
\hline
\end{tabular}

\subsubsection{Percentage of Workday Spent Interacting with Patrons}

Even employees working in the same department may have very different responsibilities so, given the potential impacts of exposure to patrons, this study also considered the percentage of each employee's workday that he or she spent interacting with patrons. Table 71 presents the PGSI results of employees grouped according to this variable. A one-way ANOVA test detected significant differences between the groups' mean PGSI scores $(\mathrm{F}=2.665, \mathrm{p}=0.031)$, but a Scheffé post-hoc test failed to differentiate between any of the groups. Also, the only noteworthy pattern is that the employees who spent the smallest portion of their workdays ( 0 to $20 \%$ ) interacting with patrons exhibited relatively low rates of moderate risk and problem gambling. 
TABLE 71. PGSI results of employees who spent different percentages of their workdays interacting with patrons

\begin{tabular}{|c|c|c|c|c|c|c|c|}
\hline $\begin{array}{l}\text { Percentage of } \\
\text { workday spent } \\
\text { interacting } \\
\text { with patrons }\end{array}$ & $\begin{array}{c}\begin{array}{c}\text { Non- } \\
\text { problem } \\
(\%)\end{array} \\
\end{array}$ & $\begin{array}{c}\text { Low risk } \\
(\%)\end{array}$ & $\begin{array}{c}\text { Moderate } \\
\text { risk }(\%)\end{array}$ & $\begin{array}{c}\text { Problem } \\
\text { gambler } \\
(\%)\end{array}$ & $\begin{array}{l}\text { Mean } \\
\text { PGSI } \\
\text { score* }\end{array}$ & SD & $\mathbf{n}$ \\
\hline $0-20 \%$ & 77.6 & 15.4 & 5.9 & 1.2 & 0.56 & 1.45 & 254 \\
\hline $21-40 \%$ & 66.7 & 20.0 & 8.3 & 5.0 & 1.18 & 2.93 & 60 \\
\hline $41-60 \%$ & 80.9 & 4.4 & 13.2 & 1.5 & 0.97 & 2.63 & 68 \\
\hline $61-80 \%$ & 74.2 & 16.7 & 5.8 & 3.3 & 0.87 & 2.43 & 120 \\
\hline $81-100 \%$ & 70.5 & 13.8 & 11.2 & 4.4 & 1.20 & 2.93 & 383 \\
\hline
\end{tabular}

Somewhat comparably, Table 72 demonstrates that those employees who spent the greatest portion of their workdays (81-100\%) interacting with patrons were the most likely to have increased their gambling since they began working in an OLG or resort casino. A chi square test detected significant differences between the groups $\left(X^{2}=27.913\right.$, $\mathrm{p}=0.032$ ). Because Table Games employees frequently claimed to spend a large portion of their workdays interacting with patrons and Table Games employees also were relatively likely to have claimed they had increased their gambling, this analysis was repeated with the Table Games employees excluded. The pattern nonetheless remained evident in this analysis, although a chi square test failed to detect any significant differences between the groups $\left(X^{2}=10.085, p=0.264, n=793\right)$.

TABLE 72. Changes in gambling experienced by employees who spent different percentages of their workdays interacting with patrons

\begin{tabular}{|l|c|c|c|c|c|c|}
\hline $\begin{array}{l}\text { Percentage of } \\
\text { workday spent } \\
\text { interacting with } \\
\text { patrons }\end{array}$ & $\begin{array}{c}\text { Decreased } \\
\text { significantly } \\
(\boldsymbol{\%})\end{array}$ & $\begin{array}{c}\text { Decreased } \\
\text { a little (\%) }\end{array}$ & $\begin{array}{c}\text { Remained } \\
\text { the same } \\
(\boldsymbol{\%})\end{array}$ & $\begin{array}{c}\text { Increased a } \\
\text { little (\%) }\end{array}$ & $\begin{array}{c}\text { Increased } \\
\text { significantly } \\
(\boldsymbol{\%})\end{array}$ & $\mathbf{n}$ \\
\hline $0-20 \%$ & 16.8 & 13.3 & 62.5 & 6.3 & 1.2 & 256 \\
\hline $21-40 \%$ & 21.2 & 10.6 & 62.1 & 6.1 & 0.0 & 66 \\
\hline $41-60 \%$ & 14.7 & 13.2 & 61.8 & 7.4 & 2.9 & 68 \\
\hline $61-80 \%$ & 23.2 & 4.8 & 60.8 & 8.0 & 3.2 & 125 \\
\hline $81-100 \%$ & 16.8 & 10.1 & 56.1 & 11.6 & 5.4 & 387 \\
\hline \hline
\end{tabular}

Table 73 presents how different workplace influences associated with exposure to the patrons were perceived by employees who spent different amounts of their workdays interacting with the patrons. As can be observed, the employees who spent more time 
interacting with patrons agreed more strongly to being dissuaded from gambling by observations of the patrons losing money and exhibiting negative gambling consequences. On the other hand, these same employees were not more likely to claim they were motivated to gamble by observing patrons winning and having fun, nor did these employees claim that they received comparably more useful gambling tips.

TABLE 73. The impacts of exposure to the patrons on employees who spent different percentages of their workdays interacting with the patrons

\begin{tabular}{|c|c|c|c|c|c|c|c|}
\hline $\begin{array}{l}\text { Percentage of } \\
\text { workday spent } \\
\text { interacting } \\
\text { with patrons }\end{array}$ & Mean* & SD & $\mathbf{n}$ & $\begin{array}{l}\text { Percentage of } \\
\text { workday spent } \\
\text { interacting } \\
\text { with patrons }\end{array}$ & Mean* & SD & $\mathbf{n}$ \\
\hline \multicolumn{4}{|c|}{$\begin{array}{l}\text { I see patrons losing money and do not want to do } \\
\text { the same }\end{array}$} & \multicolumn{4}{|c|}{$\begin{array}{l}\text { I receive gambling tips from patrons that I feel are } \\
\text { worth following }\end{array}$} \\
\hline $0-20 \%$ & $3.78^{\mathrm{a}}$ & 1.24 & 209 & $0-20 \%$ & 1.36 & 0.75 & 183 \\
\hline $21-40 \%$ & $3.80^{\mathrm{ab}}$ & 1.20 & 61 & $21-40 \%$ & 1.43 & 0.57 & 56 \\
\hline $41-60 \%$ & $4.13^{\mathrm{ab}}$ & 1.11 & 62 & $41-60 \%$ & 1.36 & 0.61 & 59 \\
\hline $61-80 \%$ & $4.26^{\mathrm{b}}$ & 0.85 & 121 & $61-80 \%$ & 1.45 & 0.91 & 116 \\
\hline $81-100 \%$ & $4.19^{\mathrm{ab}}$ & 0.99 & 391 & $81-100 \%$ & 1.38 & 0.70 & 371 \\
\hline \multicolumn{4}{|c|}{$\mathrm{F}=6.843, \mathrm{p}<0.001$} & \multicolumn{4}{|c|}{$\mathrm{F}=0.365, \mathrm{p}=0.834$} \\
\hline \multicolumn{4}{|c|}{$\begin{array}{l}\text { I see some negative consequences of gambling } \\
\text { among patrons and I do not want to be like them }\end{array}$} & \multicolumn{4}{|c|}{$\begin{array}{l}\text { I see how much fun patrons are having and I want } \\
\text { to participate too }\end{array}$} \\
\hline $0-20 \%$ & 3.69 & 1.17 & 224 & $0-20 \%$ & 2.07 & 1.02 & 228 \\
\hline $21-40 \%$ & 3.79 & 0.99 & 63 & $21-40 \%$ & 2.06 & 0.96 & 64 \\
\hline $41-60 \%$ & 4.12 & 0.98 & 65 & $41-60 \%$ & 2.11 & 1.09 & 64 \\
\hline $61-80 \%$ & 4.08 & 0.98 & 123 & $61-80 \%$ & 2.03 & 1.04 & 124 \\
\hline $81-100 \%$ & 4.10 & 1.03 & 389 & $81-100 \%$ & 2.07 & 1.08 & 384 \\
\hline \multicolumn{4}{|c|}{$\mathrm{F}=6.572, \mathrm{p}<0.001$} & \multicolumn{4}{|c|}{$\mathrm{F}=0.061, \mathrm{p}=0.993$} \\
\hline \multicolumn{4}{|c|}{$\begin{array}{l}\text { I have seen many patrons win so I think I have a } \\
\text { good chance of winning money }\end{array}$} & & & & \\
\hline $0-20 \%$ & 1.59 & 0.79 & 227 & & & & \\
\hline $21-40 \%$ & 1.73 & 0.81 & 63 & & & & \\
\hline $41-60 \%$ & 1.58 & 0.85 & 64 & & & & \\
\hline $61-80 \%$ & 1.52 & 0.82 & 123 & & & & \\
\hline $81-100 \%$ & 1.53 & 0.80 & 383 & & & & \\
\hline \multicolumn{4}{|c|}{$\mathrm{F}=0.979, \mathrm{p}=0.418$} & & & & \\
\hline
\end{tabular}

Note: Superscripts indicate groups that are significantly different based on Scheffé test $(\mathrm{p}<.05)$

Table 74 presents the average levels of belief in risk cognitions exhibited by employees who spent different percentages of their workdays interacting with patrons. A one-way ANOVA test failed to detect any significant differences between the groups 
$(\mathrm{F}=2.283, \mathrm{p}=0.059)$ and, as can be observed, the data reveal no clear patterns regarding how interacting with patrons may influence the endorsement of risk cognitions.

TABLE 74. Average level of belief in three risk cognitions by employees who spent different percentages of their workdays interacting with patrons

\begin{tabular}{|l|c|c|c|}
\hline $\begin{array}{l}\text { Percentage of workday } \\
\text { Spent interacting with } \\
\text { patrons }\end{array}$ & Mean* & SD & n \\
\hline $0-20 \%$ & 1.36 & 0.60 & 224 \\
\hline $21-40 \%$ & 1.55 & 0.71 & 58 \\
\hline $41-60 \%$ & 1.45 & 0.65 & 62 \\
\hline $61-80 \%$ & 1.45 & 0.70 & 113 \\
\hline $81-100 \%$ & 1.33 & 0.57 & 344 \\
\hline $\begin{array}{l}\text { *Mean score of three items with scale: 1=Strongly disagree, } \\
\text { 2=Disagree, 3=Neutral, 4=Agree, 5=Strongly agree }\end{array}$ \\
\hline \hline
\end{tabular}

\subsubsection{Shift}

A worker's shift is another important employment variable to consider, yet shifts also can be perceived as a workplace influence that may directly affect employees' gambling because working certain hours may mean few non-casino entertainment options are open when an employee is not at work (Hing \& Breen, 2007, 2008a, 2008b). As Table 75 shows, however, only about $15 \%$ of this study's survey respondents felt as though their shift schedules rendered casinos some of the only entertainment options available when the employees were not working. A one-way ANOVA test $(\mathrm{F}=17.161, \mathrm{p}<0.001)$ found significant differences between the shifts regarding this opinion, but these differences primarily resulted from the morning shift employees logically differing from their coworkers. A Scheffé post-hoc test confirmed the apparent differentiation between the morning shift workers and the other employees. 
TABLE 75. Agreement with the statement, "Due to my shifts, casinos are some of the only entertainment venues open when I am not at work"

\begin{tabular}{|c|c|c|c|c|c|c|c|c|}
\hline Shift & $\begin{array}{c}\text { Strongly } \\
\text { disagree } \\
(\%)\end{array}$ & $\begin{array}{c}\text { Disagree } \\
(\%)\end{array}$ & $\begin{array}{c}\text { Neutral } \\
(\%)\end{array}$ & Agree (\%) & $\begin{array}{c}\text { Strongly } \\
\text { agree }(\%)\end{array}$ & Mean* & SD & $\mathbf{n}$ \\
\hline Morning & 50.8 & 31.9 & 10.5 & 4.1 & 2.7 & $1.76^{\mathrm{a}}$ & 0.98 & 295 \\
\hline Afternoon & 24.5 & 34.8 & 16.3 & 19.0 & 5.4 & $2.46^{\mathrm{b}}$ & 1.21 & 184 \\
\hline Night-time & 33.3 & 25.2 & 23.6 & 9.8 & 8.1 & $2.34^{\mathrm{b}}$ & 1.26 & 123 \\
\hline Rotating & 39.2 & 23.6 & 17.5 & 13.7 & 6.1 & $2.24^{\mathrm{b}}$ & 1.27 & 212 \\
\hline All & 39.2 & 29.4 & 15.6 & 10.8 & 5.0 & 2.13 & 1.19 & 814 \\
\hline
\end{tabular}

Note: Superscripts indicate groups that are significantly different based on Scheffé test $(\mathrm{p}<.05)$

As Table 76 illustrates, moderate risk and problem gambling both were found to be most prevalent among the employees who primarily worked the night-time shift. A one-way ANOVA test found significant differences between the groups' mean PGSI scores $(\mathrm{F}=5.218, \mathrm{p}=0.001)$ and a Scheffé post-hoc test confirmed that the night-time workers reported mean PGSI scores significantly higher than workers of the other shifts. Nonetheless, as Table 77 demonstrates, no clear patterns existed regarding the changes in gambling that were experienced by employees working the different shifts. A chi square test confirmed that no significant differences existed between the groups $\left(X^{2}=5.968\right.$, $\mathrm{p}=0.918)$.

TABLE 76. PGSI results of employees who worked different shifts

\begin{tabular}{|c|c|c|c|c|c|c|c|}
\hline Shift & $\begin{array}{c}\text { Non- } \\
\text { problem } \\
(\%)\end{array}$ & $\begin{array}{c}\text { Low risk } \\
(\%)\end{array}$ & $\begin{array}{c}\text { Moderate } \\
\text { risk (\%) }\end{array}$ & $\begin{array}{c}\text { Problem } \\
\text { gambler } \\
(\%)\end{array}$ & $\begin{array}{c}\text { Mean } \\
\text { PGSI } \\
\text { score* }\end{array}$ & SD & $\mathbf{n}$ \\
\hline Morning & 74.2 & 15.8 & 7.6 & 2.4 & $0.81^{\mathrm{a}}$ & 2.13 & 330 \\
\hline Afternoon & 74.0 & 10.4 & 13.5 & 2.1 & $0.97^{\mathrm{a}}$ & 2.53 & 192 \\
\hline Night-time & 64.8 & 14.4 & 14.4 & 6.4 & $1.71^{\mathrm{b}}$ & 3.52 & 125 \\
\hline Rotating & 77.7 & 15.7 & 3.5 & 3.1 & $0.69^{\mathrm{a}}$ & 2.16 & 229 \\
\hline
\end{tabular}


TABLE 77. Changes in gambling experienced by employees who worked different shifts

\begin{tabular}{|l|c|c|c|c|c|c|}
\hline Shift & $\begin{array}{c}\text { Decreased } \\
\text { significantly } \\
(\boldsymbol{\%})\end{array}$ & $\begin{array}{c}\text { Decreased } \\
\text { a little (\%) }\end{array}$ & $\begin{array}{c}\text { Remained } \\
\text { the same } \\
(\mathbf{\%})\end{array}$ & $\begin{array}{c}\text { Increased a } \\
\text { little (\%) }\end{array}$ & $\begin{array}{c}\text { Increased } \\
\text { significantly } \\
(\boldsymbol{\%})\end{array}$ & n \\
\hline Morning & 16.1 & 10.4 & 61.5 & 8.7 & 3.3 & 335 \\
\hline Afternoon & 19.2 & 11.6 & 55.6 & 10.1 & 3.5 & 198 \\
\hline Night-time & 22.5 & 10.1 & 58.1 & 5.4 & 3.9 & 129 \\
\hline Rotating & 17.7 & 10.4 & 59.7 & 9.5 & 2.6 & 231 \\
\hline \hline
\end{tabular}

During the interviews, some participants opined that no relationship existed between employees' shifts and their gambling behaviours. As one interviewee stated:

No, I don't really think that it has an impact, like the different shifts, because I know people who work [night-time] and then they'll go to [another casino] for a few hours after working and that sort of thing. A lot of people go after their shift, it doesn't seem to matter which shift it is.

On the other hand, another interviewee claimed, "Depending on what shift you're on and depending on how long you're on it for, yeah, in order to have any kind of a life around kind of weird hours you need to go places that are open and a casino... would be one of those places."

Another interviewee remarked:

A lot of people would, yeah, definitely go gambling after [the night-time shift], but I think also you see a lot of [patrons] on the [night-time] shift that, I don't know, you almost feel sorry for them... It just seems to be that you see a lot of the really compulsive gamblers on the [night-time] shift. I'm not sure if that would affect the staff to not gamble, I don't know. I know, for me, it's kind of changed my perception of gambling.

This suggestion that night-time workers may be the most influenced by their exposure to the patrons was tested, and the results are shown in Table 78. As can be observed, the employees who worked later in the day did, in fact, tend to agree more strongly that they were dissuaded from gambling by their observations of patron behaviour. One-way ANOVA tests revealed notable differences existed between the groups, but they were not quite statistically significant (first item: $\mathrm{F}=2.431, \mathrm{p}=0.064$; second item: $\mathrm{F}=2.292$, $\mathrm{p}=0.077$ ). 
TABLE 78. Impacts of exposure to the patrons among employees who work different shifts

\begin{tabular}{|c|c|c|c|c|c|c|}
\hline \multirow[b]{2}{*}{ Shift } & \multicolumn{3}{|c|}{$\begin{array}{l}\text { I see patrons losing money and do not } \\
\text { want to do the same }\end{array}$} & \multicolumn{3}{|c|}{$\begin{array}{l}\text { I see some negative consequences of } \\
\text { gambling among patrons and I do no } \\
\text { want to be like them }\end{array}$} \\
\hline & Mean* & SD & $\mathbf{n}$ & Mean* & SD & $\mathrm{n}$ \\
\hline Morning & 3.96 & 1.12 & 297 & 3.88 & 1.12 & 313 \\
\hline Afternoon & 4.02 & 1.08 & 188 & 3.93 & 1.07 & 191 \\
\hline Night-time & 4.22 & 1.06 & 123 & 4.02 & 1.16 & 122 \\
\hline Rotating & 4.16 & 1.03 & 227 & 4.11 & 0.93 & 229 \\
\hline
\end{tabular}

As can be observed in Table 79, employees who worked the night-time shift were slightly more likely to believe in risk cognitions, although a one-way ANOVA test did not detect any significant differences between the different shifts $(\mathrm{F}=1.507, \mathrm{p}=0.211)$. Nevertheless, as can be seen in Table 80, employees who worked the night-time shift were much more likely to have been attracted to their jobs by prior gambling involvement, although a one-way ANOVA test again failed to detect significant differences between the groups $(\mathrm{F}=2.117, \mathrm{p}=0.097)$.

TABLE 79. Average level of belief in three risk cognitions by employees who worked different shifts

\begin{tabular}{|l|c|c|c|}
\hline Shift & Mean* & SD & n \\
\hline Morning & 1.38 & 0.59 & 297 \\
\hline Afternoon & 1.40 & 0.65 & 170 \\
\hline Night-time & 1.46 & 0.72 & 112 \\
\hline Rotating & 1.32 & 0.56 & 211 \\
\hline $\begin{array}{l}\text { *Mean score of three items with scale: 1=Strongly disagree, } \\
\text { 2=Disagree, 3=Neutral, 4=Agree, 5=Strongly agree }\end{array}$ \\
\hline \hline
\end{tabular}


TABLE 80. Levels of agreement that they were attracted to the employment because they were frequent gamblers among employees who worked different shifts

\begin{tabular}{|c|c|c|c|c|c|c|c|c|}
\hline Shift & $\begin{array}{c}\text { Strongly } \\
\text { disagree } \\
(\%)\end{array}$ & $\begin{array}{c}\text { Disagree } \\
(\%)\end{array}$ & $\begin{array}{c}\text { Neutral } \\
(\%)\end{array}$ & $\begin{array}{c}\text { Agree } \\
(\%)\end{array}$ & $\begin{array}{c}\text { Strongly } \\
\text { agree } \\
(\%)\end{array}$ & Mean* & SD & n \\
\hline Morning & 59.3 & 26.4 & 8.7 & 4.3 & 1.3 & 1.62 & 0.91 & 231 \\
\hline Afternoon & 55.8 & 23.1 & 15.0 & 5.4 & 0.7 & 1.72 & 0.96 & 147 \\
\hline Night-time & 54.3 & 21.7 & 12.0 & 4.3 & 7.6 & 1.89 & 1.24 & 92 \\
\hline Rotating & 60.7 & 24.7 & 7.9 & 6.2 & 0.6 & 1.61 & 0.92 & 178 \\
\hline
\end{tabular}

*Based on scale: 1=Strongly disagree, 2=Disagree, 3=Neutral, 4=Agree, $5=$ Strongly agree

\subsection{Demographic Characteristics}

As Table 81 shows, males participated in most forms of gambling more frequently than females, particularly when considering monthly participations rates. Nevertheless, it should be noted that a noticeably higher proportion of females participated in bingo and a fairly equal proportion of males and females played EGMs and lottery-style games. This pattern is fairly consistent with the findings of Wiebe et al. (2006), who also found that men participated in most forms of gambling more frequently than women, yet participation rates were fairly similar for EGMs and the lottery, and nearly twice as many women as men played bingo. Similarly, Duquette (1999) found that men were more likely to play casino table games, men and women played EGMs at fairly equal rates, and women were more likely to play bingo. 
TABLE 81. Previous year participation in different forms of gambling by males and females

\begin{tabular}{|c|c|c|c|c|c|}
\hline & Sex & Never $(\%)$ & $\begin{array}{c}\text { 1-11 times per } \\
\text { year }(\%)\end{array}$ & $\begin{array}{c}\text { At least once } \\
\text { per month }(\%)\end{array}$ & $\mathbf{n}$ \\
\hline \multicolumn{6}{|l|}{ Location / Companions } \\
\hline \multirow{2}{*}{ In any Casino } & Female & 43.9 & 51.2 & 4.9 & 590 \\
\hline & Male & 46.0 & 44.8 & 9.2 & 326 \\
\hline \multirow{2}{*}{$\begin{array}{l}\text { With friends or family } \\
\text { outside of a casino }\end{array}$} & Female & 73.9 & 20.5 & 5.6 & 586 \\
\hline & Male & 53.7 & 31.6 & 14.7 & 326 \\
\hline \multirow{2}{*}{ With co-workers } & Female & 73.6 & 21.0 & 5.5 & 587 \\
\hline & Male & 70.2 & 19.0 & 10.7 & 326 \\
\hline \multirow{2}{*}{ Online } & Female & 93.6 & 3.6 & 2.7 & 582 \\
\hline & Male & 80.0 & 10.8 & 9.2 & 325 \\
\hline \multicolumn{6}{|l|}{ Game } \\
\hline \multirow{2}{*}{ Lottery-style games } & Female & 6.6 & 43.7 & 49.7 & 595 \\
\hline & Male & 9.8 & 32.8 & 57.4 & 326 \\
\hline \multirow{2}{*}{ EGMs } & Female & 63.9 & 32.3 & 3.9 & 592 \\
\hline & Male & 67.9 & 27.2 & 4.9 & 327 \\
\hline \multirow{2}{*}{ Personal investments } & Female & 74.7 & 16.9 & 8.4 & 585 \\
\hline & Male & 69.0 & 18.4 & 12.6 & 326 \\
\hline \multirow{2}{*}{$\begin{array}{l}\text { Card or board games } \\
\text { outside of a casino }\end{array}$} & Female & 84.8 & 11.5 & 3.7 & 591 \\
\hline & Male & 71.2 & 20.2 & 8.6 & 326 \\
\hline \multirow{2}{*}{ Bingo } & Female & 78.5 & 15.2 & 6.3 & 585 \\
\hline & Male & 90.2 & 7.7 & 2.2 & 325 \\
\hline \multirow{2}{*}{ Horse races } & Female & 84.3 & 15.4 & 0.3 & 591 \\
\hline & Male & 81.3 & 16.0 & 2.8 & 326 \\
\hline \multirow{2}{*}{ Casino blackjack } & Female & 90.0 & 9.7 & 0.3 & 590 \\
\hline & Male & 82.0 & 15.6 & 2.4 & 327 \\
\hline \multirow{2}{*}{ Sports betting } & Female & 94.2 & 3.7 & 2.0 & 589 \\
\hline & Male & 75.2 & 13.1 & 11.6 & 327 \\
\hline \multirow{2}{*}{ Casino roulette } & Female & 92.2 & 7.5 & 0.3 & 590 \\
\hline & Male & 82.6 & 15.3 & 2.1 & 327 \\
\hline \multirow{2}{*}{ Skill games } & Female & 95.4 & 3.7 & 0.8 & 591 \\
\hline & Male & 83.4 & 12.9 & 3.7 & 326 \\
\hline \multirow{2}{*}{ Casino poker } & Female & 94.9 & 4.7 & 0.3 & 590 \\
\hline & Male & 85.7 & 11.6 & 2.7 & 328 \\
\hline \multirow{2}{*}{ Casino craps } & Female & 98.3 & 1.7 & 0.0 & 590 \\
\hline & Male & 92.4 & 6.4 & 1.2 & 327 \\
\hline \multirow{2}{*}{ Arcade games } & Female & 98.3 & 1.4 & 0.3 & 589 \\
\hline & Male & 93.8 & 5.6 & 0.6 & 322 \\
\hline \multirow{2}{*}{ Tile games } & Female & 98.3 & 1.5 & 0.2 & 591 \\
\hline & Male & 95.4 & 3.4 & 1.2 & 327 \\
\hline
\end{tabular}

Table 82 shows that the PGSI results of some demographic groups demonstrated significant patterns, while others did not. For example, male employees exhibited more 
low risk, moderate risk, and problem gambling than their female co-workers, and a t-test found the differences between the groups' mean PGSI scores to be nearly statistically significant $(\mathrm{t}=1.925, \mathrm{p}=0.055)$. This pattern is consistent with findings made both in past studies on casino employees (e.g., Duquette, 1999; Lee et al., 2008) and the general Ontario population (i.e., Wiebe et al., 2006; Williams \& Wood, 2004a). Low risk, moderate risk, and problem gambling additionally were found to be more prevalent among employees who did not identify their ethnicities as Canadian, and t-test confirmed that significant differences existed between these groups $(t=2.353, p=0.020)$. Once again, this finding is fairly similar to findings made by Williams and Wood, who considered ethnic groups different from this study's, yet also found that some minority groups were disproportionately represented among problem gamblers. This study also revealed somewhat of a negative relationship between education level and PG rates, as low risk, moderate risk, and problem gambling were lowest among those employees who had completed post-secondary school. A one-way ANOVA test found significant differences between the groups' mean PGSI scores $(F=3.174, \mathrm{p}=0.042)$, although a Scheffé post-hoc test failed to differentiate between any of the groups.

On the other hand, this study did not find any obvious patterns associated with PG rates and either age group or marital status. Employees who were single and never married exhibited the highest rates of PG, but moderate risk gambling was far lower among this group than among employees who were separated, divorced, or widowed. A one-way ANOVA test also failed to find any significant differences between the groups' mean PGSI scores $(\mathrm{F}=0.792, \mathrm{p}=0.453)$. Therefore, this finding was only somewhat consistent with Wiebe et al.'s (2006) finding that respondents who were single and never married exhibited the highest rates of both moderate risk and problem gambling. A oneway ANOVA test also found significant differences between the mean PGSI scores exhibited by different age groups $(\mathrm{F}=3.880, \mathrm{p}=0.009)$, but the data revealed no clear, linear patterns associated with the PGSI results. Additionally, this study found that the youngest age group (30 years old and younger) exhibited relatively low levels of moderate risk and problem gambling, while Wiebe et al. found that the youngest age group they considered (18 to 24 year olds) exhibited the highest levels of moderate risk and problem gambling. 
TABLE 82. PGSI results of employees in different demographic groups

\begin{tabular}{|c|c|c|c|c|c|c|c|}
\hline $\begin{array}{l}\text { Variable } \\
\text { Characteristic }\end{array}$ & $\begin{array}{c}\text { Non- } \\
\text { problem } \\
(\%)\end{array}$ & $\begin{array}{c}\text { Low risk } \\
(\%)\end{array}$ & $\begin{array}{c}\text { Moderate } \\
\text { risk (\%) }\end{array}$ & $\begin{array}{c}\text { Problem } \\
\text { gambler } \\
(\%)\end{array}$ & $\begin{array}{l}\text { Mean } \\
\text { PGSI } \\
\text { score* }\end{array}$ & SD & $\mathbf{n}$ \\
\hline \multicolumn{8}{|l|}{ Sex } \\
\hline Female & 76.9 & 12.5 & 8.1 & 2.5 & 0.82 & 2.35 & 568 \\
\hline Male & 67.9 & 17.5 & 10.5 & 4.1 & 1.16 & 2.64 & 315 \\
\hline \multicolumn{8}{|l|}{ Age group } \\
\hline$\leq 30$ years & 75.1 & 16.2 & 5.4 & 3.2 & 0.88 & 2.41 & 185 \\
\hline $31-40$ years & 69.7 & 14.4 & 10.9 & 4.9 & 1.30 & 3.21 & 284 \\
\hline $41-50$ years & 77.8 & 14.2 & 7.1 & 0.8 & 0.56 & 1.47 & 239 \\
\hline$\geq 51$ years & 72.6 & 12.3 & 11.7 & 3.4 & 0.99 & 2.32 & 179 \\
\hline \multicolumn{8}{|l|}{ Marital status } \\
\hline Single and never married & 69.0 & 18.2 & 8.0 & 4.8 & 1.10 & 2.67 & 187 \\
\hline Married or living with partner & 76.2 & 13.0 & 8.0 & 2.8 & 0.87 & 2.50 & 575 \\
\hline Separated, divorced, or widowed & 69.1 & 13.8 & 14.6 & 2.4 & 1.09 & 2.27 & 123 \\
\hline \multicolumn{8}{|l|}{ Ethnic group } \\
\hline Canadian & 74.9 & 14.1 & 8.2 & 2.7 & 0.87 & 2.42 & 778 \\
\hline Non-Canadian & 61.4 & 16.8 & 14.9 & 6.9 & 1.62 & 3.08 & 101 \\
\hline \multicolumn{8}{|l|}{ Highest level of education } \\
\hline Completed high school & 70.9 & 13.9 & 11.5 & 3.7 & 1.15 & 2.93 & 244 \\
\hline Some post-secondary school & 70.3 & 16.5 & 8.9 & 4.2 & 1.14 & 2.92 & 236 \\
\hline Completed post-secondary school & 77.0 & 13.3 & 7.4 & 2.2 & 0.72 & 1.87 & 405 \\
\hline
\end{tabular}

When asked in the interviews how gambling may relate to demographic characteristics, the interviewees tended to focus on sex and age. When discussing sex, the interviewees all claimed either that men gambled more or that men and women gambled at equal rates. For instance, when asked which sex gambled more, one interviewee stated, "My initial perception was male, but that's not the case. I think it's probably a 50-50 there," while another interviewee claimed, "I would say men gamble more in general." With regards to age, the interviewees' opinions were much more varied. For instance, when identifying the age groups that gambled most, one interviewee described, "I would say probably, about, the people from 20 to 35 , they like to gamble more," and another interviewee agreed, "Probably in their late 20s, early 30 s that play...I think it's just the age, you know, where they're looking for excitement." On the other hand, a different interviewee claimed, "It's not so much the, you know, 20-year-olds that work here. I 
would say it's 30 and up that play." Another interviewee agreed with this perception and explained, "I think the younger [employees] don't have that money to throw away." Even though some demographic characteristics revealed clear relationships with the PGSI results, no similarly clear patterns existed with regards to the changes in gambling experienced by employees with different demographic characteristics, as can be observed in Table 83. For instance, males were far more likely than females to have increased their gambling significantly, but males were actually slightly less likely to have increased their gambling a little and slightly more likely to have decreased their gambling either a little or significantly. With regards to age, the most noteworthy pattern seems to be that employees over 50 years of age were the least likely to have increased their gambling either a little or significantly and the most likely to have decreased their gambling either a little or significantly. With regards to marital status, the employees who were single and never married were more than twice as likely as their co-workers to have increased their gambling significantly, but these employees were also the least likely to have increased their gambling a little. Similarly, employees who did not identify their ethnicity as Canadian were several times more likely than their co-workers to have increased their gambling significantly, but less likely to have increased their gambling a little. With regards to education level, the employees who had completed some postsecondary school were the most likely to have increased their gambling significantly, but they were much like the other groups in their likelihood to have increased their gambling a little. 
TABLE 83. Changes in gambling experienced by employees in different demographic groups

\begin{tabular}{|c|c|c|c|c|c|c|}
\hline $\begin{array}{l}\text { Variable } \\
\text { Characteristic }\end{array}$ & $\begin{array}{c}\text { Decreased } \\
\text { significantly } \\
(\%)\end{array}$ & $\begin{array}{c}\text { Decreased a } \\
\text { little }(\%)\end{array}$ & $\begin{array}{c}\text { Remained } \\
\text { the same } \\
(\%)\end{array}$ & $\begin{array}{c}\text { Increased a } \\
\text { little }(\%)\end{array}$ & $\begin{array}{c}\text { Increased } \\
\text { significantly } \\
(\%)\end{array}$ & $\mathbf{n}$ \\
\hline \multicolumn{7}{|l|}{ Sex } \\
\hline Female & 16.9 & 9.8 & 62.4 & 9.1 & 1.7 & 580 \\
\hline Male & 19.6 & 11.4 & 54.6 & 8.5 & 6.0 & 317 \\
\hline \multicolumn{7}{|l|}{ Age group } \\
\hline$\leq 30$ years & 13.4 & 10.2 & 63.1 & 9.1 & 4.3 & 187 \\
\hline $31-40$ years & 16.4 & 8.9 & 58.9 & 10.3 & 5.5 & 292 \\
\hline $41-50$ years & 19.2 & 10.7 & 59.8 & 8.1 & 2.1 & 234 \\
\hline$\geq 51$ years & 22.9 & 12.2 & 56.9 & 7.4 & 0.5 & 188 \\
\hline \multicolumn{7}{|l|}{ Marital status } \\
\hline Single and never married & 15.1 & 9.9 & 59.9 & 8.3 & 6.8 & 192 \\
\hline Married or living with partner & 18.0 & 11.4 & 58.9 & 9.2 & 2.4 & 577 \\
\hline $\begin{array}{l}\text { Separated, divorced, or } \\
\text { widowed }\end{array}$ & 21.5 & 6.2 & 61.5 & 8.5 & 2.3 & 130 \\
\hline \multicolumn{7}{|l|}{ Ethnic group } \\
\hline Canadian & 17.5 & 10.2 & 60.5 & 9.2 & 2.7 & 785 \\
\hline Non-Canadian & 21.3 & 11.1 & 52.8 & 6.5 & 8.3 & 108 \\
\hline \multicolumn{7}{|l|}{ Highest level of education } \\
\hline Completed high school & 19.8 & 10.5 & 60.3 & 7.3 & 2.0 & 247 \\
\hline Some post-secondary school & 16.5 & 9.5 & 59.5 & 9.5 & 5.0 & 242 \\
\hline $\begin{array}{l}\text { Completed post-secondary } \\
\text { school }\end{array}$ & 17.3 & 10.7 & 59.3 & 9.5 & 3.2 & 410 \\
\hline
\end{tabular}

As can be observed in Table 84, several demographic groups expressed significantly more belief in risk cognitions than other groups. More specifically, males, older employees, those employees who did not identify their ethnicity as Canadian, and employees who were not educated beyond high school were all more likely to believe in risk cognitions. On the other hand, marital status did not exhibit any statistically significant relationship with endorsement of risk cognitions, although the employees who were separated, divorced, or widowed exhibited the highest levels of belief. 
TABLE 84. Average level of belief in three risk cognitions by employees in different demographic groups

\begin{tabular}{|c|c|c|c|c|c|}
\hline $\begin{array}{l}\text { Variable } \\
\text { Characteristic }\end{array}$ & Mean* & SD & $\mathbf{F} / \mathbf{t}$ & $\mathbf{p}$ & $\mathbf{n}$ \\
\hline \multicolumn{6}{|l|}{ Sex } \\
\hline Female & 1.31 & 0.490 & \multirow{2}{*}{3.862} & \multirow{2}{*}{$<0.001$} & 506 \\
\hline Male & 1.50 & 0.771 & & & 292 \\
\hline \multicolumn{6}{|l|}{ Age group } \\
\hline$\leq 30$ years & $1.31^{\mathrm{a}}$ & 0.594 & \multirow{4}{*}{3.326} & \multirow{4}{*}{0.019} & 172 \\
\hline $31-40$ years & $1.34^{\mathrm{ab}}$ & 0.539 & & & 270 \\
\hline $41-50$ years & $1.40^{\mathrm{ab}}$ & 0.600 & & & 205 \\
\hline$\geq 51$ years & $1.50^{\mathrm{b}}$ & 0.750 & & & 155 \\
\hline \multicolumn{6}{|l|}{ Marital status } \\
\hline Single and never married & 1.37 & 0.655 & \multirow{3}{*}{1.953} & \multirow{3}{*}{0.143} & 175 \\
\hline Married or living with partner & 1.36 & 0.559 & & & 519 \\
\hline Separated, divorced, or widowed & 1.49 & 0.781 & & & 106 \\
\hline \multicolumn{6}{|l|}{ Ethnic group } \\
\hline Canadian & 1.35 & 0.559 & \multirow{2}{*}{2.872} & \multirow{2}{*}{0.005} & 692 \\
\hline Non-Canadian & 1.60 & 0.877 & & & 104 \\
\hline \multicolumn{6}{|l|}{ Highest level of education } \\
\hline Completed high school & $1.46^{\mathrm{b}}$ & 0.682 & \multirow{3}{*}{3.314} & \multirow{3}{*}{0.037} & 225 \\
\hline Some post-secondary school & $1.32^{\mathrm{a}}$ & 0.520 & & & 212 \\
\hline Completed post-secondary school & $1.36^{\mathrm{ab}}$ & 0.618 & & & 363 \\
\hline
\end{tabular}

Note: Superscripts indicate groups that are significantly different based on Scheffé test $(\mathrm{p}<.05)$

Several demographic characteristics also were found to relate to whether or not employees had sought their employment at least in part due to prior gambling involvement. As can be seen in Table 85, males and employees who did not identify their ethnicity as Canadian were both more likely to have agreed that they were drawn to their jobs by prior gambling involvement, and these distinctions were confirmed with a pair of $\mathrm{t}$-tests (sex: $\mathrm{t}=2.982, \mathrm{p}=0.003$; ethnic group: $\mathrm{t}=2.608, \mathrm{p}=0.011$ ). Also, a one-way ANOVA test found that education level was negatively related to the likelihood that employees were attracted to their jobs by prior gambling involvement $(F=9.020, p<0.001)$. On the other hand, one-way ANOVA tests failed to detect any statistically significant differences with regards to age $(\mathrm{F}=2.428, \mathrm{p}=0.064)$ or martial status $(\mathrm{F}=1.300, \mathrm{p}=0.273)$. 
TABLE 85. Levels of agreement that they were attracted to the employment because they were frequent gamblers among employees in different demographic groups

\begin{tabular}{|c|c|c|c|c|c|c|c|c|}
\hline $\begin{array}{l}\text { Variable } \\
\text { Characteristic }\end{array}$ & $\begin{array}{c}\text { Strongly } \\
\text { disagree } \\
(\%)\end{array}$ & $\begin{array}{c}\text { Disagree } \\
(\%)\end{array}$ & $\begin{array}{c}\text { Neutral } \\
(\%)\end{array}$ & $\begin{array}{c}\text { Agree } \\
(\%)\end{array}$ & $\begin{array}{c}\text { Strongly } \\
\text { agree } \\
(\%)\end{array}$ & Mean* & SD & $\mathbf{n}$ \\
\hline \multicolumn{9}{|l|}{ Sex } \\
\hline Female & 61.1 & 25.9 & 8.0 & 3.3 & 1.8 & 1.59 & 0.901 & 398 \\
\hline Male & 53.1 & 22.7 & 14.5 & 7.8 & 2.0 & 1.83 & 1.067 & 256 \\
\hline \multicolumn{9}{|l|}{ Age group } \\
\hline$\leq 30$ years & 63.2 & 25.0 & 9.0 & 1.4 & 1.4 & 1.53 & 0.827 & 144 \\
\hline $31-40$ years & 58.8 & 20.2 & 12.3 & 6.6 & 2.1 & 1.73 & 1.045 & 243 \\
\hline $41-50$ years & 55.2 & 31.3 & 8.0 & 4.9 & 0.6 & 1.64 & 0.873 & 163 \\
\hline$\geq 51$ years & 53.3 & 23.4 & 13.1 & 6.5 & 3.7 & 1.84 & 1.117 & 107 \\
\hline \multicolumn{9}{|l|}{ Marital status } \\
\hline Single and never married & 59.6 & 21.2 & 9.6 & 6.8 & 2.7 & 1.72 & 1.068 & 146 \\
\hline Married or living with partner & 58.7 & 24.9 & 11.0 & 4.0 & 1.4 & 1.64 & 0.925 & 429 \\
\hline $\begin{array}{l}\text { Separated, divorced, or } \\
\text { widowed }\end{array}$ & 51.3 & 27.5 & 11.3 & 7.5 & 2.5 & 1.83 & 1.065 & 80 \\
\hline \multicolumn{9}{|l|}{ Ethnic group } \\
\hline Canadian & 59.5 & 24.9 & 9.8 & 4.1 & 1.7 & 1.64 & 0.939 & 582 \\
\hline Non-Canadian & 46.4 & 21.7 & 18.8 & 10.1 & 2.9 & 2.01 & 1.157 & 69 \\
\hline \multicolumn{9}{|l|}{ Highest level of education } \\
\hline Completed high school & 44.3 & 31.7 & 13.8 & 7.8 & 2.4 & $1.92^{\mathrm{b}}$ & 1.053 & 167 \\
\hline Some post-secondary school & 56.7 & 23.0 & 14.4 & 4.3 & 1.6 & $1.71^{\mathrm{ab}}$ & 0.974 & 187 \\
\hline $\begin{array}{l}\text { Completed post-secondary } \\
\text { school }\end{array}$ & 66.6 & 21.2 & 6.6 & 4.0 & 1.7 & $1.53^{\mathrm{a}}$ & 0.906 & 302 \\
\hline
\end{tabular}

Note: Superscripts indicate groups that are significantly different based on Scheffé test $(\mathrm{p}<.05)$

\subsection{Explanations for Problem Gambling Prevalence among Casino Employees}

To better understand the apparent prevalence of PG among Ontario casino employees, the three logical explanations for such prevalence were analyzed. Firstly, it seems plausible that the problem gamblers were more likely to have been somehow induced to gamble by aspects of their employment, as can be observed in Table 86. In fact, 59.3\% of the problem gamblers claimed to have increased their gambling, and the majority of these individuals claimed the increase had been significant. A chi square test could not be performed due to low expected values in several cells, but the basic pattern is evident. Secondly, it also seems plausible that problem gamblers were more likely to have been attracted to their jobs by prior gambling involvement, as can be observed in Table 87. In 
fact, $44.0 \%$ of the problem gamblers agreed with this motive. Also, a one-way ANOVA test found significant differences between the groups' mean levels of agreement $(\mathrm{F}=46.577, \mathrm{p}<0.001)$ and a Scheffé post-hoc test confirmed that significant differences existed between the employees in some of the different PGSI categories. Thirdly, however, it does not seem plausible that problem gamblers remain working in the industry for longer periods of time, as can be observed in Table 88. In fact, the average amount of time spent in the industry by the employees placed in the different PGSI categories was quite similar, and a one-way ANOVA test confirmed the lack of any significant differences $(\mathrm{F}=1.647, \mathrm{p}=0.177)$.

TABLE 86. Changes in gambling experienced by employees in different PGSI categories

\begin{tabular}{|l|c|c|c|c|c|c|}
\hline & $\begin{array}{c}\text { Decreased } \\
\text { significantly } \\
(\boldsymbol{\%})\end{array}$ & $\begin{array}{c}\text { Decreased a } \\
\text { little (\%) }\end{array}$ & $\begin{array}{c}\text { Remained } \\
\text { the same } \\
(\boldsymbol{\%})\end{array}$ & $\begin{array}{c}\text { Increased a } \\
\text { little (\%) }\end{array}$ & $\begin{array}{c}\text { Increased } \\
\text { significantly } \\
(\boldsymbol{\%})\end{array}$ & n \\
\hline Non-problem & 18.1 & 8.9 & 66.7 & 6.0 & 0.3 & 630 \\
\hline Low risk & 16.7 & 17.5 & 49.2 & 12.7 & 4.0 & 126 \\
\hline Moderate risk & 16.7 & 10.3 & 35.9 & 21.8 & 15.4 & 78 \\
\hline Problem gambler & 11.1 & 11.1 & 18.5 & 18.5 & 40.7 & 27 \\
\hline \hline
\end{tabular}

TABLE 87. Levels of agreement that they were attracted to the employment because they were frequent gamblers among employees in different PGSI categories

\begin{tabular}{|c|c|c|c|c|c|c|c|c|}
\hline PGSI category & $\begin{array}{c}\text { Strongly } \\
\text { disagree } \\
(\%)\end{array}$ & $\begin{array}{c}\text { Disagree } \\
(\%)\end{array}$ & $\begin{array}{c}\text { Neutral } \\
(\%)\end{array}$ & $\begin{array}{c}\text { Agree } \\
(\%) \\
\end{array}$ & $\begin{array}{c}\text { Strongly } \\
\text { agree } \\
(\%)\end{array}$ & Mean* & SD & $\mathbf{n}$ \\
\hline Non-problem & 67.6 & 23.2 & 6.9 & 1.8 & 0.4 & $1.44^{\mathrm{a}}$ & 0.74 & 448 \\
\hline Low risk & 37.4 & 37.4 & 15.2 & 8.1 & 2.0 & $2.00^{\mathrm{b}}$ & 1.02 & 99 \\
\hline Moderate risk & 34.9 & 25.4 & 20.6 & 12.7 & 6.3 & $2.30^{\mathrm{b}}$ & 1.25 & 63 \\
\hline Problem gambler & 24.0 & 4.0 & 28.0 & 28.0 & 16.0 & $3.08^{\mathrm{c}}$ & 1.41 & 25 \\
\hline
\end{tabular}

*Based on scale: $1=$ Strongly disagree, $2=$ Disagree, $3=$ Neutral, 4=Agree, $5=$ Strongly agree

Note: Superscripts indicate groups that are significantly different based on Scheffé test $(\mathrm{p}<.05)$ 
TABLE 88. Amount of time spent working in the gambling industry by employees placed in different PGSI categories

\begin{tabular}{|l|c|c|c|}
\hline PGSI category & $\begin{array}{c}\text { Mean months } \\
\text { in industry }\end{array}$ & SD & n \\
\hline Non-problem & 84.8 & 50.10 & 652 \\
\hline Low risk & 89.2 & 49.88 & 127 \\
\hline Moderate risk & 97.2 & 43.65 & 79 \\
\hline Problem gambler & 89.3 & 52.90 & 27 \\
\hline \hline
\end{tabular}

\subsection{Identifying Patron Problem Gamblers}

As can be seen in Table 89, the survey respondents in all of the PGSI categories clearly agreed that they felt confident in their responsibilities in responding to PG among patrons and knowledgeable about OLG's RG policies and procedures. With regards to the first item, the moderate risk gamblers exhibited particularly low confidence in their abilities to respond to patron PG, but the problem gamblers actually exhibited the highest levels of confidence. Also, a one-way ANOVA test failed to detect significant differences between the groups $(\mathrm{F}=2.105, \mathrm{p}=0.098)$. With regards to the second item, the moderate risk and problem gamblers expressed the least agreement that they understood OLG's RG policies and procedures, but the differences were quite small and a one-way ANOVA failed to detect any significant differences between the groups $(\mathrm{F}=1.358, \mathrm{p}=0.254)$.

TABLE 89. Confidence in responding to patron problem gamblers and knowledge of

OLG's RG policies and procedures among employees in different PGSI categories

\begin{tabular}{|c|c|c|c|c|c|c|}
\hline \multirow[b]{2}{*}{ PGSI group } & \multicolumn{3}{|c|}{$\begin{array}{l}\text { I feel confident that I can carry out } \\
\text { my role in responding to customers } \\
\text { who are showing signs of being in } \\
\text { trouble or who are in crisis }\end{array}$} & \multicolumn{3}{|c|}{$\begin{array}{l}\text { I feel that I have a good } \\
\text { understanding of OLG's } \\
\text { responsible gaming policies and } \\
\text { procedures }\end{array}$} \\
\hline & Mean* & SD & $\mathbf{n}$ & Mean* & SD & $\mathbf{n}$ \\
\hline Non-problem & 4.03 & 0.884 & 606 & 4.29 & 0.699 & 642 \\
\hline Low risk & 3.95 & 0.785 & 124 & 4.22 & 0.668 & 126 \\
\hline Moderate risk & 3.78 & 0.907 & 78 & 4.15 & 0.642 & 79 \\
\hline Problem gambler & 4.07 & 1.072 & 27 & 4.18 & 0.983 & 28 \\
\hline All & 4.00 & 0.880 & 835 & 4.27 & 0.701 & 875 \\
\hline
\end{tabular}


Table 90 shows the frequency with which employees placed in the different PGSI categories believed they saw patrons who the employees considered to have a gambling problem. As can be observed, the PG employees were the most likely to claim they observed patron PG on a daily basis, and a chi square test confirmed that significant differences existed between the groups $\left(\mathrm{X}^{2}=22.084, \mathrm{p}=0.037\right)$. However, because Table Games employees exhibited particularly high PG rates and also worked in positions where they were particularly likely to encounter patron PG, the same analysis was repeated with the Table Games employees excluded. The results from this analysis are presented in Table 91 and, as can be observed, the previously evident pattern no longer exists quite as strongly. Moreover, a chi square test failed to detect any significant differences between the groups $\left(\mathrm{X}^{2}=14.395, \mathrm{p}=0.276\right)$. Consequently, the survey data do not clearly indicate that PG employees were more likely to identify patron PG, yet the data also certainly do not indicate that PG employees were less likely to identify patron PG.

TABLE 90. Frequency with which employees in different PGSI categories saw patrons believed to have a gambling problem in the previous 12 months

\begin{tabular}{|l|c|c|c|c|c|c|}
\hline & Never (\%) & $\begin{array}{c}\mathbf{1 - 1 1} \text { times } \\
\text { per year } \\
(\boldsymbol{\%})\end{array}$ & $\begin{array}{c}\mathbf{1 - 3} \text { times } \\
\text { per month } \\
(\boldsymbol{\%})\end{array}$ & $\begin{array}{c}\mathbf{1 - 6} \text { times } \\
\text { per week } \\
(\boldsymbol{\%})\end{array}$ & Daily (\%) & n \\
\hline Non-problem & 16.8 & 11.7 & 9.9 & 20.7 & 40.8 & 647 \\
\hline Low risk & 11.9 & 13.5 & 16.7 & 24.6 & 33.3 & 126 \\
\hline Moderate risk & 5.1 & 7.7 & 12.8 & 28.2 & 46.2 & 78 \\
\hline Problem gambler & 10.7 & 7.1 & 3.6 & 21.4 & 57.1 & 28 \\
\hline \hline
\end{tabular}

TABLE 91. Frequency with which non-Table Games employees in different PGSI categories saw patrons believed to have a gambling problem in the previous 12 months

\begin{tabular}{|l|c|c|c|c|c|c|}
\hline & Pever (\%) & $\begin{array}{c}\mathbf{1 - 1 1} \text { times } \\
\text { per year } \\
(\boldsymbol{\%})\end{array}$ & $\begin{array}{c}\mathbf{1 - 3} \text { times } \\
\text { per month } \\
(\boldsymbol{\%})\end{array}$ & $\begin{array}{c}\mathbf{1 - 6} \text { times } \\
\text { per week } \\
(\boldsymbol{\%})\end{array}$ & Daily (\%) & n \\
\hline Non-problem & 18.3 & 11.8 & 9.9 & 20.3 & 39.7 & 585 \\
\hline Low risk & 13.6 & 15.5 & 14.5 & 23.6 & 32.7 & 110 \\
\hline Moderate risk & 6.6 & 8.2 & 14.8 & 27.9 & 42.6 & 61 \\
\hline Problem gambler & 17.6 & 5.9 & 5.9 & 29.4 & 41.2 & 17 \\
\hline \hline
\end{tabular}


Nevertheless, some of the interviewees claimed that employees who had experienced gambling problems or at least engaged in gambling may be better able to identify PG behaviours among the patrons. As one of these interviewees explained:

It depends also on what kind of hardship the employee has had [from gambling]. Have they lost a lot of money and are they having financial and family issues because of it? They might be more inclined to say something...or say, 'Hey, I know where you're coming from,' you know, 'I was there' type of thing. Another interviewee similarly stated:

If you've never gambled before you think it's ridiculous. Like, in the beginning when I first started [working here]...you feel sorry for these people. You're like, 'What are you doing and why are you doing it?' because I was not a gambler at that time... and I don't even consider myself a 'gambler' but I would go once or twice a year. But after experiencing going and doing that, it's like, 'Oh, I can see, you know, why. I get it.'...You can see how it could get out of control and how you're chasing yourself. 


\section{Chapter 5}

\section{Discussion}

\subsection{Survey Methodology}

The lack of any relationship between employees' PGSI scores and whether they returned their surveys using the collection boxes or the mail indicates that it was not necessary to provide the latter option for heavy gamblers who, it was predicted, may have preferred the greater anonymity offered by the mail. In fact, only a small percentage of the respondents chose to return their surveys via the mail, rather than simply placing them in one of the collection boxes. The mail option was utilized comparatively more by employees over the age of 31 , and it is likely that some of the respondents who used the mail would not have returned their surveys if that opportunity had not been offered, meaning the mail option may have had some value. Nevertheless, given the extra costs associated with using prepaid envelopes, this study's findings suggest that it would be reasonable to forgo this option in similar future research.

The fact that only about $80 \%$ of the employees who returned completed surveys also returned contact information sheets to enter the prize draws suggests that relatively few employees entered the prize draws by disingenuously claiming to have completed a survey. This issue was a concern because no measure existed to prevent such dishonesty, but the results indicate that it is practicable to implement an honour system in order to offer incentives while providing full anonymity.

\subsection{Gambling and Problem Gambling Among Ontario Casino Employees}

This study determined that low risk gambling, moderate risk gambling, and PG are all more prevalent among Ontario's casino employees than they are among Ontario's general population. This finding is consistent with some past research that has been conducted in other jurisdictions (e.g., Dangerfield, 2004; Shaffer et al., 1999). Therefore, this study offers additional support to the notion that casino employees exhibit particularly high rates of PG. Nevertheless, the PG rates detected in this study were lower than those detected in most other casino employee studies (e.g., Dangerfield; Duquette, 1999; Wu \& Wong, 2008), which suggests that casino employee PG rates are lower in Ontario than in 
other jurisdictions, and/or that PG rates among casino employees have declined in numerous jurisdictions since some of the other studies were completed.

The vast majority of Ontario casino employees appear to engage in at least some form of gambling on a monthly basis, although approximately half of the employees seem to spend no more than \$25 gambling each month. Moreover, employee gambling participation is now likely lower than was indicated in the survey results due to the new lottery ban affecting OLG employees. About $10 \%$ of the employees claimed to spend over $\$ 100$ gambling each month and this level of expenditure was closely related to moderate risk and problem gambling. In fact, of these individuals, $28.2 \%$ were classified as problem gamblers and $35.3 \%$ were classified as moderate risk gamblers. On the other hand, of the individuals who claimed to spend $\$ 100$ or less gambling each month, only $0.5 \%$ were classified as problem gamblers and $5.6 \%$ were classified as moderate risk gamblers. Consequently, gambling expenditure can serve as a fairly indicative risky behaviour that casinos can highlight when teaching employees about RG. Even though numerous studies have demonstrated that gamblers' retrospective estimates of gambling expenditure are quite unreliable (e.g., Blaszczynski et al., 1997, 2006; Williams \& Wood, 2004a), this lack of reliability is actually irrelevant for the purpose of highlighting expenditure as a risky behaviour in RG training. Such is the case because even if employees' estimates of their gambling expenditure are inaccurate, it is clear that those employees who estimate spending over $\$ 100$ per month on gambling run a relatively high risk of being moderate risk or problem gamblers.

When Ontario casino employees choose to spend money gambling, their preferences toward different forms of gambling are mostly consistent with the preferences shown by Ontario's general population, although casino employees simply engage in the different forms of gambling with greater frequency. For example, before the recent ban, lottery-style games constituted the most popular form of gambling for Ontario casino employees and only a tiny fraction of the employees completely abstained from playing the lottery. It is noteworthy that employees previously could purchase their lottery tickets on casino premises, and it appears as though employees frequently took advantage of this opportunity and they also often played the lottery as a group activity with other co-workers. Nevertheless, it is unclear how significantly these factors 
contributed toward the employees' high rates of participation, as some employees may have already been frequent lottery players when they were hired.

Ontario casino employees also appear to gamble in casinos somewhat frequently, and of the various casino games EGMs seem to be the most popular. Unlike lottery gambling, monthly play of EGMs and casino table games was associated with some of the highest rates of low risk, moderate risk, and problem gambling. This finding, therefore, lends tenuous support to the idea that EGMs may represent a particularly risky form of gambling, as has been suggested by some researchers (e.g., Breen \& Zimmerman, 2002; Griffiths, 1999; Harrigan \& Dixon, 2009b), although the causality behind this study's findings remains unclear. Moreover, Ontario casino employees also engage in a variety of additional forms of gambling, the most common of which are personal investments, card and board games played outside of casinos, and bingo. Even though participation in online gambling and sports gambling is fairly small, and sports gambling has certainly decreased with the ban on OLG's sports betting games, a relatively large proportion of those employees who do gamble online or on sports do so at least once per week.

\subsection{Changes in Gambling Behaviour and the Impacts of Workplace Influences}

Even though PG rates are relatively high among Ontario's casino employees, only a small fraction of the employees believed their gambling had increased since their employment began. In fact, the majority of the employees claimed their gambling had not changed at all, and over twice as many employees claimed their gambling had decreased as claimed it had increased. These results are consistent with findings made by Dangerfield (2004) and Shaffer et al. (1999), meaning the results suggest that such patterns are fairly common throughout the casino industry in different jurisdictions.

Casino employees' exposure to gambling seems to be one factor that causes some employees to decrease their gambling. Rather than becoming more attracted to the activity that pays their wages, it seems as though many employees tire of gambling and prefer to avoid it when they are not at work. Moreover, as the employment often causes the workers to learn more about the improbabilities of winning at different forms of gambling, this realization similarly seems to dissuade many employees from gambling. 
Nevertheless, some employees exhibit the opposite response to the gambling knowledge they acquire, and this knowledge actually motivates the employees to increase their gambling participation. This increase appears to sometimes occur simply because the employees now feel comfortable sitting down to play different games, which are no longer so intimidating or incomprehensible. However, in other cases the employees actually feel as though their acquired knowledge gives them an edge that can be exploited to win money. This confidence seems to develop among employees from different departments and can involve any form of gambling, but it seems to most commonly involve Table Games employees gaining confidence in their poker abilities. Unlike many other forms of gambling, poker truly does involve numerous elements of skill, so talented players have a genuine opportunity to profit in the long-term (Parke et al., 2005). Nevertheless, it is unknown how many of the employees who gain such confidence actually are able to make money consistently. It is quite possible that some of these employees, and certainly the employees who feel they have an edge in some of the other games, have simply developed a false sense of overconfidence, possibly rooted in an illusion of control.

The employees' exposure to patrons also may attract some employees toward gambling, yet this aspect of the job appears to play a particularly large role in the decrease in gambling that many employees claimed to have experienced. In the survey, the vast majority of casino employees agreed that they wanted to avoid imitating the patrons, who the employees could observe losing money and exhibiting negative consequences of gambling. Moreover, the employees claimed that they regularly observed patrons perceived to have gambling problems, with over $40 \%$ of the respondents claiming they made such observations on a daily basis. This data should not be interpreted as a reliable estimate of the prevalence of patron PG, yet it clearly shows that for many employees observing patrons with apparent gambling problems is a normal part of the job. Furthermore, during the interviews exposure to the patrons was often identified as the primary reason why many casino employees are motivated to decrease their own gambling involvement. The interviewees also introduced the issue of complaints, which is a subject that has garnered very limited attention in past research on casino employees. Dealing with patrons' complaints and negative demeanours seems to 
be a regular feature of the job for many employees, and these experiences similarly appear to disillusion many employees with gambling.

Although employees' interactions with patrons may dissuade the employees from gambling, their interactions with co-workers who regularly gamble can attract the employees toward gambling. Gambling among co-workers has certainly decreased with the lottery ban because many co-workers used to gamble together in lottery pools, but other forms of gambling among co-workers seem to be common as well. For instance, when employees visit casinos, play house games of poker, or bet on sports, they appear to often gamble with one another. Moreover, some of the facilities organize visits to other casinos so that co-workers can gamble with each other as a social activity. Nevertheless, only a very small fraction of the employees actually perceived themselves as gambling more because of gambling co-workers. Also, even though casino employees are inevitably exposed to an abundance of casino marketing, the employees clearly disagreed with the notion that this marketing tempts them to gamble. Furthermore, it was found that Ontario casino employees do not tend to find their jobs particularly stressful and only a very tiny percentage indicated that they gambled to relieve job stress. It was revealed that those employees who most strongly agreed that their jobs were stressful were more likely to be classified as problem gamblers and to have increased their gambling since beginning their jobs, but it is uncertain whether the job stress actually encouraged such behaviours or whether job stress is simply correlated with the behaviours in another way.

Although some aspects of the work environment may motivate employees to gamble, the RG training that the employees receive is designed to help prevent employee PG. On average, the employees appear to believe the RG training they receive is fairly useful in teaching them about PG and preventing them from developing gambling problems. Even though the employees tended not to agree that the training had convinced them to gamble less, it was pointed out in the interviews that the training is not designed for such a purpose. Nevertheless, many interviewees also remarked that they did not feel their RG training provided enough focus on how to gamble responsibly, but rather focused on how to identify and respond to PG among the patrons. Some of the employees felt that they could easily apply these lessons to themselves, but others thought it would 
be beneficial to receive some training that was more directly focused on employee gambling.

Ontario casinos also restrict employee gambling through regulations that limit the casinos in which the employees can gamble. Due to these regulations, the survey respondents on average lived over one hour away from the nearest casino where they were allowed to gamble. Logically, employees who lived greater distances from unrestricted casinos exhibited greater agreement that the regulations made it difficult to visit such casinos, yet overall the employees did not tend to agree that it was difficult to visit unrestricted facilities. In fact, employees who lived greater distances from permitted casinos did not exhibit lower moderate risk and problem gambling rates nor were they much less likely to have increased their gambling. Moreover, they were not much less likely to have gambled in a casino during the past year nor much more likely to have engaged in substitute forms of gambling, such as non-casino gambling with family and friends or online gambling. However, during the interviews it was made clear that these findings could not be explained by employees regularly gambling in prohibited facilities, as the interviewees all concurred that few employees would risk their jobs in such a way.

Nevertheless, these findings should not be considered evidence that the regulations are completely inconsequential. It is quite possible that prohibiting employees from gambling at the facilities where they work has a major impact, even if prohibiting the employees from gambling at other facilities is far less meaningful. Moreover, the regulations unquestionably would have a clear effect on casino gambling once the distance to the nearest permitted casino became sufficiently large. For example, if employees had to travel 12 hours to reach the nearest permitted casino then their casino gambling would surely decrease. In other words, the question is not whether such restrictions can impact employees' casino gambling, but rather at what point will their casino gambling be impacted. In this study it was found that of those employees who lived more than three hours from the nearest permitted casino $(n=21)$, none claimed to have gambled in a casino at least once per month during the previous year, and only $38.1 \%$ had done so at least once during the previous year. In comparison, $6.9 \%$ of the other respondents $(\mathrm{n}=858)$ had gambled in a casino at least once per month during the previous year, and $57.0 \%$ had done so at least once during the previous year. 
Even if regulations reduce participation in specific forms of gambling, there always exists the possibility that the regulations actually will lead to increases in substitute forms of gambling. This study did not find clear evidence to suggest that the casino gambling regulations prompted employees to increase their involvement in substitute forms of gambling, as Dangerfield (2004) hypothesized had occurred in Alberta. One the other hand, the indications that some employees had adopted substitute forms of gambling since the lottery ban suggests that this phenomenon definitely occurs. Nevertheless, it is unknown whether such substitution gambling is common or whether the new regulations on lottery gambling instead will generally prompt reductions in additional forms of gambling as well, as would be expected based on Lund's (2009) findings.

Employee PG clearly persists despite the various regulations, yet any employees suffering from gambling problems have various options for seeking assistance. The survey respondents clearly indicated that the EAP would be the most popular resource employees would use to seek PG assistance, as over half of the respondents claimed they would use the EAP under such circumstances. However, the other respondents' indication that they would not use the EAP may derive from an apparent lack of trust in the program that was mentioned by some of the interviewees. These individuals questioned the program's confidentiality, which is a guarantee that the employees must fully believe if they are going to be comfortable taking advantage of the program.

The vast majority of the survey respondents felt that if they approached their direct supervisors about a personal gambling problem then these supervisors would show the employees where to get help, although it seems as though few employees would take this step simply because they believe the supervisors would just direct employees to the EAP. Only a fraction of the employees felt they would lose their job for making such an admission to their supervisors, and only a similarly small fraction felt that even if they had a gambling problem they would not seek assistance anywhere. However, both of these groups exhibited particularly high rates of PG. It is possible that these individuals became problem gamblers partly as a result of their apparent reluctance to seek assistance as their gambling problems developed. On the other hand, it seems at least as likely that the causality is the exact opposite and these employees' PG has impacted their attitudes 
toward the different resources. In other words, it is possible that problem gamblers answered honestly in claiming they would not seek PG assistance and they also rationalized their decision not to seek help from a supervisor by convincing themselves that their supervisors would not offer help. Similarly, non-PG employees could have easily convinced themselves that they would seek assistance for PG because it was perceived as such an unrealistic scenario, and they could more genuinely view their supervisors as being potentially helpful.

\subsection{Risk Cognitions}

Several of the workplace influences that affect employee gambling - including exposure to gambling, exposure to patrons, and the RG training - also likely affect employees' beliefs about risk cognitions. It was found that the vast majority of the survey respondents correctly rejected the three risk cognitions included in the survey. Moreover, the employees seemed far less likely to endorse risk cognitions than the general Ontario population. Given that a similar pattern was found in Alberta by Dangerfield (2004), together these findings provide strong evidence that Canadian casino employees are much more knowledgeable about common risk cognitions than Canada's general population. Nevertheless, employees' PGSI categorizations were positively related with their beliefs in the risk cognitions, which is consistent with Miller and Currie's (2008) finding that endorsement of risk cognitions among the general Canadian population was positively related with risky gambling practices. Those employees who had increased their gambling significantly since their jobs began also were more likely to believe in the risk cognitions.

These patterns may exist because of the false gambling confidence held by employees who believed in the risk cognitions, as the employees who believed they could win money using their acquired gambling knowledge were more likely to endorse the risk cognitions. However, this logic is questioned by the finding that those employees who had played an EGM during the previous year were no more likely to have endorsed the EGM-related risk cognition. Also, it should be noted that although the employees widely rejected the three basic risk cognitions included in the survey, numerous interviewees 
suggested that employees sometimes developed illusions of control toward certain games, and illusions of control are themselves a type of risk cognition.

\subsection{Motives for Taking Casino Jobs}

It is clear that most of Ontario's casino employees are attracted to their jobs simply because they pay well, provide attractive benefits, and offer stability. Although less significant, the employees also seemed to be attracted by the feeling that they would enjoy different aspects of the work, which suggests a pre-existing affinity for gambling. However, these employees were not significantly more likely to increase their gambling or to be classified as problem gamblers. Many employees seemed to be mostly unfamiliar with gambling when their employment began and, as some of the interviewees highlighted, the regulations that limit employee gambling may dissuade some heavy gamblers from applying to work in Ontario casinos. In fact, very few workers felt they were attracted to the employment because they were frequent gamblers and therefore thought they would enjoy their jobs. Among this small group, the majority - and a particularly high percentage - felt as though their gambling had decreased since their employment began. In other words, working in a casino ironically may be a fairly effective means of motivating heavy gamblers to reduce their gambling. Nevertheless, PG rates were also particularly high among those individuals who were attracted to their jobs due to prior gambling involvement. Therefore, even though Ontario casino jobs do not seem to attract an abundance of heavy gamblers, and those heavy gamblers who are attracted often end up decreasing their gambling, those employees attracted due to prior gambling involvement are still particularly likely to be low risk, moderate risk, or problem gamblers.

\subsection{Employment Variables}

Although casino employees are exposed to numerous workplace influences that may encourage or discourage the employees' gambling, those employees who had spent greater amounts of time in the industry did not tend to feel they were more strongly impacted by most of these influences. Additionally, those employees who had worked for less time felt they had been impacted more strongly by their RG training. This finding is 
probably a consequence of newer employees having received their RG training more recently, much like Giroux et al. (2008) found that the benefits of such training seemed to decrease over time. Also, even though no perfectly linear patterns emerged to explain the potential relationship between time spent in the industry and PG rates or changes in gambling, it should be acknowledged that the employees who had spent less than one year in the industry exhibited the lowest rates of moderate risk and problem gambling, and were the least likely to have increased their gambling. Therefore, this evidence may indicate that those employees who end up increasing their gambling as a result of the employment do so somewhat gradually, rather than immediately upon beginning their jobs. Nevertheless, the lack of a linear trend suggests that problem gamblers are no more likely to remain in their facilities for longer periods of time.

The prevalence of PG was greater among employees who had worked elsewhere in the gambling industry before working in an OLG or resort casino. In other words, it appears as though problem gamblers may be more likely to remain in the industry when switching employers, even if problem gamblers are no more likely to remain in the industry for a longer duration. Those employees with prior industry experience also were far more likely to claim their gambling had increased since they began working in an OLG or resort casino. This finding may indicate that individuals who had worked at other gambling establishments, such as bingo halls, increased their gambling after familiarizing themselves with casino gambling in an OLG or resort casino. However, it is also possible that some of these individuals simply did not properly answer the corresponding survey question and actually meant to state that their gambling had increased since they began working in the gambling industry, and not specifically since they began working in an OLG or resort casino.

The prevalence of PG also differed between the three different types of casino facilities that exist in Ontario. It was found that moderate risk and problem gambling were most prevalent in resort casinos and least prevalent in slots facilities. Likewise, the resort casino employees were the most likely to have increased their gambling since their employment began and the slots facility employees were the least likely to have done the same. One obvious distinction between resort casinos and OLG facilities that may partly explain this pattern is the less restrictive employee gambling regulations that are imposed 
by the resort casinos. In fact, the OLG employees tended to agree that their gambling regulations made it difficult to visit an unrestricted casino, while the resort casino employees tended to disagree with the same statement. Nevertheless, because this study also found little evidence to indicate that distance from the nearest permitted casino had any major impact on employees' gambling behaviours, it is questionable whether this difference in regulations genuinely explains the higher PG rates among resort casino employees. The resort casino employees also felt less strongly impacted by their RG training, so perhaps this distinction plays a larger role in explaining the resort casino's comparatively high PG rates. Moreover, the finding also strongly suggests that the somewhat different training that these employees received was inferior to the training offered in the OLG facilities.

Employees in the different facilities also showed comparatively higher rates of participation and greater levels of increased familiarity with the forms of gambling offered in their facilities. For instance, casino and the resort casino employees exhibited high rates of participation and greater levels of increased familiarity with table games, while slots facility employees exhibited the same patterns with horseracing. It is possible that through their jobs the employees are familiarizing themselves with the different forms of gambling, and subsequently gambling on these games. However, the surveyed slots facility employees did not work directly with horseracing and the increases in table game familiarity among the casino and resort casino employees existed even among nonTable Games employees. Therefore, if employees are familiarizing themselves with certain games at work and then gambling on these games, the familiarization process is occurring even among employees whose job responsibilities do not directly relate to the games in question. On the other hand, it is also possible that employees for some reason choose to participate in the forms of gambling that exist in their facilities, and through this participation the employees familiarize themselves with these types of gambling.

It was additionally found that those employees in the departments directly involved in gambling (Slots and Table Games) exhibited the highest rates of moderate risk and problem gambling. This finding is consistent with the results of past studies (e.g., Duquette, 1999; Shaffer et al., 1999), which suggests that the pattern is fairly widespread throughout the casino industry. However, this study also examined each department 
individually and found that grouping departments based on their involvement with gambling or distance from the gambling floor actually overlooks important distinctions between individual departments. By considering each department individually, it was made quite apparent that the Table Games employees exhibited particularly high rates of moderate risk and problem gambling. In fact, even though the Tables Games employees represented just over $10 \%$ of the survey respondents, they constituted $39.3 \%$ of the problem gamblers and $20.5 \%$ of the moderate risk gamblers.

The Table Games employees predictably also engaged in many forms of gambling more often than employees from other departments. In fact, much like the results indicating that employees tended to gamble on the games that their facilities offered, the employees also tended to gamble most on the games they managed at work. More specifically, the Table Games employees gambled on table games far more than employees from the other departments, the Slots employees played EGMs more than workers from all except for one other department, and Surveillance employees showed high levels of gambling with table games, which they monitor.

The high rates of gambling participation detected among Table Games employees may be explained in part by the finding that they were especially likely to have been attracted to their jobs by prior gambling involvement, but these same employees were also especially likely to have increased their gambling since their jobs began. Possibly influencing these increases, the Table Games employees indicated in the survey that they had become comparatively more interested in and less tired of gambling, they were especially likely to have co-worker friends who gambled, and they perceived comparatively little impact from their RG training. Moreover, the Table Games employees seem to be particularly likely to feel their acquired gambling knowledge gives them a gambling edge, which likely relates to their particularly high participation rates with table game gambling. A similar phenomenon likely explains the Surveillance employees' high levels of gambling on table games, and in the survey these employees also exhibited comparatively high levels of agreement that they could win money using their acquired gambling knowledge. However, neither Surveillance employees nor the Table Games employees expressed much belief in the tested risk cognitions, which suggests that these employees are knowledgeable enough to reject well-known risk 
cognitions, such as those included in the survey, but still maintain exaggerated levels of confidence regarding their gambling abilities.

Also, it is noteworthy that the Table Games employees agreed quite strongly that they were discouraged from gambling by their exposure to patrons, even though this influence was clearly overshadowed by opposing influences. The Slots and Security departments were the other two departments in which employees most strongly agreed that they were dissuaded from gambling by exposure to the patrons, which is quite logical given that many Slots employees work on the gambling floor and the Security department plays a major role in dealing with PG patrons.

In fact, the employees who spent greater portions of their workdays interacting with patrons expressed the greatest agreement that they were dissuaded from gambling by these interactions. It would be logical to assume that these employees consequently would gamble less, but the prevalence of PG within the Table Games department highlights the inaccuracy of such an assumption. Furthermore, those employees who spent greater portions of their workdays interacting with patrons were more likely to have indicated they had increased their gambling since their jobs began. In other words, for some employees the dissuading impacts of exposure to the patrons was apparently outweighed by other countering influences.

Somewhat similarly, employees who worked the night-time shift exhibited the highest PG rates despite also agreeing most strongly that they were dissuaded from gambling by their exposure to patrons, and several interviewees concurred that employees generally observe more problematic behaviour among the night-time patrons. The odd hours worked by night-time shift employees do not seem to explain the PG prevalence within this group because these employees - and employees from all of the other shifts - generally disagreed that their shift work meant that casinos were some of the only entertainment venues open when the employees were not at work. In fact, the night-time workers were not particularly likely to claim they had increased their gambling since their employment began, yet they were especially likely to agree that they had been attracted to their jobs by prior gambling involvement, so this latter factor seems to explain much of the PG prevalence among night-time employees. 


\subsection{Demographic Characteristics}

Many of the same demographic characteristics associated with different gambling behaviours among Ontario's general population also are associated with different gambling behaviours among Ontario's casino employee population. For instance, comparatively high levels of moderate risk and problem gambling were detected among employees who were men, who claimed their ethnicity was not Canadian, and who had not graduated from a post-secondary institution. Also, the prevalence of PG, but not moderate risk gambling, was found to be especially high among employees who were single and never married. However, this study's results suggest that no clear pattern exists regarding PG rates among Ontario casino employees in different age groups. Fairly similar patterns were found regarding the changes in gambling that different groups of employees tended to experience, as employees who were men, who were single and never married, and who claimed their ethnicity was not Canadian were all more likely to have increased their gambling significantly since their jobs began. On the other hand, no clear patterns regarding these changes were found when grouping the employees by age or education level. Also, this study found that the different game preferences exhibited by male and female gamblers in Ontario's general population are similar to preferences exhibited by male and female casino employees. Consequently, this finding provides further evidence that gambling among Ontario casino employees does not differ considerably from other Ontarians except for the fact that the employees gamble more frequently.

\subsection{Casino Benefits of Reducing Employee Problem Gambling}

The PG that exists within the employee population does not seem to induce employee turnover, as no evidence was found to suggest that employees with PG remain in their jobs for less time than their co-workers. Several of the interviewees commented on the high turnover rates among the employees, but this study's findings suggest that most Ontario casino employees spend fairly long periods of time in the industry, as about twothirds of the survey respondents claimed they had worked in the industry for over five years. Also, it does not appear as though employees who were moderate risk or problem gamblers were any less likely to identify patrons as problem gamblers. In fact, this 
study's results suggest that if any effect exists it is more probable that gambling actually makes employees more adept at identifying patron PG. In other words, it does not appear as though reducing PG among employees would directly benefit casinos in the two ways that this study tested, yet these results should not be misconstrued as indicating the casinos would not benefit at all from such reductions, as numerous other possible benefits exist which were not investigated.

\subsection{Reasons for the High Problem Gambling Rates among Casino Employees}

Although most studies on casino employee gambling conclude that casino employees tend to gamble more frequently and exhibit more PG than the general population, it remains unclear why this pattern exists. Logically, however, it must be explained by at least one of three phenomena: Being employed in a casino somehow induces employees to gamble more, casinos attract individuals who are already problem gamblers, or problem gamblers remain in the industry for longer periods of time (Dangerfield, 2004; Shaffer et al., 1999). The results from this study suggest that the first two of these phenomena play a role in explaining PG rates among Ontario casino employees, while the third phenomenon is inapplicable.

Casino employment includes many influences that may dissuade employees from gambling, and it appears as though many more employees find themselves repelled from gambling than attracted to it. Nevertheless, there is no question that workplace influences do, in fact, motivate some employees to increase their gambling, and it appears as though PG is particularly prevalent within this group. In fact, even though only $3.3 \%$ of the sample claimed they had increased their gambling significantly since beginning their jobs, $36.7 \%$ of these individuals were classified as problem gamblers and $40.0 \%$ were classified as moderate risk gamblers. This same pattern also can be examined by comparing moderate risk and problem gamblers with the rest of the sample. Among nonproblem gamblers $6.3 \%$ had increased their gambling, among low risk gamblers $16.7 \%$ had done so, among moderate risk gamblers $37.2 \%$ had done so, and among problem gamblers $59.3 \%$ had done so, with just over $40 \%$ having increased their gambling significantly. 
Similarly, it seems as though very few Ontario casino employees are attracted to their jobs by prior gambling involvement, but the small number of employees who are attracted for such reasons exhibit very high PG rates. In fact, even though only $6.8 \%$ of the sample agreed that they had chosen their work at least in part because they were frequent gamblers and therefore thought it would be fun, $25.6 \%$ of these individuals were classified as problem gamblers and $27.9 \%$ were classified as moderate risk gamblers. Once again, this pattern also can be examined by comparing moderate risk and problem gamblers with the rest of the sample. Among non-problem gamblers $2.1 \%$ agreed that they had chosen the job because of prior gambling involvement, among low risk gamblers $10.1 \%$ agreed with this motive, among moderate risk gamblers $19.0 \%$ agreed with this motive, and among problem gamblers $44.0 \%$ agreed with this motive.

In other words, Ontario casinos jobs do not typically induce employees to increase their gambling, nor do the jobs attract a plethora of heavy gamblers. However, among the small group of employees who fall into either category, moderate risk and problem gambling is prevalent. In fact, at least one of these two explanations applied to $83.3 \%$ of the problem gamblers and $54.0 \%$ of the moderate risk gamblers. Also, the two explanations were somewhat mutually exclusive, as both explanations only applied to $25.0 \%$ of the problem gamblers. Moreover, it also was found that those employees who were attracted to their jobs by prior gambling involvement were particularly likely to have decreased, not increased, their gambling since their jobs began. Therefore, it appears as though the relatively high PG rates among Ontario casino employees are explained by two distinct phenomena: employees increasing their gambling involvement after beginning their jobs and individuals with prior gambling involvement being attracted to the jobs.

On the other hand, the PG rates exhibited by Ontario casino employees do not seem to result from problem gamblers continuing to work in the industry for disproportionately long periods of time. Even though it was found that PG rates were comparatively high among employees who had chosen to remain in the gambling industry when switching employers, the lack of any relationship between PG rates and length of time spent working in the industry suggests that the retention of problem 
gamblers does not play a significant role in explaining PG rates within the employee population.

\subsection{Recommendations}

Ontario casinos already take various steps to prevent PG among their workforces, but this research suggests that some additional actions may prove beneficial. Nine different recommendations are provided, and these recommendations are derived directly from this study's results. Several of the recommendations focus on RG training, as this appears to be one area in which numerous improvements can be made. Some of the recommendations are applicable only to Ontario casinos, whereas others can be applied more generally.

1) Focus more of the $R G$ training on employee gambling. Numerous interviewees mentioned that their RG training focused predominately on patron PG, with little or no attention paid to the employees themselves. Although various employees claimed they could interpret the lessons on a personal level, there is little doubt that the employees would benefit from training that explicitly highlighted employee gambling and the influences behind such gambling.

2) Give some departments higher levels of $R G$ training. Currently, all employees without a supervisory or management role receive the same level of RG training, regardless of their department. However, it is clear that some departments - especially the Table Games department - exhibit particularly high rates of PG. Therefore, it would be beneficial to offer higher levels of RG training to employees in the departments that exhibit the highest rates of moderate risk and problem gambling.

3) Use a standardized schedule for follow-up RG training. It appears as though employees who received their RG training more recently viewed it as more effective, which is essentially consistent with Giroux et al.'s (2008) findings from Quebec casinos. OLG already has plans to establish a standardized schedule of refresher training ( $\mathrm{J}$. Berkovitz, personal communications, November 18 and 19, 2009), and this development should most likely increase the effectiveness of the RG training. 


\section{4) Harmonize the OLG facilities' and the resort casinos' $R G$ training, while}

simultaneously testing new training ideas at different facilities. It would seem beneficial to provide standardized RG training to all Ontario casino employees, rather than having differences between the training offered in the OLG facilities and the resort casinos. This study's results indicate that the employees at OLG facilities perceive their RG training as more effective than do the employees at the resort casino involved in this study, so the standardized training should more closely resemble OLG's RG training. However, the RG training offered by the various resort casinos is not identical, so it should not be assumed that all of the resort casinos' RG training is inferior to OLG's. Additionally, although it may be useful to harmonize RG training throughout the Ontario casino industry, the ability to test the effectiveness of different RG training elements in certain facilities provides a valuable opportunity that should be exploited.

\section{5) In the RG training, teach more about the genuine odds associated with different} gambling games. Many employees are knowledgeable about different gambling games, and the employees also appear quite knowledgeable about standard risk cognitions. Nonetheless, some employees' gambling issues appear to be rooted in unwarranted levels of confidence in their gambling abilities. Consequently, these employees may benefit from RG lessons focusing on the losing probabilities that gamblers face in different gambling games.

6) Teach employees about behaviours that may relate to employee PG. This study has identified several behaviours that are strongly associated with PG: spending over $\$ 100$ per month on gambling, increasing one's gambling after beginning one's job, and choosing one's job because of prior gambling involvement. Even though the casinos cannot determine which employees are characterized by any of these behaviours, if the employees are taught that these behaviours are associated with high rates of PG then perhaps the employees will be better equipped to properly examine their own gambling.

7) Make the $R G$ training more interesting. Several employees remarked that their training was far more effective when it was made interesting, such as through visual tools 
demonstrating different probabilities. Information on topics like probabilities is naturally quite dry, so it is important to use captivating teaching techniques to keep the employees engaged.

8) Do not assume employee gambling regulations will prevent problems. Although the resort casino employees, who face far less stringent regulations than their OLG counterparts, exhibited comparatively high PG rates, the data does not indicate that these problems were caused by the laxer regulations. In fact, no significant relationships were found between how far employees had to travel to reach their nearest unrestricted casinos and the employees' PGSI scores. Such results do not signify that regulations are useless, but the results do suggest that the impact of such regulations should not be taken for granted. If further regulations are imposed then they may successfully reduce PG within the workforce, but this reduction may occur simply because heavy gamblers are dissuaded from applying for employment and not because existing employees are reducing their gambling. Given that the majority of the employees who were attracted to their jobs by prior gambling involvement actually decreased their gambling involvement after their jobs began, such changes may actually have the unintended consequence of repelling those individuals most likely to reduce their gambling once their jobs begin.

9) Assure employees that the EAP is confidential. It is clear that the EAP is well-known and perceived by a large portion of the employees as the optimal resource for seeking assistance. However, the lack of confidence that numerous employees expressed toward the program undoubtedly reduces its value. The employees must be fully assured about the program's confidentiality in order for it to be truly effective.

\subsection{Limitations}

All gambling studies run the risk of respondents' answers being tainted by various biases, and this study is no exception. Because this study used self-reported data, there is no reason to doubt that some respondents provided biased answers that did not accurately depict their genuine gambling behaviours or attitudes. For example, heavy gamblers may have struggled to acknowledge their high levels of gambling involvement, or they also may have been either eager or reluctant to explain this involvement as resulting from 
certain workplace influences. Also, numerous survey items asked employees about their perceptions of certain influences, which are not necessarily simple to assess. For instance, compared to remembering how frequently one bet on horse races during the previous year, it is much more complicated to evaluate how influences like marketing or job stress affected one's gambling. Additionally, there is even the possibility that respondents deliberately provided inaccurate responses in order to influence the study's results. The lottery ban that was instituted just before the survey was distributed was hugely unpopular, so it is possible that employees downplayed their actual levels of gambling involvement in the fear that this study's results could trigger the establishment of further regulations.

Moreover, the quantity of moderate risk and particularly problem gamblers identified in the sample was relatively small. Consequently, seemingly significant patterns and relationships that were detected may simply reflect the behaviours and attitudes of a small group of moderate risk and problem gamblers who are not accurately representative of Ontario's moderate risk and problem gambling casino employees. It is also quite possible that non-response biases influenced this study's results. For instance, a disproportionately high percentage of females returned completed surveys, and this imbalance is noteworthy because the males and females differed considerably in several gambling measures. More generally, it is possible that frequent gamblers were more reluctant to participate in this study due to the sensitive nature of the topic. In fact, the interview sample did not appear to involve an especially large quantity of heavy gamblers, although this could not be tested reliably because personal gambling was not a topic directly broached in the interviews. On the other hand, it is also quite possible that non-gamblers were the least likely to participate in the study due to a lack of interest or a belief that their answers would not be valuable. For example, Williams and Volberg (2009) tested PG rates in an Ontario region with a survey that was described to potential respondents as either a "gambling" survey or a "health and recreational activities survey," and the authors found that PG rates for the "gambling" survey were far higher because "gamblers and problem gamblers are intrinsically more interested in 'gambling' surveys and therefore participate at a much higher rate than nongamblers" (p. 113). 
The external validity of this study also has some clear limitations. The results are most applicable to the Ontario casino industry, yet it should be noted that this study only involved five of the 27 casino facilities that exist in Ontario. Each particular facility will have unique characteristics that could encourage or discourage employee gambling (e.g., having staff members more adept at teaching RG classes or being located a further distance from the closest permitted casino), so it should not be assumed that the results obtained from this study are perfectly representative of all Ontario casino facilities. Such limitations obviously increase in significance when considering the casino industry outside of Ontario. It seems clear that some basic patterns are common among casino employees in numerous jurisdictions, but given the vast differences that exist between different gambling jurisdictions, one must recognize that this study's findings may not fully apply to other jurisdictions.

\subsection{Future Research}

The results from this study raise numerous important questions and issues that should be considered in future research. For example, the ban on lottery-style games that was recently instituted undoubtedly will have some major impacts on OLG employee gambling, simply because such lottery-style games appear to have been so popular. However, the precise nature of these impacts is unknown and a better understanding of these impacts would provide useful information about the general effects of casino employee gambling regulations. For instance, given that OLG employees easily can still gamble on the lottery indirectly through a spouse or friend who buys the tickets, it is unclear exactly how significantly the ban will reduce employee lottery participation. Also, it is unknown whether the ban will lead to a more widespread decrease in other forms of gambling, as was found by Lund (2009), or whether the employees will move toward substitute forms of gambling, such as online gambling. Additionally, it would be useful to determine whether the ban actually deters heavy gamblers from applying to work in OLG facilities. A natural control group even exists to research these questions, as the ban only applies to OLG facilities and not resort casinos. However, it should be remembered that this study found differences between resort casino employees' gambling 
and OLG employees' gambling that seemed to derive from factors besides the facilities' differing regulations.

To investigate the changes in gambling behaviour that casino employees experience, it would be useful to conduct longitudinal research that would permit employee changes to be tracked over time. Some past studies already have involved longitudinal methodologies (i.e., Dangerfield, 2004; Shaffer et al., 2002), but these studies looked at how all employees changed over a given period and such an approach only offers limited value because many of the changes in an employee's gambling may have already occurred before the research commenced. For instance, an employee may have worked in a casino for three years prior to the research and changed his or her gambling dramatically during the first two years before maintaining a steady level of gambling in the subsequent years, meaning the changes would not be detected in the study. Therefore, a longitudinal study solely involving new employees would offer far more valuable insights. Running such a study obviously would pose certain logistical challenges, but it also is undoubtedly feasible.

The varying impacts associated with working in different departments also deserve concerted attention in future studies. Of all the employment variables this study considered, department appears to be the one that explained the greatest differences between employees' work experiences and gambling behaviours. Moreover, this study's results suggest that future research on this variable should consider each department individually, as even departments which it may seem logical to group together may have very different characteristics. For instance, although Table Games and Slots employees both work on the gambling floor, this study's results clearly suggest that PG is far more common among Table Games employees and the influences causing changes in their gambling are much different. Similarly, although Surveillance employees may be physically removed from the gambling floor, they actually have a unique position from which they can learn about gambling without being directly exposed to any patrons.

This study also identified several workplace influences that have garnered relatively little attention in past research: the gambling edge that some employees believe they acquire, the comfort in playing games with which one has become familiar, and the complaints that employees frequently receive from patrons. All three of these factors 
seem to play major roles in impacting employees' gambling and, therefore, demand greater focus in future studies. Firstly, the gambling edge that some employees believe they acquire must be viewed as distinct from the common risk cognitions that are typically tested, because in some cases the advantage actually may be valid (e.g., with talented poker players), and even falsely perceived advantages often seem to be rooted in beliefs that are more complex than standard risk cognitions. It would be useful to examine the process through which employees develop this confidence in winning and to determine how frequently the employees genuinely can win. For those employees' whose confidence is rooted in erroneous beliefs, it would be useful to discern how this overconfidence relates to more commonly considered risk cognitions. Secondly, it also should be recognized that employees may play the games the employees know best not because they erroneously believe they can win, but rather because they are familiar enough with the games to feel comfortable sitting down to play them. Therefore, future research should more directly consider how employees may increase their comfort levels with certain games, and how these comfort levels may relate to the employees' decisions to gamble on those games. Thirdly, the direct complaints that employees receive seem to disillusion some employees with gambling. A better understanding of the nature of these complaints and the types of employees (e.g., by department) who receive them may be useful in examining why so many casino employees end up decreasing their gambling involvement.

\subsection{Conclusion}

The future research topics that have been suggested will provide greater insights into the gambling behaviours of casino employees, who comprise a particularly interesting subgroup of gamblers due to the various influences they experience in their workplace. Moreover, even though casino employees benefit directly from the gambling industry, they ironically also exhibit PG at particularly high rates, meaning future research is necessary to promote RG throughout this population. This study has found that casino employees in Ontario are fairly similar to casino employees elsewhere, in that Ontario casino employees gamble more frequently and exhibit more PG than Ontario's general population. These patterns seem to result from the employment sometimes attracting 
individuals who are already heavy gamblers and from the employment sometimes inducing workers to increase their gambling. Nevertheless, it also seems as though the employment dissuades employees from gambling more often than it motivates them to gamble. In other words, the experience of working in a casino can affect different individuals quite differently. Certain employment variables, and particularly one's department, help explain some of these differences, in part because of the varied experiences had by employees with different types of jobs. With continued research into such issues, casinos will become better equipped to minimize $\mathrm{PG}$ and promote RG among their employees. 


\section{References}

Aasved, M. (2002). The Psychodynamics and Psychology of Gambling: The Gambler's Mind - Volume I. Springfield, IL: Charles C Thomas Publisher.

Adams, G. R., Sullivan, A.M., Horton, K.D., Menna, R., \& Guilmette, A.M. (2007). A study of differences in Canadian university students' gambling and proximity to a casino, Journal of Gambling Issues, 19, 9-17.

American Gaming Association. (2009). 2009 State of the States: The AGA Survey of Casino Entertainment. Retrieved from http://www.americangaming.org/assets/files/uploads/aga_sos2009web_FINAL.pd $\mathrm{f}$

Argusa, J., \& Lema, J.D. (2007). An examination of Mississippi gulf coast casino management styles with implications for employee turnover. UNLV Gaming Research and Review Journal, 11,(1), 13-26.

Arthur, D., Tong, W.L., Chen, C.P., Hing, A.Y., Sagara-Rosemeyer, M., Kua, E.H., \& Ignacio, J. (2008). The validity and reliability of four measures of gambling behaviour in a sample of Singapore university students. Journal of Gambling Studies, 24(4), 451-462.

Bergh, C., \& Kühlhorn, E. (1994). Social, psychological and physical consequences of pathological gambling in Sweden. Journal of Gambling Studies, 10,(3), 275-285.

Bersabé, R., \& Arias, R.M. (2000). Superstition in gambling. Psychology in Spain, 4(1), 28-34.

Blaszczynski, A. (2005). To formulate gambling policies on the premise that problem gambling is an addiction may be premature. Addiction, 100(9), 1230-1231.

Blaszczynski, A., Dumlao, V., \& Lange, M. (1997). "How much do you spend gambling?" Ambiguities in survey questionnaire items. Journal of Gambling Studies, 13(3), 237-252.

Blaszczynski, A., Ladouceur, R., Goulet, A., \& Savard, C. (2006). 'How much do you spend gambling?': Ambiguities in questionnaire items assessing expenditure. International Gambling Studies, 6(2), 123-128.

Blaszczynski, A., Ladouceur, R., \& Shaffer, H.J. (2004) A science-based framework for responsible gambling: The Reno model. Journal of Gambling Studies, 20(3), 301317.

Blaszczynski, A., \& Nower, L. (2002). A pathways model of problem and pathological gambling. Addiction, 97(5), 487-499.

Blevins, A., \& Jensen, K. (1998). Gambling as a community development quick fix. The ANNALS of the American Academy of Political and Social Science, 556(1), 109123.

Bondolfi, G., Osiek, C., \& Ferrero, F. (2000). Prevalence estimates of pathological gambling in Switzerland. Acta Psychiatrica Scandinavica, 101(6), 473-475.

Boutin, C., Tremblay, N., \& Ladouceur, R. (2009). Impact of visiting an onsite casino information centre on perceptions about randomness and gambling behaviours. Journal of Gambling Studies, 25(3), 317-330.

Bouts, P., \& Avermaet, E.V. (1992). Drawing familiar or unfamiliar cards: Stimulus familiarity, chance orientation, and the illusion of control. Personality and Social Psychology Bulletin, 18(3), 331-335. 
Bowden, D. (2009, February 4). Ont. lotto insiders raked in \$200M. The Gazette. Retrieved from http://www.montrealgazette.com/news/canada/lotto+insiders+raked+200M/12537 68/story.html

Breen, R.B., \& Zimmerman, M. (2002). Rapid onset of pathological gambling in machine gamblers. Journal of Gambling Studies, 18(1), 31-43.

Burger, J.M. (1986). Desire for control and the illusion of control: The effects of familiarity and sequence of outcomes. Journal of Research in Personality, 20(1), 66-76.

Campbell, C.S. (2009). Canadian Gambling Policies. In J.F. Cosgrave \& T.R. Klassen (Eds.), Casino state: Legalized gambling in Canada (pp. 69-90). Toronto: University of Toronto Press.

Campbell, C.S., \& Smith, G.J. (1998). Canadian gambling: Trends and public policy issues. The ANNALS of the American Academy of Political and Social Science, 556(1), 22-35.

Canadian Gaming Association. (2008). Economic Impact of the Canadian Gaming Industry: Key Findings Report. Retrieved from http://www.canadiangaming.ca/media_uploads/pdf/60.pdf

Canadian Gaming Association. (2009). Canadian Gaming Association - About the CGA. Retrieved on October 3, 2009 from http://cga.bristolnet.ca/english/home/index.cfm?id=151

Canadian Partnership for Responsible Gambling. (2008). Canadian Gambling Digest 2007-2008. Retrieved October 19, 2009 from http://www.cprg.ca/articles/Canadian_Gambling_Digest_2007_2008.pdf

The Canadian Press. (2007, May 2). B.C. casino workers see gambling problems: Survey. $C T V$. Retrieved from http://www.ctv.ca/servlet/ArticleNews/story/CTVNews/20070502/bc_casinos_07 0502

The Canadian Press. (2009, September 13) Ont. retailers can't play their own lottery tickets. $C T V$. Retrieved from:

http://toronto.ctv.ca/servlet/an/local/CTVNews/20090913/Ontario_Lottery_09091 3 ?hub=TorontoNewHome

CBC News. (2009). CBC News - The fifth estate: Luck of the draw. Retrieved 19 October from http://www.cbc.ca/fifth/luckofthedraw/

Coman, G.J., Burrows, G.D., \& Evans, B.J. (1997). Stress and anxiety as factors in the onset of problem gambling: Implications for treatment. Stress Medicine, 13(4), 235-244.

Cosgrave, J.F., \& Klassen, T.R. (2009). The shape of legalized gambling in Canada. In J.F. Cosgrave \& T.R. Klassen (Eds.), Casino state: Legalized gambling in Canada (pp. 3-16). Toronto: University of Toronto Press.

Cresswell, J.W. (2003). Research design: qualitative, quantitative, and mixed methods approaches $\left(2^{\text {nd }}\right.$ ed.). London: Sage Publications.

Dangerfield, L. (2004). Job satisfaction, substance abuse, and gambling behaviour of northern Albertan casino employees. Unpublished Master's thesis, University of Lethbridge. Retrieved from http://www.uleth.ca/dspace/bitstream/10133/553/1/dangerfield,\%20lyndsey.pdf. 
Delfabbro, P. (2004). The stubborn logic of regular gamblers: Obstacles and dilemmas in cognitive gambling research. Journal of Gambling Studies, 20(1), 1-21.

Dowling, N., Smith, D., \& Thomas, T. (2005). Electronic gaming machines: Are they the 'crack-cocaine' of gambling? Addiction, 100(1), 33-45.

Duquette, K.B. (1999). Casino employee gambling behaviour. Unpublished Master's thesis, University of Nevada, Las Vegas.

Eadington, W.R. (1996). The legalization of casinos: Policy objectives, regulatory alternatives, and cost/benefit considerations. Journal of Travel Research, 34(3), 38.

Eadington, W.R. (1998). Contributions of casino-style gambling to local economies. The ANNALS of the American Academy of Political and Social Science, 556(1), 53-65.

Eadington, W.R. (2001). The spread of casinos and their role in tourism development. In D.G. Pearce \& R.W. Butler (Eds.), Contemporary issues in tourism development (pp. 127-142). New York: Routledge.

The Economist (2009, September 3). Indian gold: A new pact is negotiated with the Seminole tribe. The Economist. Retrieved from http://www.economist.com/displayStory.cfm?story_id=14367209.

Ferris, J., \& Wynne, H. (2001). The Canadian problem gambling index: Final report. Prepared for the Canadian centre on substance abuse (CCSA). Retrieved from http://www.ccsa.ca/2003\%20and\%20earlier\%20CCSA\%20Documents/ccsa008805-2001.pdf

Flick, U. (2002). An introduction to qualitative research ( $2^{\text {nd }}$ ed.). Thousand Oaks, CA: Sage Publications.

Gaming Control Act. (1992). Retrieved on September 9, 2008 from http://www.elaws.gov.on.ca/index.html

Giroux, I., Boutin, C., Ladouceur, R., Lachance, S., \& Dufour, M. (2008). Awareness training program on responsible gambling for casino employees. International Journal of Mental Health and Addiction, 6(4), 594-601.

Grant, J.E., \& Kim, S.W. (2001). Demographic and clinical features of 131 adult pathological gamblers. The Journal of Clinical Psychiatry, 62(12), 957-962.

Griffiths, M.D. (1990). The cognitive psychology of gambling. Journal of Gambling Studies, 6(1), 31-42.

Griffiths, M.D. (1999). Gambling technologies: Prospects for problem gambling. Journal of Gambling Studies, 15(3), 265-283.

Griffiths, M.D. (2005). Does gambling advertising contribute to problem gambling? International Journal of Mental Health and Addiction, 3(2), 15-25.

Grinols, E.L. (2004). Gambling in America: Costs and benefits. Cambridge, UK: Cambridge University Press.

Hall, C.M., \& Hamon, C. (1996). Casinos and urban redevelopment in Australia. Journal of Travel Research, 34(3), 30-36.

Hanna, J. (2009, September 1) Revenue-hungry Kansas will be owner of new casinos. AP News. Retrieved from http://apnews.myway.com/article/20090901/D9AEDGS00.html

Harrigan, K.A. (2007). Slot machine structural characteristics: Distorted player views of payback percentages. Journal of Gambling Issues, 20, 215-234. 
Harrigan, K.A. (2009). Slot machines: Pursuing responsible gaming practices for virtual reels and near misses. International Journal of Mental Health and Addiction, 7(1), 68-83.

Harrigan, K.A., \& Dixon, M. (2009a). Government sanctioned "tight" and "loose" slot machines: How having multiple versions of the same slot machine game may impact problem gambling. Journal of Gambling Studies. Published online September 16, 2009.

Harrigan, K.A., \& Dixon, M. (2009b). PAR Sheets, probabilities, and slot machine play: Implications for problem and non-problem gambling. Journal of Gambling Issues, 23, 81-110.

Henriksson, L.E., \& Lipsey, R.G. (1999). Should provinces expand gambling? Canadian Public Policy, 25(2), 259-275.

Hing, N., \& Breen, H. (2001). An empirical study of sex differences in gaming machine play among club members. International Gambling Studies, 1(1), 66-86.

Hing, N., \& Breen, H. (2007). Workplace factors that encourage and discourage gambling amongst gaming venue employees: A managers' perspective. International Journal of Mental Health and Addiction, 5(4), 346-366.

Hing, N., \& Breen, H. (2008a). How working in a gaming venue can lead to problem gambling: The experiences of six gaming venue staff. Journal of Gambling Issues, 21, 11-29.

Hing, N., \& Breen, H. (2008b). Risk and protective factors relating to gambling by employees of gaming venues. International Gambling Studies, 8(1), 1-23.

Hope, J., \& Havir, L. (2002). You bet they're having fun! Older Americans and casino gambling. Journal of Aging Studies, 16(2), 177-197.

Hraba, J., \& Lee, G. (1996). Gender, gambling and problem gambling. Journal of Gambling Studies, 12(1), 83-101.

Hutchinson, B. (1999). Betting the house: Winners, losers and the politics of Canada's gambling obsession. Toronto: Viking.

Jones, L.V. (2008) Even the greatest ad campaign can't overcome a crabby dealer. Canadian Gaming Business, 2(4), 17-18.

Joukhador, J., Blaszczynski, A., \& Maccallum, F. (2004). Superstitious beliefs in gambling among problem and non-problem gamblers: Preliminary data. Journal of Gambling Studies, 20(2), 171-180.

Kale, S.H. (2007). Internal marketing: An antidote for Macau's labor shortage. UNLV Gaming Research and Review Journal, 11(1), 1-11.

Keith, M.M., Cann, B., Brophy, J.T., Hellyer, D., Day, M., Egan, S., Mayville, K., \& Watterson, A. (2001). Identifying and prioritizing gaming workers' health and safety concerns using mapping for data collection. American Journal of Industrial Medicine, 39(1), 42-51.

Keren, G., \& Lewis, C. (1994). The two fallacies of gamblers: Type I and type II. Organizational Behavior and Human Decision Processes, 60(1), 75-89.

Kimber, S. (1997). When the casinos came to town. Chatelaine, 70(6), 40-46.

Kirn, W., \& Ressner, J. (2004, July 26). Poker's new face. Time. Retrieved from http://www.time.com/time/magazine/article/0,9171,994714-1,00.html

Ladouceur, R. (1996). The prevalence of pathological gambling in Canada. Journal of Gambling Studies, 12(2), 129-142. 
Ladouceur, R., Jacques, C., Ferland, F., \& Giroux, I. (1999). Prevalence of problem gambling: A replication study 7 years later. Canadian Journal of Psychiatry, 44(8), 802-804.

Ladouceur, R., Sylvain, C., Boutin, C., Lachance, S., Doucet, C., \& Leblond, J. (2003). Group therapy for pathological gamblers: A cognitive approach. Behavior Research and Therapy, 41(5), 587-596.

Ladouceur, R., Sylvain, C., Letarte, H., Giroux, I., \& Jacques, C. (1998). Cognitive treatment of pathological gamblers. Behaviour Research and Therapy, 36(12), 1111-1119.

Langer, E.J. (1975). The illusion of control. Journal of Personality and Social Psychology, 32(2), 311-328.

Langer, E.J., \& Roth, J. (1975). Heads I win, tails it's chance: The illusion of control as a function of the sequence of outcomes in a purely chance task. Journal of Personality and Social Psychology, 32(6), 951-955.

Lee, T.K., LaBrie, R.A., Rhee, H.S., \& Shaffer, H.J. (2008). A study of South Korean casino employees and gambling problems. Occupational Medicine, 58(3): 191197.

Leiper, N. (1989). Tourism and gambling. GeoJournal, 19(3): 269-275.

Levens, S., Dyer, A.M., Zubritsky, C., Knott, K., \& Oslin, D.W. (2005). Gambling among older, primary-care patients: An important public health concern. American Journal of Geriatric Psychiatry, 13(1), 69-76.

Loriggio, P., \& Benzie, R. (2009, February 6). Lottery bosses banned from playing after probe. The Star. Retrieved from http://www.thestar.com/News/Ontario/article/583295

Lund, I. (2009). Gambling behaviour and the prevalence of gambling problems in adult EGM gamblers when EGMs are banned. A natural experiment. Journal of Gambling Studies, 25(2), 215-225.

Macleod, M. (2008, April 9). Canada hits jackpot of gambling revenue. The Hamilton Spectator. Retrieved from http://www.thespec.com/News/Business/article/351754

Mandal, V.P., \& Doelen, C.V. (1999). Chasing lightning: Gambling in Canada. Toronto: United Church Publishing House.

Marin, A. (2007). A game of trust: Ombudsman report. Retrieved from http://www.ombudsman.on.ca/media/3268/a_game_of_trust_20070326.pdf

Marshall, D. (2005). The gambling environment and gambler behaviour: Evidence from Richmond-Tweed, Australia. International Gambling Studies, 5(1), 63-83.

Marshall, K., \& Wynne, H. (2003, December) Fighting the Odds. Perspectives, 5-13.

Mayring, P. (2000) Qualitative content analysis. Forum: Qualitative Social Research, 1(2). Retrieved from http://www.qualitativeresearch.net/index.php/fqs/article/view/1089/2386

McCready, J., \& Adlaf, E. (2006). Performance and enhancement of the Canadian problem gambling index (CPGI): Report and Recommendations - Final Report. Retrieved from http://www.gamblingresearch.org/download.sz/CPGI\%20Review\%20\%20Final\% 20Report\%20English\%20Web\%20Version.pdf?docid=7974 
McMillen, J. (1996). Understanding gambling: History, concepts and theories. In J. McMillen (Ed.), Gambling Cultures: Studies in History and Interpretation (pp. 642). New York: Routledge.

McMillen, J., \& Wenzel, M. (2006). Measuring problem gambling: Assessment of three prevalence screens. International Gambling Studies, 6(2), 147-174.

McNeilly, D.P., \& Burke, W.J. (2000). Late life gambling: The attitudes and behaviors of older adults. Journal of Gambling Studies, 16(4), 393-415.

McNeilly, D.P., \& Burke, W.J. (2001). Gambling as a social activity of older adults. International Journal of Aging and Human Development, 52(1), 19-28.

Miller, N.V., \& Currie, S.R. (2008). A Canadian population level analysis of the roles of irrational gambling cognitions and risky gambling practices as correlates of gambling intensity and pathological gambling. Journal of Gambling Studies, 24(3), 257-274.

Mitrovic, D.V., \& Brown, J. (2009). Poker mania and problem gambling: A study of distorted cognitions, motivation and alexithymia. Journal of Gambling studies, 25(4), 489-582.

Morse, E.A., \& Goss, E.P. (2007). Governing Fortune: Casino Gambling in America. Ann Arbor, MI: The University of Michigan Press.

Neighbors, C., Lostutter, T.W., Cronce, J.M., \& Larimer, M.E. (2002). Exploring college student gambling motivation. Journal of Gambling Studies, 18(4), 361-370.

Neuman, S. (2009, August 21) Revenue-hungry states take new look at gaming. NPR. Retrieved from http://www.npr.org/templates/story/story.php?storyId=111862331

New Jersey Casino Control Act. (2008). Retrieved September 23, 2008 from http://www.newjersey.gov/casinos/actreg/act/

Nickerson, N.P. (1995). Tourism and gambling content analysis. Annals of Tourism Research, 22(1), 53-66.

Ontario Lottery and Gaming. (2006). Annual report: 2005-2006.

Ontario Lottery and Gaming. (2007). Annual report: 2006-2007. Retrieved from http://www.olg.ca/assets/documents/annual_report/annual_report_06-07.pdf

Ontario Lottery and Gaming. (2009a). OLG - OLG Slots and Casinos. Retrieved on November 3, 2009 from http://www.olg.ca/about/economic_benefits/slots_casinos.jsp

Ontario Lottery and Gaming (2009b, March 17). Supplemental OLG Rules and Conditions to Interprovincial Lottery Corporation Games. Retrieved from http://www.olg.ca/assets/documents/game_conditions/ilc_supplemental.pdf

Ontario Problem Gambling Research Centre. (2009). Problem gambling framework. Retrieved on October 19, 2009 from http://www.gamblingresearch.org/contentdetail.sz?cid=2007

Orford, J., Boulay, S., Copello, A., Graves, N., Purser, B., \& Day, E. (2003). Gambling and problem gambling among clients, and staff attitudes, in an alcohol and drug problems treatment service in the English midlands. International Gambling Studies, 3(2), 171-181.

Parke, A., Griffiths, M., \& Parke, J. (2005). Can playing poker be good for you? Poker as a transferable skill. Journal of Gambling Issues, 14, 1-7.

Parke, J., \& Griffiths, M. (2002). Slot machine gamblers - Why are they so hard to study? The Electronic Journal of Gambling Issues, 6, 1-11. 
Patton, M.Q. (1990). Qualitative evaluation of research methods ( $2^{\text {nd }}$ ed.). Newbury Park, CA: Sage Publications

Persky, J. (1995). Impact studies, cost-benefit analysis and casinos. Journal of Gambling Studies, 11(4), 349-360.

Petry, N.M., \& Mallya, S. (2004). Gambling participation and problems among employees at a university health center. Journal of Gambling Studies, 20(2), 155170.

Raylu, N., \& Oei, T.P. (2004). Role of culture in gambling and problem gambling. Clinical Psychology Review, 23(8), 1087-1114.

Reid, A. (2009, December 6). County wants gambling: Commissioner says more venues could boost jobs, revenue, business. Sun Sentinel. Retrieved from http://articles.sun-sentinel.com/2009-12-06/news/0912050213_1_gambling-dealpalm-beach-kennel-club-tax-revenue-gambling

Revheim, T., \& Buvik, K. (2009). Opportunity structure for gambling and problem gambling among employees in the transport industry. International Journal of Mental Health and Addiction, 7(1), 217-228.

Romano, J. (1991, July 14). Casino employees seeking permission to gamble. The New York Times. Retrieved from http:/query.nytimes.com/gst/fullpage.html?res=9D0CE2D61038F937A25754C0 A967958260

Room, R., Turner, N.E., \& Ialomiteanu A. (1999). Community effects of the opening of the Niagara casino. Addiction, 94(10), 1449-1466.

Ross, L., Greene, D., \& House, P. (1977). The "false consensus effect": An egocentric bias in social perception and attribution processes. Journal of Experimental Social Psychology, 13(3), 279-301.

Rush, B., Moxam, R.S, \& Urbanoski, K.A. (2002). Characteristics of people seeking help from specialized programs for the treatment of problem gambling in Ontario. The Electronic Journal of Gambling Issues, 6, 1-23.

Rutsey, B. (2008). It's time to legalize single event betting. Canadian Gaming Business, $3(3), 6$.

Ryan, T.P., \& Speyrer, J.F. (1999). Gambling in Louisiana: A Benefit/Cost Analysis. Prepared for the Louisiana Gaming Control Board. Retrieved from http://business.uno.edu/dber/gambling1998/CasEmpR.pdf

Scherrer, J.F., Slutske, W.S., Xian, H., Waterman, B., Shah, K.R., Volberg, R., \& Eisen, S.A. (2007). Factors associated with pathological gambling at 10-year follow-up in a national sample of middle-aged men. Addiction, 102(6), 970-978.

Schwartz, D.G. (2006). Roll the Bones: The History of Gambling. Toronto: Gotham Books.

Sévigny, S., \& Ladouceur, R. (2003). Gamblers' irrational thinking about chance events: the 'double switching' concept. International Gambling Studies, 3(2), 149-161.

Shaffer, H.J., Bilt, J.V., \& Hall, M.N. (1999). Gambling, drinking, smoking and other health risk activities among casino employees. American Journal of Industrial Medicine, 36(3), 365-378.

Shaffer, H.J., \& Hall, M.N. (2002). The natural history of gambling and drinking problems among casino employees. The Journal of Social Psychology, 142(4), 405-424. 
Sherman, W.R. (1991). A casino company's response to compulsive gambling. In W.R. Eadington \& J.A. Cornelius (Eds.), Gambling and public policy: International perspectives (pp. 671-678). Reno, NV: Institute for the Study of Gambling and Commercial Gaming.

Singer, E., Von Thurn, D.R, \& Miller, E.R. (1995). Confidentiality assurances and response: A quantitative review of the experimental literature. Public Opinion Quarterly, 59(1), 66-77.

Smith, G. J., \& Hinch, T.D. (1996). Canadian casinos as tourist attractions: Chasing the pot of gold. Journal of Travel Research, 34(3), 37-45.

SooToday.com. (2009, September 14). Lottery Corp limits retailer ticket buying. SooToday.com. Retrieved from http://www.sootoday.com/content/news/full_story.asp?StoryNumber=41627.

Statistics Canada. (2009, July). Perspectives on Labour and Income: Gambling. Retrieved from http://www.statcan.gc.ca/pub/75-001-x/topics-sujets/pdf/topicssujets/gambling-jeuxdehasard-2009-eng.pdf

Stedham, Y., \& Mitchell, M.C. (1996). Voluntary turnover among non-supervisory casino employees. Journal of Gambling Studies, 12(3), 269-290.

Steenbergh, T.A., Meyers, A.W., May, R.K., \& Whelan, J.P. (2002). Development and validation of the gamblers' belief questionnaire. Psychology of Addictive Behaviors, 16(2), 143-149.

Sternlieb, G., \& Hughes, J.W. (1983). The Atlantic City Gamble. Cambridge, MA: Harvard University Press.

Stokowski, P.A. (1996). Riches and regrets: Betting on gambling in two Colorado mountain towns. Niwot, CO: University Press of Colorado.

Stutz, H. (2005, September 13). Las Vegas Sands launches problem-gambling program. Casino City Times. Retrieved from http://www.casinocitytimes.com/news/article.cfm?contentID=153413

Thompson, A., Walker, M., Milton, S., \& Djukic, E. (2005). Explaining the high false positive rate of the south oaks gambling screen. International Gambling Studies, $5(1), 45-56$.

Toneatto, T., Blitz-Miller, T., Calderwood, K., Dragonetti, R., \& Tsanos, A. (1997). Cognitive distortions in heavy gambling. Journal of Gambling Studies, 13(3), 253-266.

Toneatto, T. (1999). Cognitive psychopathology of problem gambling. Substance Use \& Misuse, 34(11), 1593-1604.

Tourangeau, R., \& Yan, T. (2007). Sensitive questions in surveys. Psychological Bulletin, 133(5), 859-883.

Volberg, R.A., Abbott, M.W., Rönnberg, S., \& Munck, I.M.E. (2001). Prevalence and risks of pathological gambling in Sweden. Acta Psychiatrica Scandinavica, 104(4), 250-256.

Walker, M.B. (1992a). Irrational thinking among slot machine players. Journal of Gambling Studies, 8(3), 245-261.

Walker, M.B. (1992b). The psychology of gambling. New York: Pergamon Press.

Walker, G.J., Hinch, T.D., \& Weighill, A.J. (2005). Inter- and intra-gender similarities and differences in motivations for casino gambling. Leisure Sciences, 27(2), 111130. 
Wall, G., \& Mathieson, A. (2006). Tourism: Change, Impacts and Opportunities. Toronto: Pearson Prentice Hall.

Walters, G.D. (1997). Problem gambling in a federal prison population: Results from the south oaks gambling screen. Journal of Gambling Studies, 13(1), 7-24.

Welte, J.W., Barnes, G.M., Wieczorek, W.F., Tidwell, M.O., \& Hoffman, J.H. (2007). Type of gambling and availability as risk factors for problem gambling: A tobit progression analysis by age and gender. International Gambling Studies, 7(2), 183-198.

Welte, J.W., Barnes, G.M., Wieczorek, W.F., Tidwell, M.O., \& Parker, J.C. (2004). Risk factors for pathological gambling. Addictive Behaviors, 29(2), 323-335

Wiebe, J., \& Cox, B.J. (2001). A profile of Canadian adults seeking treatment for gambling problems and comparisons with adults entering an alcohol treatment program. Canadian Journal of Psychiatry, 46(5), 418-421.

Wiebe, J., Mun, P., \& Kauffman, N. (2006). Gambling and Problem Gambling in Ontario 2005. Final report submitted to the Ontario Problem Gambling Research Centre. Retrieved from http://www.responsiblegambling.org/articles/gambling_and_problem_gambling_i n_ontario_2005.pdf

Wiebe, J., Single, E., \& Agata Falkowski-Ham, A. (2001). Measuring gambling and problem gambling in Ontario. Final report submitted to the Canadian Centre on Substance Abuse Responsible Gambling Council (Ontario). Retrieved from http://www.responsiblegambling.org/articles/CPGI_report-Dec4.pdf

Williams, B. (2005, March 6). Casino workers face even tougher battle. The San Diego Union Tribune. Retrieved from http://www.signonsandiego.com/uniontrib/20050306/news_1n6casino.html

Williams, R.J., \& Connolly, D. (2006). Does learning about the mathematics of gambling change gambling behaviour? Psychology of Addictive Behaviours, 20(1), 62-68

Williams, R.J., \& Volberg, R.A. (2009). Impact of survey description, administration format, and exclusionary criteria on population prevalence rates of problem gambling. International Gambling Studies, 9(2),101-117.

Williams, R.J., \& Wood, R.T. (2004a). The demographic sources of Ontario gaming revenue: Final report. Prepared for the Ontario Problem Gambling Research Centre. Retrieved from http://www.uleth.ca/dspace/bitstream/10133/380/1/Williams_Wood_Demographi c_Sources.pdf

Williams, R.J., \& Wood, R.T. (2004b). The proportion of gaming revenue derived from problem gamblers: Examining the issues in a Canadian context. Analyses of Social Issues and Public Policy, 4(1), 33-45.

Wilson, C. (2008, April 9). Gambling creates 16,400 jobs in province. Times Colonist. Retrieved from http://www.canada.com/victoriatimescolonist/news/business/story.html?id=a7c02 9a9-93f4-4f8e-8e16-b9dc410079e6

Windsor Star. (2008, April 15). Casino games. Windsor Star. Retrieved from http://www.canada.com/windsorstar/news/editorial/story.html?id=98c511472143-44cd-abe1-fe82aaa286b7 
Wu, A.M.S., \& Wong, E.M.W. (2008). Disordered gambling among Chinese casino employees. Journal of Gambling Studies, 24(2), 207-217.

Wynne, H.J. (2003). Introducing the Canadian problem gambling index. Wynne Resources. Retrieved from http://www.gamblingresearch.org/download.sz/The\%20CPGI\%20V5\%20$\% 20$ from $\% 20$ Hal.pdf?docid $=6446$

Wynne, H.J., \& Shaffer, H.J. (2003). The socioeconomic impact of gambling: The Whistler symposium. Journal of Gambling Studies, 19(2), 111-121.

Young, M., Stevens, M., \& Morris, M. (2008). Problem gambling within the nonindigenous population of the Northern Territory of Australia: A multivariate analysis of risk factors. International Gambling Studies, 8(1), 77-93 


\section{Appendices}

Appendix A: Introductory Letter

April 1, 2009

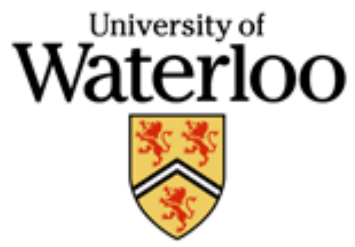

Dear OLG facility employee:

\section{Re: Confidential survey of casino employee gambling behaviours}

I am a Master's student in Tourism Policy \& Planning at the University of Waterloo, and I am conducting my thesis on the gambling behaviours of OLG facility employees. This study is being co-supervised by Dr. Kevin Harrigan (kevinh@uwaterloo.ca) from the Department of Drama and Speech Communication and Dr. Stephen Smith (slsmith@healthy.uwaterloo.ca) from the Department of Recreation and Leisure Studies. The research is funded by the Ontario Problem Gambling Research Centre and is being conducted with the cooperation of OLG.

In two weeks, you and all of your co-workers will receive a 10-15 minute survey about your personal gambling behaviours and your experiences working in an OLG facility. This survey is completely anonymous-you will not be asked to write your name on the survey. A total of about 4,700 surveys will be distributed, and upon completion of the survey you may enter yourself into five prize draws, each for a $\$ 40$ gift certificate valid in Swiss Chalet, Kelsey's, Montana's, Milestone's, and Harvey's. You will enter this draw by writing your name and mailing address on a separate sheet of paper to protect your anonymity.

You will also be asked to participate in an interview lasting approximately 30 minutes that will focus on the gambling behaviours of OLG facility employees, with only minor attention paid to your personal gambling behaviours. You can complete the survey without volunteering for an interview, or vice versa. Interviews will be held in a private conference room at your work or close by. Interviews will not be held during work hours, but can be scheduled at a convenient time such as just before or after work. Complete confidentiality will be provided to the interviewees, as neither names nor other identifying information will be connected to any of the comments made during the interviews. A total of twenty interviews will be conducted and individuals who participate in the interviews will have their names entered in three draws, each for a $\$ 40$ restaurant gift certificate. These three draws are in addition to the five draws for the survey respondents.

This research is being conducted wholly independently of OLG, but with OLG's cooperation. At the conclusion of the study OLG will receive general information on the results, but OLG will not have access to individual responses and OLG also will not be made aware of which employees have participated.

This research has been reviewed and ethics clearance has been granted from the Office of Research Ethics at the University of Waterloo.

Thank you in advance for your interest in this project.

Sincerely,

Daniel Guttentag

dguttent@uwaterloo.ca 
Dear OLG or Resort Casino employee:

\section{Re: Confidential survey of casino employee gambling behaviours}

\section{Overview of Study}

I am a Master's student at the University of Waterloo and two weeks ago I sent you a letter describing my thesis research on the gambling behaviours of OLG and Resort Casino employees. This study is being co-supervised by Dr. Kevin Harrigan from the Department of Drama and Speech Communication and Dr. Stephen Smith from the Department of Recreation and Leisure Studies. The research is funded by the Ontario Problem Gambling Research Centre and is being conducted with the cooperation of OLG.

\section{Participation}

Regardless of whether or not you gamble, your participation will be valued.

Survey: Attached to this letter please find my survey, which should take approximately 10-15 minutes to complete. The survey items focus on your personal gambling behaviours and various aspects of your employment at an OLG or Resort Casino. This survey is completely anonymous-you are not asked to write your name on the survey. Participation in the survey is voluntary and you may omit any question you prefer not to answer. There are no known or anticipated risks to you as a participant in this study.

Please return your completed survey by April 29, 2009. We have provided a sealed, secure collection box in each facility for you to place your completed survey. If you prefer, you may instead return your completed survey by mailing the prepaid envelope which has been provided. After completing the survey, enter the prize draws described below with the separate sheet of paper you will find accompanying the survey. This paper is separate from the survey to protect your anonymity. Once you have written your contact information on this sheet, it may be returned by either placing it in the same collection box used for the surveys or mailed with the prepaid envelope. If you wish, you may return your survey using the prepaid envelope and your contact information sheet by placing it in the collection box, or vice versa.

Interview: On the paper used to enter the draw you may also volunteer to participate in an interview that will focus on the gambling behaviours of OLG and Resort Casino employees, with only minor attention paid to your personal gambling behaviours. As with the survey, you can decline to answer any of the interview questions if you so wish. You can complete the survey without volunteering for an interview, or vice versa. Interviews will last approximately 30 minutes and will be held in a private conference room on or near your work premises. Interviews will not be held during work hours, but can be scheduled at a convenient time, such as just before or after work. The interviews will be audio recorded, but neither names nor other identifying information will be connected to any of the comments made during the interviews in order to protect your anonymity.

\section{Confidentiality}

This research is being conducted wholly independently of OLG, but with OLG's cooperation. At the conclusion of the study OLG will receive general information on the results, but OLG will not have access to individual responses and OLG also will not be made aware of which employees have participated. 
All data from both the surveys and the interviews will be kept confidential and will not contain personal identifiers. The data will be retained in the office of Dr. Harrigan and/or stored on a password-protected computer, and after five years the data will be destroyed.

\section{Token of Appreciation}

In order to show our appreciation to study participants, numerous prize draws will be held in which will be awarded $\$ 40$ gift certificates valid in Swiss Chalet, Kelsey's, Montana's, Milestone's, and Harvey's. About 4,700 surveys will be distributed and five prize draws, each for a $\$ 40$ gift certificate, will be held for those employees who have completed a survey and submitted a separate contact information sheet. Also, twenty interviews will be conducted and an additional three prize draws, each for a $\$ 40$ gift certificate, will be held for those employees who participate in an interview.

\section{Contact Information}

If you have any questions about this study, please contact myself or one of my co-supervisors: Daniel Guttentag: dguttent@uwaterloo.ca Dr. Harrigan: kevinh@uwaterloo.ca or 519-888-4567 ext 36652

Dr. Smith: slsmith@healthy.uwaterloo.ca or 519-888-4567 ext 84045

\section{Ethics Clearance}

I would like to assure you that this study has been reviewed and received ethics clearance through the Office of Research Ethics at the University of Waterloo. However, the final decision about participation is yours. Should you have any comments or concerns resulting from your participation in this study, please contact Dr. Susan Sykes in the Office of Research Ethics at 519-888-4567 Ext. 36005.

Once the study is complete, a summary of the results will be made available at the website of the Ontario Problem Gambling Research Centre (http://www.gamblingresearch.org).

Thank you,

Daniel Guttentag 
Appendix C: Survey

\title{
Survey for OLG and Resort Casino Employees
}

\author{
TO GUARANTEE YOUR ANONYMITY, PLEASE DO NOT WRITE YOUR NAME ON THIS SURVEY
}

1. At which facility are you employed?

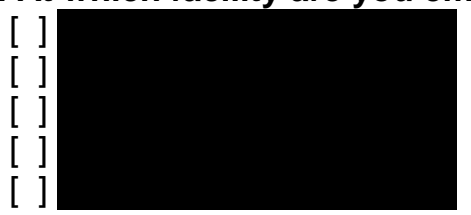

*The names of the facilities have been blacked out to

maintain their anonymity.

2. How much time have you spent employed in the gaming industry (with OLG, a Resort Casino or elsewhere)?

$$
\text { year(s) and }
$$
month(s)

3. Before working in an OLG or Resort Casino, did you have any previous experience working in the gaming industry? If so, please identify your previous type of employment.

[ ] No previous experience in the gaming industry.

[ ] Yes, with a land-based casino outside of Ontario.

[ ] Yes, with a roving charity casino in Ontario.

[ ] Yes, on a cruise ship.

[ ] Yes, other (please specify)

4. What is your current department?

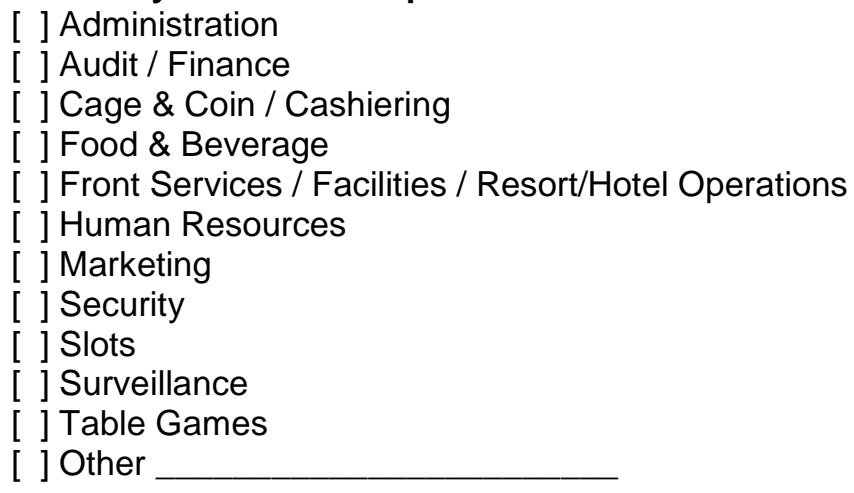

5. Roughly what percentage of your workday is spent interacting with patrons?
[ ] $0 \%-20 \%$
[ ] $21 \%-40 \%$
[ ] $41 \%-60 \%$
[ ] $61 \%-80 \%$
[ ] $81 \%-100 \%$

6. What shift do you most frequently work (please select one)?
[ ] Morning / Day
[ ] Afternoon / Swing
[ ] Nighttime / Grave
[ ] Rotating 


\begin{tabular}{|c|c|c|c|c|c|c|}
\hline $\begin{array}{l}\text { 7. Why did you choose to work in } \\
\text { an OLG or Resort Casino? }\end{array}$ & $\begin{array}{l}\text { Strongly } \\
\text { Agree }\end{array}$ & Agree & Neutral & Disagree & $\begin{array}{l}\text { Strongly } \\
\text { Disagree }\end{array}$ & $\begin{array}{l}\text { Doesn't } \\
\text { Apply }\end{array}$ \\
\hline I needed a job .......................... & $\mathrm{O}$ & $\mathrm{O}$ & O & $\mathrm{O}$ & O & O \\
\hline $\begin{array}{l}\text { I thought I would enjoy the } \\
\text { atmosphere } \ldots \ldots \ldots \ldots \ldots \ldots \ldots\end{array}$ & O & O & O & O & O & O \\
\hline 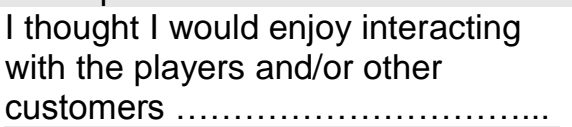 & O & O & ○ & O & O & O \\
\hline $\begin{array}{l}\text { I thought I would enjoy the nature of } \\
\text { the work (e.g. dealing cards, } \\
\text { attending slots, etc.) } \ldots \ldots \ldots \ldots \ldots \ldots \ldots \ldots\end{array}$ & O & O & O & O & O & O \\
\hline $\begin{array}{l}\text { I already knew and liked members } \\
\text { of the staff } \ldots \ldots \ldots \ldots \ldots \ldots \ldots \ldots \ldots \ldots \ldots \ldots \ldots\end{array}$ & O & O & O & ○ & O & O \\
\hline 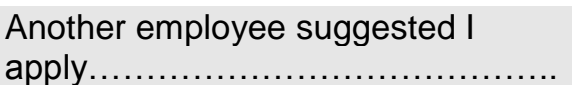 & O & O & O & O & O & O \\
\hline 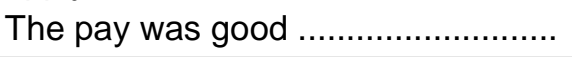 & O & O & O & O & O & O \\
\hline The hours appealed to me ............ & O & O & O & O & 0 & O \\
\hline $\begin{array}{l}\text { It provided an opportunity for career } \\
\text { advancement } \ldots \ldots \ldots \ldots \ldots \ldots \ldots \ldots \ldots \ldots \ldots \ldots \ldots \ldots\end{array}$ & O & O & O & O & O & ○ \\
\hline It offered good benefits ................ & 0 & O & O & O & O & 0 \\
\hline $\begin{array}{l}\text { I thought it would be easy because I } \\
\text { was already familiar with most } \\
\text { casino games ......................... }\end{array}$ & O & O & ○ & O & O & O \\
\hline $\begin{array}{l}\text { I was a frequent gambler so I } \\
\text { thought I would enjoy the work ...... }\end{array}$ & O & O & O & O & O & O \\
\hline $\begin{array}{l}\text { I had previous experience working } \\
\text { in a casino } \ldots \ldots \ldots \ldots \ldots \ldots \ldots \ldots \ldots \ldots \ldots \ldots\end{array}$ & O & O & O & O & O & O \\
\hline
\end{tabular}

8. Has your gambling behaviour changed since you began working in an OLG or Resort Casino (please select one)?

[ ] My gambling has increased significantly.

[ ] My gambling has increased a little.

[ ] My gambling has remained the same.

[ ] My gambling has decreased a little.

[ ] My gambling has decreased significantly. 


\begin{tabular}{|c|c|c|c|c|c|c|c|c|}
\hline \multicolumn{9}{|l|}{$\begin{array}{r}\text { 9. In the past year (12 months), how often did } \\
\text { you gamble... }\end{array}$} \\
\hline In any casino & O & O & O & O & O & O & O & O \\
\hline Online & 0 & O & 0 & 0 & 0 & O & 0 & O \\
\hline At a lottery outlet & 0 & O & O & O & O & O & O & O \\
\hline $\begin{array}{r}\text { With friends or family members outside of a casino } \\
\text { (e.g. betting on poker in a house game) }\end{array}$ & O & O & O & O & O & O & O & O \\
\hline $\begin{array}{r}\text { Inside or outside of a casino with friends or family } \\
\text { members who are also co-workers }\end{array}$ & O & O & O & O & O & O & O & O \\
\hline \multicolumn{9}{|l|}{$\begin{array}{r}\text { 10. In the past year (12 months), how often did } \\
\text { you bet or spend money on..... }\end{array}$} \\
\hline $\begin{array}{r}\text { Lottery, instant win, scratch, raffle, or fundraising } \\
\text { tickets }\end{array}$ & O & O & O & O & O & O & O & O \\
\hline Horse races (live at the track and/or off-track) & 0 & O & O & O & O & O & O & O \\
\hline Bingo & O & O & O & O & O & O & O & O \\
\hline $\begin{array}{r}\text { Electronic gaming machines (slot machines, video } \\
\text { poker, or video lottery) }\end{array}$ & O & O & O & O & O & O & O & O \\
\hline Poker in a casino & O & O & O & O & O & O & O & O \\
\hline Blackjack in a casino & 0 & O & O & O & O & O & O & O \\
\hline Roulette in a casino & O & O & O & O & O & O & O & O \\
\hline Keno in a casino & 0 & O & O & O & O & O & O & O \\
\hline Craps in a casino & O & O & O & O & O & O & O & O \\
\hline Sports betting & O & O & O & O & O & O & O & O \\
\hline $\begin{array}{r}\text { Betting on card games or board games played } \\
\text { outside of a casino }\end{array}$ & O & O & O & O & O & O & O & 0 \\
\hline Betting on tile games (e.g. mahjong, dominoes) & 0 & O & O & O & O & O & O & O \\
\hline Betting on games of skill (e.g. pool, bowling, darts) & O & O & O & O & O & O & O & O \\
\hline Betting on arcade or video games & 0 & O & O & O & O & O & O & O \\
\hline $\begin{array}{r}\text { Personal investment in stocks, options, or } \\
\text { commodities markets }\end{array}$ & O & O & O & O & O & O & O & O \\
\hline \multicolumn{9}{|l|}{ 11. When you are at work... } \\
\hline $\begin{array}{r}\text { How frequently do you see patrons who you would } \\
\text { consider to have a gambling problem? }\end{array}$ & O & O & $\mathrm{O}$ & O & O & 0 & 0 & 0 \\
\hline
\end{tabular}


12. This item is meant to determine if you have become more familiar with certain games since you began working at an OLG or Resort Casino. In the table below, please rate your level of familiarity with the following games, as you perceive it was on your first day ('First Day') of work at an OLG or Resort Casino, and how you perceive it is today ('Now').

\begin{tabular}{|c|c|c|c|c|c|c|c|}
\hline & \multicolumn{7}{|c|}{ First Day } \\
\hline & \multicolumn{3}{|c|}{ Very Familiar } & & \multicolumn{3}{|c|}{ Very Unfamiliar } \\
\hline $\begin{array}{l}\text { Lottery, instant win, } \\
\text { scratch, raffle, or } \\
\text { fundraising tickets }\end{array}$ & 0 & 0 & 0 & 0 & 0 & 0 & 0 \\
\hline $\begin{array}{l}\text { Horse races (live at the } \\
\text { track and/or off-track) }\end{array}$ & 0 & O & 0 & O & 0 & 0 & 0 \\
\hline Bingo & O & O & 0 & O & O & O & 0 \\
\hline $\begin{array}{r}\text { Electronic gaming } \\
\text { machines (slot } \\
\text { machines, video poker, } \\
\text { or video lottery) }\end{array}$ & 0 & 0 & 0 & 0 & 0 & 0 & 0 \\
\hline Poker & O & O & 0 & O & 0 & ○ & O \\
\hline Blackjack & 0 & O & 0 & O & 0 & O & 0 \\
\hline Roulette & O & O & 0 & O & 0 & O & O \\
\hline Keno & 0 & O & 0 & 0 & 0 & 0 & 0 \\
\hline Craps & O & O & O & O & 0 & ○ & 0 \\
\hline Sports betting & 0 & O & 0 & O & 0 & 0 & 0 \\
\hline
\end{tabular}

\begin{tabular}{lll}
\hline Very Familiar & Now & \\
& Very Unfamiliar \\
\hline
\end{tabular}

$\begin{array}{lllllllllllllllll}0 & 0 & 0 & 0 & 0 & 0 & 0\end{array}$

$\begin{array}{lllllll}0 & 0 & 0 & 0 & 0 & 0 & 0 \\ 0 & 0 & 0 & 0 & 0 & 0 & 0\end{array}$

$\begin{array}{lllllllllllllll}0 & 0 & 0 & 0 & 0 & 0 & 0\end{array}$

\begin{tabular}{lllllll}
0 & 0 & 0 & 0 & 0 & 0 & 0 \\
0 & 0 & 0 & 0 & 0 & 0 & 0 \\
0 & 0 & 0 & 0 & 0 & 0 & 0 \\
0 & 0 & 0 & 0 & 0 & 0 & 0 \\
0 & 0 & 0 & 0 & 0 & 0 & 0 \\
0 & 0 & 0 & 0 & 0 & 0 & 0 \\
\hline
\end{tabular}

13. Roughly how much money do you spend on gambling in a typical month (Include all forms of gambling: casino, online, lottery, sports pools, etc.)?

$\$$

14. Using your normal mode of transportation, about how long does it take you to go from your residence to the nearest casino where you are allowed to gamble?

hour(s) and minute(s) 
15. The following table lists some statements about possible influences your employment may have had on your gambling. Please indicate the degree to which you agree or disagree with each statement.

After work I want to avoid spending

\begin{tabular}{|c|c|c|c|c|}
\hline $\begin{array}{c}\text { Strongly } \\
\text { Agree }\end{array}$ & Agree & Neutral & Disagree & $\begin{array}{l}\text { Strongly } \\
\text { Disagree }\end{array}$ \\
\hline
\end{tabular}

even more time in a casino or

involved with gambling

Due to my shifts, casinos are some of the only entertainment venues open when I am not at work

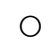

I believe I can win money because I have become more knowledgeable about casino games

I receive gambling tips from patrons that I feel are worth following I see patrons losing money and do not want to do the same

I spend so much time surrounded by gambling that it is no longer interesting

My friends who also work in the facility gamble a lot so I gamble with them

Gambling relieves the stress from my job

The marketing and advertising that I see at work tempts me to gamble.. My job's regulations about employee gambling make it difficult for me to visit a casino where I am allowed to gamble My friends who also work in the facility rarely or never gamble so I rarely or never gamble My facility's training about problem gambling convinced me to gamble less

I see some negative consequences of gambling among patrons and I do not want to be like them I see how much fun patrons are having and I want to participate too

I have seen many patrons win so I think I have a good chance of winning money I have become more interested in gambling so I wanted to participate As I have become more knowledgeable about the games I have realized that I cannot overcome the house odds in most games

\begin{tabular}{|c|c|c|c|c|c|}
\hline O & O & O & 0 & 0 & 0 \\
\hline O & O & 0 & 0 & 0 & 0 \\
\hline 0 & 0 & 0 & 0 & 0 & 0 \\
\hline 0 & 0 & 0 & 0 & 0 & 0 \\
\hline 0 & 0 & 0 & 0 & 0 & 0 \\
\hline 0 & 0 & 0 & 0 & 0 & 0 \\
\hline O & 0 & 0 & 0 & 0 & 0 \\
\hline 0 & 0 & 0 & 0 & 0 & 0 \\
\hline 0 & 0 & 0 & 0 & 0 & 0 \\
\hline O & O & 0 & 0 & 0 & 0 \\
\hline O & O & 0 & 0 & 0 & 0 \\
\hline 0 & 0 & 0 & 0 & 0 & 0 \\
\hline O & 0 & 0 & 0 & 0 & 0 \\
\hline 0 & 0 & 0 & 0 & 0 & 0 \\
\hline 0 & 0 & 0 & 0 & 0 & 0 \\
\hline O & O & 0 & 0 & 0 & O \\
\hline 0 & O & 0 & 0 & 0 & 0 \\
\hline
\end{tabular}


16. What do you think your direct supervisor would likely do if you approached him or her indicating you had a gambling problem (please select one)...

[ ] Do nothing.

[ ] Simply advise you to stop gambling.

[ ] Show you where to get help.

[ ] Show you where to get help, but also terminate you.

[ ] Terminate you without providing any assistance.

17. If you felt you may have a gambling problem, you would most likely seek assistance by (please select one)...

[ ] Calling a helpline. (Which one: )

[ ] Seeking help through work.

[ ] Going to a counseling centre. (Which one:

[ ] Using the employee assistance plan.

[ ] Seeking help from family or friends.

[ ] I don't know of anywhere to seek assistance for problem gambling.

[ ] I wouldn't seek assistance anywhere.

\begin{tabular}{|c|c|c|c|c|c|c|}
\hline $\begin{array}{l}\text { 18. Please mark your opinions } \\
\text { regarding the following } \\
\text { statements: }\end{array}$ & $\begin{array}{c}\text { Strongly } \\
\text { Agree }\end{array}$ & Agree & Neutral & Disagree & $\begin{array}{l}\text { Strongly } \\
\text { Disagree }\end{array}$ & $\begin{array}{l}\text { Don't } \\
\text { Know / } \\
\text { Doesn't } \\
\text { Apply }\end{array}$ \\
\hline $\begin{array}{l}\text { I feel that I have a good } \\
\text { understanding of OLG's responsible } \\
\text { gaming policies and procedures .... }\end{array}$ & O & O & O & O & O & O \\
\hline $\begin{array}{l}\text { I feel confident that I can carry out } \\
\text { my role in responding to customers } \\
\text { who are showing signs of being in } \\
\text { trouble or who are in crisis ............. }\end{array}$ & O & 0 & O & O & O & O \\
\hline $\begin{array}{l}\text { My facility's problem gambling } \\
\text { training course was useful in } \\
\text { teaching me about problem } \\
\text { gambling ............................. }\end{array}$ & O & O & ○ & O & O & O \\
\hline $\begin{array}{l}\text { My facility's problem gambling } \\
\text { training course has reduced the } \\
\text { chances that I will ever become a } \\
\text { problem gambler ..................... }\end{array}$ & O & O & O & O & O & ○ \\
\hline $\begin{array}{l}\text { I am aware of employee outreach } \\
\text { tools that OLG facility employees } \\
\text { can use if concerned they may have } \\
\text { a gambling problem ................... }\end{array}$ & O & O & O & O & O & O \\
\hline $\begin{array}{l}\text { When I am gambling, after losing } \\
\text { many times in a row I am more likely } \\
\text { to win } \ldots \ldots \ldots \ldots \ldots \ldots \ldots \ldots \ldots \ldots \ldots \ldots \ldots \ldots \ldots \ldots \ldots \ldots \ldots \ldots \ldots \ldots \ldots \ldots \ldots \ldots\end{array}$ & O & O & O & O & O & 0 \\
\hline $\begin{array}{l}\text { There are certain things I do when I } \\
\text { am betting (for example, tapping a } \\
\text { certain number of times, holding a } \\
\text { lucky coin in my hand, crossing my } \\
\text { fingers, etc.) which increase the } \\
\text { chances that I will win ............................ }\end{array}$ & O & O & O & O & O & O \\
\hline $\begin{array}{l}\text { My gambling wins on slot machines } \\
\text { are evidence that I have skill and } \\
\text { knowledge related to gambling } . . . \ldots \ldots\end{array}$ & O & O & O & O & O & O \\
\hline I typically win when I gamble ........... & O & O & O & O & O & O \\
\hline I find my job stressful .................... & O & O & 0 & O & O & O \\
\hline
\end{tabular}




\begin{tabular}{|c|c|c|c|c|c|}
\hline 19. Thinking about the past 12 months... & Never & $\begin{array}{c}\text { Some- } \\
\text { times }\end{array}$ & $\begin{array}{l}\text { Most of } \\
\text { the Time }\end{array}$ & $\begin{array}{l}\text { Almost } \\
\text { Always }\end{array}$ & $\begin{array}{l}\text { Don't } \\
\text { Know }\end{array}$ \\
\hline $\begin{array}{l}\text { How often have you bet more than you could } \\
\text { really afford to lose? }\end{array}$ & O & O & O & O & O \\
\hline $\begin{array}{l}\text { How often have you needed to gamble with larger } \\
\text { amounts of money to get the same feeling of } \\
\text { excitement? }\end{array}$ & O & O & O & O & 0 \\
\hline $\begin{array}{l}\text { How often have you gone back another day to try } \\
\text { to win back the money you lost? }\end{array}$ & O & O & ○ & ○ & O \\
\hline $\begin{array}{l}\text { How often have you borrowed money or sold } \\
\text { anything to get money to gamble? }\end{array}$ & O & O & O & ○ & O \\
\hline $\begin{array}{l}\text { How often have you felt that you might have a } \\
\text { problem with gambling? }\end{array}$ & O & O & O & O & O \\
\hline $\begin{array}{l}\text { How often have people criticized your betting or } \\
\text { told you that you had a gambling problem, } \\
\text { regardless of whether or not you thought it was } \\
\text { true? }\end{array}$ & O & O & O & O & O \\
\hline $\begin{array}{l}\text { How often have you felt guilty about the way you } \\
\text { gamble, or what happens when you gamble? }\end{array}$ & O & O & O & O & O \\
\hline $\begin{array}{l}\text { How often has your gambling caused you any } \\
\text { health problems, including stress or anxiety? }\end{array}$ & O & O & O & O & O \\
\hline $\begin{array}{l}\text { How often has your gambling caused any } \\
\text { financial problems for you or your household? }\end{array}$ & 0 & O & O & O & 0 \\
\hline
\end{tabular}

20. What is your age group?

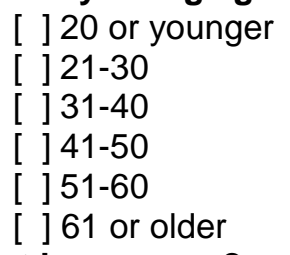

21. What is your sex? [ ] Female [ ] Male

22. What is your marital status (please select one)?

[ ] Single and never married

[ ] Married or living with a partner

[ ] Divorced or separated

[ ] Widowed

23. With which ethnic group do you most strongly identify (please select one)?

[ ] Canadian

[ ] Aboriginal

[ ] Asian

[ ] Caribbean

[ ] European

[ ] Other

24. What is the highest level of education you have achieved (please select one)?

[ ] Some high school / junior high or less

[ ] Completed high school

[ ] Some post secondary school

[ ] Completed university, technical school, or vocational college

[ ] Completed post graduate education

Thank you very much for completing this survey. Please now write your contact information on the accompanying sheet of paper to enter your name in the prize draws and/or volunteer to participate in an interview. Please return your survey and contact information sheet by depositing them in your facility's sealed collection box or mailing them in the prepaid envelope provided. You may return one of these items using the collection box and the other using the mail if you wish. 
Appendix D: Contact Information Sheet

Name:

Mailing Address:

\author{
City: \\ Postal Code :
}

I have completed and submitted the accompanying survey. Please enter my name in the five prize draws, each for a $\$ 40$ gift certificate valid at Swiss Chalet, Kelsey’s, Montana's, Milestone's, and Harvey's. (About 4,700 surveys were distributed.)

I am willing to participate in a brief interview regarding the gambling behaviours of OLG and Resort Casino employees.*

If you would like to participate in an interview, then please enter your preferred method of contact:

Email:

Phone:

* This interview will last approximately 30 minutes and will be held at your work premises or close by. Unlike the survey, the interview will focus primarily on your perceptions of the gambling behaviours of OLG and Resort Casino employees, rather than your personal gambling behaviours. A total of twenty interviews will be conducted and by participating in an interview your name will be entered in three draws, each for a $\$ 40$ restaurant gift certificate.

\title{
THANK YOU
}


Dear X,

I am Daniel Guttentag, the University of Waterloo Master's student who is conducting a study on the gambling behaviours of OLG and Resort Casino employees. You previously expressed your willingness to participate in an interview in which you will be asked about some of the topics this study is investigating, and I am writing to arrange a time for this interview.

As a reminder, the interview will last approximately 30 minutes and it will be audio recorded. The questions will focus primarily on your perceptions of gambling among OLG and Resort Casino employees, rather than your own gambling, and you may choose to not answer any question if you so wish. A total of twenty interviews will be conducted and by participating in an interview you will be eligible for three prize draws, in each of which a $\$ 40$ restaurant gift certificate will be given away.

This research is being conducted wholly independently of OLG, but with OLG's cooperation. At the conclusion of the study OLG will receive general information on the results, but OLG will not have access to individual responses and OLG also will not be made aware of which employees have participated.

I am arranging my interviews for $\mathrm{X}$ (casino) on $\mathrm{X}$ (dates). Please tell me if there is a time on one of these dates that is convenient for you.

I very much look forward to speaking with you and thank you in advance for your assistance in this project.

Sincerely,

Daniel Guttentag 
Appendix F: Letter for Interviewees and Consent Form

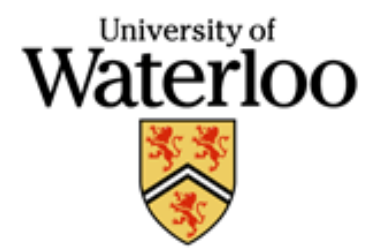

Date:

Dear OLG or Resort Casino employee:

This letter is an invitation to be interviewed for a study I am conducting as part of my Master's degree in the Department of Geography and Environmental Management at the University of Waterloo under the supervision of Dr. Kevin Harrigan from the Department of Drama and Speech Communication and Dr. Stephen Smith from the Department of Recreation and Leisure Studies. Although you have previously noted your willingness to participate in such an interview, I would like to provide you with more information about this project and what your involvement would entail if you decide to take part.

The casino industry is often promoted for the employment it generates, but past research has demonstrated that some casino employees may exhibit gambling problems. Nevertheless, it is unclear what factors are associated with casino employee gambling behaviour, or whether employee problem gambling is generally a result of the work experience or pre-existing gambling affinities. Also, it is not known whether the results from studies investigating casino employee gambling conducted outside of Ontario can be applied to Ontario facilities. The purpose of this study, therefore, is to investigate whether problem gambling is prevalent among Ontario casino employees and what factors may relate to different gambling behaviours.

The study will focus on a variety of factors that may relate to casino employee gambling. These factors have been identified through the survey conducted with OLG and Resort Casino employees and in other past research on casino employee gambling. Some of the various factors that will be considered include duration of employment, job type, gambling preferences, and socio-demographic characteristics. I would like to include you in my study so that you can describe your experiences as an employee at an OLG or Resort Casino.

Participation in this study is voluntary. It will involve an interview of approximately 30 minutes in length to take place in a private conference room on your work premises or close by. The interview will focus on your observations of gambling behaviours exhibited by employees of OLG and Resort Casinos, with only minor attention paid to your personal gambling behaviours. You will be asked, for example, whether employees with certain jobs gamble more than others or whether employees tend to gamble more or less after they begin working with an Ontario casino. You may decline to answer any of the interview questions if you so wish. Furthermore, you may decide to withdraw from this study at any time without any negative consequences by advising the researcher. With your permission, the interview will be audio recorded to facilitate collection of information, but all information you provide is considered completely confidential. Neither your name nor any other information that could be used to identify you will appear in any thesis or report resulting from this study; however, with your permission anonymous quotations may be used. Data collected during this study will be retained for five years in the office of Dr. Harrigan or stored on the student researcher's password-protected computer. Only University of Waterloo researchers associated with this project will have access. There are no known or anticipated risks to you as a participant in this study. 
If you have any questions regarding this study, you may contact me by email at dguttent@uwaterloo.ca. You can also contact either of my co-supervisors: Professor Kevin Harrigan at 519-888-4567 ext. 36652 or email kevinh@uwaterloo.ca, or Professor Stephen Smith at 519-888-4567 ext. 84045 or email slsmith@healthy.uwaterloo.ca.

I would like to assure you that this study has been reviewed and received ethics clearance through the Office of Research Ethics at the University of Waterloo. However, the final decision about participation is yours. If you have any comments or concerns resulting from your participation in this study, please contact Dr. Susan Sykes of this office at 519-888-4567 Ext. 36005 or ssykes@uwaterloo.ca.

I hope that the results of my study will be of benefit to those organizations directly involved in the study, other gambling-related organizations not directly involved in the study, as well as to the broader research community.

I very much look forward to speaking with you and thank you in advance for your assistance in this project.

Sincerely,

Daniel Guttentag 


\section{CONSENT FORM}

I have read the information presented in the information letter about a study being conducted by Daniel Guttentag of the Department of Geography and Environmental Management at the University of Waterloo. I have had the opportunity to ask any questions related to this study, to receive satisfactory answers to my questions, and any additional details I wanted.

I am aware that I have the option of allowing my interview to be audio recorded to ensure an accurate recording of my responses.

I am also aware that excerpts from the interview may be included in the thesis and/or publications to come from this research, with the understanding that the quotations will be anonymous.

I was informed that I may withdraw my consent at any time without penalty by advising the researcher.

This project has been reviewed by, and received ethics clearance through, the Office of Research Ethics at the University of Waterloo. I was informed that if I have any comments or concerns resulting from my participation in this study, I may contact the Director, Office of Research Ethics at 519-888-4567 ext. 36005 .

With full knowledge of all foregoing, I agree, of my own free will, to participate in this study.

\section{$\square$ YES $\square$ NO}

I agree to have my interview audio recorded.

$\square$ YES $\square$ NO

I agree to the use of anonymous quotations in any thesis or publication that comes of this research.

\section{$\square$ YES $\square$ NO}

Participant Name: (Please print)

Participant Signature:

Witness Name: (Please print)

Witness Signature:

Date: 


\section{Appendix G: Interview Guide}

Choosing casino employment

Why do people choose to work in a casino?

Anything particular about casino?

Or just needed job + good pay/benefits? These answers most common, even though many thought they'd enjoy atmosphere.

Is it what people expect?

What do people like most and least?

Why did you choose to work in a casino?

How long do you see yourself staying in industry?

Why would you leave it?

Are employees generally familiar with gambling before they begin working?

Change in gambling

How does gambling behaviour change (increase or decrease)?

Different for any particular groups (gender, etc)?

Length of employment impact?

Immediate spike in interest that drops off? Gradual?

Emps become interested/enamoured with gambling, or sick of it? (Seems latter)

Job type influence?

Emps seem to learn more and play games they work?

Or ones available at particular casino.

Do table workers rotate games?

But strong indication that know will lose? So what's explanation?

Employees perceived lots of (problem) gambling among patrons.

What is impact? (Seems to be very impactful)

Shift? (More night time PG, but little indication that no other entertainment options)

Are regulatory restrictions significant?

Decrease gambling?

Do emps follow them?

Would be hard to visit other casino?

Are new lottery rules significant?

Are they followed?

Are emps substituting other types of gambling?

What is the general opinion toward the rules?

Marketing and stress don't seem to be major issues?

What jobs are most stressful? Why? 


\section{General Gambling}

Who?

Age, gender, ethnicity?

Dept or job type? (Table, front services, food, cage/coin, marketing, security, slots, surveillance)

Length of employment? (Those working the longest).

Why?

Longer employment leads to more gambling or vice versa?

Where (casino - resort or USA, house, etc)?

What?

Why so much lotto?

Do groups of co-workers generally gamble together?

Where?

Lotto?

Does gambling influence group formation or vice versa?

Culture of gambling? Supervisors?

Entertainment or money?

Do emps think they're skilled (EGMs/lotto)?

Do they hold common false gambling beliefs (e.g. fallacy)?

Any relation (pos or neg) between gambling and job performance?

Is gambling or PG a problem among emps?

What is the cause?

Additional things that casinos should do in response?

$\underline{\text { Training }}$

Is PG training useful/impactful?

How frequent?

How could it be improved?

What is Employee Assistance Plan?

Is it used?

Are supervisors perceived as potentially helpful and understanding?

Do emps ever approach supervisors w/problems?

Do gamblers react to patrons differently? PG clients?

Are there frequent interventions? 